$R \wedge C$

Kaspar Gubler - Rainer Christoph Schwinges (Hrsg.)

\title{
Gelehrte Lebenswelten \\ im 15. und 16. Jahrhundert
}

Repertorium Academicum Germanicum (RAG)

Forschungen 2 


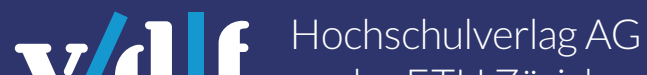 an der ETH Zürich}

\section{Liebe Leserin, lieber Leser}

Wir freuen uns, dass Sie unsere Open-Access-Publikation

heruntergeladen haben. Der vdf Hochschulverlag fördert Open Access aktiv und publiziert seit 2008 Gratis-eBooks in verschiedenen Fachbereichen:

\section{Übersicht Open-Access-Titel}

\section{Möchten auch Sie Open Access publizieren?}

Der vdf Hochschulverlag stellt Ihre Publikation u.a. im eigenen Webshop sowie der ETH-Research-Collection zum Download bereit!

Kontaktieren Sie uns unter verlag@vdf.ethz.ch

Gerne informieren wir Sie auch in Zukunft über unsere

(Open-Access-)Publikationen in Ihrem Fachbereich.

\section{Newsletter abonnieren}

Auch Sie können Open Access unterstützen.

Hier geht's zum Spenden-Button

Herzlichen Dank! 
Kaspar Gubler · Rainer Christoph Schwinges (Hrsg.)

\section{Gelehrte Lebenswelten im 15. und 16. Jahrhundert}

Redaktion: Ursula Bütschli 


\section{Publiziert mit Unterstützung der Schweizerischen Akademie der Geistes- und Sozialwissenschaften (SAGW)}

Umschlagbild: Dr. theol. Henricus Gorinchem, Studium in Paris und Köln.

Bayerisches Hauptstaatsarchiv. Geheimes Hausarchiv, Handschrift 12, fol. 10r.

Bibliografische Information der Deutschen Nationalbibliothek

Die Deutsche Nationalbibliothek verzeichnet diese Publikation in der Deutschen Nationalbibliografie; detaillierte bibliografische Daten sind im Internet über http://dnb.dnb.de abrufbar.

Download open access:

ISBN 978-3-7281-3929-0 / DOI 10.3218/3929-0

www.vdf.ethz.ch

(C) 2018, vdf Hochschulverlag AG an der ETH Zürich

Das Werk einschliesslich aller seiner Teile ist urheberrechtlich geschützt. Jede Verwertung ausserhalb der engen Grenzen des Urheberrechtsgesetzes ist ohne Zustimmung des Verlages unzulässig und strafbar. Das gilt besonders für Vervielfältigungen, Übersetzungen,

Mikroverfilmungen und die Einspeicherung und Verarbeitung in elektronischen Systemen. 


\section{Inhalt}

Vorwort .......................................................................................................... VII

Rainer Christoph Schwinges

Doctores so in den püchern lesen.

Lebenswege deutscher Gelehrter des 15. bis 16. Jahrhunderts

und das Repertorium Academicum Germanicum (RAG)......................... 1

Ursula Bütschli

Bildung und Geld.

Die Vermögensverhältnisse der Schaffhauser

Universitätsbesucher im Spätmittelalter (1460-1529)........................... 23

Elena Magli

Ritter an der Universität.

Universitätsbesuch der niederadligen

Familie Friedingen (1324-1540)

Silvia Böhnert

So soll der jung Adel sich auff das Studieren geben:

Die Wetterauer Grafen an den Universitäten des

Alten Reiches (1450-1550). 65

Carmen Tellenbach

Ladislaus Ulricher, Professor der Theologie.

Ein gelehrter Betrüger an der Universität Basel (um 1500). 87

Kaspar Gubler

Universitas Dolana:

Juristen- und Transituniversität

im Land der Legisten (1498-1601) 
Lotte Kosthorst

Gelehrte Mediziner am Niederrhein.

Das Italienstudium der Ärzte am Hof

Wilhelms V. von Jülich-Kleve-Berg (1539-1592).

Anna-Lena Wendel

Der Humanistenkreis in Erfurt und die Reformation

in Hessen (ca. 1500-1550)

Vanessa Decker

Die Professoren der Universität Marburg zwischen

Universitäts- und Landesdienst (1527-1567)

Anschriften der Autorinnen und Autoren. 


\section{Vorwort}

Dies ist das zweite Buch aus der Reihe «Repertorium Academicum Germanicum (RAG) Forschungen», die grundsätzlich das Medium des E-Books verwendet. Der Zugang ist frei gemäss dem Grundsatz des Open-Access zu wissenschaftlicher Literatur.

Das RAG (www.rag-online.org) ist ein Forschungsprojekt, das die biographischen, sozialen und kulturellen Daten der universitären Gelehrten des Alten Reiches bis 1550 in einer Datenbank erfasst und auswertet. Diese Datenbank präsentiert die Studien-, Lebens- und Wissenswege der Magister der Artistenfakultäten, der Besucher und Absolventen der drei höheren Fakultäten der Jurisprudenz, der Theologie und der Medizin sowie der Universitätsbesucher aus dem Adel, auch wenn sie nicht promoviert worden sind. Damit hat das RAG das Ziel, die Geschichte der kulturellen Reichweiten geistiger Führungsgruppen der Vormoderne zu entwickeln und mit mehr als 60'000 Personen einen umfassenden Einblick in die mittelalterlichen Ursprünge moderner Wissensgesellschaften zu gewinnen.

Dieses Buch haben die Mitarbeiterinnen und Mitarbeiter des RAG der beiden Arbeitsstellen in Bern (Schweiz) und Giessen (Deutschland) in den Jahren 2017 und 2018 gestaltet, nachdem die notwendig gewordene Datenbankmigration bewältigt war. Die Beiträge basieren unter Nutzung des RAG im neuen Umfeld zumeist auf akademischen Qualifikationsschriften von der Master- bis zur Doktorandinnenstufe an den Universitäten Bern und Giessen. So finden sich - neben einem einführenden Text zum RAG - Arbeiten, die sowohl dem regionalen Schwerpunkt der Arbeitsstellen (Rheinraum, Hessen, Thüringen oder Burgund, Süddeutschland, Schweiz) als auch den jeweils persönlichen Forschungsinteressen geschuldet sind. Letztere betreffen Finanz- und Studienstatus in Schaffhausen, adlige Studienstrategien beim süddeutschen Ritter- und Wetterauer Grafenadel, das italienische Studium der Hofmediziner am Niederrhein oder das französisch-juristische an der für Reichsverhältnisse wichtigen burgundischen Universität zu Dôle. Ferner geht es um Erfurter Humanisten und ihren reformatorischen Einfluss in Hessen sowie um den Universitäts- und Landesdienst der Marburger Professoren, und nicht zuletzt wird der Fall eines gelehrten Hochstaplers an der Basler Universität aufgerollt. Alle Beiträge mögen vermitteln, wie sehr das RAG mit seinen Visualisierungsmöglichkeiten seit den Anfängen im Jahre 2001 mehr und mehr zu einem Forschungs- und Arbeitsinstrument geworden ist. Es basiert auf der Software Nodegoat (http://nodegoat.net from LAB1100).

Herzlicher Dank gebührt allen Beitragenden, sodann der Schweizerischen Akademie der Geistes- und Sozialwissenschaften (SAGW), die diese Publikation wesentlich unterstützt hat, und Frau Ursula Bütschli M. A., die nicht nur den eigenen Text, sondern auch Redaktion und Satz mit grosser Sorgfalt bewältigt hat. 


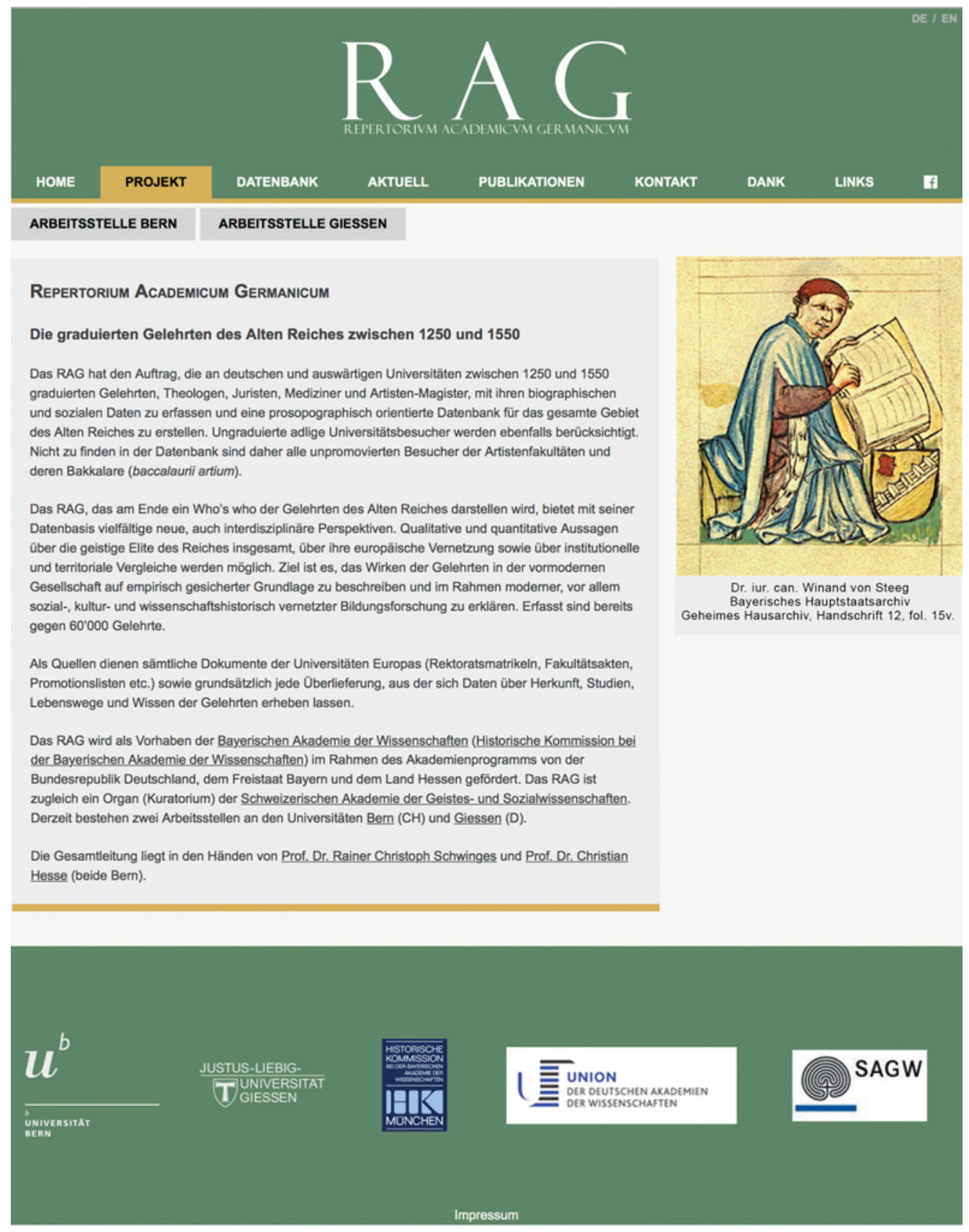

Abb. 1 Website des RAG mit Winand von Steeg (Bayerisches Hauptstaatsarchiv, Geheimes Hausarchiv, Handschrift 12, fol. 15v) 


\section{Doctores so in den püchern lesen}

\section{Lebenswege deutscher Gelehrter des 15. bis 16. Jahrhunderts und das Repertorium Academicum Germanicum (RAG) ${ }^{1}$}

Ich habe das Vergnügen, Sie mit Dr. Winand von Steeg bekannt machen zu dürfen, diesem freundlich blickenden Herrn auf der Website des RAG, der gerade dabei ist, damals um 1425, ein Gutachten zu verfassen. Er scheint noch ein wenig nachdenklich zu sein, um den rechten Anfang zu finden. Vielleicht will er auch im Bild noch etwas nachtragen, denn er hat sich selbst in dieser Lage portraitiert. Lassen wir ihn also noch einen Moment in Ruhe nachdenken, bevor er uns verraten wird, was es mit ihm auf sich hat.

Inzwischen kann ich Ihnen berichten, weshalb ich mich fast 600 Jahre nach seinem Erdenleben für ihn und weitere seiner Kollegen, die ich gleich noch vorstellen werde, interessiere. Abgesehen von allem anderen an seiner Persönlichkeit macht Winand bereits die Tatsache interessant, dass er ein Mann mit Universitätsbildung ist, in diesem Fall ein Mann des gelehrten Rechts von Heidelberg und Würzburg mit entsprechender Tätigkeit. Und so ister ein Proband in einem Forschungsunternehmen, das sich Repertorium Academicum Germanicum (RAG) nennt. Dieses RAG hat sich vorgenommen, die Lebenswege deutscher Gelehrter, darunter die doctores so in den püchern lesen prosopografisch zu erforschen und ihr Wissen, ihre gesellschaftliche Wirkung und die sich dabei entwickelnde spezifische Kultur von den Anfängen bis zur Mitte des 16. Jahrhunderts zu erkunden. Dazu gibt es eine Datenbank zur Recherche sowie unter anderem einen digitalen Atlas zur Analyse und Visualisierung der Ergebnisse. Was ich Ihnen präsentiere, sind freilich noch keine abgeschlossenen Forschungen, sondern ist 〈work in progress ${ }^{2}$.

Dass man ein solches RAG machen kann, hat gerade im deutschen Sprachraum besonders gute Voraussetzungen. Betrachtet man nämlich die Geschichte mittelalterlichvormoderner Bildung und Wissenschaft samt ihren Institutionen rein chronologisch, so wird man selbstverständlich nicht umhin können, zuerst auf Frankreich und Italien zu blicken mit ihren europäischen Zentren für Theologie und Philosophie in Paris, für Rechtswesen und Medizin in Bologna, Padua, Pavia, Ferrara oder Montpellier. Die entsprechenden, rund 150 Jahre späteren Ereignisse und Prozesse im Alten Reich, beginnend mit Prag (1348) als der ersten Universität nördlich der Alpen, wird man

1 Vortrag anlässlich der Jahresversammlung der Historischen Kommission bei der Bayerischen Akademie der Wissenschaften und der Monumenta Germaniae Historica in der Bayerischen Akademie der Wissenschaften in München am 8. März 2017. Die Redeform ist weitgehend beibehalten. Erstabdruck in: Jahresbericht 2016 der Historischen Kommission bei der Bayerischen Akademie der Wissenschaften, München 2017, S. 30-52. Hier wiedergegeben mit verändertem Kartenmaterial und notwendigen Anpassungen.

2 Näheres unter Repertorium Academicum Germanicum (RAG), [www.rag-online.org], 25.4.2018 
demgegenüber nicht gerade in den Vordergrund stellen können. Diese Tatbestände sind deutlich verspätet und werden quantitativ und qualitativ im Vergleich mit West- und Südeuropa noch recht lange zurückstehen. Sieht man aber auf die Sozial- und Kulturgeschichte der Gelehrten und darauf, was sie als graduierte Absolventen der Theologie, des kirchlichen und weltlichen Rechts, der Medizin und der Artes Liberales studiert, geleistet und bewirkt haben, auch im Hinblick auf «Staat), Städte, Kirche und Gesellschaft, dann muss man die Regionen des Alten Reiches mit weitem Abstand in den Mittelpunkt des Interesses rücken. Denn nirgends in Europa kann man so viel über so viele gelehrte Personen in Erfahrung bringen wie gerade hier. Dies war die Ausgangslage für das RAG, das von Peter Moraw in Giessen und mir in Bern gerade deswegen als ein rein digitales Projekt geplant und als Abteilung der Historischen Kommission bei der Bayerischen Akademie der Wissenschaften eingerichtet worden ist ${ }^{3}$.

Als Gelehrte im Sinne des RAG verstehen wir nicht sämtliche Universitätsbesucher, sondern nur jene, die an einer Universität Europas zum Magister Artium oder zum Bakkalarius, Licentiatus, Magister oder Doktor einer der höheren Fakultäten der Rechte, der Medizin oder der Theologie promoviert worden sind. Als Gelehrte gelten zudem jene, die nachweislich ein Studium an einer der höheren Fakultäten absolvierten, ohne sich jedoch einem Examen mit anschliessender Promotion zu unterziehen, darunter viele Adlige, die Universitätsbildung zwar nicht missen wollten, deren Standesqualitäten einem universitären Abschluss aber immer noch überlegen waren, was sich aber nach 1500 allmählich besonders für den Ritteradel zu ändern begann. Für diesen Kreis erwarten wir für die Zeit zwischen 1250 und 1550 mehr als 60'000 gelehrte Personen. Diese wollen wir mit soweit wie möglich vollständigen Lebensläufen auf empirisch ausreichend breiter Quellengrundlage erfassen. Pro Person gibt es im Durchschnitt sechs Ereignisse (Lebensstationen/ Beziehungen) bei freilich grossen Abweichungen zwischen 2 und derzeit 296 - damit gemeint

3 Das RAG wird im Förderprogramm der Union der deutschen Akademien von der Bayerischen Akademie betreut, und auch die Schweizerische Akademie der Geistes- und Sozialwissenschaften (SAGW) trägt das ihre dazu bei. Zum Konzept siehe Rainer Christoph Schwinges, Repertorium Academicum Germanicum. Ein Who's Who der graduierten Gelehrten des Alten Reiches (1250-1550), in: Gesammelte Beiträge zur Deutschen und Europäischen Universitätsgeschichte, hg. von Peter Moraw (Education and Society in the Middle Ages and Renaissance 31), Leiden/Boston 2008, S. 577-602; ders., Das Repertorium Academicum Germanicum (RAG). Ein digitales Forschungsvorhaben zur Geschichte der Gelehrten des Alten Reiches (1250-1550), in: Jahrbuch für Universitätsgeschichte 17 (2013 [2015]), S. 215-232; ders. u. Peter Moraw, Repertorium Academicum Germanicum (RAG) - Das Who's Who der graduierten Gelehrten des Alten Reiches (1250-1550), in: Jahresbericht der Historischen Kommission bei der Bayerischen Akademie der Wissenschaften, München 2004, S. 27-43; zuletzt Kaspar Gubler und Rainer Christoph Schwinges, Repertorium Academicum Germanicum (RAG): A new Database for web-based analysis and data visualization, in: Annali die Storia delle universà italiane 21.1 (2017), S. 13-24. Christian Hesse, Das Repertorium Academicum Germanicum (RAG). Perspektiven zur Erforschung der Gelehrten, ihrer Netzwerke und ihres Wirkens im Alten Reich (1250-1550), in: Stand und Perspektiven der Sozial- und Verfassungsgeschichte zum römisch-deutschen Reich. Der Forschungseinfluss Peter Moraws auf die deutsche Mediävistik, hg. von Christine Reinle, Affalterbach 2016, S. 53-64; ders., Das Wirken der Gelehrten in der Gesellschaft. Möglichkeiten und Perspektiven des Repertorium Academicum Germanicum (RAG), in: Wykształcenie uniwersyteckie i społeczeństwo Europy Środkowej w XV-XVIII wieku (Universitätsstudium und Gesellschaft in Mitteleuropa vom 15. bis zum 18. Jahrhundert), hg. von Krzysztof Ożóg et al. (Historia et Monumenta Universitatis Jagellonicae 5), Krakau 2018, S. 253-264. 
sind Geburt, Studium, Promotionen und verschiedenste Tätigkeiten - Schreiber, Schulmann, Pfarrer, Domherr usw. Rund 800 solcher Ereignisse sind uns bisher bekannt.

Die genannten ca. 60'000 Graduierten standen an der Spitze von mehr als 300'000 Studierenden aus dem Reich bis zur Mitte des 16. Jahrhunderts, machten also 20 Prozent aus. Für die damaligen Universitätsverantwortlichen waren diese 20 Prozent nach eigener Einschätzung die akademische Elite ${ }^{4}$. Dass man solche Zahlen überhaupt nennen kann, hängt fundamentalmit der vorzüglichen Quellenlage zusammen-damit, dass das Personalschriftgut, die entsprechenden Rektoratsmatrikeln und die anderen Universitäts- und Fakultätsakten einschliesslich jener der Deutschen Nationen in Frankreich und Italien in unerreichter Fülle erhalten und zugänglich sind. Anderswo in Europa fehlen diese Quellen, sodass man solche Forschungen, wie wir sie betreiben, gar nicht machen könnte . Diese universitären Quellen sind aber nur die Ausgangsquellen. Für die Lebensläufe der Gelehrten, die man auch erst einmal identifizieren muss, steht uns praktisch die Gesamtüberlieferung gegenüber und fordert mächtig heraus. Nicht alle Quellen sind so bequem zugänglich wie die römischen Repertorien oder die Produktionen der Historischen Kommission, zum Beispiel die Reichstagsakten und die Neue Deutsche Biographie (NDB) bzw. die digitale Deutsche Biographie. Der fundamentale Unterschied zwischen der erfreulich wachsenden Anzahl einschlägiger Veröffentlichungen zu einzelnen Gelehrten und dem RAG besteht darin, dass dort von oft günstigen, inselhaften Quellenbeständen aus durchaus ins Neue vorgestossen wird, während wir uns um ein umfassendes Grundlagenwerk bemühen, dass sich 〈guten〉 wie 〈schlechten〉 Quellen aussetzen und die Vergleichbarkeit immer für den gesamten Raum des Alten Reiches herstellen muss.

Der Gewinn ist jedoch, dass man sich mit Fragen an die Gelehrten weit über die Universitätsgeschichte hinaus Antworten auf eine ganze Reihe von zentralen Fragen holen kann, Fragen zum Beispiel, die der Nutzung der erworbenen schriftlichen und mündlichen Kompetenzen im öffentlichen Leben gelten, der Ausarbeitung und Anwendung von Herrschafts- und Verwaltungstechniken, der Bildung von Gelehrten- und Wissenschaftsnetzwerken, den Reichweiten des Wissens und seiner Vermittlung sowie der methodischen Schulung in Hof- und Verwaltungskarrieren, in Kirchen, in Gerichten und Schulen, königlichen, territorialen und städtischen Ämtern, in selbstständig bestimmten Professionen nicht nur der medizinischen und juristischen Praxis und nicht zuletzt auch in der Laufbahn des sich herausbildenden Universitätsprofessors. Gelehrte und ihr Wirken antworten aber auch auf Fragen, die weiter reichen, zum Beispiel nach den Möglichkeiten

4 Zum Graduierungs- bzw. Promotionsverhalten siehe Christian Hesse, Acta Promotionum II. Die Promovierten der Universitäten im spätmittelalterlichen Reich. Bemerkungen zu Quantität und Qualität, in: Examen, Titel, Promotionen. Akademisches und staatliches Qualifikationswesen vom 13. bis zum 21. Jahrhundert, hg. von Rainer Christoph Schwinges (Veröffentlichungen der Gesellschaft für Universitäts- und Wissenschaftsgeschichte 7), Basel 2007, S. 229-250.

5 Siehe Jacques Paquet, Les matricules universitaires (Typologie des sources du moyen âge occidental 65), Turnhout 1992; Rainer Christoph Schwinges, Warum gab es fast nur im deutschen Reich allgemeine Universitätsmatrikeln? Eine Frage der Reichweite, in: Reichweiten. Dynamiken und Grenzen kultureller Transferprozesse in Europa, ca. 1400-1520, hg. von Frank Rexroth et al., Göttingen (im Druck). 
sozialer Mobilität, dem Entstehen neuer Berufs- und Führungsgruppen, neuer oder ergänzter Eliten und der Akzeptanz von wissenschaftlich ausgebildeten Experten, letztlich auch deswegen nach dem Gefüge, dem Funktionieren und dem Wandel von Gemeinwesen in Stadt und Land.

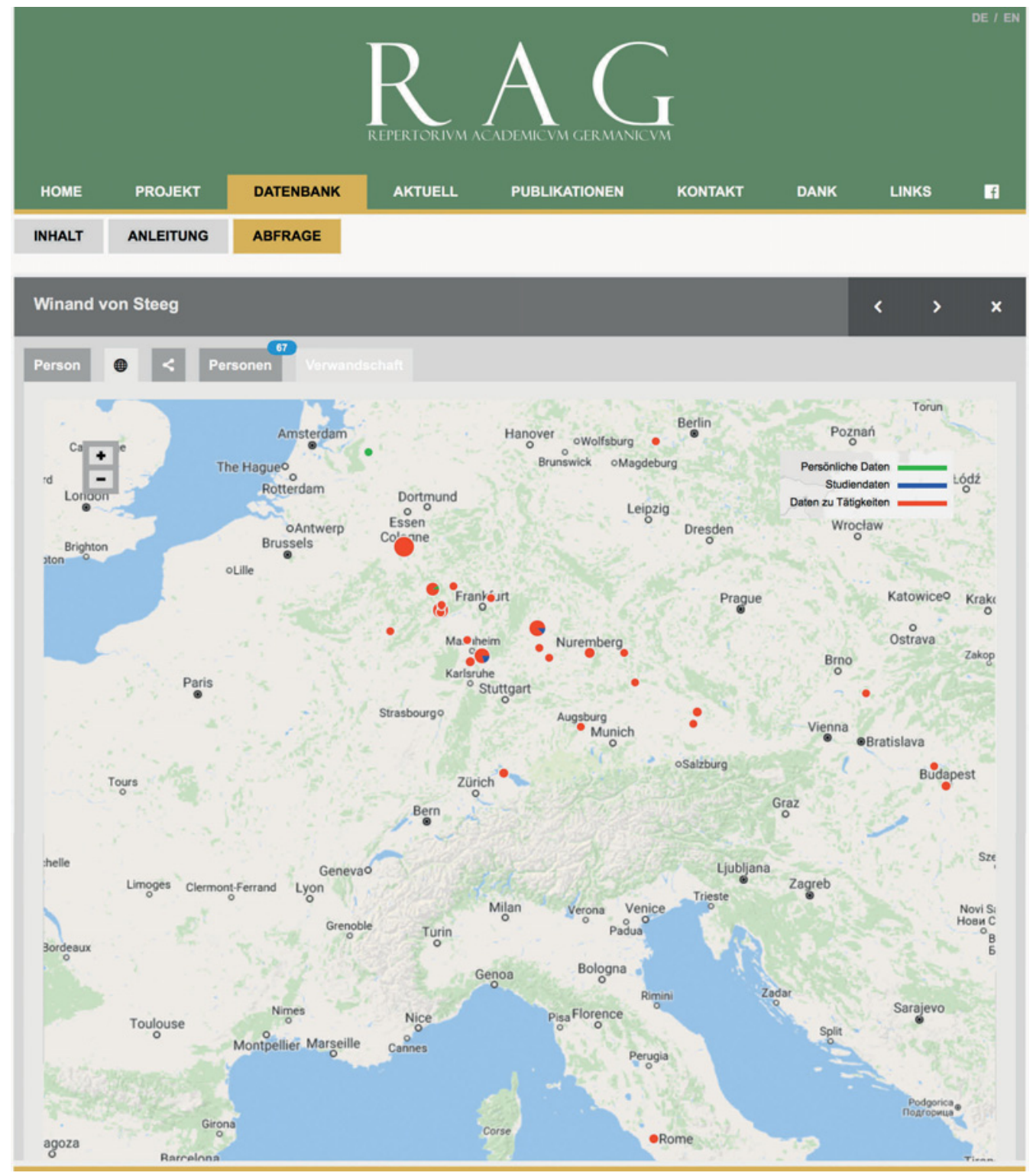

Abb. 2 Winand von Steeg, besuchte Orte/Lebensstationen 
Im Folgenden möchte ich das RAG in einigen Funktionen erläutern. Dabei werden uns drei Gewährsleute helfen, kleinere und grössere Persönlichkeiten des damaligen Gelehrtenlebens, wobei die Leitfrage immer mitgestellt ist, ob wohl das Studium für den späteren Lebens- und Berufsweg wichtig geworden ist oder nicht. Mit den ausgewählten Biographien wird zugleich eine Generationenfolge aus den deutschen Universitäten vom 15. bis zum 16. Jahrhundert angesprochen. In einem zweiten Schritt seien dann diese Biographien mit den Grundlagen und allgemeinen Beobachtungen der universitären Gelehrtengeschichte konfrontiert, wobei Recherchen und Visualisierungen demonstriert werden.

\section{Die Gewährsleute}

Winand von Steeg haben wir eingangs schon kennengelernt. Im RAG erscheint sein Profil wahlweise nach Ereignissen oder in chronologischer Folge (Abb. 2). Winand ist 1371 in eine vermutlich wohlsituierte Beamtenfamilie hinein geboren im Dorf Steeg, das zu Bacharach am Rhein gehörte ${ }^{6}$. Eine Bildungsreise führte ihn schon früh in die Niederlande und nach Rom. An der Kurie 1391 knüpft er für später wichtige Kontakte, so etwa mit dem apostolischen Protonotar Oddo Colonna, dem späteren Papst Martin V. 1394 ist er mit guten Pfründen ausgestattet zurück und beginnt ein Studium an seiner Landesuniversität zu Heidelberg, wo er 1401 zum Bakkalar des Kirchenrechts promoviert wurde. Als sein Kommilitone Johann von Egloffstein 1400 Fürstbischof von Würzburg geworden war und seinen Ehrgeiz daran setzte, auch in seinem Landesstaat eine Universität zu gründen, folgte ihm Winand dorthin, wurde Doktor und übernahm 1403 die Kirchenrechtsprofessur. Nach dem Tod ihres Förderers 1411 war diese erste Würzburger Gründung nicht mehr zu halten. Die akademischen Lehrer und Studenten verliessen Würzburg, so auch Winand von Steeg. Gerichts- und Beraterfunktionen, parallel zur Professur, wie damals üblich, hatten ihm schon wertvolle Kontakte gebracht, die nun spielten: Er wurde Rechtskonsulent der Reichsstadt Nürnberg und vielfach zu auswärtigen Missionen eingesetzt, darunter besonders wichtig zum Konstanzer Konzil, das bei allem anderen auch eine Bühne der Gelehrten war. Und «networking〉wäre hier ein Stichwort, so auch in Richtung des königlichen Kanzlers, des Passauer Fürstbischofs Georg von Hohenlohe. Dieser empfahl ihn dem König, und Sigismund nahm ihn mit nach Ungarn und ernannte ihn 1419 in Buda zum königlichen secretarius. Dem Gelehrten gefiel es aber nicht am Königshof, schon gar nicht an einem Reisehof, der ihn zwang, seine Bücherkiste immer mitzuschleppen (wie er selbst sagte). Winand hatte bald genug, nahm Urlaub von König und Kanzler und reiste nach Nürnberg zurück, wo er seine Konsulententätigkeit wieder aufnahm. Sein eigentliches Ziel war jedoch, sein

6 Über ihn vgl. Alois Schmidt und Hermann Heimpel, Winand von Steeg (1371-1453). Ein mittelrheinischer Gelehrter und Künstler und die Bilderhandschrift über Zollfreiheit des Bacharacher Pfarrweins auf dem Rhein aus dem Jahr 1426 (Handschrift 12 des Bayerischen Geheimen Hausarchivs zu München) (Abhandlungen der Bayerischen Akademie der Wissenschaften, Philosophisch-Historische Klasse, N. F. 81), München 1977; Enno Bünz, Winand von Steeg (1371-1453), in: Rheinische Lebensbilder, Band 5, hg. von Franz-Josef Heyen, Köln 1995, S. 43-64. 
Reisen zu beenden zugunsten einer Gelehrtenstube. (Man kann sich die besuchten Orte im Personenprofil von Abb. 2 darstellen lassen). Winand wollte die Werke dieser Jahre vollenden, juristische und theologische Abhandlungen, Predigtsammlungen, konziliare Reformschriften und nicht zuletzt einen Kommentar zur hebräischen Bibel, womit er zu den ganz frühen Hebraisten der deutschen akademischen Welt zählte.
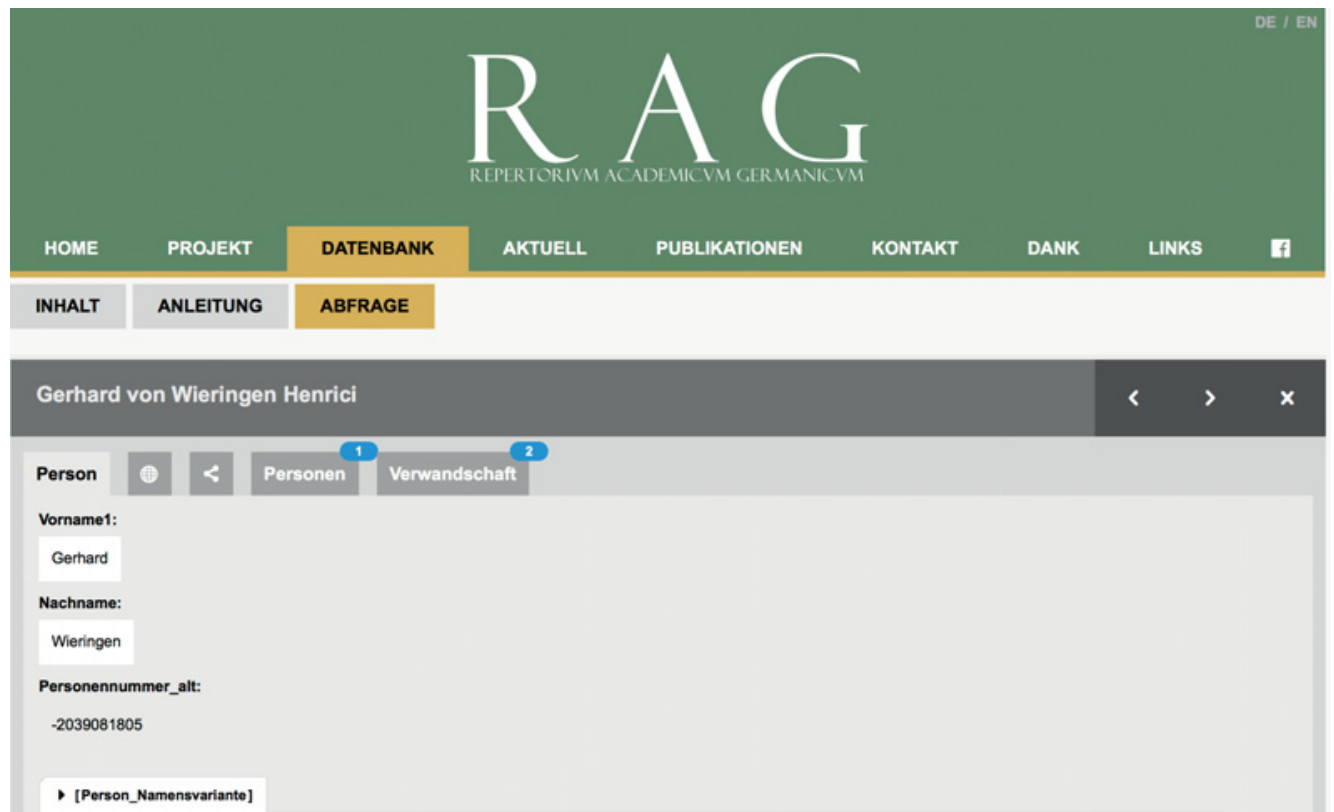

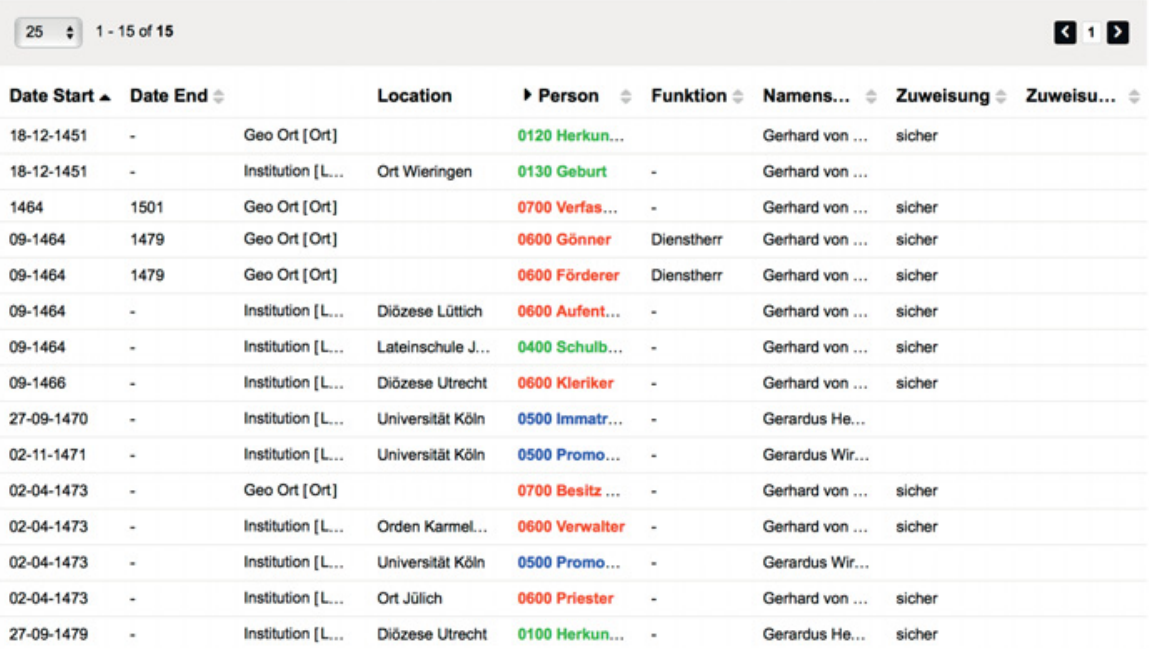

Abb. 3 Gerhard von Wieringen, Profil 
1421 konnte er sein Ziel endlich erreichen. Er wurde Chorherr an St. Andreas in Köln, und zwar zielgenau mit jener Präbende, mit der zugleich die Pfarrei St. Peter in Bacharach an seinem Heimatort verbunden war, wo das Andreasstift die Patronatsrechte innehatte. St. Peter war eine der reichsten Pfarreien am Mittelrhein, deren Einkommen v.a. auf dem Ertrag von zahlreichen Weinbergen beruhte und die nach alter Gewohnheit den Wein für das Kölner Stift zu liefern hatte. Daraus entstand 1425/26 ein spezieller Konflikt, der Winand besonders bekannt machen sollte und der sich in der in München aufbewahrten Handschrift 12 des Geheimen Hausarchivs niedergeschlagen hat. Gemeint ist sein Rechtsgutachten über die Zollfreiheit des Weintransports auf dem Rhein, die der Kurfürst negierte. Winand verfasste das Gutachten aber nicht allein, sondern holte sich die Hilfe von insgesamt 69 Personen, grösstenteils Professoren der Universitäten Heidelberg und Köln. Und er hatte noch mehr getan: Als er dem Kurfürsten Ludwig das Libellum übergeben durfte (eben die Handschrift 12), erfuhr dieser eine geballte Demonstration der zeitgenössischen Gelehrsamkeit, denn Winand hatte allen 69 Gutachten Abbildungen der Gelehrten beigegeben und dabei versucht, Portraitähnlichkeit anzustreben. Nun traten sie vereint vor den Kurfürsten, forderten und mahnten: denn natürlich ging es nicht um den Pfarrwein. In diesen Zeiten der Hussitenkriege ging es vielmehr darum, dem Kurfürsten klarzumachen, dass, wer sich am Kirchengut vergreift, nicht besser ist als ein Hussit, ein Ketzer. Wehret den Anfängen, war also die Idee des Ganzen, und sie hatte am Ende Erfolg, auch wenn es gelehrte Gegenmeinungen gab, die von Winand freilich nicht in sein Büchlein aufgenommen wurden ${ }^{7}$. Über den Inhalt hinaus, der uns den ganzen Gelehrtenhabitus, die geradezu professionelle Deutungsmacht der Expertise vor Augen führt, erleben wir im Libellum aber auch ein ausgezeichnetes und punktgenaues Funktionieren eines Gelehrtennetzwerkes mit gelehrten Kollegen und politischen Gönnern (es liesse sich auch für Winand im Personenprofil darstellen wie in Abb. 4). Nach vielen Jahren als Kirchenmann und Rat, gelehrter Autor und Maler ist Winand von Steeg 1453 in Koblenz gestorben.

Unser zweiter Gewährsmann, eine Generation später, ist Gerhardus Henrici de Wyringia oder Gerhard von Wieringen (Abb. 3). Er war ein Durchschnittsgelehrter, wie er tausendfach im RAG aus den verschiedensten Universitäten erscheint, für diesen Beitrag jedoch bewusst ausgewählt wegen einer kleinen Besonderheit, die zugleich eine grosse Seltenheit für das 15. Jahrhundert ist, ein privates Notizbuch ${ }^{8}$. Gerhard wurde im Dezember 1451 in einer Familie von Fischern, Käsern oder Torfstechern geboren, auf der früheren Insel Wieringen in der Zuidersee in Nordholland, was keineswegs heisst, dass er mittelloser Herkunft gewesen sei. Man konnte dem jungen Mann ein Studium finanzieren, wenigstens zu einem Teil. Für den Rest sorgten - viel wertvoller letzten Endes - gelehrte geistliche Onkel, die Magister Franko und Volker, Pfarrer in Jülich der

7 Dazu jetzt Tobias Daniels, Der Streit um die Zollfreiheit des Bacharacher Pfarrweis auf dem Rhein. Neue Rechtsgutachten zur Handschrift Winand von Steegs, in: Blätter für deutsche Landesgeschichte 150 (2104), S. 325-356.

8 Zu ihm Rainer Christoph Schwinges, Stiefel, Wams und Studium oder: Wozu hat man einen geistlichen Onkel. Aus Notizen des Kölner Studenten Gerhard von Wieringen aus der zweiten Hälfte des 15. Jahrhunderts, in: Reich, Regionen und Europa in Mittelalter und Neuzeit. Festschrift für Peter Moraw, hg. von Paul-Joachim Heinig, Sigrid Jahns et al., Berlin 2000, S. 543-563. 
eine, Pfarrer in Bergstein bei Düren der andere. Beide nahmen Gerhard unter ihre Fittiche, als er 1470 im normalen Alter von 18 Jahren zum Studium nach Köln kam, und wie viele seiner Landsleute aus Nordholland in der Burse des Magisters Cornelius von Dordrecht, wo auch schon die Onkel studiert hatten, bei Kost und Logis Unterricht erhielt. Gerhard durchlief das Studium in der Burse problemlos und vergleichsweise rasch, wurde Bakkalar 1471 und Magister der Artes bereits 1473 nach nur drei Jahren und suchte anschliessend dem familiären Wunsch gemäss sein Auskommen in der Kirche. Bemerkenswerterweise sorgte die Familie bzw. die ganze Verwandtschaft dafür, dass in jeder Generation mindestens eines ihrer Mitglieder studierte und in einer einträglichen Pfründe platziert wurde. Die Notizen in Gerhards Büchlein reichen über gut 40 Jahre hinweg von 1461 bis 1501 und betreffen vor allem seine Studienzeit. Nur erfahren wir leider nichts über Studienangelegenheiten oder gar Studieninhalte, sondern in aller Regel nur etwas über Käufe und Verkäufe alltäglicher Dinge sowie über einen auffälligen Hang für die Mode seiner Zeit, vor allem für Aufhellungen seiner dunklen Gelehrtentracht und die persönlichen Noten, die er mit Farben, Pelzen und Seidenfutter setzen wollte. Aus den zeitgenössischen Statuten des Freiburger Collegium Sapientiae ersieht man, was eigentlich verboten ist, aber gerade das wollte Gerhard haben - rote Hosen für den Ausgang9. Am Ende leitete er die Terminei der Karmeliten in Jülich. Nach 1501 ist er verstorben, nach einer bescheidenen Karriere, mit der er aber dann wieder einem Wieringer der nächsten Generation als gelehrter, geistlicher Onkel behilflich sein konnte.

Der dritte und jüngste Gewährsmann ist Huldrich Zäsi, später bekannt und berühmt als der Rechtslehrer Ulrich Zasius (Abb. 4) ${ }^{10} .1461$ wurde er in Konstanz geboren. Über seinen familiären Hintergrund ist nichts direkt bekannt. Erst mit 21 Jahren - als andere schon zum Magister promoviert wurden - schrieb er sich 1481 an der Universität Tübingen ein und erwarb 1483 den Grad eines baccalarius artium. Eine weitere akademische Karriere hatte Zasius zunächst nicht im Sinn; er kehrte vielmehr nach Konstanz zurück und übernahm um 1486, wofür selbst der unterste Grad der Universität offensichtlich auszureichen schien, einen Notarsposten in der bischöflichen Kanzlei zu Konstanz. 1489 wechselte er in gleicher Funktion in die Reichsstadt Buchhorn am Bodensee (heute Friedrichshafen) und im gleichen Jahr noch nach Baden im Aargau, wo er die Stadtschreiberei übernahm, eine trotz Kleinstadt bedeutende Position, weil hier die Tagsatzung der Eidgenossen zu Hause war. Zasius war damit zugleich scriba confederatorum und damit zuständig für alle Schreiben in die umliegenden Länder. Offenbar machte er sich damit bekannt. 1494 bot ihm die Stadt Freiburg im Breisgau ihr Stadtschreiberamt an. Zasius akzeptierte, übersiedelte nach Freiburg und begann dort zugleich mit privaten Rechtsstudien. Um diesen mehr Zeit widmen zu können, legte er das Amt 1496 nieder und übernahm das zumindest zeitlich weniger anspruchsvolle Amt des

9 Dazu mit Abbildungen Rainer Christoph Schwinges, Between Gown and Fashion: a Student's Clothing in the late 15th Century, in: Fashion and Clothing in Late Medieval Europe, hg. von dems. und Regula Schorta, Basel 2010, S. 25-35.

10 Über ihn Steven Rowan, Ulrich Zasius. A Jurist in the German Renaissance 1461-1535, Frankfurt am Main 1987; Karl Heinz Burmeister, Ulrich Zasius (1461-1535). Humanist und Jurist, in: Humanismus im deutschen Südwesten. Biographische Profile, hg. von Paul Gerhard Schmidt, Sigmaringen 2000, S. 105-123. 
Rektors der Freiburger Lateinschule, bis er auch dieses 1499 aufgab, um sich endgültig den Rechtswissenschaften zuwenden zu können. Bereits zwei Jahre später 1501 wurde er zum Doktor des weltlichen Rechts (dr. legum) promoviert. Zasius hatte sich damit zur Universitätslaufbahn entschieden, las zunächst Poesie und Rhetorik, übernahm dann ab 1503 die juristische Anfängervorlesung über die Institutionen, bis man ihm nicht zuletzt auf Druck der Studierenden 1506 die Lectura ordinaria legum übertrug, die er bis zum Tod 1535 innehatte. In dieser Zeit war Zasius einer der erfolgreichsten Rechtslehrer des Reiches, und dies, obwohl er nicht - wie die meisten seiner Kollegen in dieser Zeit - in Italien oder Frankreich studiert hatte (immerhin aber bei Paolo Cittadini aus Mailand).
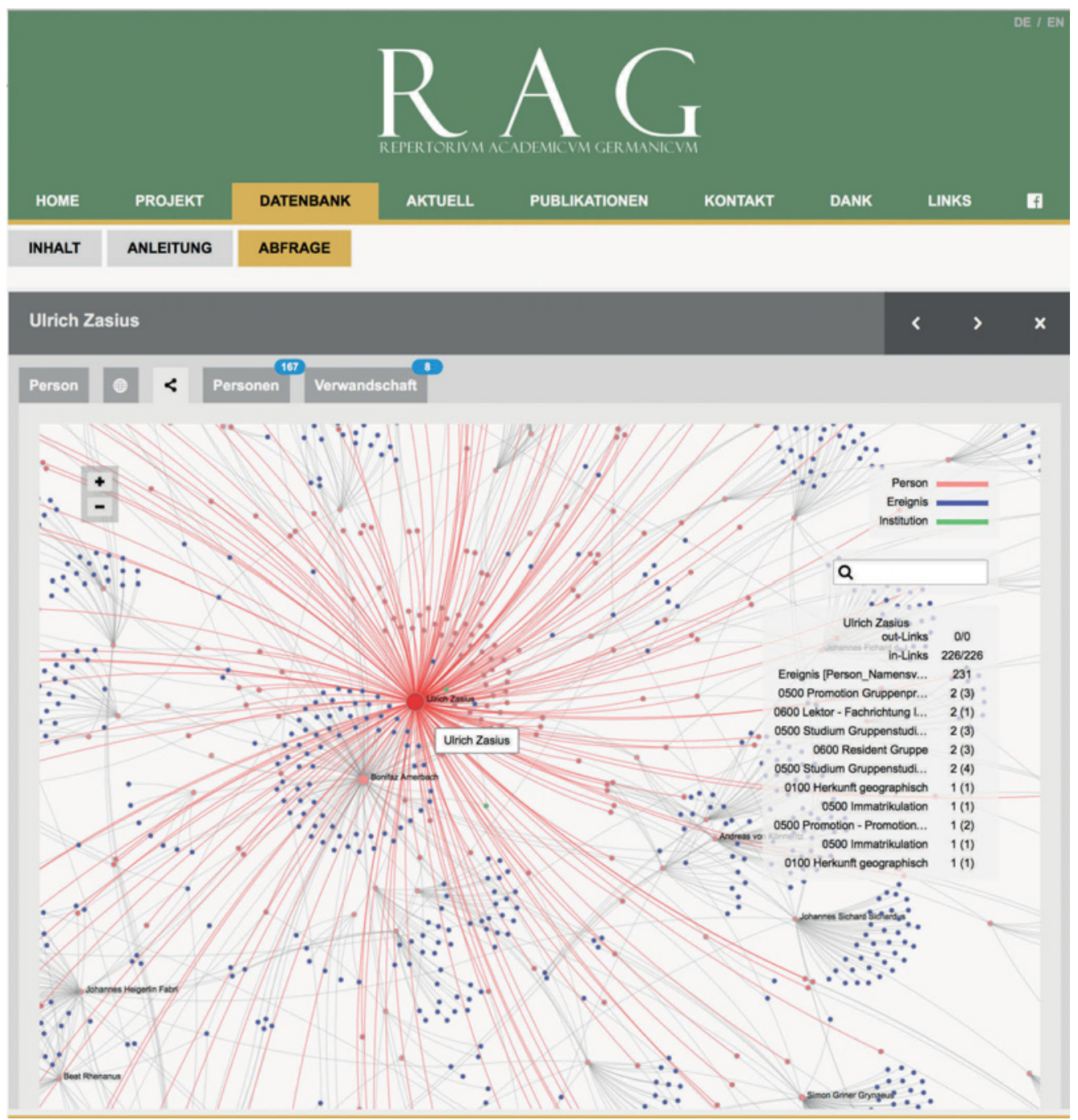

Abb. $4 \quad$ Ulrich Zasius, Netzwerk 
Er führte ein grosses Haus, war zweimal verheiratet, und über 130 seiner Schüler kann man namhaft machen (Abb. 4). Neben seiner Professur war Zasius noch vielfach als Berater und Anwalt tätig. In diesem Rahmen entstand seine Neufassung des Freiburger Stadtrechts von 1520, worin er in humanistischer Manier nach der ratio legis fragte und den rein praktischen Zweck jeder Regelung betonte, was damals enorm Schule machte.

Drei Beispiele - drei Erfahrungen im Umgang mit Universität bzw. gelehrter Bildung, wie man ihnen im Forschungsalltag begegnet: zum einen der vielgereiste, vielseitig begabte Heidelberger und Würzburger Rechtsgelehrte Winand, Künstler, Fachschriftsteller und Kirchenmann, begabt auch im «networking〉, dessen Ziel aber eigentlich die Gelehrtenstube war. Dagegen war für den Mann aus Wieringen und mit ihm für seine ganze Familie das Studium bis zum magister artium bereits ein grosser Schritt, der ihm dann immerhin ein Auskommen im niederen Klerus bescherte. Und schliesslich als neuer Typ um die Jahrhundertwende der Freiburger Professor Zasius, der ausgehend von einer Kanzleikarriere ohne jeden klerikalen Hintergrund nur noch Hochschullehrer war, überdies - auch das jetzt neu - ein verheirateter Hochschullehrer war, und verglichen mit Winand in einem relativ engen regionalen Rahmen agierte. Drei Beispiele - drei Erfahrungen, aber keineswegs repräsentative für die Tausenden Personen im RAG, deren Biographien man in gleicher Manier, wie hier gezeigt, über den Index online abrufen könnte. Aber man sieht schon die Spannweiten. Dies gilt es nun einzuordnen, und damit zugleich zu weiteren Arten der Darstellung zu kommen - zur Visualisierung von Rechercheergebnissen über die einzelnen Personen hinaus. Auch dazu noch einmal der Vermerk: Es ist «work in progress〉.

\section{Grundlagen und Einordnungen}

Als Universitäten auch nördlich der Alpen entstanden, Prag, Krakau, Wien, Heidelberg, Köln, Erfurt, Leipzig, Rostock, Löwen, wurden sie umgehend akzeptiert. Die Zahlen der Besucher und Absolventen stiegen seit dem ausgehenden 14. Jahrhundert unaufhörlich an. Wo man die entsprechenden Quellen hat, wie eben im Reichsraum die Matrikeln, kann man diese Entwicklungen auch gut beziffern (Abb. 5).

Die Universitäten erzeugten mit einer Wachstumsrate von 1,75 Prozent pro Jahr seit 1400 und einer Gesamtkapazität von über 4000 Universitätsbesuchern pro Jahr bereits in den 1480er- und 1490er-Jahren ein bis dahin unbekanntes Potenzial ${ }^{11}$. Bis 1550 aufsummiert, kann man mit den vorhin genannten 300'000 Personen rechnen, darunter die 60’000 Graduierten magistri und doctores, die im RAG berücksichtigt werden. Ein solches Wachstum fiel auch den Zeitgenossen auf. Nur eine Stimme unter vielen war der St. Galler Sattlermeister Johannes Kessler, der 1519 feststellte: ja kain Dorf, da nit zwen,

11 Rainer Christoph Schwinges, Deutsche Universitätsbesucher im 14. und 15. Jahrhundert. Studien zur Sozialgeschichte des Alten Reiches (Veröffentlichungen des Instituts für Europäische Geschichte Mainz, Universalgeschichte, 123), Stuttgart 1986, S. 30-36, ders., Universitätsbesuch im Reich vom 14. zum 16. Jahrhundert: Wachstum und Konjunkturen, in: Geschichte und Gesellschaft. Zeitschrift für Historische Sozialwissenschaften 10 (1984), S. 5-30. 
dry pfaffen oder studenten zu den fenster ußlugend ${ }^{12}$. Zur gleichen Zeit ca. 1519 kam es jedoch (Abb. 5) zum sogenannten Frequenzeinbruch durch die Reformationsereignisse ${ }^{13}$. Dies hatte weniger mit der Wissenschaftsfeindlichkeit der frühen Reformatoren zu tun als vielmehr mit der Tatsache, dass nun abrupt die Pfründen und mit diesen fundierte Stipendien vielfach wegbrachen und für viele Universitätsbesuch und Graduierung vorerst verunmöglichten. Bis dahin jedoch wurde das Angebot an Universitätsgebildeten immer grösser, weil auch die im Laufe des 15. Jahrhunderts neu entstandenen Universitäten (Greifswald, Freiburg, Basel, Ingolstadt, Tübingen, Wittenberg) Bildungsreserven zusätzlich aus dem jeweils regionalen Umfeld schöpften.

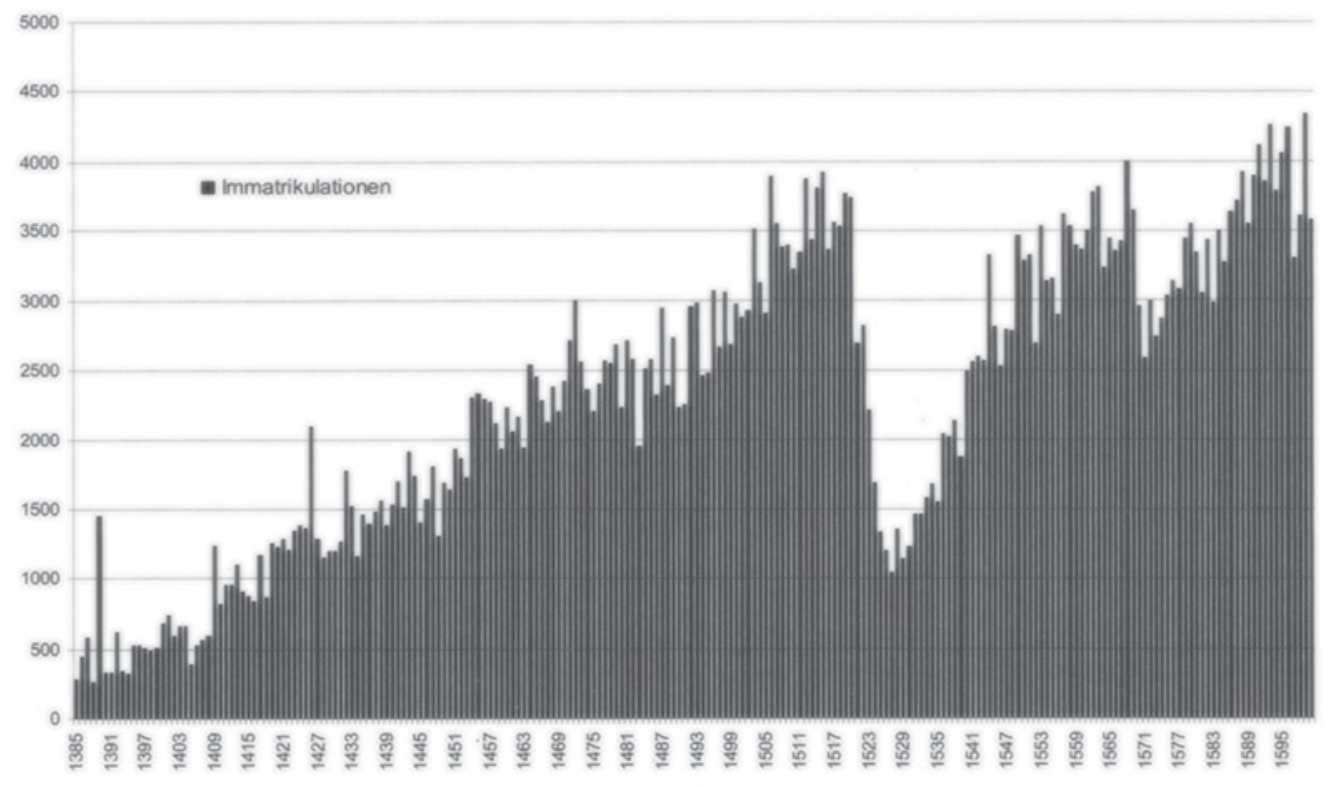

Abb. 5 Reichsfrequenz (1385-1600). Quelle: Beat Immenhauser, Bildungswege (wie Anm. 13)

Das RAG ist inzwischen in der Lage, was es bisher in diesem Forschungsfeld noch nie gegeben hat, in einem digitalen Atlas nach den Prinzipien 〈incoming) und 〈outgoing〉 vergleichende Einblicke in Räume zu gewähren, zum einen in Einzugsräume von Universitäten (incoming), zum anderen in Tätigkeits- oder Berufsräume von Absolventen (outgoing). Die zugrunde liegenden Karten kann man wählen, auch eine Diözesankarte des Reiches, da die kirchliche Raumgliederung in den Universitäten selbst noch nach der

12 Zitiert nach Beat Immenhauser, Bildungswege - Lebenswege. Universitätsbesucher aus dem Bistum Konstanz im 15. und 16. Jahrhundert (Veröffentlichungen der Gesellschaft für Universitäts- und Wissenschaftsgeschichte 8), Basel 2007, S. 11.

13 Ebd., S. 608; dazu auch ders., Universitätsbesuch zur Reformationszeit. Überlegungen zum Rückgang der Immatrikulationen nach 1521, in: Jahrbuch für Universitätsgeschichte 6 (2003), S. 69-88. 
Reformation weit verbreitet war. Alle Suchergebnisse lassen sich auch in Tabellenform oder in Statistiken ausgeben oder auf dem digitalen Atlas so visualisieren, dass sie zu neuen Analysen animieren.

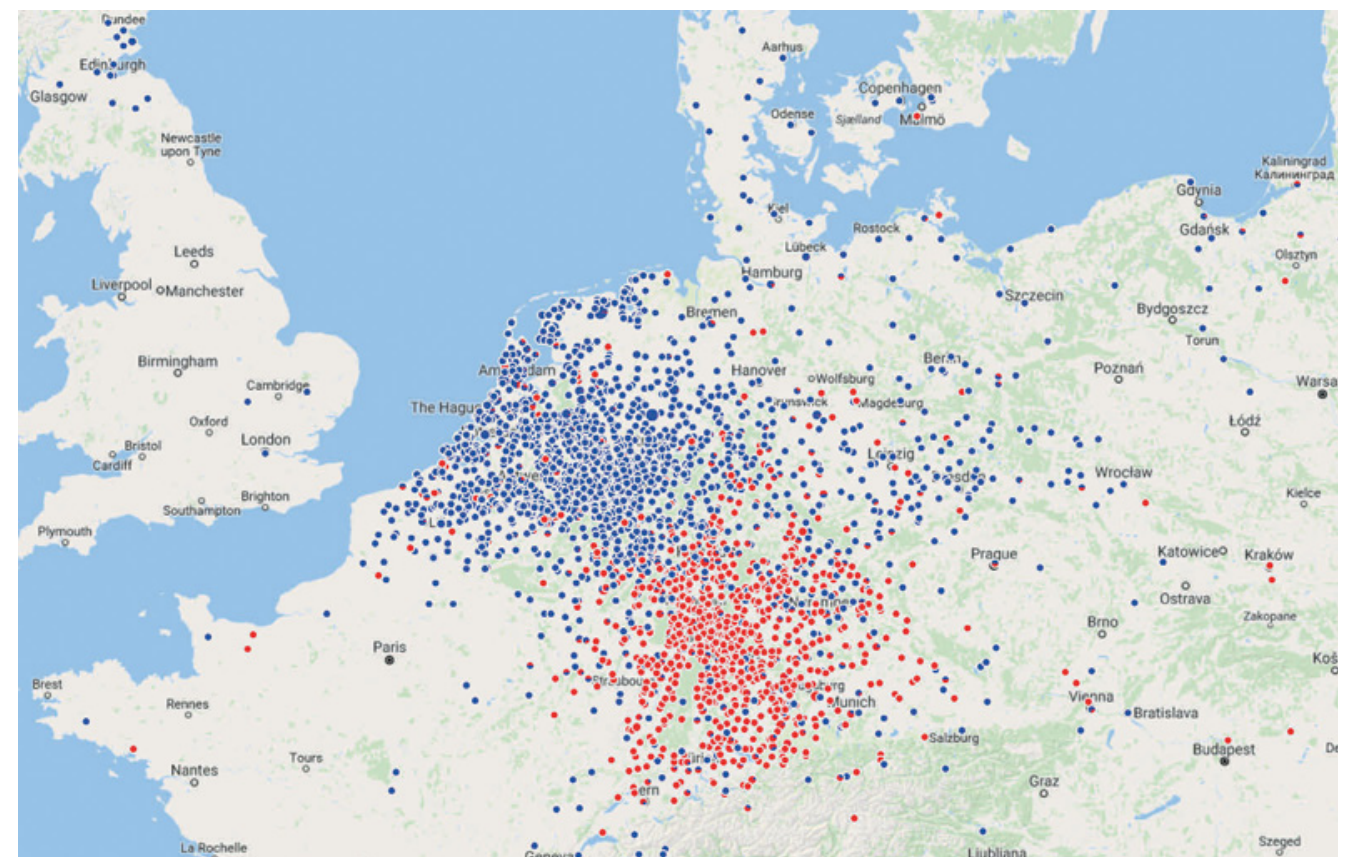

Abb. 6 Einzugs- und Kommunikationsräume der Universitäten Heidelberg (rot) und Köln (blau) 1450-1550 (Jahresschritte)

\section{Einzugsräume (incoming)}

Zunächst einige Beispiele zu Einzugsräumen, die zugleich Migrations- und Kommunikationsräume der Gelehrten sind: Abb. 6 zeigt den Einzugsraum der Universität Heidelberg, wo Winand von Steeg studierte (1400-1550). Man könnte sich via Zeitleiste jeden Raum in Ein- oder in Mehrjahresschritten differenziert ansehen und dazu in die Karten hineinzoomen, um einen kleineren Ausschnitt, in Prinzip bis auf die Dorfebene, zu erhalten. Jede Universität schöpft aus einem Kernraum, dem regionalen Umland - hier Mittel- und Oberrhein ${ }^{14}$. Was darüber hinausgeht, muss man gesondert erklären können, wie das starke Ausgreifen zum Beispiel in die Niederlande. Dies war einerseits der ersten Generation der Heidelberger Gelehrten geschuldet (nach 1386), die vielfach aus den

$14 \mathrm{Zu}$ solchen Raumstudien siehe Schwinges, Deutsche Universitätsbesucher (Anm. 10), S. 221-341; ders., Entre régionalité et mobilité: Les effectifs des universités dans l'Empire romain germanique aux XVe et XVIe siècles, in: Les Échanges entre les Universités Européennes à la Renaissance, hg. von Michel Bideaux et Marie-Madeleine Fragonard, Genève 2003, S. 359-373. 
Niederlanden stammten und Landsleute nachzogen, andererseits später den Folgen der Reformation. Die alten Niederlande gehörten aber auch zusammen mit Niederrhein und Westfalen zum Kernraum der Kölner Universität (Abb. 6), woher unser Gewährsmann Gerhard von Wieringen stammte. Man sieht sofort die grosse Überregionalität Kölns.

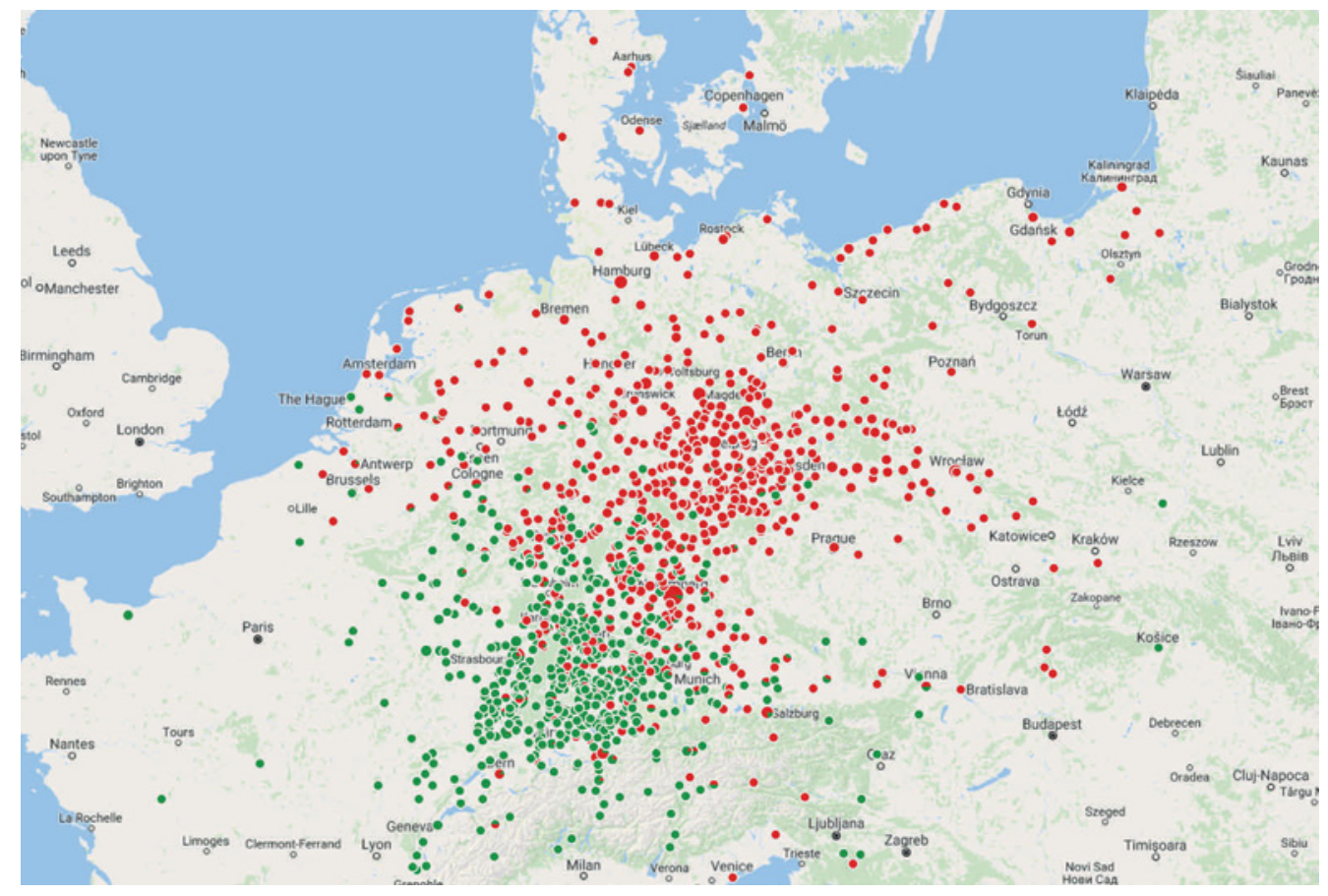

Abb. 7 Einzugs- und Kommunikationsräume der Universitäten Freiburg im Breisgau (grün) und Wittenberg (rot) 1500-1550 (Jahresschritte)

Hier folgen offensichtlich die Wege der Gelehrten denen der Kaufleute der grossen Fernhandels- und Hansestadt europaweit. Ein weiteres Beispiel zeigt die Gelehrten im Einzugsraum bzw. in der Reichweite der Universität Freiburg (Abb. 7), dem Wirkungsort von Ulrich Zasius. Auch hier sieht man wieder die klare Konzentration auf die Kernregion, Vorderösterreich, Nordostschweiz und Schwaben, dazu in einem weiteren Umkreis Gebiete, die zum Teil wohl der Tatsache, dass Freiburg habsburgische Landesuniversität war, zuzuschreiben sind, wie zum Beispiel Burgund, Lothringen/ Luxemburg im Westen oder Franken im Norden, woher gerade etliche studierende Angehörige ritteradeliger Familien stammten. Auch dass Freiburg nach der Reformation katholische Universität blieb, spielte dabei eine Rolle.

Das Stichwort Reformation lässt auch nach der Reichweite Wittenbergs fragen, hier im Vergleich mit Freiburg (Abb. 7) für die Zeit zwischen 1502 (der Gründung Wittenbergs) und 1550. Man sieht, dass Wittenberg zwar einen kleinen, wenig auffallenden Kernraum in Sachsen hatte, aber von Anfang an wesentlich überregional rekru- 
tierte, und seine gelehrten Absolventen praktisch das gesamte Reich, insbesondere in der Mitte bis hinunter in den Süden, repräsentierten. Kein Wunder, dass nach der Reformation deren Ideen auch aus der akademischen Perspektive eine solche Reichweite bekamen. Als Letztes in der Serie der Einzugsräume sei der Raum von Ingolstadt (dem Vorläufer der Münchner Universität) gezeigt (Abb. 8). Wären wir online, so könnte man sehen, wie sich via Zeitleiste ein solcher Raum in Ein- oder Mehrjahresschritten aufbaut. Man könnte dann erkennen, wie sich in den Jahren von 1472 bis 1550 ein klarer Kernraum von Franken und Bayern ausgehend bildete und sich dieser am Ende (aufsummiert bis 1550, wie man hier sieht) auf fast ganz Süddeutschland ausdehnte. Für alles Weitere darüber hinaus muss man die entsprechenden Fragen stellen.

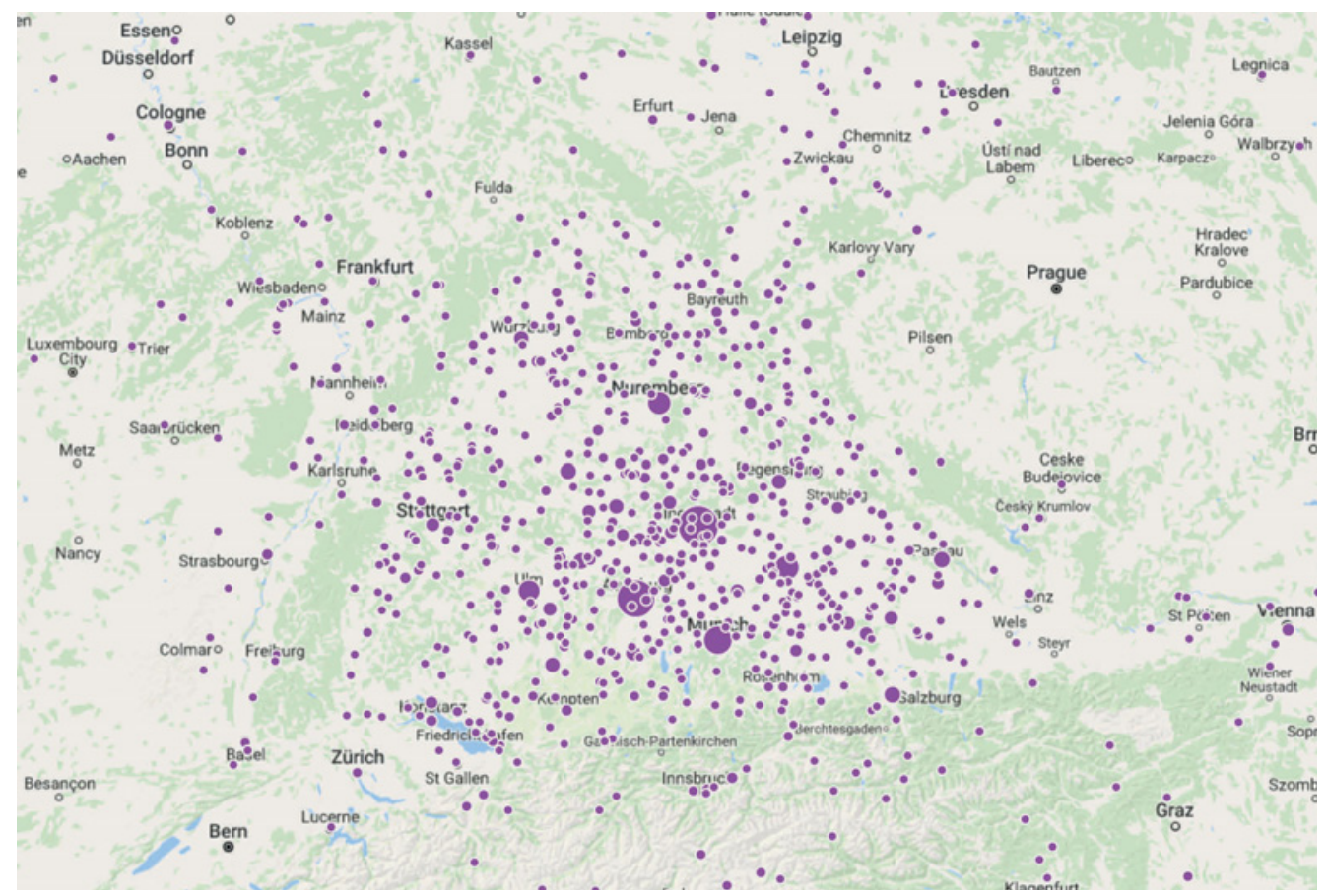

Abb. 8 Einzugs- und Kommunikationsraum der Universität Ingolstadt 1472-1550 (Jahresschritte) 


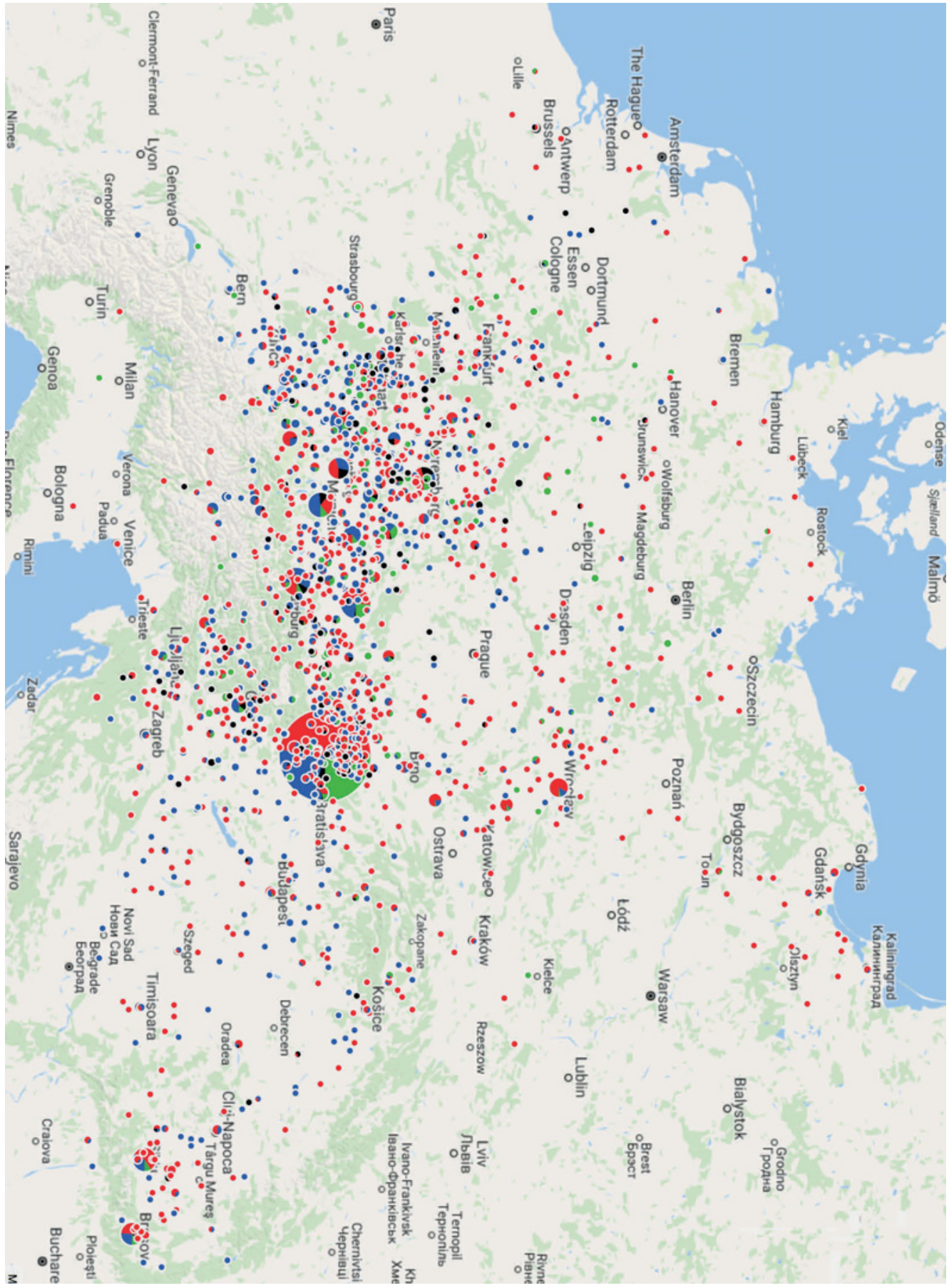

Abb. 9 Einzugs- und Kommunikationsräume der Wiener Artistenmagister (blau) und der graduierten Juristen (rot), Mediziner (grün) und Theologen (schwarz) 1400-1550 
Betrachtet haben wir bisher die Einzugsräume insgesamt, nun wollen wir sie nach Fakultäten bzw. Fachrichtungen aufteilen. Doch zunächst gilt es, wieder einzuordnen. Das Angebot der universitären Ausbildung wurde im Reich zwar stark frequentiert, jedoch mit höchst unterschiedlichen Anteilen an den vier Fakultäten der Theologie, der beiden Rechte, der Medizin und der artes liberales. Man darf dies in keiner Diskussion um die Wirkung und Leistung der mittelalterlich-vormodernen Universität und der gelehrten Tätigkeiten ausser Acht lassen. Denn im Gegensatz zu den süd- und westeuropäischen Juristen- und Mediziner-Zentren rekrutierten die deutschen Universitäten ihre Besucher im Durchschnitt zu 80 Prozent und mehr als Artisten. Keineswegs nur die kleineren Universitäten, wie man aus Kapazitätsgründen denken könnte, waren fast reine Artistenschulen. Zwischen 1402 und 1502 gehörten im Schnitt nur 8 Prozent der Wiener Universitätsbesucher der dortigen juristischen Fakultät an, knapp 6 Prozent der theologischen, knapp ein Prozent der medizinischen, mithin 85 Prozent der artistischen Fakultät $^{15}$. Was das bedeutet hat, etwa für die geistige Entwicklung im deutschsprachigen Raum, ist eine noch völlig ungelöste Frage, die man aber auch erst einmal stellen muss ${ }^{16}$.

Der Einzugsraum der Artistenfakultät der Universität Wien, repräsentiert durch ihre Magister, ist hier bis 1550 aufsummiert (Abb. 9). Bei der hohen Zahl der Wiener Artisten kommt dieser praktisch dem Gesamteinzugsraum sehr nahe. Deutlich erkennt man den regional weit gespannten Schwerpunkt Wiens von Niederösterreich nach Westen bis zum Rhein, aber auch nach Osten hin nach Ungarn. Besonders deutlich sieht man hier ebenfalls, was aber für alle universitären Einzugsräume der Zeit gilt, wie Böhmen weitgehend ausgeblendet wird - Böhmen ist Hussitenland. Die Juristen folgen den Artisten schwerpunktmässig, setzen aber auch im überregionalen Rahmen Akzente, was noch deutlicher bei den Medizinern (Abb. 9) zu sehen ist. Möglicherweise spielte dabei die Konzentration der Wiener Fakultät auf die Pestmedizin eine Rolle. Die Theologen dagegen entstammten fast ganz dem Kernraum von Wien bis Schwaben, fast gar nicht aus dem Osten, mit 〈Ausreissern〉 lediglich am Niederrhein. Man bemerkt, dass durch die Visualisierung der Recherchen die Quellen in einen anderen Aggregatzustand überführt werden und dass dieser sofort zu neuen Fragen lenkt. Was bedeuten solche Konstellationen? Antworten wird man durch eine jetzt gezielte, vergleichende Analyse der beteiligten Personen bzw. ihrer Biographien erwarten können.

15 Siehe Beat Immenhauser, Wiener Juristen. Zur Sozialgeschichte der juristischen Besucherschaft der Universität Wien von 1402 bis 1519, in: Mitteilungen der Österreichischen Gesellschaft für Wissenschaftsgeschichte 17 (1997), S. 61-102, hier: 67.

16 Vgl. zum Beispiel Rainer Christoph Schwinges, Das Reich im gelehrten Europa. Ein Essay aus personengeschichtlicher Perspektive, in: Heilig - Römisch - Deutsch. Das Reich im mittelalterlichen Europa, hg. von Bernd Schneidmüller und Stefan Weinfurter, Dresden 2006, S. 227-250, hier: 243-247. 


\section{Tätigkeitsräume (outgoing)}

Betrachten wir abschliessend ein paar Beispiele zum outgoing, dazu, was aus gelehrten Absolventen geworden ist. Man muss sich zuvor freilich klarmachen - auch eine der wichtigen Grundlagen -, dass dem wachsenden Angebot an Universitätsleuten noch kein angemessener Bedarf gegenüberstand und folglich auch kaum entsprechende Nachfrage, weder an Königs- und Fürstenhöfen noch in den Städten, Schulen, Ämtern und Gerichten, noch in der Kirche. Unsere bald 60'000 Gelehrten im RAG sind zunächst einmal nur eine Quantität, die auf qualitative Aussagen wartet. Es ist eine schon alte Erkenntnis, dass man die akademische Wachstumsgeschichte nicht eins zu eins in eine Erfolgsgeschichte umdeuten kann, nicht gleich in neue Qualitäten der beruflichen Tätigkeit oder gar der Professionalität. Dennoch wird man erwarten dürfen, dass Berufsfelder entstanden sind, in denen universitär erworbenes Wissen wirkungsvoll und förderlich umgesetzt werden konnte. Die eingangs vorgestellten Gewährsleute haben schon etwas davon demonstriert. Meine These ist seit Längerem, dass der pure Angebotsdruck, auch der massenhafte Druck durch die Artisten, die Dinge neu in Bewegung brachte und berufliche Möglichkeiten ausweitete, sodass das eindringende akademisch gebildete Personal schliesslich auch für sich selbst die Aufgabenbereiche definierte, was ich für ausserordentlich zukunftsträchtig halte. Das alles geschah allerdings unter grossen regionalen Schwankungen mit entsprechenden zeitlichen Verzögerungen ${ }^{17}$.

Die folgende Karte (Abb. 10) zeigt Tätigkeitsorte von Gelehrten im Berufsfeld Stadtschreiber bis 1550. Sie ist anders als bei den Einzugsräumen eine Momentaufnahme aus dem Forschungsprozess, die sich bald wieder verändern kann. Aber eine Tendenz ist jetzt schon sehr deutlich zu sehen: Nicht dass es nicht überall Stadtschreiber gegeben hätte, im Süden jedoch, am Oberrhein, in Schwaben, Franken und Bayern beschäftigte man bereits mehr akademisch gebildete Stadtschreiber als im Norden. Problematisch ist dabei nur, was man bis weit ins 16. Jahrhundert immer wieder bemerken wird, dass kaum strukturelle und personelle Kontinuitäten aufkamen, man für bestimmte Positionen keine akademische Qualifikation voraussetzen darf, nur weil diese einmal Gelehrte innegehabt hatten. Alles hing eigentlich immer noch sehr von jenen Personen $\mathrm{ab}$, die gerade vorhanden waren oder sich anboten. Gelehrten- und Amtsdynastien, die das Studium in ihre Familienstrategie aufnahmen, steckten noch in den Anfängen. Problematisch ist ferner, dass man immer auch Personen in den genannten Tätigkeitsbereichen findet, die die Universitäten ohne jede Graduierung verlassen oder gar nie eine Universität besucht haben, und zwar in mindestens ebenso grosser Zahl wie die der nachweislich Graduierten. Immer gab es Alternativen zum Akademiker. Unser Gewährsmann Ulrich Zasius war erst der dritte Gelehrte im Freiburger Stadtschreiberamt, als er die Kanzlei 1494 übernahm, und er hatte nur noch einen gelehrten Nachfolger.

17 Vgl. dazu und zum Folgenden Rainer Christoph Schwinges, Zur Professionalisierung gelehrter Tätigkeit im deutschen Spätmittelalter, in: Recht und Verfassung im Übergang vom Mittelalter zur Neuzeit, Teil II: Bericht über Kolloquien der Kommission zur Erforschung des Spätmittelalters. 1996-1997, hg. von Hartmut Boockmann et al. (Abhandlungen der Akademie der Wissenschaften in Göttingen, phil.-hist. Klasse, 3. Folge 239), Göttingen 2001, S. 473-493. 
Danach beschäftigte die Stadt bis 1598 nur mehr nicht gelehrte Personen, die offenbar in den Stadtkanzleien selbst als Schreiber und Notare ausgebildet werden konnten ${ }^{18}$. Es ist jedenfalls ein langwieriger Prozess gewesen, bis sich gelehrtes Personal durchgesetzt hat und mit seinem universitär erworbenen Wissen so als Experten akzeptiert wurden, dass ihre Positionen oder Berufsfelder ihnen nicht mehr von anderen streitig gemacht werden konnten.

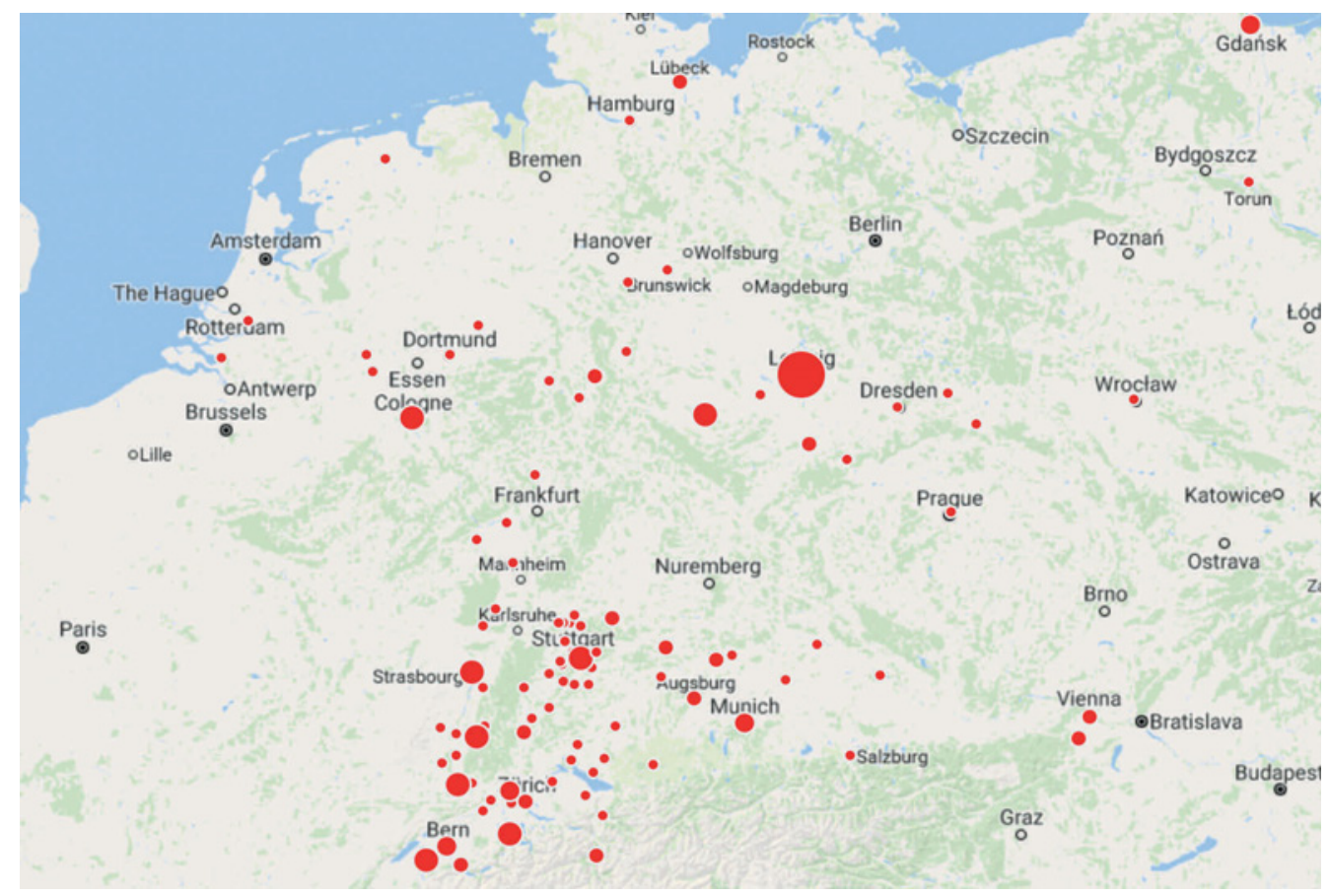

Abb. 10 Gelehrte Stadtschreiber bis 1550

Ein bisschen schneller ging es wohl in der Kirche, wo etwa zwei Drittel aller Gelehrten - so wie Winand von Steeg und Gerhard von Wieringen - ihren Platz fanden. Das lag sicher auch an den studienfördernden Dekreten der Konzilien des 15. Jahrhunderts ${ }^{19}$. Die Domstifte z.B. waren schon relativ früh nach dem Prinzip status aut gradus (entweder adlig oder graduiert) besetzt. Die Karte in Abb. 11 zeigt alle Absolventen deutscher und auswärtiger Universitäten an ihren jeweiligen Studienorten, die zugleich oder später als Domherren tätig geworden sind (rote Punkte), verglichen mit jenen davon, die auch zum Doktor des Kirchenrechts oder beider Rechte promoviert worden sind (blaue Punkte).

18 Vgl. Folkmar Thiele, Die Freiburger Stadtschreiber im Mittelalter, Freiburg im Breisgau 1973.

19 Dazu Heribert Müller, Universitäten und Gelehrte auf den Konzilien von Pisa (1409), Konstanz (1414-1418) und Basel (1431-1449), in: Universität, Religion und Kirchen, hg. von Rainer Christoph Schwinges (Veröffentlichungen der Gesellschaft für Universitäts- und Wissenschaftsgeschichte 11), Basel 2011, S. 109-144. 
Die deutschen Domkapitel waren schon recht stark mit Juristen besetzt. Das ist eigentlich nicht das Erstaunliche; man weiss um die Präsenz der Juristen in der Kirche. Dass aber bis 1550 überhaupt kein promovierter Theologe in einem deutschen Domstift erscheint, ist dann - ich betone in der Tendenz - doch schon auffällig. Daran werden erst die Bildungsreformen des Konzils von Trient nach 1563 etwas - langsam - ändern. Bis dahin waren die Nichtjuristen in den allermeisten Fällen entweder Artistenmagister oder ungraduierte adelige Universitätsbesucher.

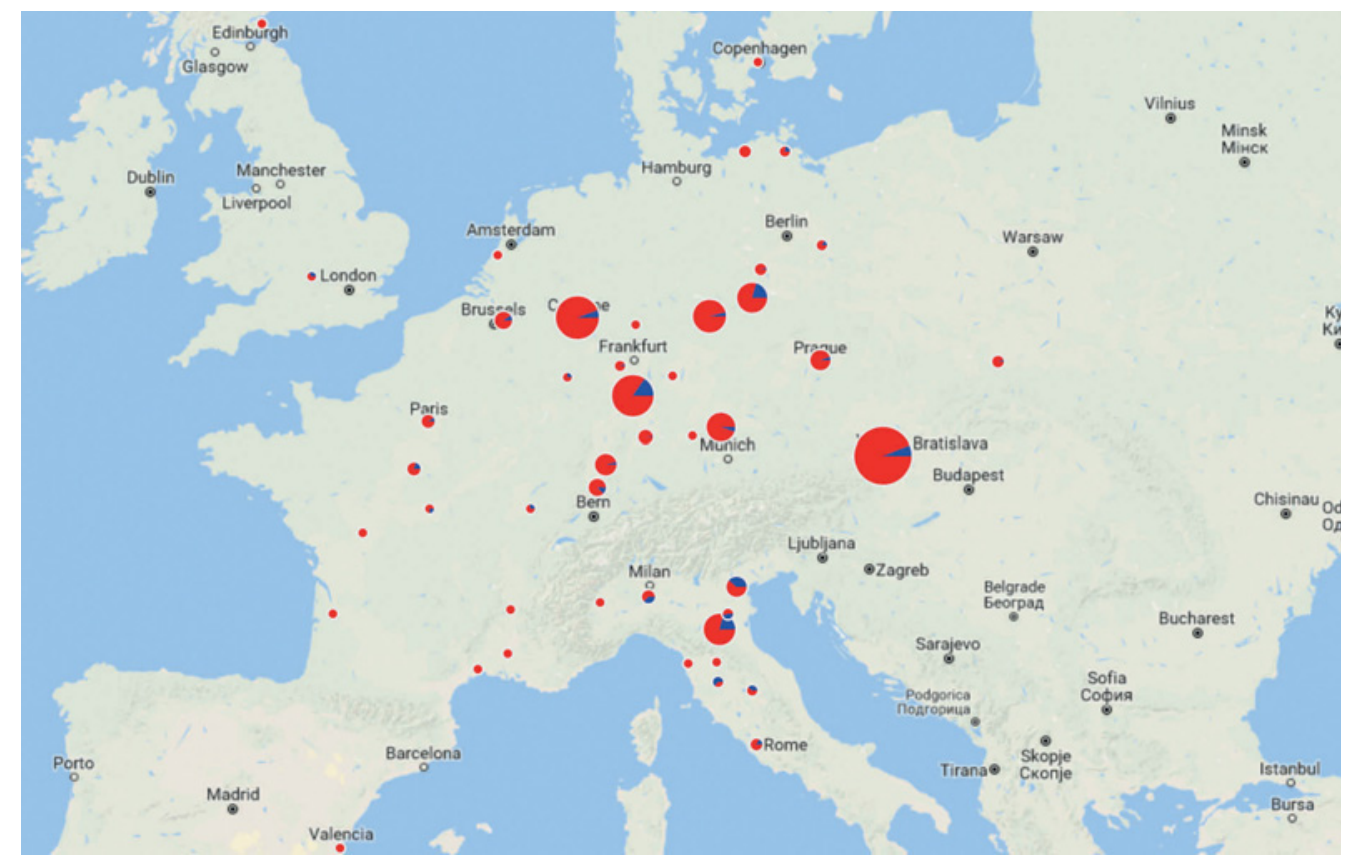

Abb. 11 Domherren (rot) im Vergleich zu juristisch promovierten Domherren unter innen (blau) an ihren jeweiligen Studienorten bis 1550

Die einzigen Tätigkeiten, in denen Gelehrte eine gewisse Alleinstellung erzielten, wenn man von der Universität einmal absieht, wo natürlich nur ein Graduierter einen Professorenplatz besetzen konnte, waren die freiberuflichen, etwa bei den Stadtärzten. Gewiss gab es vielfach medizinisches Personal für die städtische Krankenversorgung, aber für den Posten des Stadtphysikus brauchte es doch den gelehrten Doktor der Medizin. Die obige Karte (Abb. 12) - wiederum eine Momentaufnahme im Forschungsprozess - zeigt aber jetzt schon in der Tendenz, wann, wie und wo sich innerhalb des Reiches eine akademische Stadtärzteschaft heranbildete. Wären wir wie im obigen Ingolstädter Beispiel (Abb. 7) online, so könnte man ebenfalls via Zeitverlauf sehen, wie zuerst kurz nach 1400 Städte entlang des Rheins erscheinen, ihre Zahl sich mehrt und auch die Zahl der Ärzte an einem Ort in einer gewissen Kontinuität des Amtes zunimmt. Dann treten ab ca. 1470 süddeutsche Städte hinzu und erst nach 1500 Städte im 
mittleren und nördlichen Deutschland, die sich Stadtphysici leisteten. Es ist eine bekannte Erscheinung, die hier wiederum sichtbar wird, dass der rheinische Raum auf seiner ganzen Länge sowie der südliche Raum vor allem der schwäbischen Reichsstädte in vieler Hinsicht Vorsprungslandschaften innerhalb des Reiches waren ${ }^{20}$, was offenbar auch für den Einsatz von Stadtschreibern und Stadtärzten zu gelten scheint.

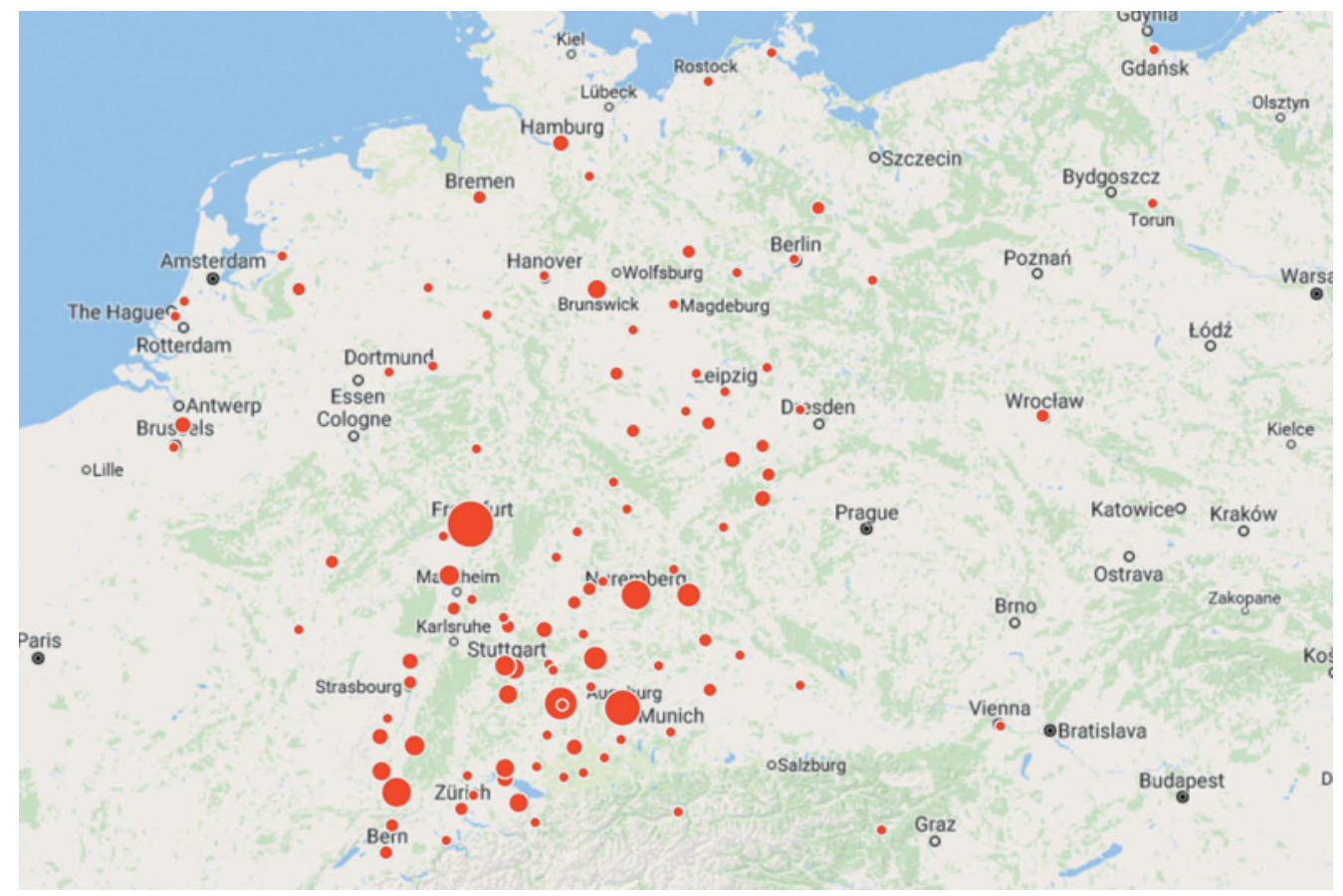

Abb. 12 Stadtärzte (dr. med.), ca. 1400-1550

\section{Schlusswort}

Die deutschen Universitäten haben seit dem ausgehenden 14. Jahrhundert Absolventen, graduierte Gelehrte, in stetig wachsendem Masse in die Welt entlassen. Aber niemand hat auf sie gewartet und ihr Angebot an fachlicher Expertise in gleichem Masse angenommen. Selbst in der Kirche mussten sie ihre Plätze gegen vielfache Konkurrenz und auch gegen Widerstände erst finden, was bis weit ins 16. Jahrhundert hinein andauern sollte. Das RAG ist dazu da, diesen Findungsprozess zu begleiten und seine Usance aufzudecken. So nett vielleicht das Zitat im Titel des Beitrags klingt, doctores so in den

20 Zum Phänomen vgl. auch Werner Paravicini (Hg.), Nord und Süd in der deutschen Geschichte des Mittelalters, Sigmaringen 1990; Rainer Christoph Schwinges, Innovationsräume und Universitäten in der älteren deutschen Vormoderne in: Innovationsräume. Woher das Neue kommt - in Vergangenheit und Gegenwart, hg. von dems., Paul Messerli und Tamara Münger, Zürich 2001, S. 31-44. 
püchern lesen, so nett war es zunächst gar nicht gemeint. Albrecht Achilles, Markgraf von Ansbach und Kurfürst von Brandenburg, einer der wichtigsten Reichsfürsten der zweiten Hälfte des 15. Jahrhunderts, hatte zu Gelehrten zunächst ein sehr kritisches Verhältnis. Zu Beginn seiner Regierungszeit, seit 1440 in Ansbach, hielt er noch wenig von den Doctores, so in den püchern lesen. Dadurch sie maynen, allem einen schein zu geben, es hab grund oder nicht. Und Albrecht stand um die Mitte des Jahrhunderts mit dieser Ansicht beileibe nicht allein. Irgendwie gebraucht, immerhin, aber nicht sonderlich geachtet, schien das Los der Gelehrten zu sein - doch der Brandenburger schien bald einmal, vor allem nach Übernahme der Kurwürde 1470, gelernt zu haben, wie nützlich ihm und seinen Landesstaaten Gelehrte sein konnten: Bei seinem Rat Hertnidt von Stein, einem Doktor des Zivilrechts von Bologna, bedankte er sich für erfolgreiches Wirken zugunsten Brandenburgs an der Römischen Kurie mit den Worten: Schick einen weysen und bevihle im wenig, so richt er vil auß oder schick einen toren und bevihle im vil, so richt er nichts auß. Am Ende seiner Regierungszeit $(+1486)$ hatte Albrecht nach dem Kaiser von allen deutschen Reichsfürsten die meisten Gelehrten als Räte um sich geschart, adlige und bürgerliche Juristen, aber auch Theologen und Mediziner, und gerne lieh er sie mit spezieller Empfehlung an Standesgenossen aus, die das Niveau seiner Räte zu schätzen wussten ${ }^{21}$. Albrecht und mit ihm so mancher Standesgenosse hatten erkannt, dass hinter den «Bücherdoktoren〉 und 〈Besserwissern〉 doch mehr steckte als der blosse Schein.

21 Zitate nach Ernst Schubert, Albrecht Achilles, Markgraf und Kurfürst von Brandenburg (1414-1486), in: Fränkische Lebensbilder. Neue Folge der Lebensbilder aus Franken, Band 4, hg. von Gerhard Pfeiffer, Würzburg 1971, S. 130-172, hier: S. 145; zur Einordnung siehe Suse Andresen, Im fürstlichen Auftrag. Die gelehrten Räte der Kurfürsten von Brandenburg aus dem Haus Hohenzollern im 15. Jahrhundert (Schriftenreihe der Historischen Kommission bei der Bayerischen Akademie der Wissenschaften 94), Göttingen 2017. 


\section{Bildung und Geld}

\section{Die Vermögensverhältnisse der Schaffhauser Universitätsbesucher im Spätmittelalter (1460-1529)}

Im Wintersemester 1464 liess sich Johannes Reger de Schaffhusen in den Rektoratsmatrikeln der Universität Basel immatrikulieren'. Rund zehn Jahre später, im Wintersemester 1475, inskribierte sich Beatus Barther de Schaffhusen an derselben Hochschule². Drei Jahre später schloss Beat sein Studium mit dem Grad eines baccalaueus artium $\mathrm{ab}^{3}$. Beide Universitätsbesucher stammten aus der Rheinstadt Schaffhausen und studierten an der Artistenfakultät in Basel. Doch damit scheinen die Gemeinsamkeiten bereits ausgeschöpft zu sein. Johannes Reger konnte aufgrund seines finanziellen Hintergrundes nur zwei Drittel (IV $\beta$, quia pauper) der geforderten Immatrikulationsgebühr von 6 Schilling begleichen ${ }^{4}$. Zum Zeitpunkt der Immatrikulation seines Sohnes Johannes deklarierte Heinrich Reger als Hausvorstand der Herkunftsfamilie ein geringes Vermögen von 13 Gulden und lebte nach der im spätmittelalterlichen Schaffhausen angewandten Steuerpraxis unter der Armutsgrenze ${ }^{5}$. Somit hatte er eine Kopfsteuer von 5 Schilling zu entrichten ${ }^{6}$. Obwohl er nur über geringe finanzielle Mittel verfügte, war er Mitglied bei der Weberzunft und vertrat diese im Grossen Rat der Stadt Schaffhausen?

Der Kaufmannssohn Beat Barter hingegen stammte aus einem der reichsten Schaffhauser Bürgergeschlechter, welches sich durch Haini Barter der Kofmann erstmals im Jahr 1376 in Schaffhausen nachweisen lässt ${ }^{8}$. Im Zeitraum von 1464 bis 1476 besetzte die Familie im Ranking der reichsten Geschlechter jeweils den ersten Platz'. Ihr Vermögen erwirtschafteten sie sich vor allem im Salzhandel. Sie zählten sowohl zur politischen als auch wirtschaftlichen Elite der Stadt. Die Familie besass mehrere

1 Hans Georg Wackernagel (Hg.), Die Matrikel der Universität Basel, 2 Bde., Bd. I: 1460-1529, Basel 1951, Bd. II: 1532/33-1600/01, Basel 1956, hier: Bd. I, S. 50, Nr. 19.

2 Ebd., S. 139, Nr. 50.

3 Ebd.

4 Ebd., S. 50, Nr. 19.

5 Stadtarchiv Schaffhausen, Steuerbücher, Behebbuch 1464, A II.06.01.043, S. 74. Zur mittelalterlichen Steuerpraxis der Stadt Schaffhausen siehe Karl Schmuki, Steuern und Staatsfinanzen. Die bürgerliche Vermögenssteuer in Schaffhausen im 16. und 17. Jahrhundert, Zürich 1988, S. 55-75.

6 Ebd., S. 61.

7 Staatsarchiv Schaffhausen, Ratsprotokolle, RP V, S. 170-173.

8 Hektor Amman, Schaffhauser Wirtschaft im Mittelalter, Thayngen 1949, S. 284.

9 Stadtarchiv Schaffhausen, Steuerbücher, Behebbuch 1464, A II.06.01.043, S. 90, Steuerbuch 1475, A II.06.01.050, S. 109. 
städtische Immobilien und erwarb im Laufe des 15. Jahrhunderts Besitzungen in der Landschaft Schaffhausen ${ }^{10}$. Durch Konnubialbeziehungen waren sie sowohl mit vermögenden Schaffhauser Kaufmannsfamilien wie den Zieglers und Krons als auch mit dem Stadtadel der im Thurm und Hagk vernetzt. Mitglieder dieser Familie vermochten sowohl die höchsten politischen als auch die lukrativsten verwaltungstechnischen Ämter zu besetzen. Mit Heinrich, Johannes und Konrad vertraten sowohl Beats Grossvater, Vater und Bruder die Gesellschaft der Kaufleute im Kleinen Rat der Stadt und amtierten als Bürgermeister ${ }^{11}$.

Der eine stammte aus einer Handwerkerfamilie, welche an der Grenze zur Armut lebte, der andere war das Kind reicher Eltern, welche zur wirtschaftlichen und sozialen Elite der Stadt Schaffhausen zählten. Obwohl die wirtschaftlichen Unterschiede zwischen diesen zwei jungen Männern kaum grösser sein könnten, erscheinen sie beide in den Basler Rektoratsmatrikeln als Studenten der artistischen Fakultät. Dieser Umstand wirft die Frage nach der Bedeutung des wirtschaftlichen Status der Herkunftsfamilien der Universitätsbesucher auf. Oder mit der Terminologie von Pierre Bourdieu gefragt: Inwiefern war ökonomisches Kapital eine grundsätzliche Voraussetzung für den Erwerb von inkorporiertem (akademisches Wissen) und institutionalisiertem (akademische Grade) Kulturkapital, und welchen Stellenwert nahm dabei das soziale Kapital (Netzwerk) ein ${ }^{12}$ ? De Jure standen die Tore der spätmittelalterlichen Universitäten im Alten Reich allen männlichen Christen offen. In den folgenden Ausführungen soll jedoch der Frage nach einem möglichen monetären numerus clausus und einer damit einhergehenden sozialen Differenzierung sowohl innerhalb einer regionalgeschichtlichen Untersuchung einer mittelalterlichen Kleinstadt nachgegangen werden ${ }^{13}$.

Dabei wurde die Korrelation zwischen dem finanziellen Hintergrund und der Investition in akademische Bildung am Beispiel der Schaffhauser Bevölkerung im ausgehenden Spätmittelalter untersucht. Auf mikrohistorischer Ebene wurde die Rolle des wirtschaftlichen Status der Familien der Universitätsbesucher für die Investition in akademische Bildung sowohl für die aktelle Familienstrategie als auch die nachfolgende Generation betrachtet. Dabei stellt die These, dass ein gewisses elterliches Vermögen Voraussetzung für ein Universitätsstudium war, den Ausgangspunkt folgender Untersuchung dar. Die Vermögensverhältnisse bilden in der vorliegenden Untersuchung jedoch nur ein, wenn auch ein hervorstechendes Lagemerkmal. Kapital

10 Johann Jakob Rüeger, Chronik der Stadt und Landschaft Schaffhausen, Bd. 2, Schaffhausen 1892, S. 641-644; Oliver Landolt, Barter, in: Historisches Lexikon der Schweiz, Bd. 1, Basel 2002, S. 733.

11 Staatsarchiv Schaffhausen, Ratsprotokolle, RP III, S. 195-RP V, S. 267 u. RP V, S. 43 u. RP V, S. 109 u. RP V, S. 219 u. RP V, S. 321

12 Zur Definition von kulturellem und ökonomischem Kapitel siehe Pierre Bourdieu, Ökonomisches Kapital, kulturelles Kapital, soziales Kapital, in: Soziale Ungleichheiten, hg. v. Reinhard Kreckel, Göttingen 1983, S. 183-198.

13 Als Grundlage für die folgenden Ausführungen siehe Ursula Bütschli, Bildung und Geld. Eine sozioökonomische Studie der Schaffhauser Universitätsbesucher von 1460 bis 1529, 2 Teile, unveröffentlichte Masterarbeit Philosophisch-historische Fakultät Bern 2017. 
manifestiert sich nicht nur im ökonomischen Sinne, sondern auch in Form von sozialem und kulturellem Kapital, welches nicht greif- und messbar ist ${ }^{14}$. Aus diesem Grund wurden neben dem primären Lagemerkmal der finanziellen Verhältnisse auch der soziale Status, die Partizipation an der politischen Macht sowie die Belegung von judikativen und verwaltungstechnischen Ämtern berücksichtigt. Der Ansatz, eine im wirtschaftlichen als auch sozialen Sinn heterogene kleinstädtische Gruppe zu wählen und anhand dieser die Korrelation zwischen ökonomischem und kulturellem Kapital zu untersuchen, ist in der Forschung zur Universitätsgeschichte ein noch kaum beschrittener Weg ${ }^{15}$.

Als Quelle zur Recherche der an einer Universität im Alten Reich immatrikulierten Schaffhauser dienten die universitären Quellen, allen voran die Rektoratsmatrikeln der verschiedenen Universitäten. Diese sind mit Ausnahme der Universitäten Mainz und Trier für alle Hochschulen im genannten Untersuchungszeitraum überliefert und liegen in edierter Form vor ${ }^{16}$. Als weitere primäre Quelle wurden die Steuerakten der Stadt Schaffhausen ausgewertet ${ }^{17}$. Dadurch konnten die Geschlechter-

14 Bourdieu, Kapital (Anm. 12), 183-187.

15 Untersuchungen zu Universitätsbesuchern aus einem klar umrissenen Herkunftsgebiet umfassen fast ausschliesslich ein grossräumiges Gebiet wie eine Diözese oder eine Region. Vgl. dazu Beat Immenhauser, BildungswegeLebenswege. Universitätsbesucher aus dem Bistum Konstanz im 15. und 16. Jahrhundert (Veröffentlichungen der Gesellschaft für Universitäts- und Wissenschaftsgeschichte 8), Basel 2007; Rolf Häfele, Die Studenten der Städte Nördlingen, Kitzingen, Mindelheim und Wunsiedel bis 1580. Studium, Berufe und soziale Herkunft (Trierer Historische Forschung 13), 2 Teile, Trier 1988; Ingrid Matschinegg, Österreicher als Universitätsbesucher in Italien (15001630). Regionale und soziale Herkunft - Karrieren - Prosopographie, Dissertation an der Geisteswissenschaftlichen Fakultät Karl-Franzens-Universität Graz, Graz 1999. Die soziale Herkunft der Universitätsbesucher einer bestimmten Stadt untersuchte Peter Moraw in Peter Moraw, Heidelberg: Universität, Hof und Stadt im ausgehenden Mittelalter, in: Studien zum städtischen Bildungswesen des späten Mittelalters und der frühen Neuzeit, hg. v. Bernd Moeller (Abhandlungen der Akademie der Wissenschaften in Göttingen 137), Göttingen 1983, S. 524-552. Zu bestimmten sozialen und (wirtschaftlichen〉 Gruppen an den Universitäten siehe Ulrike Denk, Alltag zwischen Studieren und Betteln. Die Kodrei Goldberg, ein studentisches Armenhaus an der Universität Wien, in der frühen Neuzeit (Schriften des Archivs der Universität Wien 16), Wien 2013; Rainer Christoph Schwinges, Pauperes an deutschen Universitäten des 15. Jahrhunderts, in: Studenten und Gelehrte. Studien zur Sozial- und Kulturgeschichte deutscher Universitäten im Mittelalter, hg. v. Rainer Christoph Schwinges (Education and Society in the Middle Age and Renaissance 32), Leiden/Boston 2008, S. 237-264; Rainer A. Müller, Universität und Adel. eine soziostrukturelle Studie zur Geschichte der bayerischen Landesuniversität Ingolstadt 1472-1648 (Ludovico Maximilianea. Universität IngolstadtLandshut-München. Forschungen und Quelle 7), Berlin 1974; John M. Fletcher, Wealth and Poverty in the Medieval German Universities with Particular Reference to the University of Freiburg, in: Europe in the Late Middle Age, hg. v. John R. Hale et al., London 1965; James H. Overfield, Nobles and Pauperes at German Universities to 1600, in: Societas. A Review of Social History 4 (1974), S. 175-210; Jacques Paquet, L'universitaire 〈pauvre〉 au Moyen Age: Problèmes, documentations, questions de Méthode, in : The Universities in the Late Middle Age, hg. v. Jozef Jisewjin and Jaques Paquet, Leuven 1978, S. 399-425; zur Universitätsgeschichte im Allgemeinen vgl. auch Rainer Christoph Schwinges, Deutsche Universitätsbesucher im 14. und 15. Jahrhundert. Studien zur Sozialgeschichte des Alten Reichs (Veröffentlichungen des Instituts für europäische Geschichte, Abteilung Universalgeschichte 123; Beiträge zur Sozial- und Verfassungsgeschichte des Alten Reichs 6), Stuttgart 1986.

16 Systematisch ausgewertet wurden die Rektoratsmatrikeln der Universitäten Basel, Erfurt, Freiburg i. Br., Heidelberg, Ingolstadt, Köln, Leipzig, Tübingen, Wien und Wittenberg.

17 Stadtarchiv Schaffhausen, Steuerbücher, Steuerbuch 1459 bis Behebbuch 1545, A II. 06.01.039 -A II. 06.01.088. 
namen der ermittelten Schaffhauser Universitätsbesucher mit den Namen der jeweiligen Steuerposten verknüpft werden. Das Stadtarchiv Schaffhausen beherbergt neben den spätmittelalterlichen Steuerbüchern auch noch die Behebbücher, in denen das jeweilige Gesamtvermögen der Steuerpflichtigen eingetragen wurde. Sowohl die Steuer- als auch die Behebbücher stellen durch ihre hohe Überlieferungsdichte für die sozioökonomische Forschung einen aussergewöhnlichen Fundus dar. Diese Quellen ermöglichen sowohl einen Einblick in die Vermögensstrukturen der Schaffhauser Bevölkerung als auch eine Rekonstruktion des Steuersystems der spätmittelalterlichen Rheinstadt $^{18}$. Als wertvolles Hilfsmittel erwies sich die Datenbank des Forschungsprojekts Repertorium Academicum Germanicum, kurz RAG, aus dessen Fundus an prosopographischen Daten wertvolle Informationen über den akademischen Werdegang und die weiteren Lebensstationen sowie über den sozialen und wirtschaftlichen Hintergrund der Schaffhauser Universitätsbesucher ausgewertet werden konnten ${ }^{19}$.

\section{Der finanzielle Hintergrund}

Im Zeitraum von 1460 bis in das Jahr 1529 liessen sich 103 Erstimmatrikulationen von Schaffhauser Universitätsbesuchern an einer Universität innerhalb der Grenzen des Alten Reiches ermitteln. Mit 62 Personen, rund $60 \%$, wählte die Mehrheit bei ihrer Erstimmatrikulation als Studienort die nahe gelegenen Universitäten Freiburg i. Br. und Basel. Die restlichen 41 Schaffhauser Universitätsbesucher verteilten sich auf die Universitäten Köln, Tübingen, Ingolstadt, Leipzig, Wien, Erfurt, Wittenberg und Kra$\mathrm{kau}^{20}$. Von den 103 erstimmatrikulierten Schaffhausern konnten 13 aufgrund ihres finanziellen Hintergrunds die geforderte Immatrikulationsgebühr nur teilweise beziehungsweise gar nicht begleichen und wurden als pauperes in den Rektoratsmatrikeln eingetragen. ${ }^{21}$

Anhand der Schaffhauser Steuerakten liessen sich 60 Studierende 41 Schaffhauser Herkunftsfamilien zuordnen ${ }^{22}$. Aufgrund ihrer deklarierten Vermögenswerte konnten die

18 Zum Schaffhauser Steuersystem siehe: Schmuki, Steuern (Anm. 5), S. 37-169.

19 Repertorium Academicum Germanicum (RAG), [www.rag-online.org], 8.5.2018.

20 Erstimmatrikulationen: 34 Basel, 28 Freiburg i. Br., 13 Köln, 7 Tübingen, je 5 Ingolstadt, Leipzig, Wien, je 2 Erfurt und Wittenberg und 1 Krakau.

21 Dies entspricht annähernd dem von Rainer Christoph Schwinges ermittelten Anteil von $15 \%$ pauperes bezogen auf die Gesamtheit aller Immatrikulierten an den Universitäten des Alten Reiches im 15. Jahrhundert. Diese Zahl von 13 Prozent kann jedoch nur als Annährungswert verstanden werden, denn es liess sich aufgrund fehlender Angaben zu der bezahlten Gebühr in verschiedenen Editionen der Rektoratsmatrikeln keine vollständige Untersuchung zum Anteil der pauperes der Schaffhauser Universitätsbesucher ermitteln. Es ist jedoch anzunehmen, dass dieser Wert heraufgesetzt werden müsste. Vgl. dazu Schwinges, Pauperes (Anm. 15), S. 244.

22 In der Regel besassen die Universitätsbesucher bei ihrer Erstimmatrikulation noch kein eigenes Vermögen und waren, um die Kosten für das Studium und den Lebensunterhalt zu stemmen, auf die finanzielle Unterstützung ihrer Familien angewiesen. Deshalb wurden in der vorliegenden Arbeit nicht die individuellen Vermögen der Universitätsbesucher, sondern die deklarierten Beträge der jeweiligen Hausvorstände in die statistische Auswertung aufgenommen. 
Herkunftsfamilien drei Steuerklassen zugeordnet werden, wobei für die Klassifizierung die spätmittelalterliche Steuerpraxis Schaffhausens übernommen wurde ${ }^{23}$. Folgende Grafik (Abb. 1) zeigt die Entwicklung des Steuertarifs der Steuerklasse vom 15. bis 17. Jahrhundert für kleine bis mittlere und für hohe bis sehr hohe Vermögen auf. Steuerpflichtige mit einem Vermögen unter der Armutsgrenze von 17 Gulden steuerten in der niedrigsten Steuerklasse und hatten eine Kopfsteuer von 2 bis 5 Schilling zu entrichten ${ }^{24}$.

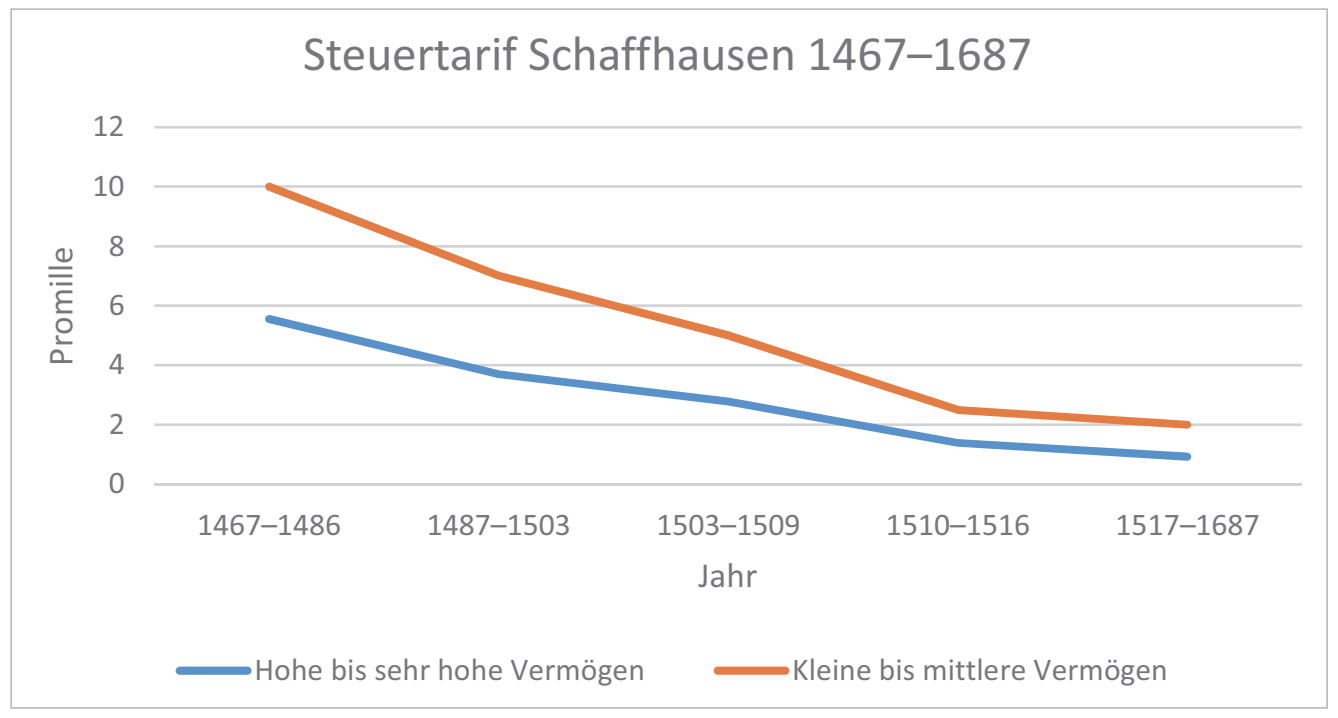

Abb. 1 Entwicklung des Steuertarifs der mittleren und hohen Steuerklasse der Stadt Schaffhausen von 1467-1687

Anhand der folgenden Grafik (Abb. 2) lässt sich bezüglich der Vermögenswerte der Herkunftsfamilien eine eindeutige Tendenz zugunsten der höchsten Steuerklasse erkennen $^{25}$. Rund drei Viertel der Geschlechter (32 Familien) verfügten über ein durchschnittliches Vermögen von über 252 Gulden und wurden mit dem Steuertarif der höchsten Steuerklasse besteuert. Die restlichen neun Familien konnten mit einem Vermögen zwischen der Armutsgrenze von 17 Gulden und dem magischen Richtwert von

23 Die spätmittelalterliche Steuerpraxis Schaffhausens kannte drei Steuerklassen: niedrigste Steuerklasse für keine bis geringe Vermögen (0-17 Gulden), mittlere Steuerklasse für kleine bis mittlere Vermögen (18 [34] Gulden bis 252), höchste Steuerklasse für hohe und sehr hohe Vermögen (über 252 Gulden). Vgl. dazu Schmuki, Steuer (Anm. 5), S. 60-61, 102-108.

24 Die Höhe des Grenzwertes zwischen der niedrigsten und der mittleren Steuerklasse konnte in den verschiedenen Behebjahren aufgrund Konjunkturanpassungen variieren. In den Jahren von 1467-1486 lag dieser bei 17 Gulden, von $1487-1503$ bei 28 Gulden, von $1503-1516$ bei 27 Gulden und von $1517-1587$ bei 33 Gulden. Vgl. dazu Schmuki, Steuern (Anm. 5), S. 62.

25 Die Vermögen der betreffenden Herkunftsfamilien konnten über unterschiedlich lange Zeiträume ermittelt werden. Um eine statistische Auswertung zu ermöglichen, wurde der jeweilige Mittelwert berechnet. 
252 Gulden der mittleren Steuerklasse zugeordnet werden. Keine der Familienvorstände deklarierte ein durchschnittliches Vermögen von weniger als 17 Gulden. ${ }^{26}$

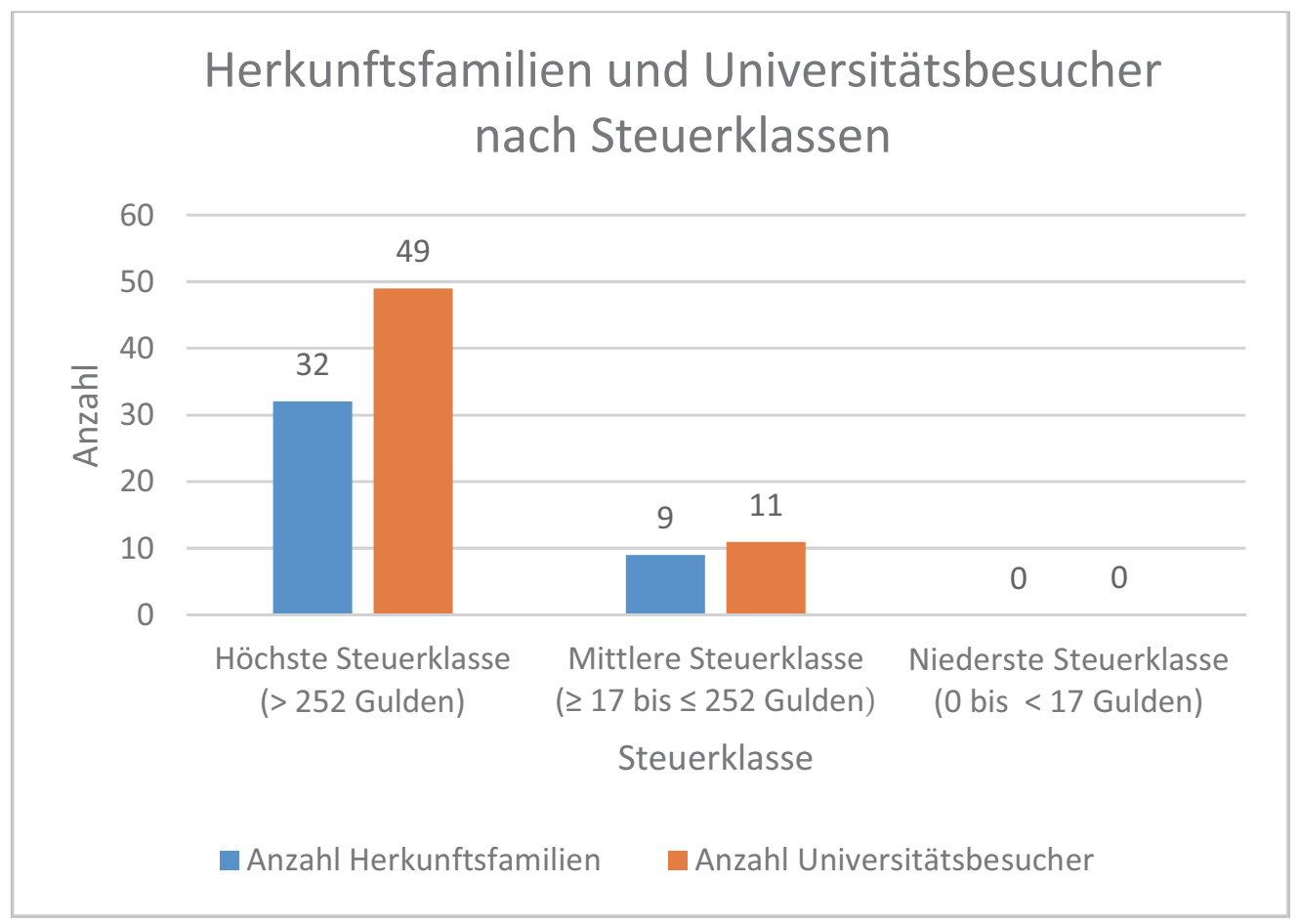

Abb. 2 Klassifizierung der Herkunftsfamilien und Universitätsbesucher nach Steuerklassen

Aufgrund der breiten Streuung der Vermögen innerhalb der höchsten Steuerklasse von 252 Gulden aufwärts bot sich eine weitere Aufteilung innerhalb dieser Steuerklasse an. Zwölf von 32 Familien (mehr als ein Drittel) besassen ein Vermögen über 3'000 Gulden. Diese Herkunftsfamilien lassen sich zu der städtischen Wirtschaftselite zählen. Knapp ein Drittel der Herkunftsfamilien deklarierte noch ein Vermögen zwischen 1'001 und 3'000 Gulden und zählte noch zur begüterten Oberschicht der Stadt. Das verbleibende Drittel verfügte über ein durchschnittliches Vermögen von 253 bis 1'000 Gulden.

Der Vergleich mit der Schaffhauser Gesamtbevölkerung zeichnet ein gegenläufiges Bild. Bei der Auswertung aller Steuerposten für das Jahr 1464 ergab sich im Gegensatz zur Klassifizierung der Herkunftsfamilien eine hohe Konzentration von fast der Hälfte aller Steuerzahler in der mittleren Steuerklasse. Gerade noch ein Viertel der

26 Einzelne Herkunftsfamilien wie die Familie Reger deklarierten temporär Beträge unter 17 Gulden. Ihr berechnetes Durchschnittsvermögen belief sich jedoch auf über 17 Gulden. 
Gesamtbevölkerung verfügte über ein Vermögen von über 252 Gulden und wurde der höchsten Steuerklasse zugeteilt. Davon deklarierten gerade noch acht Familien Beträge über 3’000 Gulden. Gut ein Viertel verfügte also über ein geringes beziehungsweise gar kein Vermögen und hatte nur eine Kopfsteuer zu entrichten. In den gut 40 Jahren bis 1505 lässt sich eine Verarmung des 〈Mittelstandes〉 erkennen. Der prozentuale Anteil der Mittellosen steigt um $14 \%$, während jener der mittleren Vermögen um $10 \%$ sinkt. Auch in der höchsten Steuerklasse lässt sich ein geringer Rückgang von $4 \%$ erkennen. Im Gegenzug haben sich die Familien mit einem Vermögen über 3'000 Gulden von acht auf 17 Geschlechter verdoppelt.

Tab. 1 Prozentualer Anteil aller Schaffhauser Steuerposten für die drei Steuerklassen der Jahre 1464, 1485 und 1505

\begin{tabular}{|l|l|l|l|}
\hline Steuerklassen SK & $\mathbf{1 4 6 4}$ & $\mathbf{1 4 8 5}$ & $\mathbf{1 5 0 5}$ \\
\hline niedrigste SK $0-\leq 17$ & $25 \%$ & $32 \%$ & $39 \%$ \\
\hline mittlere SK $>17-\leq 252$ & $49 \%$ & $46 \%$ & $39 \%$ \\
\hline höchste SK $>252$ & $26 \%$ & $22 \%$ & $22 \%$ \\
\hline
\end{tabular}

Im Gegensatz zur Gesamtbevölkerung verfügte die Mehrheit der Herkunftsfamilien über ein hohes bis sehr hohes Durchschnittsvermögen und stellte die städtische 〈Wirtschaftselite〉 dar. Mit knapp einem Viertel versteuerte nur ein kleiner Teil der Herkunftsfamilien Beträge der mittleren Steuerklassen. Im Vergleich verfügte der Grossteil der gesamten städtischen Bevölkerung nur über geringe bis mittlere Vermögen.

\section{Die Herkunftsfamilien der städtischen Oberschicht}

Zur Untersuchung des sozialen Standes der Herkunftsfamilien wurden vor allem die Ämter- und Amtsträgerverzeichnisse der Schaffhauser Ratsmanuale als primäre Quelle ausgewertet ${ }^{27}$. Diese enthalten unter anderem eine Aufzählung der Klein- und Gross- 
räte nach ihrer Zunft- oder Gesellschaftszugehörigkeit ${ }^{28}$. Mithilfe dieser Listen konnten die Herkunftsfamilien der Schaffhauser Universitätsbesucher nach ihrer sozialen Herkunft eingeteilt werden. Die adligen Familien waren vorwiegend in der Gesellschaft der Herren, die Kaufmannsfamilien in jener der Kaufleute und die Handwerkerfamilien in einer der zehn Zünfte inkorporiert. In folgender Grafik wird der soziale Hintergrund von Herkunftsfamilien und Universitätsbesucher dargestellt (Abb. 3).

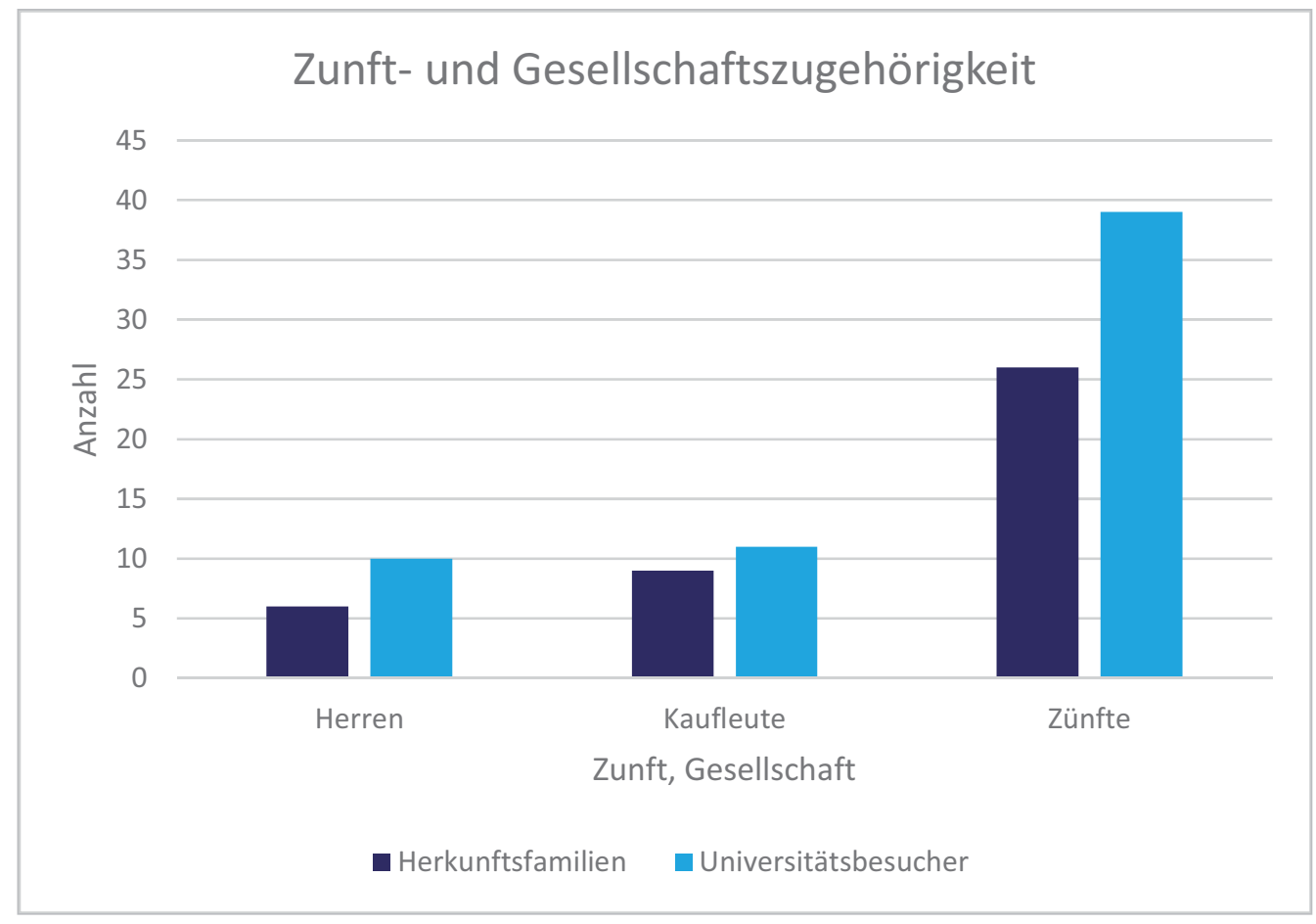

Abb. 3 Die Zunft- und Gesellschaftszugehörigkeit der Herkunftsfamilien und der Schaffhauser Universitätsbesucher

Die numerische Differenz zwischen der Anzahl der Herkunftsfamilien und der Universitätsbesucher ergibt sich daraus, dass aus gewissen Familien mehrere Mitglieder an einer Universität nachgewiesen werden konnten. Dies trifft vor allem auf die adeligen Familien der Gesellschaft der Herren und die Universitätsbesucher aus Zunftfamilien zu. Mit 39 Universitätsbesuchern aus 26 Herkunftsfamilien stammten mehr als zwei Drittel aus zünftigen Familien. Rund ein Viertel der Herkunftsfamilien waren in

28 Im Jahr 1411 wurde in Schaffhausen eine Zunftverfassung eingeführt, nach der aus den 10 Zünften (Fischer, Gerber, Schuhmacher, Schmiede, Schneider, Pfister, Rebleute, Krämer, Metzger und Weber) und den zwei Gesellschaften (Herren und Kaufleute) je zwei Räte in den Kleinen Rat und je fünf Räte in den Grossen Rat gewählt wurden. Vgl. dazu Karl Schib, Die Entstehung und der politische Sieg der Zünfte im Jahr 1411, in: Schaffhauser Beiträge zur vaterländischen Geschichte, 38 (1961), S. 7-17; Ernst Rüedi, Die Schaffhauser Zunftverfassung 1411/1535, in: Schaffhauser Beiträge zur vaterländischen Geschichte, 38 (1961), S. 18-45. 
der Gesellschaft der Kaufleute inkorporiert und ein Sechstel in der Adelsgesellschaft der Herren. Inwiefern spiegelt nun der soziale Status der Herkunftsfamilien die soziale Struktur der spätmittelalterlichen Stadt Schaffhausen wider? Rainer Christoph Schwinges schreibt in seinem Artikel über die pauperes an den Universitäten im Alten Reich Folgendes dazu:

«Die spätmittelalterliche Universität war keine isolierte Bildungsgemeinschaft, nur durch einen frei zugänglichen Aufstiegskanal mit der Außenwelt verbunden, sondern von Anfang an ein getreues Spiegelbild der sie umgebenden, im Wesentlichen städtischen Gesellschaft. $\rangle^{29}$

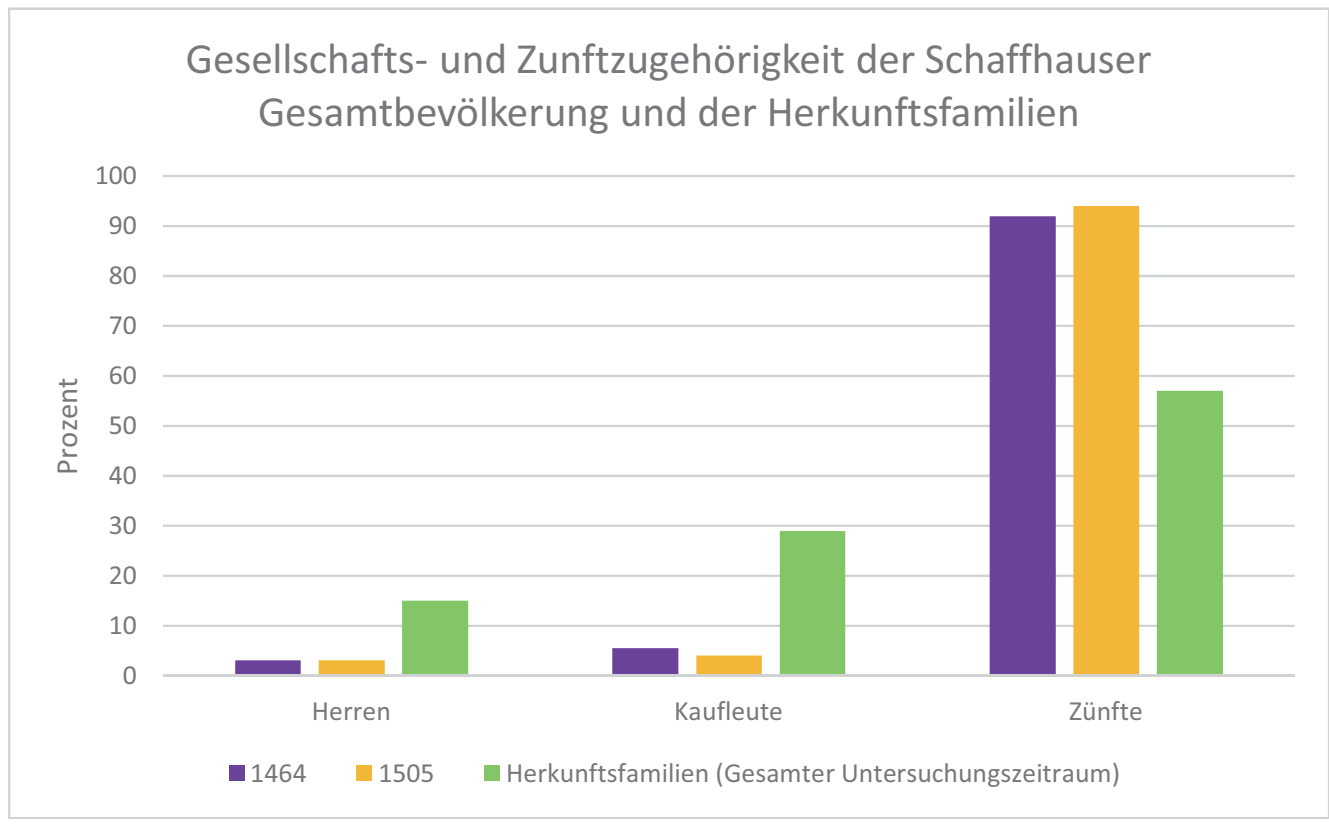

Abb. 4 Prozentualer Anteil der Zunft- und Gesellschaftszugehörigkeit der Herkunftsfamilien im Vergleich zu der Schaffhauser Gesamtbevölkerung

Der Vergleich zwischen dem sozialen Stand der Herkunftsfamilien und der Schaffhauser Gesamtbevölkerung zeigt bei den Herkunftsfamilien eine numerische Konzentration auf die Adelsgesellschaft der Herren und die Gesellschaft der Kaufleute (Abb. 4). Gemessen an der Gesamtbevölkerung bildete der Adel in den Jahren 1464 und 1505 mit knapp $2.5 \%$ die zahlenmässig geringste soziale Gruppe innerhalb des städtischen Sozialkörpers. Eine ebenfalls numerische geringe Gruppe mit einem Anteil von $5.5 \%$ (1464) und $3.7 \%$ (1505) bildeten die Kaufmannsfamilien. Die zünftigen Geschlechter der Stadt stellten mit über $90 \%$ die grösste numerische Gruppe innerhalb der Stadtbevölkerung dar. Die Gegenüberstellung der Herkunfts-

29 Schwinges, Pauperes (Anm. 15), S. 241. 
familien der Schaffhauser Universitätsbesucher mit allen Schaffhauser Geschlechtern bezüglich ihres sozialen Standes für die Jahre 1464 und 1505 zeigt deutlich, dass im Vergleich zum geringen Anteil an der Gesamtbevölkerung vor allem Geschlechter aus den Gesellschaften der Kaufleute und in einem geringeren Masse aus dem städtischen Adel in akademische Bildung investierten. Die Söhne zünftiger Familien waren hinsichtlich der grossen zahlenmässigen Dominanz an der Gesamtbevölkerung unterproportional an den Universitäten vertreten.

Wie verhält es sich nun mit dem wirtschaftlichen Hintergrund der unterschiedlichen sozialen Gruppen? In folgender Grafik sind jene Herkunftsfamilien aufgeführt, die ein durchschnittliches Vermögen von über 252 Gulden versteuerten und somit der höchsten Steuerklasse der hohen bis sehr hohen Vermögen zugerechnet wurden (Abb. 5). Die blauen Balken kennzeichnen die adligen Geschlechter, die grünen die Kaufmannsfamilien und die roten die Zunftfamilien. Die gelben Balken markieren die beiden «Stadtschreiberfamilien), in deren Reihen dieses Amt über mehrere Generationen weitergegeben wurde und die keiner Zunft oder Gesellschaft zugeordnet werden konnten ${ }^{30}$.

Wie der Grafik (Abb. 5) zu entnehmen ist, weisen die reichsten vier Herkunftsfamilien mit einem durchschnittlichen Vermögen von über 5'000 Gulden eine bürgerliche Herkunft auf. Sie können als soziale und wirtschaftliche 〈Aufsteiger〉 betrachtet werden, die durch den Handel ein beachtliches Vermögen erwirtschafteten, das ihnen den Zugang zu den bedeutendsten politischen Ämtern sicherte sowie Konnubialbeziehungen zum städtischen Adel ermöglichte. Angeführt wird das Ranking der reichsten Herkunftsfamilien von dem Kaufmannsgeschlecht Barter mit einem aussergewöhnlich hohen Vermögen von über 13'000 Gulden ${ }^{31}$. Mit dem Basler Studenten Beat Barter wurde eingangs bereits ein Sprössling dieser Familie vorgestellt $t^{32}$. Auf das Geschlecht der Barter folgen die Zunftfamilien Peyer mit den Wecken ${ }^{33}$ und Jünteler ${ }^{34}$. Erstere waren ursprünglich als Schmiede tätig. Ihr Stammvater, Johannes Peyer (ca. 1410-1478) war der Hufschmid der Stadt. Aufgrund seiner für das Gemeinwohl der Stadt wichtigen Funktion wurde er von der Steuer befreit und in den Steuerakten als fry eingetragen ${ }^{35}$. Dass er durch seine Tätigkeit bereits einen gewissen Wohlstand

30 Elisabeth Breiter, Die Schaffhauser Stadtschreiber. Das Amt und seine Träger von den Anfängen bis 1798, Dissertation der Rechts- und staatswissenschaftlichen Fakultät der Universität Zürich, Zürich 1962, S. 79-90.

31 Stadtarchiv Schaffhausen, Steuerbücher, Steuerbuch 1467, A II. 06. 01. 044, S. 90, Behebbuch 1470, A II. 06. 01. 044, S. 93, Steuerbuch, A II. 06. 01.050, S. 109.

32 Siehe dazu auch Bütschli, Bildung Geld II (Anm. 13), Nr. 2.

33 Nicht identisch mit der Schaffhauser Kaufmannsfamilie Peyer im Hof. Vgl. zu den Peyer mit den Wecken Rüeger, Chronik Schaffhausen II (Anm. 10), S. 891-898; Reinhard Frauenfelder, Geschichte der Familie Peyer mit den Wecken 1410-1932, Schaffhausen 1932; Peter Scheck, Peyer im Hof, in: Historisches Lexikon der Schweiz, Bd. 9, Basel 2010, S. 656; Amman, Schaffhauser Wirtschaft (Anm. 8), S. 297-299; Hans Wilhelm Harder, Die Gesellschaft zun Kaufleuten - ein Beitrag zur Zunft- und Sittengeschichte der Stadt Schaffhausen, Schaffhausen 1866 (Neuauflage 1974).

$34 \mathrm{Zu}$ der Familie Jünteler vgl. Rüeger, Chronik Schaffhausen II (Anm. 10), S. 877; Amman, Schaffhauser Wirtschaft (Anm. 8), S. 294-296.

35 Stadtarchiv Schaffhausen, Steuerbücher, Steuerbuch 1442, A II.06.01.026. S. 35. 


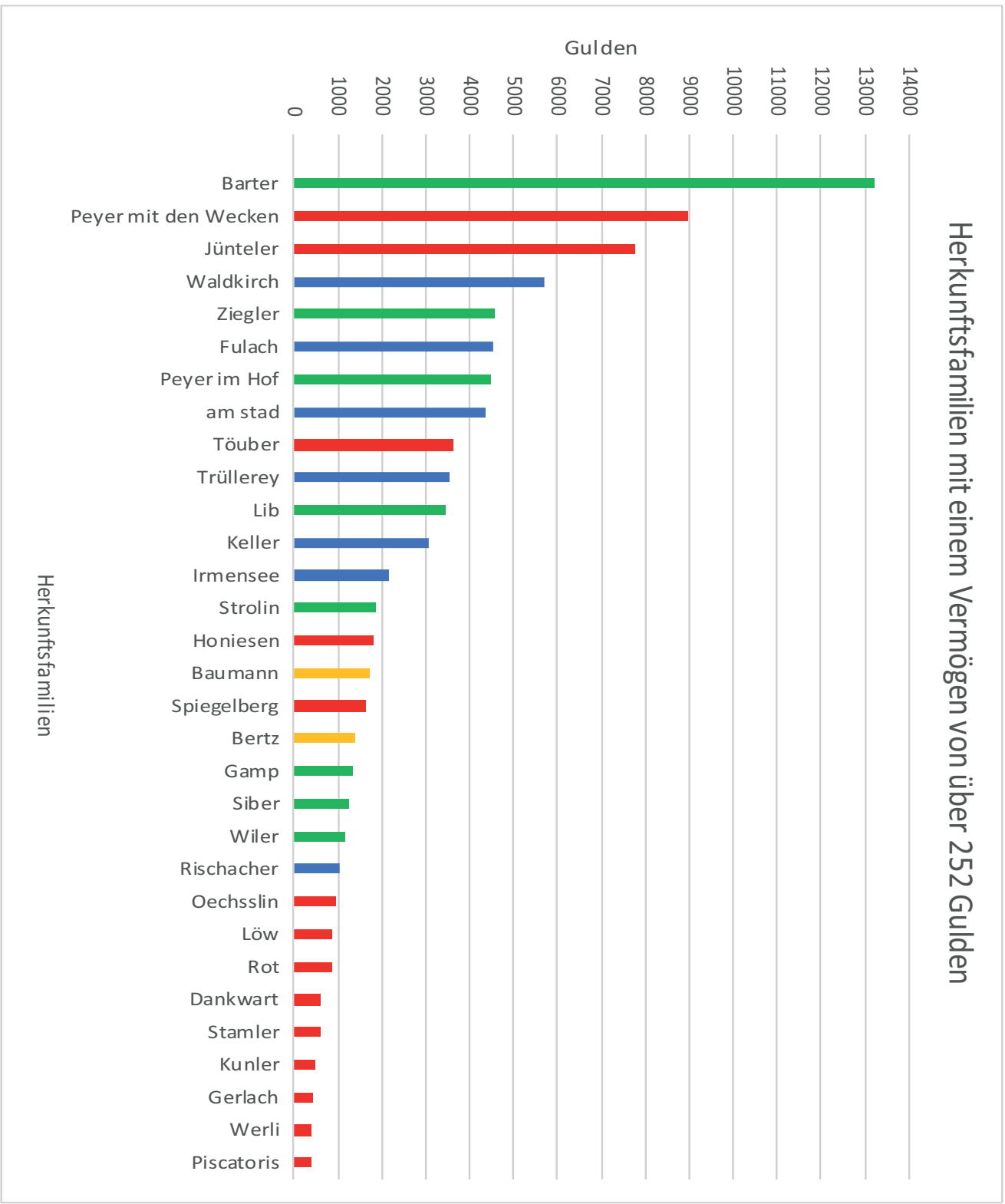

Abb. 5 Die Zunft- oder Gesellschaftszugehörigkeit der Herkunftsfamilien mit einem Vermögen über 252 Gulden 
erarbeitet hatte, bezeugt ein Darlehen an die Stadt von 3'000 Goldgulden ${ }^{36}$. Sein Sohn Heinrich immatrikulierte sich im Sommersemester 1488 in Freiburg i. Br., wo er die Artes-Fakultät besuchte und ihm im Wintersemester 1490 der Grad eines magister artium verliehen wurde ${ }^{37}$. Kurz darauf soll er als Advokat im Dienst des Bischofs von Augsburg gestanden haben. 1493 ist er in seine Geburtsstadt zurückgekehrt, um als Schulmeister der städtischen Lateinschule tätig zu werden ${ }^{38}$. Heinrich Peyer mit den Wecken kam als erstes Mitglied der Familie in den Genuss einer akademischen Bildung. In den folgenden Generationen lässt sich jeweils mindestens ein Mitglied der Familie an einer Universität im Reich nachweisen. Mit Alexander ${ }^{39}$, Johannes Jakob $^{40}$ und Martin ${ }^{41}$ partizipierten gleich drei Neffen Heinrichs an akademischer Bildung. Die beiden Letztgenannten studierten an einer juristischen Fakultät und erwarben an einem unbekannten Studienort den Grad eines licentiatus iuris (Johannes Jakob) ${ }^{42}$ und an der Universität Dôle jenen eines doctor utriusque iuris (Martin) ${ }^{43}$. Ihr Bruder Alexander kehrte ohne Graduierung von seinen Studien an der Universität Freiburg i. Br. nach Schaffhausen zurück, wo er in die politischen Fussstapfen seines Vaters Johannes trat. Er vertrat die Schmiedezunft im Kleinen Rat und amtete von 1547 bis 1577 während 30 Jahren im Zweijahreszyklus als Bürger- und Unterbürgermeister ${ }^{44}$. Sein Sohn Alexander besuchte im Wintersemester 1543 die Universität Basel. Nach seinem Artes-Studium reiste er weiter nach Oberitalien, wo er an der Universität Padua zum Doktor der Medizin promoviert wurde ${ }^{45}$. Als ein weiteres Mitglied dieser Familie lässt sich Bartholomäus Peyer am 22. Februar 1586 in Orléans, am 14. Mai 1588 an der Juristenuniversität in Padua und ein Jahr später in Bologna und Siena nachweisen. Als er sich am 9. Oktober in Basel immatrikuliert, zierte ihn der akademische Grad eines doctor utriusque iuris ${ }^{46}$.

Wie die Peyer mit den Wecken stammten auch die Jünteler ursprünglich aus der städtischen Handwerkerschaft. Diesem Geschlecht gelang es, im Laufe des 15. Jahrhunderts einen beispielhaften wirtschaftlichen Aufstieg zu vollziehen. Innerhalb von einer

36 Frauenfelder, Geschichte Familie Peyer (Anm. 33), S. 3.

37 Hermann Mayer (Hg.), Die Matrikel der Universität Freiburg im Breisgau von 1460-1656, Bd. 1, 2 und Register, Freiburg i. Br. 1907-1910, Bd. 1, S. 90, Nr. 2.

38 Rüeger, Chronik Schaffhausen II (Anm. 10), S. 890; RAG (Anm. 19), Heinrich Peyer - UniquID: ngPF2e870On6yelBjPYe8, 22.5.2018.

39 Rüeger, Chronik Schaffhausen II (Anm. 10), S. 890; Bütschli, Geld Bildung II (Anm. 13), Nr. 49.

40 Ebd., Nr. 50.

41 RAG (Anm. 19), Martin Peyer - UniquID: ngPF2A870OH6yelPjPYe2, 22.5.2018.

42 Rüeger, Chronik Schaffhausen II (Anm. 10), S. 898.

$43 R A G$ (Anm. 19), Martin Peyer - UniquID: ngPF2A870OH6yelPjPYe2, 22.5.2018.

44 Frauenfelder, Geschichte Peyer (Anm. 33), S. 63; Rüeger, Chronik Schaffhausen II (Anm. 10), S. 282; Amman, Schaffhauser Wirtschaft (Anm. 8), S. 297-299; Staatsarchiv Schaffhausen, Ratsprotokolle, RP IX, S. 193/ PR XIV, f. $172 \mathrm{r}$.

45 RAG (Anm. 19), Alexander Peyer - UniquID: ngCS9T375BK13ryKwBbroAoJ3DP, 22.5.2018.

46 Wackernagel, M Basel II (Anm. 1), S. 408, Nr. 75. 
Generation konnte Johannes Ulrich Jünteler durch den Weinhandel aus einer Familie der Mittelschicht bis zum reichsten Bürger der Stadt aufsteigen ${ }^{47}$. Von 1467 bis 1484 vertrat er die Zunft der Rebleute im Kleinen Rat ${ }^{48}$. Seine letzten Lebensjahre wurden von der Wahl zum Bürgermeister gekrönt ${ }^{49}$. Zwei seiner Söhne, Georg ${ }^{50}$ und Johannes Ulrich $^{51}$, immatrikulierten sich zusammen im Wintersemester 1477 an der Artistenfakultät in Basel. Beide schlossen 1482 mit dem Grad eines Magister ihr Artes-Studium $\mathrm{ab}^{52}$. Georg trat dann in die juristische Fakultät ein, an der er den Grad eines licentatus in decretis erwarb und in den Lehrkörper der Artistenfakultät aufgenommen wurde, welcher er im Sommersemester 1489 als Dekan vorstand ${ }^{53}$. Weitere Nachweise seiner akademischen Karriere liessen sich nicht finden. In den 90er-Jahren gab er seine Lehrtätigkeit auf und zog sich mit seiner Familie auf das Schloss Jestetten zurück ${ }^{54}$. Im Behebbuch von 1490 wird er als Ussburger zusammen mit seinen pueri aufgeführt, die aus seiner Ehe mit Barbara Eglin stammen ${ }^{55}$. Im Gegensatz zu Georg verliert sich die Spur seines Bruders Johannes Ulrich nach seinem Basler Studium. Er lässt sich weder in den städtischen Steuerakten noch in den Ratsmanualen finden, was aufgrund der hervorgehobenen politischen und wirtschaftlichen Bedeutung seines Vaters erstaunt. In der Forschungsliteratur wird er zum Teil mit seinem Vater gleichen Namens verwechselt ${ }^{56}$. Möglich wäre, dass bei seiner Immatrikulation in Basel sein Name falsch

47 Amman, Schaffhauser Wirtschaft (Anm. 8), S. 294-296; Rüeger, Chronik Schaffhausen II (Anm. 10), S. 877.

48 Staatsarchiv Schaffhausen, Ratsprotokolle, RP I, S. 1- RP II, S. 287/ RP VI, S. 123-RP X, S. 47.

49 Oliver Landolt, Der Finanzhaushalt der Stadt Schaffhausen im Spätmittelalter (Vorträge und Forschungen 48), Ostfildern 2004, S. 623-624; Kaspar Gubler, Strafjustiz im Spätmittelalter im Südwesten des Reichs. Schaffhausen und Konstanz im Vergleich, Dissertation der Philosophischen Fakultät der Universität Zürich 2009, Zürich 2015, S. 36, Tab. 4; Amman, Schaffhauser Wirtschaft (Anm. 8), S. 296; Staatsarchiv Schaffhausen, Ratsprotokolle, RP I, S. 1- RP II, S. 287/ RP VI, S. 123-RP X, S. 47.

50 RAG (Anm. 19), Georg Jünteler - UniquID: ngJZ2g274KR04yfNdTCy7, 22.5.2018.

$51 R A G$ (Anm. 19), Johannes Jünteler - UniquID: ngDT4O274C306szbxDcs6BpO, 22.5.2018.

52 Wackernagel, M Basel I (Anm. 1), S. 151, Nr. 20 ,21.

53 Ebd.

54 Ebd.; Amman, Schaffhauser Wirtschaft (Anm. 8), S. 296.

55 Rüeger, Chronik Schaffhausen II (Anm. 10), S. 896; Stadtarchiv Schaffhausen, Steuerbücher, Behebbuch, A II.06.01.060, S. 137.

56 Rüeger verordnet Hanns Ulrich als Neffe von Georg und Sohn von Hanns Urban Jünteler. In der Basler Rektoratsmatrikel werden diese aber als Brüder bezeichnet. Sowohl Wackernagel als auch Sieber verordnen ihn als Bürgermeister der Stadt Schaffhausen. Wackernagel verwechselt ihn mit seinem Vater gleichen Namens, welcher 1486 als Schaffhauser Bürgermeister in den Ratsprotokollen nachzuweisen ist. Sieber stützt sich auf die Liste der Schaffhauser Bürgermeister im Historisch-Biographischen Lexikon der Schweiz über die Stadt Schaffhausen, in der ein Hanns Ulrich Jünteler für das Jahr 1505 als Bürgermeister genannt wird. In den Ämterlisten der Ratsprotokolle amtete in diesem Jahr Hanns Trüllerey als Bürgermeister. Ein Hanns Ulrich Jünteler lässt sich in der ersten Hälfte des 16. Jh. in den Ämterlisten der Ratsprotokolle nicht nachweisen. Vgl. dazu Rüeger, Chronik Schaffhausen II (Anm. 10), S. 896; Wackernagel, M Basel I (Anm. 1), S. 151, Nr. 21; Marc Sieber, Die Universität Basel und die Eidgenossenschaft 1460-1529. Eidgenössische Studenten in Basel, Basel 1960, S. 119; O. Stiefel, Verzeichnis der Bürgermeister der Stadt Schaffhausen, in: Historisch-Biographisches Lexikon der Schweiz, Bd. 6, Neuenburg 1931, S. 131, hier: S. 131; Staatsarchiv Schaffhausen, Ratsprotokolle, RP V, S. 169. 
eingetragen beziehungsweise falsch transkribiert wurde und er mit Johannes Urban Jünteler identisch sein könnte. Dieser war ein weiterer Bruder Georgs. Er bekleidete hohe politische und judikative Ämter innerhalb des Rates und der Verwaltung und führte das elterliche Handelsunternehmen weiter. Nachfolgende Generationen der Jünteler sind nicht mehr an den Universitäten des Reiches nachzuweisen.

Das auf Platz vier der reichsten Herkunftsfamilien rangierende Geschlecht der Waldkirch wurden aufgrund der Verleihung eines Adels- und Wappenbriefs durch Kaiser Friedrich III. im Jahr 1487 in der vorliegenden Untersuchung zu den adeligen Geschlechtern gezählt. ${ }^{57} \mathrm{Ihr}$ Ahnherr war jedoch ein im 14. Jahrhundert aus dem breisgauischen Städtchen Waldkirch zugezogener Goldschmied ${ }^{58}$. Wie den Peyer mit den Wecken und den Jünteler gelang es der Familie Waldkirch, im Laufe des 15. Jahrhunderts ein beachtliches Vermögen zu erwirtschaften. Im Gegensatz jedoch zu den Peyer mit den Wecken, die, um ihr Handelsunternehmen auszubauen, Konnubialbeziehungen zu den Basler und St. Galler Kaufmannsfamilien pflegten, versuchten die Waldkirch vermehrt in den städtischen Adel einzuheiraten und deren Lebensweise zu übernehmen. Davon zeugt nicht nur der oben erwähnte Adelsbrief, sondern auch der Erwerb von repräsentativen Patrizierhäusern wie dem Haus zum Ritter innerhalb als auch von Grundbesitz und Herrschaftsrechten ausserhalb der Stadtmauern ${ }^{59}$. Vor allem die Konnubialbeziehungen zum alteingesessenen städtischen Dienstadel ermöglichten einzelnen Familienmitgliedern im ausgehenden 15. Jahrhundert die Aufnahme in die adelige Gesellschaft der Herren ${ }^{60}$. Mit Johannes Waldkirch ${ }^{61}$ lässt sich ein Mitglied dieser Familie am 9. April 1507 in einer Gruppenimmatrikulation mit Kaspar Gerlach aus Schaffhausen und Michael von Blumegg an der Universität Freiburg i. Br. nachweisen ${ }^{62}$. Rund zehn Jahre später, am 21. Januar 1517, erscheint ein Johannes Waldkirch erneut in den Freiburger Rektoratsmatrikeln ${ }^{63}$. Eher als um dieselbe Person dürfte es sich um einen Verwandten des Erstgenannten handeln. Es fällt auf, dass die Familie Waldkirch, nachdem sie sich sowohl wirtschaftlich als auch durch Konnubialbeziehungen zum Stadtadel und durch Erwerb von Herrschaftsrechten sozial in der städtischen Oberschicht etabliert hatte, vermehrt in akademische Bildung für ihren Nachwuchs investierte. So lassen sich mit den Brüdern Johannes Konrad ${ }^{64}$ und Christoph $^{65}$ zwei Söhne Johannes Waldkirchs für das Wintersemester 1535 an der Universität Basel nachweisen ${ }^{66}$. Erstgenannter immatrikulierte sich ein Jahr später an der

57 Rüeger, Chronik Schaffhausen II (Anm. 10), S. 1050.

58 Ebd., Amman, Schaffhauser Wirtschaft (Anm. 8), S. 288.

59 Rüeger, Chronik Schaffhausen II (Anm. 10), S. 1054.

60 Franz von Mandach, Die Geschichte der «Oberen Gesellschaft zun Herren〉. Ein Beitrag zur Kulturgeschichte der Stadt Schaffhausen 1235-1860, Thayngen 1931, S. 12.

$61 R A G$ (Anm. 19), Johannes von Waldkirch - UniquID: ngSI0N577SK39hoAmSLh9Qeh, 22.5.2018.

62 Mayer, M Freiburg I (Anm. 38), S. 175, Nr. 55.

63 Ebd., S. 229, Nr. 19.

$64 R A G$ (Anm. 19), Johannes Waldkirch - UniquID: ngYO6B375Xw13nuGsXxn4WkF, 22.5.2018.

65 Ebd., Christoph von Waldkirch - UniquID: ngBR1A476Bz25qxNvBUq4ZnA, 22.5.2018.

66 Wackernagel, M Basel II (Anm. 1), S. 8, Nr. 4. 
Universität in Tübingen ${ }^{67}$. In den folgenden Generationen besuchten mit Johannes Konrad in Heidelberg (WS 1562) ${ }^{68}$ und Basel (WS 1562) ${ }^{69}$, Johannes Jakob in Freiburg i. Br. (WS 1570) ${ }^{70}$ und Johannes Christoph in Basel (WS 1599) ${ }^{71}$ weitere Mitglieder dieses Geschlechts Universitäten im Reich.

Mit den Ziegler, von Fulach, Peyer im Hof, am Stad, Töuber, Trülleray, Lib und Keller von Schleitheim zählen weitere acht Herkunftsfamilien zu den reichsten Schaffhauser Geschlechtern mit einem deklarierten Durchschnittsvermögen von über 3'000 Gulden. Die Familien von Fulach, am Stad, Trülleray und Keller von Schleitheim zählten zum städtischen Dienstadel und waren bei der Gesellschaft der Herren inkorporiert $^{72}$. Mit den Brüdern Adam (SS 1481, Tübingen) ${ }^{73}$, Johannes Wilhelm (WS 1471, Basel) ${ }^{74}$ und Kaspar (WS 1504, Basel) ${ }^{75}$ lassen sich gleich drei Vertreter des Geschlechts der von Fulach an den Universitäten in Basel und Tübingen nachweisen. Alle drei beendeten ihr Studium ohne Graduierung. Adam verstarb kurz darauf im französischen Kriegsdienst, Kaspar schlug eine geistliche Karriere ein und wurde in das Domkapitel Chur aufgenommen. Johannes Wilhelm trat das Erbe seiner Eltern Wilhelm von Fulach und Anna im Thurm an. Die von Fulachs verfügten über umfangreichen Grundbesitz sowie Herrschaftsrechte in der Landschaft Schaffhausen. Im Jahr 1444 ging das Schloss und die Herrschaft Laufen in den Besitz der Familie über ${ }^{76}$.

Von den übrigen drei adligen Herkunftsfamilien liess sich jeweils nur ein Vertreter an einer Universität im Reich nachweisen. Konstanz Keller von Schleitheim, dessen Vorfahren aus der Ministerialität des Klosters Reichenau in den Stadtadel aufstiegen, schlug eine diplomatische Laufbahn ein. Er trat in die Dienste des Kardinals Matthäus Schiner und der Stadt Bern, wo er sich als geschickter Diplomat und eifriger Pfründensamler entpuppte ${ }^{77}$. Sein Vater Hartman Keller amtete als Stadtrichter und

67 Heinrich Hermelink (Hg.), Die Matrikeln der Universität Tübingen, Bd. 1: Die Matrikeln von 1477-1600, Bd. 2: Register, Stuttgart 1906/1931, S. 284, Nr. 30.

68 Gustav Toepke (Hg.), Die Matrikel der Universität Heidelberg von 1386-1662, 3 Bde., Heidelberg 1884-1893, hier: Bd. II, S. 31.

69 Wackernagel, M Basel II (Anm. 1), S. 142, Nr. 93.

70 Mayer, M Freiburg II (Anm. 37), S. 516, Nr. 55

71 Wackernagel, M Basel II (Anm. 1), S. 488, Nr. 102.

72 Mandach, Gesellschaft Herren (Anm. 60), S. 17-18.

$73 R A G$ (Anm. 19), Adam von Fulach - UniquID: ngFV1E870F963ubJzFYurDrc, 22.5.2018; Hermelink, M Tübingen I (Anm. 67), S. 35, Nr. 25.

$74 R A G$ (Anm. 19), Johannes von Fulach - UniquID: ngEU6H971FM71taSyDNt2CqD, 22.5.2018; Wackernagel, M Basel I (Anm. 1), S. 103, Nr. 13.

$75 R A G$ (Anm. 19), Kaspar von Fulach - UniquID: ngZP6G476Zx24ovZtY6okXlU, 22.5.2018; Wackernagel, M Basel I (Anm. 1), S. 275, Nr. 14.

76 Rüeger, Chronik Schaffhausen II (Anm. 10), S. 729.

77 RAG (Anm. 19), Konstanz Keller - UniquID: ngVL6o072Ut84krppVOk3Tho, 22.5.2018; Heinrich Türler, Der Berner Chorherr Constans Keller, Bern 1905; Rüeger, Chronik Schaffhausen II (Anm. 10), S. 813; Kathrin TrempUtz, Die Chorherren des Kollegiatsstifts St. Vinzenz in Bern von der Gründung bis zur Aufhebung 1484/1485-1528, Bern 1984, S. 68. 
vertrat die Gesellschaft der Kaufleute im Kleinen $\mathrm{Rat}^{78}$. Johannes am $\mathrm{Stad}^{79}$, welcher sich am 18. Januar 1478 an der Universität Freiburg i. Br. immatrikulierte, stammte aus einer alteingesessenen, ursprünglich bürgerlichen Familie, welche zu Beginn des 14. Jahrhunderts in den Niederadel aufsteigen konnte und die Ritterwürde erlangte ${ }^{80}$. Mitglieder der Familie standen sowohl im militärischen und landesherrlichen Dienst der österreichischen Herzöge und besetzten die höchsten politische Ämter innerhalb der Stadt Schaffhausen. Durch Kauf, Heirat und Übernahme von Lehensträgerschaften gelangte der Familienzweig zu Besitz- und Vogteirechten in der Landschaft Schaffhausens ${ }^{81}$. Mit dem oben erwähnten Johannes am Stad starb das Geschlecht in der männlichen Linie aus. Ebenfalls der letzte Namensträger seines Geschlechts war der im Wintersemester 1487 in Basel immatrikulierte Gangolf Trülleray ${ }^{82}$. Das ritteradlige Geschlecht besass sowohl in Aarau als auch in Schaffhausen Immobilien und Vogteirechte und besetzte in beiden Städten politische Spitzenpositionen ${ }^{83}$. Gangolf trat nach seinem Studium in Basel, welches er ohne Graduierung beendete, mehrmals als Gesandter für die Stadt Schaffhausen auf und vertrat die Gesellschaft der Herren im Kleinen Rat von Schaffhausen. Als Altgläubiger gab er nach der Einführung der Reformation in Schaffhausen sein Bürgerrecht auf und verbrachte die letzten Jahre bis zu seinem Tod 1547 in Luzern.

Die Familien Ziegler, Peyer im Hof und Lib waren bei der Gesellschaft der Kaufleute inkorporiert ${ }^{84}$. Die Intention hinter der Investition in akademische Bildung für ihren Nachwuchs mag bei diesen Familien so unterschiedlich gewesen sein wie die Lebenswege ihrer studierenden Sprösslinge. Zum Zeitpunkt ihrer Immatrikulation, zusammen mit ihren Ordensbrüdern Johannes Irmensee und Konrad Sifried (Pistoris), im Sommersemester 1507 an der Universität Freiburg i. Br. waren Konrad und Leonhard Ziegler bereits in das Benediktinerkloster Allerheiligen in Schaffhausen eingetreten ${ }^{85}$. Die Entscheidung für einen Universitätsbesuch lag daher nicht mehr in den elterlichen Händen. Ihre Brüder Franziskus, Itelhanns und Johannes Martin liessen sich nicht an

78 Landolt, Finanzhaushalt Schaffhausen (Anm. 49), S. 618-625; Staatsarchiv Schaffhausen, Ratsprotokolle, RP I, S. 231-RP II, S. 335/ RP VII, S. 173-RP XI, S. 1.

$79 R A G$ (Anm. 19), Johannes Amstad - UniquID: ngRH5g678SJ47gnR1Q8gbPdQ, 22.5.2018.

80 Mayer, M Freiburg I (Anm. 37), S. 65, Nr. 7; Rüeger, Chronik Schaffhausen II (Anm. 10), S. 955; Oliver Landolt, Brümsi, in: Historisches Lexikon der Schweiz, Bd. 2, Basel 2003, S. 742-743, hier: S. 742. Die am Stad waren ein abgespaltener Zweig der ehemals bürgerlichen Familie Brümsi. Diese konnten sich im Laufe des 14. Jahrhunderts in die Adelsgesellschaft der oberen Stube einkaufen.

81 Landolt, Brümsi (Anm. 80), S. 742-743.

$82 R A G$ (Anm. 19), Gangolf Trüllerey - UniquID: ngYO1X173X29jnuQsYRn1Wkr, 22.5.2018; Wackernagel, M Basel I (Anm. 1), S. 200, Nr. 18.

83 Rüeger, Chronik Schaffhausen II (Anm. 10), S. 1005; Wackernagel, M Basel I (Anm. 1), S. 200, Nr. 18; O. Stiefel, Trüllerey, in: Historisch-Biographisches Lexikon der Schweiz, Bd. 7, Neuenburg 1934, S. 65, hier: S. 65; Christian Baertschi, Trüllerey Gangwolf, in: Historisches Lexikon der Schweiz, Bd. 12, Basel 2013, S. 503, hier: S. 503; Staatsarchiv Schaffhausen, Ratsprotokolle, Rp V, S. 267-RP V, S. 321.

84 Harder, Gesellschaft Kaufleute (Anm. 33), S. 63.

85 Mayer, M Freiburg I (Anm. 37), S. 177, Nr. 36, 43. 
einer Universität nachweisen. Erstgenannter führte das elterliche Handelsunternehmen erfolgreich weiter und deklarierte Mitte des 16. Jahrhunderts Beträge an die 50'000 Gulden $^{86}$. Mit Johannes Konrad ${ }^{87}$ und Matthias Peyer im Hof ${ }^{88}$ besuchten zwei weitere Kaufmannssöhne der reichsten Familien Schaffhausens eine Hohe Schule innerhalb der Reichsgrenzen. Matthias immatrikulierte sich zusammen mit Ludwig Oechsslin (Bovillus $^{89}$ aus Schaffhausen im Wintersemester 1520 an der entfernten Universität Wittenberg ${ }^{90}$. Nachdem er sein Studium ohne Graduierung beendet hatte, kehrte er nach Schaffhausen zurück, wo er als Konventherr und später als Baumeister tätig war ${ }^{91}$. Die Spuren seines Bruders Johannes Konrad verlieren sich nach dessen Studium.

Eine aussergewöhnliche Laufbahn schlug der Kaufmannsohn Johannes Lib ein ${ }^{92}$. Bereits sein Vater Johannes studierte in Padua die Rechte und wurde 1460 in Ferrara zum Lizentiat beider Rechte promoviert ${ }^{93}$. Sein Sohn gleichen Namens immatrikuliertemsich am 25. April 1500 an der Universität in Tübingen ${ }^{94}$. Sieben Jahre später wurde er an einem nicht näher benannten Studienort zum doctor in decretis promoviert ${ }^{95}$. Die Doktorwürde verhalf ihm unter anderem zu Pfründen am Konstanzer und Basler Domkapitel ${ }^{96}$.

Die Gruppe der reichsten Herkunftsfamilien der Schaffhauser Universitätsbesucher mit einem Vermögen von über 3'000 Gulden wird von dem Geschlecht der Töuber abgeschlossen. Aus dieser bei der Zunft der Metzger inkorporierten Familie lassen sich mit Johannes (WS 1494) ${ }^{97}$ und Konstans Töuber (WS 1529) ${ }^{98}$ generationenübergreifend zwei Mitglieder an der Universität Freiburg i. Br. ermitteln. Erstgenannter schloss sein Studium mit dem baccalaureus artium $\mathrm{ab}^{99}$. Nach seiner Rückkehr nach

86 Jürg Zimmermann, Die Vermögensverhältnisse der Familie Ziegler von Schaffhausen in der 1. Hälfte des 16. Jahrhunderts, in: Schaffhauser Beiträge zur Geschichte, 47 (1970), S. 54-61, hier: S. 58-59.

87 Bütschli, Bildung Geld II (Anm. 13), Nr. 47.

88 Ebd., Nr. 48.

89 RAG (Anm. 19), Ludwig Bovillus - UniquID: ngFV1E870F963ubvzF0u2DrE, 22.5.2018.

90 Karl Eduard Förstemann, Otto Hartwig und Karl Gerhard (Hg.), Album Academicae Vitebergensis. Ältere Reihe. 1501-1602, Bd. 1, Halle 1976, S. 100.

91 Rudolf Henggeler, Die Mönche von Allerheiligen, in: Schaffhauser Beiträge zur Geschichte, 19 (1942), S. 21-61, hier: S. 52; Rüeger, Chronik Schaffhausen II (Anm. 10), S. 886, Fn. 1.

92 RAG (Anm. 19), Johannes Lyb - UniquID: ngPF5e476PH2belLjPYe5NbG, 22.5.2018.

93 RAG (Anm. 19), Johannes Lyb - UniquID: ngPF5e476PH2zelDjPIe9NbG, 22.5.2018; Guiseppe Pardi, Titoli dottorali conferiti dallo studio di Ferrara nei sec. XV e XVI, Lucca 1900, S.38.

94 Hermelink, M Tübingen I (Anm. 67), S. 127, Nr. 42.

95 Werner Kuhn, Die Studenten der Universität Tübingen zwischen 1477 und 1534. Ihr Studium und ihre spätere Lebensstellung, Göppingen 1971, S. 356, Nr. 2169.

96 Ebd.; Jürg Abbühl, Die Konstanzer Domherren von 1487-1526, Dissertation Philosophisch-historische Fakultät Zürich, Zürich 1987, S. 151; Peter-Johannes Schuler, Notare Südwestdeutschland. Ein prosopographisches Verzeichnis für die Zeit von 1300 bis ca. 1520, Textband, Stuttgart 1987, S. 268-269, Nr. 784.

97 Mayer, M Freiburg I (Anm. 37), S. 112, Nr. 8.

98 Ebd., S. 276, Nr. 3.

99 Ebd., S. 112, Nr. 8. 
Schaffhausen konnte er kontinuierlich sein Vermögen bis auf 8'652 Gulden im Jahr 1523 anwachsen lassen und erfuhr mit der Vermählung mit Fronegk von Waldkirch, der Schwester des bereits vorgestellten Johannes Waldkirch ${ }^{100}$, und der Aufnahme in die Gesellschaft der Kaufleute einen sozialen Aufstieg ${ }^{101}$. Die Spur von Konstans Töuber verliert sich nach seinem Immatrikulationseintrag. Es lassen sich nach 1529 keine weiteren Familienmitglieder an einer Hohen Schule im Reich nachweisen.

Die hier vorgestellten zwölf Herkunftsfamilien eint die Investition in akademische Bildung sowie ein finanzieller Hintergrund, durch den sie zur wirtschaftlichen Elite der Stadt zählten. Sie bilden jedoch bezüglich des sozialen Standes, der generationenübergreifenden Bildungstradition als auch des Studienverhaltens der Zöglinge eine doch sehr heterogene Gruppe. Gerade bei den Kaufmannsfamilien lassen sich sowohl individuelle Bildungstraditionen- und Strategien feststellen. Vor allem die 〈Aufsteigerfamilien〉 aus der Handwerkerschaft investierten erst in akademische Bildung für ihren Nachwuchs, nachdem sie sich in der sozialen und wirtschaftlichen Elite der Stadt etabliert hatten. Dies unterscheidet sie von jenen Herkunftsfamilien, die über ein durchschnittliches Vermögen von weniger als 3'000 Gulden verfügten und die obere Mittelschicht bildeten. Mit 19 Geschlechtern (46 \%) lässt sich der grösste Anteil der Herkunftsfamilien dieser Schicht zuordnen. Es handelt sich dabei vorwiegend um zünftige Familien, welche einen Sitz im Kleinen oder Grossen Rat besassen. Im Gegensatz zu den Untersuchungen von Marianne Hovorka über die Anteile der Söhne aus der ansässigen Handwerkerschaft an der Universität Wien und von Peter Moraw über die Universität Heidelberg lässt sich für Schaffhausen keine Dominanz von Universitätsbesuchern aus einem gewissen Handwerkszweig feststellen ${ }^{102}$. Diese breite Streuung spiegelt die wirtschaftliche Situation der spätmittelalterlichen Stadt Schaffhausen wider, bei der keine der unterschiedlichen Wirtschaftszweige eine dominierende Rolle sowohl in der Gesamtproduktion als auch im Handel einnehmen konnten ${ }^{103}$.

\section{Die Herkunftsfamilien der unteren Mittelschicht}

Eine weitere Gruppe bilden die Herkunftsfamilien der sogenannten unteren Mittelschicht, welche ein durchschnittliches Vermögen von 17 bis 252 Gulden versteuerten. Folgende Grafik illustriert sowohl die Vermögensverhältnisse als auch die soziale

100 RAG (Anm. 19), Johannes von Waldkirch - UniquID: ngSI0N577SK39hoAmSLh9Qeh, 22.5.2018.

101 Schmuki, Steuern (Anm. 5), S. 519.

102 Marianne Hovorka kam bei ihrer Untersuchung der Wiener an der Universität Wien im Spätmittelalter zum Ergebnis, dass vor allem Sprösslinge aus Kürschner-, Zinngiesser- und Fleischhauerfamilien die hiesige Universität besuchten. Marianne Hovorka, Die Wiener als Studenten an der Wiener Universität im Spätmittelalter (1365-1518), Wien 1982, S. 29-30. Für die Universität Heidelberg konnte Peter Moraw bei der Auswertung eines Heidelberger Schatzungsverzeichnisses aus dem Jahre 1439 eine starke Dominanz der Mitglieder von Schuhmacherfamilien als Studenten an der Heidelberger Universität feststellen Moraw, Heidelberg (Anm. 13.), S. 524-552.

103 Amman, Schaffhauser Wirtschaft (Anm. 8), S. 54-65. 
Herkunft dieser Familien (Abb. 6). Ausser dem Kaufmannsgeschlecht der Wys waren die Herkunftsfamilien der mittleren Steuerklasse alle in einer Zunft inkorporiert.

Jene Familien, welche Vermögenswerte um die 100 Gulden deklarierten, verfügten über einen gewissen Rückhalt, um unvorhersehbare finanzielle Rückschläge, wie eine durch Hagel zerstörte Ernte, temporär zu kompensieren. Hielt die Krise jedoch über eine längere Zeit an, konnten diese Familien sehr schnell in die Mittellosigkeit fallen. Ulrike Denk bezeichnet in ihrer Studie über das Armenkolleg (Kodrei) Goldberg dieses Schicksal als «sekundäre Armut» ${ }^{104}$.

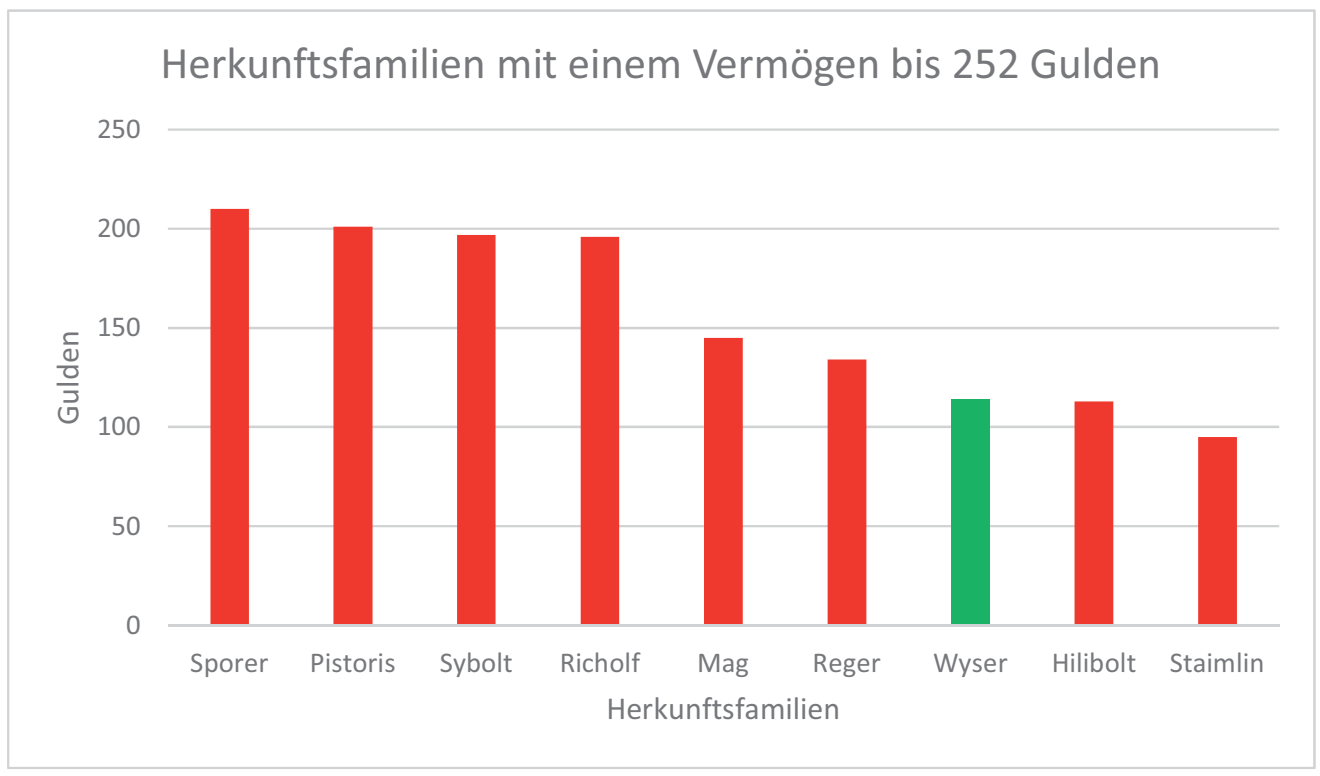

Abb. 6 Die Vermögensverhältnisse der Herkunftsfamilien der Mittelschicht nach ihrem sozialen Stand ${ }^{105}$

Von den Schaffhauser Universitätsbesuchern, deren Herkunftsfamilien in den Steuerakten identifiziert werden konnten, waren drei (5\%) teilweise oder vollständig von der Immatrikulationstaxe befreit ${ }^{106}$. Deren Familien zählen alle aufgrund ihrer durchschnittlichen Vermögenswerte zwischen 100 und 150 Gulden zu der unteren Mittelschicht.

104 Ulrike Denk definiert die primäre Armut als einen dauerhaften Zustand, in dem man, um das Überleben zu sichern, auf die Hilfe Dritter angewiesen ist. Im Gegensatz dazu fallen unter die sekundäre Armut Personen, welche über genügend Eigenmittel verfügen, um ihre Grundbedürfnisse zu decken, sich aber nahe an der Grenze zur primären Armut bewegen. Siehe dazu Denk, Alltag Studieren Betteln (Anm. 14), S. 14-15.

105 Die Einfärbung der Balken entspricht jener von Abb. 5

106 Von allen Schaffhauser, denen eine im Untersuchungszeitraum eine Erstimmatrikulation an einer Universität im Alten Reich nachgewiesen werden konnte, waren von 103 Immatrikulierten 13 (13\%) teilweise oder vollständig von der Immatrikulationsgebühr befreit. 
Es handelt sich dabei um Johannes Reger, Johannes Mag und Johannes Wys. Folgende Grafik (Abb. 7) zeigt die Vermögenswerte der oben genannten Familien auf.

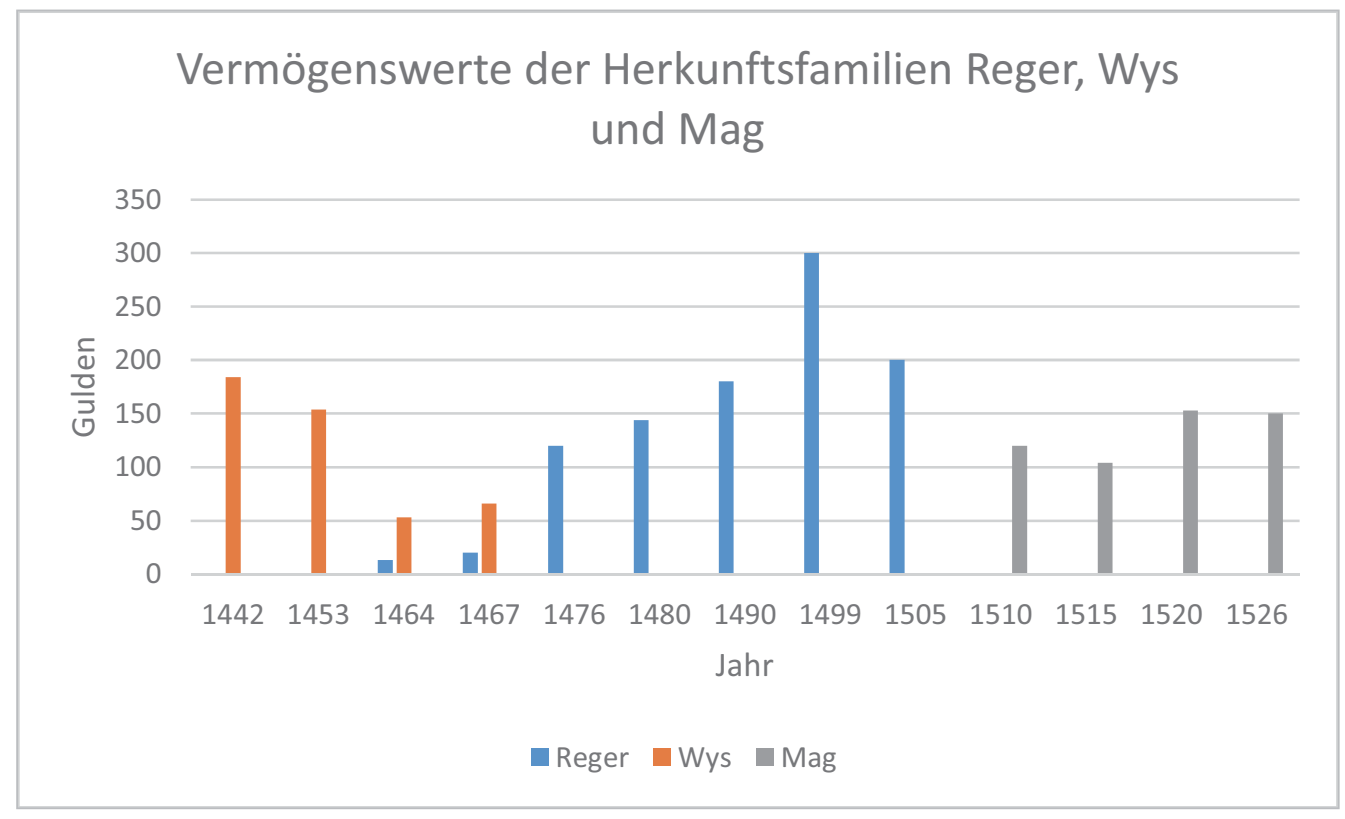

Abb. 7 Vermögenswerte der Herkunftsfamilien Reger, Wys und Mag

Die Herkunftsfamilie des Basler Studenten Johannes Reger wurde eingangs bereits vorgestellt. Deshalb soll im Folgenden auf die beiden letztgenannten Universitätsbesucher und ihre Herkunftsfamilien näher eingegangen werden. Der aus einer Krämerfamilie stammende Johannes Mag (Mägis) immatrikulierte sich im Jahr 1519 an der landesfürstlichen Universität Wien ${ }^{107}$. Sein Vater Anton verfügte zu diesem Zeitpunkt über ein Vermögen von 153 Gulden ${ }^{108}$. Somit versteuerte er sein Vermögen nach dem Tarif der mittleren Steuerklasse und zählte somit zu der unteren Mittelschicht. Abgesehen von dem kleinen elterlichen Vermögen könnte es sich bei Johannes Mag auch aufgrund der weiten und kostspieligen Reise bis nach Wien um temporäre Mittellosigkeit gehandelt haben.

Ebenso spärlich sind die Hinweise, die sich über den Kaufmannssohn Johannes Wys finden liessen ${ }^{109}$. Er immatrikulierte sich im Sommersemester 1474 an der Universität

107 Franz Gall und Willy Szaivert (Hg.), Die Matrikel der Universität Wien (Publikationen des Instituts für Österreichische Geschichtsforschung. Quellen zur Geschichte der Universität Wien, 1. Abteilung. Die Matrikel der Universität Wien), Bd. 3: 1518-1579, Wien/Köln/Graz 1971, S. 8, Zn. 129.

108 Stadtarchiv Schaffhausen, Steuerbücher, Behebbuch 1520, A II.06.01.073, S. 34.

109 Wackernagel, M Basel I (Anm. 1), S. 128, Nr. 24. 
in Basel, wobei er nur vier anstelle der geforderten sechs Schilling Immatrikulationsgebühr beglich. Drei Jahre später wurde er zum baccalaureus artium promoviert ${ }^{110}$. Auch bei ihm könnte es sich möglicherweise nur um eine zeitlich begrenzte Durststrecke gehandelt haben, denn wie aus dem Immatrikulationseintrag zu entnehmen ist, beglich er zu einem späteren Zeitpunkt die geforderte Gebühr vollständig. Das elterliche Vermögen zum Zeitpunkt seiner Immatrikulation konnte leider nicht ermittelt werden.

In welchem Verhältnis stehen nun diese Vermögenswerte der oben erwähnten Herkunftsfamilien der unteren Mittelschicht zu den Kosten eines universitären Studiums? Eine mögliche Antwort auf diese Frage lässt sich möglicherweise aus einem kurzen Überblick über die veranschlagten Studien- und Lebensunterhaltskosten eines spätmittelalterlichen Universitätsbesuchers ableiten. In den Statuten des an der Heidelberger Universität neugegründeten Armenkollegs Dionysianum wurde die Höhe der erlaubten jährlichen Einkünfte bei 12 Gulden angesetzt ${ }^{111}$. An der Universität Tübingen wurden die Einkommensgrenze für eine Gebührenbefreiung im Jahr 1488 auf 16 Gulden festgelegt $\mathrm{t}^{12}$. In der zweiten Hälfte des 15. Jahrhunderts wurden an der Leipziger Universität 20 Gulden für die jährlichen Lebensunterhaltskosten eines Studenten veranschlagt $t^{113}$. Dieser Wert wurde von den Gründungsvätern der Universität Basel als Richtwert für den studentischen Jahresetat übernommen ${ }^{114}$. Nach den Berechnungen von Berta Scharnke in ihrer Dissertation über die Zusammensetzung und sozialen Verhältnisse der Heidelberger Universitätsangehörigen im 15. Jahrhundert bildeten 20 bis 25 Gulden den durchschnittlichen Jahresbedarf eines Artes-Studenten an der Heidelberger Universität ${ }^{115}$. In dieser Summe sind die Promotionskosten miteinberechnet. Für die Studenten der juristischen Fakultät wurde die doppelte Summe von 50 Gulden als Armutsgrenze angesetzt ${ }^{116}$.

Dies entspricht der Hälfte des Vermögens der Herkunftsfamilien Wys, Hilibolt oder Staimlin (Abb. 6). Gerade solche Familien sahen sich bei einem Studium an einer höheren Fakultät mit einem finanziellen numerus clausus konfrontiert. Aber auch der Besuch einer artistischen Fakultät mit einem jährlichen Mindestaufwand um die 25 Gulden konnte nicht von jeder Familie gestemmt werden. Für 〈arme〉 Studenten existierte die Mög-

110 Ebd.

111 Eduard Winkelmann, Urkundenbuch der Universität Heidelberg, Bd. 1. Heidelberg 1886, S. 167, Nr. 111.

112 Fletcher, Wealth Poverty (Anm. 15), S. 424-425.

113 Friedrich Paulsen, Organisation und Lebensformen der deutschen Universitäten im Mittelalter, in: Historische Zeitschrift, Bd. 45 (1881), S. 385-440, hier: S. 431-432.

114 Edgar Bonjour, Zur Gründungsgeschichte der Universität Basel, in: Basler Zeitschrift für Geschichte und Altertumskunde, Bd. 54 (1955), S. 27-50, hier: S. 40.

115 Berta Scharnke, Über Zusammensetzung und soziale Verhältnisse der Heidelberger Universitätsangehörigen im 15. Jahrhundert, Heidelberg 1921, S. 87-88.

116 Christoph Fuchs, Dives, Pauper, Nobilis - Magister, Frater, Clericus. Sozialgeschichtliche Untersuchungen über Heidelberger Universitätsbesucher des Spätmittelalters (1386-1450) (Education and Society in the Middle Age ans Renaissance 5), Leiden/New York/Köln 1995, S. 60. 
lichkeit, sich von den Immatrikulations- und Promotionsgebühren befreien zu lassen ${ }^{117}$. Der Bittsteller musste einem universitären Gremium mit dem amtierenden Rektor als Vorsitzenden überzeugend seine Mittellosigkeit darlegen können ${ }^{118}$. Mit der Befreiung von den universitären Gebühren war aber noch nicht die finanzielle Seite des Studiums abgesichert. Der mittellose Student war, um seinen Lebensunterhalt bestreiten zu können, auf eine Nebentätigkeit angewiesen. Oftmals bestand keine andere Möglichkeit als zu betteln. Daneben war der mittellose Student auf finanzielle Unterstützung Dritter, wie zum Beispiel Stiftungen und Stipendien, angewiesen. Ein wichtiger Aspekt dabei war die soziale Vernetzung innerhalb und ausserhalb des Sozialkörpers der Universität ${ }^{11}$. Ein Dienstverhältnis als servitor oder famulus wirkte sich nicht nur positiv auf die Geldbörse, sondern auch auf die Laufbahn in und ausserhalb der Universität aus ${ }^{120}$. Wie das Beispiel Gerhards von Wieringen zeigt, konnte ein geistlicher Onkel bei der Finanzierung des Studiums und der Planung der weiteren Laufbahn von grossem Nutzen sein ${ }^{121}$.

Die spätmittelalterlichen Hochschulen waren keine isolierten Bildungsgemeinschaften sozial Gleichgestellter, sondern spiegelten vor allem die soziale Schichtung der städtischen Gesellschaft wider. Jeder Scholar hatte entsprechend seiner Herkunft seinen fest zugewiesenen Platz in der universitären Gemeinschaft ${ }^{122}$. Innerhalb der universitären Hierarchie waren die pauperes, sowohl in der Rangordnung als auch in der Wahl des Bildungsangebots, benachteiligt. Die Ungleichstellung spiegelte sich auch in der Verteilung der Sitzplätze während des akademischen Unterrichts wider. Für den 〈Geburts- und Geldadel〉 waren die vorderen Reihen, für die pauperes die hintersten Bänke reserviert ${ }^{123}$. Auch in den Immatrikulationseinträgen der Rektoratsmatrikeln einiger Universitäten kann eine soziale Rangordnung abgelesen werden. So wurden in den Matrikeln der Universität Erfurt nach 1470 die Studenten nicht mehr nach dem Immatrikulationsdatum eingetragen, sondern nach ihrem sozialen Status, dem Beziehungs-

117 Seit Mitte des 15. Jahrhunderts wurde von verschiedenen Universitäten eine Verschärfung der Gebührenerlasse angestrebt. Diese reichten von Teilzahlungssystemen bis hin zur Aufhebung des privilegium paupertatis, was zum Beispiel in Erfurt zu einer Politik des nulli parcere führte. Siehe dazu Schwinges, Pauperes, S. 244-246; ders., Universitätsbesucher (Anm. 14), S. 375-465; Hermann Weissenborn (Hg.), Acten der Erfurter Universität, 3 Bde., Halle 1881, hier: Bd. 1, S. 12f., 16.

118 Vgl. dazu Schwinges, Pauperes (Anm. 15), S. 244.

119 Christian Hebeisen und Thomas Schmid, De Zusato, Coloniensis dioecesis. Über Herkunftsräume armer Universitätsbesucher im Alten Reich (1375 bis 1550), in: Jahrbuch für Universitätsgeschichte, hg. von Rüdiger vom Bruch, Stuttgart 6 (2003), S. 28-50, hier: S. 30.

120 Schwinges, Pauperes (Anm. 15), S. 259.

121 Siehe dazu ders., Stiefel, Wams und Studium oder: Wozu hat man einen geistlichen Onkel? Aus den Notizen des Kölner Studenten Gerhard von Wieringen aus der zweiten Hälfte des 15. Jahrhunderts, in: Studenten und Gelehrte. Studien zur Sozial- und Kulturgeschichte deutscher Universitäten im Mittelalter, hg. v. Rainer Christoph Schwinges (Education and Society in the Middle Age and Renaissance 32), Leiden/Boston 2008, S. 529-552.

122 Vgl. dazu Schwinges, Universitätsbesucher (Anm. 15), S. 5 u. 341-342; ders., Pauperes (Anm. 15), S. 141; Peter Moraw, Zur Sozialgeschichte der deutschen Universität im späten Mittelalter, in: Giessener Universitätsblätter, Bd. 8 (1975), S. 44-60.

123 Schwinges, Pauperes (Anmerkung 15), S. 241-244. 
netz und der Höhe der bezahlten Gebühr ${ }^{124}$. Oftmals wurden «arme〉 Studenten von 〈armen〉 Magistern unterrichtet, was den pauperes eine Anknüpfung zu wirtschaftlich und sozial höhergestellten Kreisen praktisch verunmöglichte und diese Gruppe in eine soziale Isolation drängte ${ }^{125}$.

Wie lässt sich nun diese Randgruppe innerhalb des universitären Sozialkörpers quantitativ und qualitativ fassen? Aufgrund der Vermerke als pauper in den Immatrikulationseinträgen in den Rektoratsmatrikeln konnte Rainer Christoph Schwinges im Zeitraum von 1400 bis 1500 an den Universitäten im Alten Reich eine «Armenquote〉 von $15 \%$ ermitteln ${ }^{126}$. In seinen sozialgeschichtlichen Untersuchungen zur Universität Heidelberg von 1386 bis 1450 errechnete Christoph Fuchs einen Anteil von pauperes von rund $23 \% \%^{127}$. Die Schwierigkeit bei der Ermittlung der 〈Armenquote〉 für die Universitäten des Alten Reiches liegt unter anderem in den zum Teil unvollständigen beziehungsweise fehlenden Angaben zu der Höhe der bezahlten Gebühr. Es darf auch nicht angenommen werden, dass alle als pauper eingetragenen Studenten wirklich mittellos waren. Dieser Vermerk gibt nur Auskunft über die unmittelbare finanzielle Situation des Universitätsbesuchers zum Zeitpunkt seiner Immatrikulation. Der betreffende Student konnte in eine kurzfristige, reversible Notlage, verursacht durch irgendwelche malitia temporum, geraten sein ${ }^{128}$.

\section{Die besuchten Fakultäten und erworbenen Graduierungen}

Abschliessend soll noch ein kurzer Blick auf die mögliche Korrelation des elterlichen Vermögens und der sozialen Herkunft mit den erworbenen akademischen Grade der Universitätsbesucher geworfen werden. Folgende Grafik (Abb. 8) zeigt die erworbenen Grade in Relation mit der Höhe des elterlichen Vermögens auf.

Anhand der Grafik ist zu erkennen, dass mehr als die Hälfte, bei den geringeren Vermögen sind es sogar $80 \%$, der Schaffhauser Universitätsbesucher ihr Studium ohne eine Graduierung abschlossen. Aufgrund der hohen finanziellen und zeitlichen Aufwendungen, welche ein Studium an einer höheren Fakultät, insbesondere der Theologie, voraussetzte, erstaunt es nicht, dass vor allem die Zöglinge aus der wirtschaftlichen Oberschicht eine solche besuchten und einen akademischen Grad erwarben. In einer leicht geringeren Anzahl schlossen diese ihren akademischen Werdegang mit einer Graduierung an einer artistischen Fakultät ab. Die Universitätsbesucher aus Herkunftsfamilien der Mittelschicht erwarben, wenn überhaupt, fast ausschliesslich den Grad eines baccalaureus oder magister artium. Gerade bei dieser Gruppe der Herkunftsfamilien der Mittelschicht lässt sich eine Korrelation zwischen der Höhe des elterlichen

124 Ebd., S. 243.

125 Ebd., S. 247-248.

126 Ebd., S. 244.

127 Fuchs, Dives (Anm. 116), S. 56.

128 Ebd., S. 57; Jaques Paquet, Recherches sur l'universitaire 〈pauvre` au moyen âge, in : Revue Belge de Philologie et d'Histoire 56 (1978), S. 301-353, hier: S. 320. 
Vermögens und dem Erwerb akademischer Grade erkennen. Je vermögender die Herkunftsfamilie war, umso mehr liess sich bei den Universitätsbesuchern ein akademischer Grad der Freien Künste nachweisen. Von den Universitäsbesuchern mit einem elterlichen Vermögen von 253 bis 3'000 Gulden erwarben zwei Fünftel den magister oder baccalaureus artium als höchste Graduierung. Bei der Gruppe der geringeren Vermögen schlossen hingegen gerade noch ein Fünftel der Studenten ihr Studium mit einem baccalaureus artium ab. Grundsätzlich lässt sich feststellen, dass mit sinkendem finanziellen Hintergrund auch die Bereitschaft beziehungsweise die Möglichkeit zum Erwerb eines akademischen Grades schwindet.

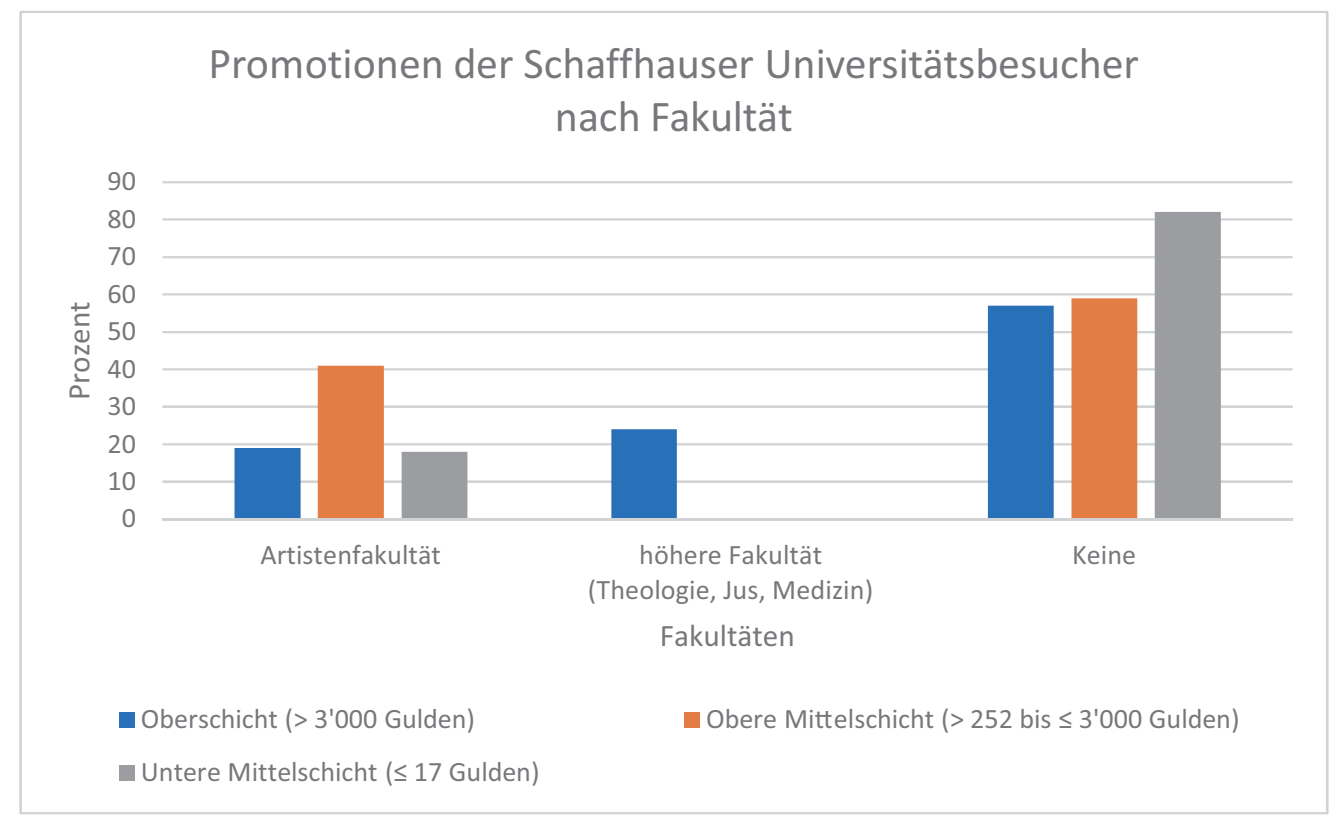

Abb. 8 Graduierungen der Schaffhauser Universitätsbesucher anhand ihres wirtschaftlichen Hintergrunds

Betrachtet man das Graduierungsverhalten nach dem sozialen Hintergrund der Schaffhauser Universitätsbesucher, lässt sich erkennen, dass der Adel, wenn er überhaupt akademische Grade anstrebte, sich an einer höheren Fakultät promovieren liess. Im Falle der Schaffhauser Adelsprösslinge liessen sich ausschliesslich Graduierungen an einer juristischen Fakultät nachweisen. Der Gruppe der adligen Universitätbesucher gegenübergestellt, erwarben fast die Hälfte der Kaufmannssöhne einen akademischen Grad an einer artistischen Fakultät. Eine Ausnahme bildet dabei Johannes Lib ${ }^{129}$, der sich zum doctor decretorum promovieren liess, um sich wie seine adeligen Kommilitonen eine 
Pfründe an einem Domkapitel zu sichern ${ }^{130}$. Von den Studenten aus einer Zunftfamilie schlossen rund ein Drittel ihr Studium mit dem Grad eines baccalaureus oder magister artium ab. Aus dieser Gruppe besuchte einzig Georg Jünteler ${ }^{131}$ eine höhere Fakultät und erwarb in Basel den Grad eines licentiatus decretorum ${ }^{132}$.

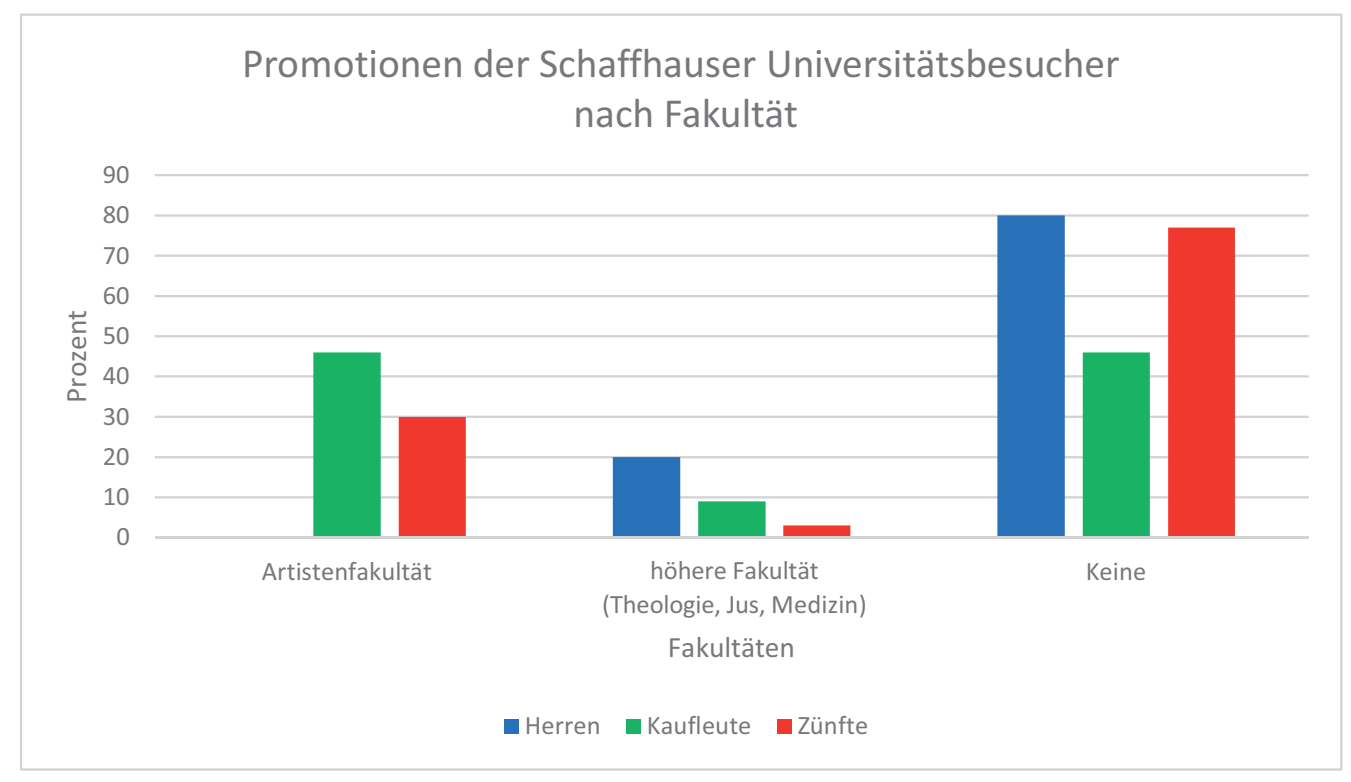
Abb. 9 Graduierungen der Schaffhauser Universitätsbesucher anhand ihres
sozialen Hintergrunds

\section{Fazit}

Abschliessend lässt sich feststellen, dass aufgrund der kleinen Untersuchungsgruppe eher individuelle Wege denn allgemeine Tendenzen aufgezeigt werden konnten. Die Beweggründe beziehungsweise Familienstrategien, die hinter der Investition in universitäre Bildung standen, konnten, je nach dem wirtschaftlichen und sozialen Status der Familien, sehr unterschiedlich ausfallen. Deshalb lässt sich auch schwerlich eine Aussage über die Intention hinter der Investition in akademische Bildung treffen. Die Finanzierung eines universitären Studiums muss vor allem für die Familien der unteren Mittelschicht mit einem Vermögen von bis zu 252 Gulden mit grossen finanziellen und personellen Entbehrungen verbunden gewesen sein. Deshalb ist davon auszugehen, dass es sich um eine wohlüberlegte Entscheidung handeln musste, an die hohe Erwartungen

130 Kuhn, Studenten Tübingen (Anm. 95), S. 356, Nr. 2169.

$131 R A G$ (Anm. 19), Georg Jünteler - UniquID: ngJZ2g274KR04yfNdTCy7, 22.5.2018.

132 Wackernagel, M Basel I (Anm. 1), S. 51, Nr. 20. 
geknüpft wurden. Es erstaunt daher nicht, dass der Nachwuchs dieser Familien ihr Studium mehrheitlich ohne Graduierung abschloss. Die geringe Graduierungsrate innerhalb dieser Gruppe lässt sich vor allem mit den hohen Kosten einer Promotion erklären. Zudem war für diese Familien der Erwerb von Bildung und deren praktische Anwendung in den späteren Tätigkeitsfeldern für die Existenzsicherung von Bedeutung und nicht der akademische Grad. Aufgrund der fehlenden Angaben zu den weiteren Lebenswegen dieser Studenten lässt sich jedoch nur vermuten, dass viele dieser Personen nach ihrem Universitätsbesuch in den elterlichen Handwerksbetrieb eintraten und ihr Studium nur marginal ihre Laufbahn beeinflusste.

Die Beispiele der Familien Reger, Mag und Wys zeigen, auch wenn sie im Vergleich zu der Gesamtzahl der Herkunftsfamilien der Schaffhauser Universitätsbesucher eine Minderheit darstellen, dass auch Familien mit einem bescheidenen finanziellen Hintergrund ihrem Nachwuchs die Möglichkeit eröffneten, akademische Bildung zu erlangen. Anhand dieser Familien konnte aufgezeigt werden, dass hinter dem Vermerk pauper in den Rektoratsmatrikeln nicht unbedingt die völlige Mittellosigkeit des betreffenden Universitätsbesuchers und dessen Familie stehen musste.

Diesen Familien aus der unteren Mittelschicht müssen jene Zunft- und Kaufmannsfamilien gegenübergestellt werden, welche innerhalb weniger Generationen ein beachtliches Vermögen erwirtschaften konnten und, damit einhergehend, sich als Konkurrenz zum ansässigen Adel in der wirtschaftlichen und politischen Elite der Stadt etablierten. Diese 〈Aufsteigerfamilien〉 investierten mehrheitlich erst in akademische Bildung für ihren Nachwuchs, nachdem sie ihre Führungspositionen innerhalb des städtischen Gefüges abgesichert hatten. Über die Hälfte (58 \%) der Universitätsbesucher aus diesen Familien des «Geldadels〉 schlossen ihr Studium zumindest mit dem baccalaureus artium ab. Sogar ein Viertel besuchte eine juristische Fakultät, an der sie zum licentiatus beziehungsweiche doctor promoviert wurden. Ein juristischer Doktortitel konnte die bürgerliche Herkunft teilweise kompensieren und als Toröffner zu einem Kanonikat dienen. Für die Söhne des Geburtsadels hingegen war der Erwerb eines akademischen Grades nicht das vordergründige Ziel eines universitären Studiums. Wenn überhaupt strebten sie die Doktorwürde an einer höheren Fakultät wie der juristischen an.

Ob diesen Geschlechtern aus dem Stadtadel, der Kaufmannsgilde und der Handwerkerschaft durch die Investition in akademische Bildung ein wirtschaftlicher, politischer oder sozialer Vorteil erwachsen ist, lässt sich nicht durch eine allgemeine Formel beantworten. Vielmehr müssen die individuellen Konzepte und Bildungstraditionen der einzelnen Familien betrachtet werden. 


\title{
Ritter an der Universität
}

\section{Universitätsbesuch der niederadligen Familie Friedingen (1324-1540)}

\begin{abstract}
Es ist auch der zeit ein solicher hass oder verachtung über die studia gewesen, dessen sich zu verwundern, gleichwol, wie man sagt, die künsten nit grössere widersecher haben, dann die unwissenden und die sie nit könden. ${ }^{l}$
\end{abstract}

Graf Froben Christoph von Zimmern äusserte sich in dieser Art in seiner ¿Zimmerischen Chronik> über das Verhältnis seiner adligen Standesgenossen zur universitären Bildung $^{2}$. Froben Christoph von Zimmern selbst war ein hochgelehrter Mann, der seine Studien 1532 in Tübingen begonnen und in Bourges, Köln, Löwen, Paris, Angers und Tours weitergeführt hatte ${ }^{3}$. Für einen Adligen war der Gang an die Universität lange Zeit eine Seltenheit. Mittelalterliche Erziehungsprogramme für adlige Söhne sahen den Universitätsbesuch nicht als selbstverständlich oder gar notwendig $a^{4}$. Etwa seit der Mitte des 15. Jahrhunderts fand hinsichtlich des Verhältnisses von Adel und Universität aber ein Wandel statt: Der Adel, und vor allem der niedere Adel, begann in immer grösserer Zahl an die Universitäten zu gehen ${ }^{5}$. Als Grund dafür wird in der Forschungsliteratur gemeinhin die Bedrängnislage der Adligen zwischen dem sich

1 Christoph Froben von Zimmern, Zimmerische Chronik, Bd. 3, hg. von Karl August Barak, Freiburg/Tübingen 18811882, S. 216.

2 Die 〈Zimmerische Chronik〉 ist Mitte des 16. Jahrhunderts entstanden und gilt als eine der bekanntesten Adelschroniken dieser Zeit. Vgl. Gerhard Wolf, Von der Chronik zum Weltbuch. Sinn und Anspruch südwestdeutscher Hauschroniken am Ausgang des Mittelalters (Quellen und Forschungen zur Literatur- und Kulturgeschichte 18/252), Berlin/New York 2002, S. 24-46.

3 Alle Angaben zu den einzelnen Personen sind, sofern nicht anders zitiert, dem Repertorium Academicum Germanicum (RAG) entnommen. Die Schreibweise der Personennamen sind vom RAG übernommen. Einsehbar unter: Repertorium Academicum Germanicum (RAG), [http://www.rag-online.org], 28.5.2018.

4 Gerhard Fouquet, «begehr nit doctor zu werden, und habs Gott seys gedanckht, nit im Sünn» - Bemerkungen zu Erziehungsprogrammen ritterschaftlicher Adliger in Südwestdeutschland (14.-17. Jahrhundert), in: Wirtschaft - Gesellschaft - Städte. Festschrift für Bernhard Kirchgässner zum 65. Geburtstag, hg. von HansPeter Brecht und Jörg Schadt, Ubstadt-Weiher 1998, S. 95-127, hier: S. 103-105; Siehe dazu ebenfalls Rainer A. Müller, Norm und Praxis adliger Bildung 1350-1550, in: Gelungene Anpassung? Adelige Antworten auf gesellschaftliche Wandlungsvorgänge vom 14. bis zum 16. Jahrhundert, hg. von Horst Carl und Sönke Lorenz (Schriften zur südwestdeutschen Landeskunde 53), Ostfildern 2005, S. 139-164; Benjamin Müsegades, Fürstliche Erziehung und Ausbildung im spätmittelalterlichen Reich (Mittelalter-Forschungen 47), Ostfildern 2014, S. 119-131.

5 Zuletzt Rainer C. Schwinges, Keeping up with the Elite. Noblemen at German Universities (15.-16. century) with a Special Regard to Freiburg im Breisgau, in: The elite University - Roles and Models, hg. von Ditlev Tamm (Scientia Danica. The Royal Danish Academy of Sciences and Letters 8/15), Copenhagen 2017, S. 62-85, hier: S. 66. 
verdichtenden Fürstenstaat und den aufstrebenden städtisch-bürgerlichen Führungsgruppen angegeben, welche sie zusammen mit der sich verändernden wirtschaftlichen Lage unter erheblichen Anpassungsdruck stellte. Um sich gegen den Bedeutungsverlust und den damit verbundenen sozialen Abstieg zu wehren, suchten die Adligen nach neuen Strategien und erlernten neue Verhaltensmuster. Eine davon war der Universitätsbesuch ${ }^{6}$.

Im Folgenden wird am Beispiel des niederadligen Geschlechts der von Friedingen ${ }^{7}$ aus dem Hegau und Oberschwaben die Funktion beleuchtet, die der Universitätsbesuch in einer niederadligen Familie einnahm. Die Umstände, unter welchen eine Familie ihren Nachwuchs an eine Universität sandte, und die Lebenswege dieser Familienmitglieder nach dem Studium stehen besonders im Fokus. Der Universitätsbesuch wird zu diesem Zweck in den Kontext der Familiengeschichte gesetzt und mit den Karrieren nicht studierter Verwandter kontrastiert.

Die Friedinger gehörten im Spätmittelalter zum reichsunmittelbaren Ritteradel, wie er für die Gebiete Hegau und Oberschwaben typisch war. Der schwäbische Adelsraum war geprägt von Niederadligen aus der ehemaligen Ministerialität und zeichnete sich durch eine hohe Dichte an kleinen und Kleinstherrschaften aus ${ }^{8}$. Im Gegensatz zu anderen Regionen im Reich konnte im nördlichen Bodenseeraum kein Fürst seine Machtansprüche durchsetzen und es entstand keine übergreifende Landesherrschaft, welche den regionalen Adel mediatisiert hätte 9 . Der Stammsitz des Geschlechts der Friedinger lag auf der namensgebenden Burg Hohenfriedingen beim Dorf Friedingen im Hegau. Sie waren in ihren Ursprüngen ein edelfreies Geschlecht ${ }^{10}$. Zu Beginn des 13. Jahrhunderts begaben sich die Friedinger aber in die Ministerialität der Abtei Reichenau, wo sie Vögte von Radolfzell wurden und das Amt des Truchsessen einnahmen. Dadurch stiegen sie von einem edelfreien Geschlecht, aus denen im Spätmittelalter der Hochadel erwuchs, in den unfreien Status der Ministerialen ab. Im weiteren Verlauf des Mittelalters konnten sie sich weitgehend - wenn auch nicht ohne Probleme - als niederadlige Familie im Adelsstand halten ${ }^{11}$.

6 Stellvertretend für diese Sicht siehe Winfried Schulze, Deutsche Geschichte im 16. Jahrhundert. 1500-1618, Frankfurt am Main 1987, S. 237; Rainer A. Müller, Adel und Universität. Eine sozio-kulturelle Studie zur Geschichte der bayerischen Landesuniversität Ingolstadt 1472-1648 (Ludovico Maximilianea. Forschungen 7), Berlin 1974, S. 17-32; Christian Wieland, Status und Studium. Breisgauischer Adel und Universität im 16. Jahrhundert, in: Zeitschrift für Geschichte des Oberrheins 148 (2000), S. 97-125, hier: S. 98.

7 Die Grundlage für die folgenden Ausführungen zur Familiengeschichte der Friedinger ist die detaillierte Studie über das Geschlecht von Eberhard Dobler, Burg und Herrschaft Hohenkrähen im Hegau, Sigmaringen 1986.

8 Peter Blickle, Politische Landschaft in Oberschwaben, in: Politische Kultur in Oberschwaben, hg. von dems., S. 9-42, hier: S. 11; Werner Rösener, Adelige Herrschaft in einer alten Königslandschaft. Herrschaftspraktiken und Lebensformen des oberschwäbischen Adels im Spätmittelalter, in: Politische Kultur in Oberschwaben, hg. von Peter Blickle, Tübingen 1993, S. 119-146, hier: S. 122.

9 Werner Hechberger, Adel, Ministerialität und Rittertum im Mittelalter (Enzyklopädie deutscher Geschichte 72), München 2004, S. 41.

10 Julius Kindler von Knobloch, Oberbadisches Geschlechterbuch, Bd. 1: A-Ha, Heidelberg 1898-1910, S. 394.

11 Dobler, Hohenkrähen (Anm. 7), S. 67. Zum edelfreien Adel und der Ministerialität siehe Karl-Heinz Spiess, Ständische Abgrenzung und soziale Differenzierung zwischen Hochadel und Ritteradel im Spätmittelalter, in: Rheinische Vierteljahresblätter 56 (1992), S. 181-205, hier: S. 185; Hechberger, Ministerialität (Anm. 9), S. 17-34. 
Insgesamt neun Mitglieder der Familie von Friedingen besuchten im Mittelalter bis in die Anfänge der Frühneuzeit hinein eine Universität. Die folgenden Ausführungen sind chronologisch aufgebaut, die Universitätsbesucher der Familie werden mit ihrem jeweiligen Universitätsbesuch und Lebensweg einzeln thematisiert und mit der aktuellen Situation der ganzen Familie in Zusammenhang gebracht. Dabei liegt der Fokus auf den Universitätsbesuchern um 1500. Zum Abschluss wird das Studium der Friedinger in Zusammenhang mit allgemeinen Aussagen zum Universitätsbesuch von Adligen im Heiligen Römischen Reich gesetzt.

\section{Die ersten Universitätsbesucher aus dem Hause Friedingen im 14. Jahrhundert}

Die ersten Universitätsbesucher der Familie finden wir zu Beginn und Ende des 14. Jahrhunderts wieder. 1324 ist Ulrich II. von Friedingen als dominus Ulricus de Fridinge ${ }^{12}$ in den Akten der deutschen Nation an der prestigeträchtigen Universität Bologna eingetragen ${ }^{13}$. Es darf angenommen werden, dass er dort kanonisches Recht studierte $^{14}$. Während seines Studiums in Bologna besass er bereits zwei Pfründen, ohne die sich die Familie den teuren Aufenthalt in der Ferne wahrscheinlich nicht hätte leisten können. In den Jahren darauf kamen weitere Pfründen dazu, darunter eine Domherrenstelle in Freising. Am 27. Juni 1341 wurde er vom Papst zusätzlich noch mit einem Domkanonikat in Konstanz providiert, wobei die Verwandtschaft mit dem damaligen Konstanzer Bischof Nikolaus von Frauenfeld sicherlich geholfen hat. Ulrichs Karriere erreichte am 9. September 1355 ihren Höhepunkt, als er vom Konstanzer Domkapitel zum neuen Bischof gewählt wurde. Er wurde jedoch vom Papst nicht bestätigt und gab kurz darauf seine Ansprüche auf den bischöflichen Stuhl auf, ohne vorher um seine Anerkennung gekämpft zu haben ${ }^{15}$.

Zur Zeit Ulrichs II. von Friedingen hatte sich das Geschlecht bereits in zwei Linien getrennt. Er selbst entstammte der Krähener Linie, die ihren Hauptsitz auf der Burg Hohenkrähen bei Singen im Hegau hatte. Seit dem Ende des 13. Jahrhunderts residierte eine zweite Linie als Burgmannen auf der habsburgischen Burg Bussen in Oberschwaben. Die neue Bussener Linie besass aber bis zu ihrer «Rückkehr» am Ende des 15. Jahrhunderts immer Güter im Hegau, so zum Beispiel den Stammsitz Hohenfriedingen $^{16}$. Der zweite Student aus der Familie Friedingen, Georg I. von Frie-

12 Ernst Friedländer und Carlo Malagola (Hg.), Acta Nationis Germanicae. Universitatis Bononiensis ex archetypis tabularii Malvezziani (Athenaeum. Biblioteca di storia della scuola e delle università 24), Berlin 1887, S. 85, Z. 39.

13 Die Nummerierungen sind von Eberhard Dobler übernommen. Siehe beispielsweise Dobler, Hohenkrähen (Anm. 7), S. 451-455.

$14 \mathrm{Zu}$ den Studiengewohnheiten deutscher Universitätsbesucher in Bologna vgl. Jürg Schmutz, Juristen für das Reich. Die deutschen Rechtsstudenten an der Universität Bologna 1265-1425, Teil 1: Text, Basel 2000.

15 Vgl. Gustav C. Knod, Deutsche Studenten in Bologna (1289-1562). Biographischer Index zu den Acta nationis Germanicae universitatis Bononiensis, Berlin 1899, S. 136, Nr. 966.

16 Dobler, Hohenkrähen (Anm. 7), S. 394. 
dingen, stammte aus dieser Bussener Linie. Georg wurde 1414 ebenfalls Domherr in Konstanz ${ }^{17}$. Er hatte sich im Sommersemester 1397 an der Universität Wien immatrikuliert. Ob er damals bereits eine Pfründe besass, ist allerdings nicht bekannt. Die Wahl der Universität Wien als Studienort ist in Bezug auf die enge Bindung seiner Familie zu den Habsburgern nicht erstaunlich. Zudem war ein Angebot an universitären Studien in der unmittelbaren Nachbarschaft zur Heimatregion in dieser Zeit noch nicht vorhanden. Georg I. stellt eine Ausnahme unter den friedingischen Studenten dar: Auch wenn er in Wien 〈bloss baccalaureus der Artes wurde, ist er trotzdem nur einer von zwei Friedingern, die je einen universitären Abschluss erwarben.

\section{Die Friedinger an der Universität im 15. Jahrhundert}

Im Einklang mit der ansteigenden Adelsfrequenz an den Universitäten des Reiches gab es in der friedingischen Familie am Ende des Mittelalters eindeutig mehr Universitätsbesucher als zuvor: In der zweiten Hälfte des 15. Jahrhunderts waren drei Friedinger an einer Universität immatrikuliert und in der ersten Hälfte des 16. Jahrhunderts waren es gar vier. Wie eingangs bereits erwähnt, wird die Ursache für den Anstieg der Anzahl adliger Universitätsbesucher in der zunehmenden Bedrängnislage gesehen, in der sich der Niederadel gegen Ende des Mittelalters befand. Die ausgreifende Landesherrschaft drängte die Niederadligen dazu, ihre kleinen, aber eigenständigen Herrschaften aufzugeben und in den Dienst eines Fürsten oder Grafen zu treten. Gleichzeitig durchlief die herrschaftliche Verwaltung einen Rationalisierungsprozess, der die Anstellung von studierten Nichtadligen in Verwaltungspositionen und auch in Ratspositionen begünstigte. Auch in der Kirche übernahmen Gelehrte aus der städtischen Bürgerlichkeit vermehrt Positionen, die bis dato dem Adel vorbehalten waren ${ }^{18}$. In dieser «doppelten Frontstellung $\rangle^{19}$ wurde der Universitätsbesuch für Adlige vermehrt attraktiv, um neue Einnahmequellen am Fürstenhof zu finden beziehungsweise ihre angestammten Positionen in Kirche, Verwaltung und am Hof zu behalten ${ }^{20}$.

Dass die Friedinger sich im 15. Jahrhundert teilweise vor einem sozialen Abstieg fürchten mussten, kann mit Blick auf ihre Geschichte angenommen werden. Um 1400 sah es für die Bussener Linie noch vielversprechend aus. Sie hatten ihre Position in der Gegend um den Bussen gefestigt und mit dem Erwerb von Daugendorf sogar eine kleine Grundherrschaft aufbauen können ${ }^{21}$. Von König Sigismund hatten sie 1417 das Privile-

17 Ebd., S. 126. Die Bussener blieben zwar noch eine Zeitlang reichenauische Lehensträger, sie hatten die Vogtei Radolfzell für reichenauische Lehen in der Gegend ihrer neuen Heimat getauscht. Ebd.

18 Schwinges, Elite (Anm. 5), S. 67 u. 72.

19 Müller, Adel (Anm. 6), S. 17.

20 Dazu ausführlich: ebd., S. 17-29.

21 Leopold Stierle, Herren von Friedingen, die das Wappen Alt-Friedingen geführt haben, in: Zeitschrift für Hohenzollerische Geschichte 36 (2000), S. 73-90, hier: S. 77-78. 
gium de non evocando verliehen bekommen ${ }^{22}$. Im Jahr 1415 aber verkauften sie ihre Besitzungen um den Bussen und kauften sich dafür die Herrschaft Blumegg im Schwarzwald $^{23}$. Auslöser für diesen Ortswechsel könnte der Bruder des oben erwähnten Georg I. Rudolf IX. von Friedingen gewesen sein, der zusammen mit seinem Vater und einem weiteren Bruder die Herrschaft Blumegg im Schwarzwald kaufte und als Ehemann der Witwe des Truchsessen von Diessenhofen auf der nahe gelegenen Burg Tengen residierte $^{24}$. Der Ortswechsel war für die Familie allerdings kein Erfolg, bereits 1432 mussten die Friedinger die Herrschaft Blumegg wegen Streitigkeiten mit dem ursprünglichen Verkäufer an das Kloster St. Blasien weiterverkaufen. Die Bussener hatten somit fortan keine eigenständige Besitzbasis mehr, sondern verfügten nur noch über kleinere Lehen $^{25}$. Eberhard Dobler bewertet diese Vorgänge folgendermassen: «Mit Rudolf IX. und seinem älteren, aber anscheinend weniger bedeutenden Bruder Heinrich IX. ist in die Bussener Linie der Friedinger eine Unruhe hineingekommen, an der auch alle folgenden Generationen zu tragen haben..${ }^{26}$ Die Familie begab sich Mitte des 15. Jahrhunderts mit einem Teil ihrer Güter in württembergische Lehenshoheit, womit eine neue und für die Zukunft des Geschlechts prägende Abhängigkeit von Württemberg geschaffen wurde, ${ }^{27}$ die sich für die Studierenden aus der Familie auch in der Wahl ihrer Universität niederschlagen wird.

Die Krähener Linie war ebenfalls vom sozialen Abstieg bedroht. Im Unterschied zu den Bussenern war er zum grössten Teil politisch motiviert: Im Jahr 1479 begannen sie eine Fehde mit Graf Eberhard von Württemberg ${ }^{28}$. Diese ging so weit, dass sich die Habsburger, die einen Vorstoss der Württemberger in den weitgehend habsburgischen Hegau befürchteten, und die Eidgenossen, die einen friedlichen Hegau wollten, einmischten. Der Konflikt konnte erst 1481 durch einen Friedensvertrag zwischen Württemberg und Österreich und einem Vergleich zwischen Württemberg und den Friedingern beendet werden. Graf Eberhard erliess ihnen zwar schlussendlich alle Entschädigungen aus der Fehde, die Friedinger mussten aber in den gräflichen Dienst treten und ihm das Öffnungsrecht für den Hohenkrähen zusichern ${ }^{29}$. Somit war auch die Krähener Linie fortan eng an Württemberg gebunden. Politische Auseinandersetzungen setzten dem Status der Familie auch weiterhin zu: 1512 verloren sie den Hohenkrähen an den Schwäbischen Bund, nachdem sie Raubritter auf ihrer Burg beheimatet und von

22 Dobler, Hohenkrähen (Anm. 7), S. 408.

23 Stierle, Herren (Anm. 21), S. 79.

24 Dobler, Hohenkrähen (Anm. 7), S. 409.

25 Ebd., S. 413-414.

26 Ebd., S. 413.

27 Ebd., S. 395.

28 Ausführlich zur Fehde Eberhard Dobler, Burg und Herrschaft Mägdeberg (Hegau-Bibliothek 2), Singen 1959, S. 77-86.

29 René Moeri, Die Edlen von Friedingen. Streiflichter aus der Geschichte eines süddeutschen Adelsgeschlechts, in: Zwingliana 15 (1982), Nr. 7, S. 549-570, hier: S. 566-567; Der Hohenkrähen war übrigens im Gegensatz zu ihrer Stammburg Hohenfriedingen Eigentum der Herren von Friedingen. Ebd., S. 565. 
dort aus Raubzüge in die Umgebung unternommen hatten. Auf Initiative des Kaisers hin unternahm der Schwäbische Bund als Landfriedenseinigung eine militärische Aktion gegen den Hohenkrähen und konnte die Burg am 13. November 1512 nach der Flucht der adligen Burginsassen ohne grosse Mühe einnehmen. Den Krähener Friedingern wurde darauf die Burg sowie alle unmittelbar zur Burg gehörenden Besitzungen entzogen. $\mathrm{Zu}$ dieser Zeit residierte auch die Bussener Linie wieder auf dem Krähen, nachdem Martin II. von Friedingen 1497 einem Krähener ohne Nachkommen seine Anteile an der Burg und den dazugehörenden Gütern abgekauft hatte. Die Burg Hohenkrähen ging nach dem Eingreifen des Schwäbischen Bundes auch für ihn verloren, die dazu gehörenden Güter wie zum Beispiel die Hälfte des Dorfes Duchtlingen konnte er jedoch behalten ${ }^{30}$. In den Jahren 1521/1522 musste er aber alle zum Hohenkrähen gehörenden Güter wegen eines wahrgenommenen Wiedergaberechts an die Krähener Linie zurückgeben. Die Bussener Linie war fortan praktisch mittelos ${ }^{31}$.

Der erste Universitätsbesucher des 15. Jahrhunderts aus dem Hause Friedingen ist in der Familiengeschichte nicht eindeutig einzuordnen. Es ist möglich, dass er ein Bruder des oben erwähnten Martin II. war, doch ist sich Dobler fast sicher, dass diese Zuweisung falsch ist. Stattdessen ordnet er ihn in die Krähener Linie ein, als nachgeborenen Sohn von Hans Wilhelm und Anna von Grünenberg ${ }^{32}$. Georg (III.) immatrikulierte sich im Winter 1469 in Basel, wo er 1471 zum bacc. art. promovierte. Damit war er der zweite und sogleich letzte Friedinger, der einen universitären Grad erlangte. Im Sommersemester 1478 immatrikulierte er sich auch noch an der neu gegründeten Universität Tübingen. Da es eher unwahrscheinlich ist, dass er nach dieser langen Zeit sein Studium der Artes noch hätte abschliessen wollen, ist anzunehmen, dass er dort eine der höheren Fakultäten besuchte. Möglich wäre aber auch, dass es sich bei dieser Immatrikulation hauptsächlich um eine Loyalitätsbekundung der Familie gegenüber dem württembergischen Universitätsgründer Graf Eberhard im Bart handelte. Georg (III.) startete mit seiner Immatrikulation in Tübingen eine Familientradition. Alle nach ihm folgenden friedingischen Universitätsbesucher immatrikulierten sich ebenfalls - wenn auch nicht ausschliesslich - dort. Dass die württembergische Landesuniversität Tübingen der Hauptfokus der studentischen Bemühungen der Friedinger wurde, ist angesichts der Situation der Familie mit Württemberg als hauptsächlichem Lehns- und Dienstherrn nicht weiter erstaunlich ${ }^{33}$. Georg (III.) ist 1471 als Pfarrer in Ammerswyl belegt und starb zwischen 1488 und 1491.

Die zwei weiteren Universitätsbesucher des 15. Jahrhunderts sind die Brüder Johannes VIII. und Rudolf XIV. Im Gegensatz zu Georg (III.) sind sie mit Sicherheit die Brüder des oben erwähnten Martin II. und somit Mitglieder der Bussener Linie.

30 Ausführlich zur Eroberung des Hohenkrähen durch den Schwäbischen Bund Dobler, Hohenkrähen (Anm. 7), S. 216-233.

31 Ausführlich ebd., S. 212 u. 262-271.

32 Ebd., S. 156-157.

33 Zur Universität Tübingen als landesherrliche Universität siehe Sönke Lorenz, Eberhard im Bart und seine Universität. Eine Einführung, in: Tübingen in Lehre und Forschung um 1500. Zur Geschichte der Eberhard-Karls-Universität Tübingen, hg. von dems. et al. (Tübinger Bausteine zur Landesgeschichte 9), Ostfildern 2009, S. 1-59. 
Rudolf XIV. immatrikulierte sich am 25. November 1482 an der Universität Tübingen. Seine Immatrikulation in die Rektoratsmatrikel erfolgte aber nicht in Tübingen, sondern in Dornstetten ${ }^{34}$, vermutlich weil zu dieser Zeit die Pest in Tübingen herrschte und sich die Universität deshalb in rurale Gebiete zurückgezogen hatte ${ }^{35}$. Rudolfs Studium war wohl denkbar kurz, in der Rektoratsmatrikel wurde sein Eintrag wieder gestrichen und am Rand vermerkt: renunciavit privilegiis ${ }^{36}$. Die Gründe für seine «Exmatrikulation〉 sind nicht überliefert. Möglicherweise wollte er den zur Immatrikulation gehörende Eid gegenüber der Universität nicht schwören. An gewissen Universitäten genossen Adlige zwar das Privileg nicht schwören zu müssen, ${ }^{37}$ doch ist anzunehmen, dass Rudolf aus dem eher unbedeutenden hegauischen Niederadelsgeschlecht dieses Privileg nicht zugesprochen wurde. Rudolf widmete seinen weiteren Lebensweg dem Deutschen Orden, in dem er eine beeindruckende Karriere machte ${ }^{38}$. Er wurde 1497 Komtur der Deutschordenskommende in Sumiswald und 1503 in Köniz ${ }^{39}$. Aus dieser Zeit sind zwei Bildnisse von ihm erhalten geblieben: eine Figurenscheibe von Johannes Dachselhofer in Sumiswald und eine Abbildung in Niklaus Manuels Totentanz, in der er als aufrichtiger Ritter dargestellt ist. Zusätzlich befindet sich im Berner Münster noch eine Wappenscheibe Rudolfs ${ }^{40}$. Seine Karriere erreichte ihren Höhepunkt, als er 1521 Landkomtur der Ballei Elsass-Burgund wurde. Vielleicht war es Rudolf, der 1512, kurz bevor das Heer des Schwäbischen Bundes den Stammsitz der Familie Hohenkrähen eroberte, den damaligen Landkomtur des Deutschen Ordens dazu bewegte, beim Bund ein gutes, wenn auch erfolgloses Wort für die Friedinger einzulegen ${ }^{41}$.

Im Gegensatz zu seinem Bruder hatte Johannes VIII. eine längere und intensivere Beziehung zur Universität. Er begann sein Studium in Heidelberg, wo er sich am 27. April 1479 als professus in Bebenhausen ${ }^{42}$ einschrieb. Er war zu dieser Zeit also bereits Mönch im württembergischen Zisterzienserkloster Bebenhausen. Johannes

34 Heinrich Hermelink (Hg.), Die Matrikeln der Universität Tübingen, Bd. 1: Die Matrikeln von 1477-1600, Stuttgart 1906, S. 41, Nr. 20.

35 Vgl. Beat Immenhauser, Bildungswege - Lebenswege. Universitätsbesucher aus dem Bistum Konstanz im 15. und 16. Jahrhundert (Veröffentlichungen der Gesellschaft für Universitäts- und Wissenschaftsgeschichte 8), Basel 2007, S. 54, Figur 5.

36 Hermelink, Matrikeln Tübingen (Anm. 34), S. 41, Nr. 20.

37 Rainer C. Schwinges, Deutsche Universitätsbesucher im 14. und 15. Jahrhundert. Studien zur Sozialgeschichte des Alten Reiches (Veröffentlichungen des Instituts für europäische Geschichte, Abteilung für Universalgeschichte 123 und Beiträge zur Sozial- und Verfassungsgeschichte des Alten Reiches 6), Stuttgart 1986, S. 378-379 mit Anm. 19. Die Befreiung von der Eidesleistung war eigentlich nur für Hochadlige gedacht. In Tübingen gab es sogar eine eigene Eidesformel für Besucher von hohem Stand. Ebd.

38 Ausführlich zum Leben von Rudolf von Friedingen Moeri, Edlen (Anm. 29), S. 549-551 u. 554-560.

39 Beides im heutigen Kanton Bern.

40 Beschreibungen sowie Abbildungen der Kunstwerke (ausser der Sumiswalder Figurenscheibe) siehe ebd., S. 549-550 u. 554-556.

41 Zur Rolle des Landkomturs in diesen Verhandlungen siehe Dobler, Hohenkrähen (Anm. 7), S. 222-223.

42 Gustav Toepke (Hg.), Die Matrikel der Universität Heidelberg von 1368-1662, 1. Teil: Von 1386 bis 1553, Heidelberg 1884, S. 359. 
verweilte lange, bis etwa 1483, an der Hohen Schule in Heidelberg ${ }^{43}$. Zwischenzeitlich tauchte er auch kurz in Tübingen auf, wo er sich am 16. Februar 1481 ebenfalls als professus in Bebenhausen ${ }^{44}$ immatrikulierte. Die Immatrikulation in Tübingen ergibt nicht nur vor dem Hintergrund der Nähe seiner Familie zum württembergischen Herrscherhaus einen Sinn, sondern auch im Hinblick auf das Kloster Bebenhausen, das nur einige wenige Kilometer von der Universitätsstadt entfernt liegt. Johannes war einer von nur zwei Adligen aus der gesamten Untersuchungsgruppe dieser Studie, der den Weg an die Universität in Heidelberg unternahm. Möglicherweise immatrikulierte Johannes sich in Heidelberg aufgrund der intensiven Kontakte, die der Zisterzienserorden mit der Universität Heidelberg pflegte. Pfalzgraf Ruprecht hatte dem Orden 1386 das St. Jakobs-Kolleg als eigenes Studienhaus in der Stadt zur Verfügung gestellt ${ }^{45}$. Johannes nahm 1482 in Heidelberg an einer Disputation über den Schulstreit von Johannes Wesel teil ${ }^{46}$. Eine kurze Inhaltsangabe zu seinem Beitrag ist erhalten: Frater Johannes de Frydingen professus in Bebenhusen [Zusatz von obiger Hand: modo abbas loci 1499] ad hanc respondit questionem anno 1482 videlicet prima principia complexa demonstrativa sint nobis naturaliter cognita etc. ${ }^{47}$

$\mathrm{Zu}$ welchem Zeitpunkt Johannes VIII. in das Kloster Bebenhausen eintrat, ist nicht bekannt, ausser dass er 1479 bei der Immatrikulation schon die Profess geleistet hatte. Das Zisterzienserkloster wird für sein Studium aufgekommen sein, was sein Eintritt in die Universität und die vierjährige Studienzeit wenn nicht ermöglichte, so sicherlich erleichterte $^{48} .1490$ wurde er zum Pfleger des Zisterzienserklosters in Stuttgart und später in Plieningen ${ }^{49}$. Das Zisterzienserkloster Bebenhausen war das reichste Kloster in Württemberg und seine Äbte hatten Einfluss auf die Landespolitik ${ }^{50}$. Am 5. Juni 1493 wurde Johannes VIII. zum Abt ebendieses Klosters gewählt und hatte somit, wie später sein Bruder Rudolf XIV., eine hohe Position in der Kirche und im politischen Gefüge von Südwestdeutschland inne. In der Bestätigungsurkunde zu seiner Abtwahl wird er als venerabilis dominus Johanes de Fridingen liberalium arcium determinator ${ }^{51}$ bezeichnet. Eine Promotion Johannes' ist in universitären Quellen nicht überliefert, er scheint aber intensiv die freien Künste studiert zu haben, um sich eine solche Benennung von

43 Jürgen Sydow, Die Zisterzienserabtei Bebenhausen, in: Bd. 2: Das Bistum Konstanz (Germania Sacra. Historischstatistische Beschreibung der Kirche des Alten Reiches, Neue Folge 16: Die Bistümer der Kirchenprovinz Mainz), Berlin/New York 1984, S. 242.

44 Hermelink, Matrikeln Tübingen (Anm. 34), Bd. 1, S. 33, Nr. 32.

45 Vgl. Immenhauser, Bildungswege (Anm. 35), S. 162.

46 Sydow, Bebenhausen (Anm. 42), S. 342.

47 Gottfried Zedler (Hg.), Die Handschriften der Nassauischen Landesbibliothek zu Wiesbaden, 63. Beiheft zum Zentralblatt für Bibliothekswesen, Leipzig 1931, S. 57.

48 Vgl. Immenhauser, Bildungswege (Anm. 35), S. 153.

49 Hans Gerhard Brand, Hubert Krins und Siegwalt Schieck(Hg.), Die Grabdenkmale im Kloster Bebenhausen (Beiträge zur Tübinger Geschichte 2), Stuttgart 1989, S. 57.

50 Sydow, Bebenhausen (Anm. 42), S. 55-61.

51 Hauptstaatsarchiv Stuttgart, A 474 U 72. 
seinen Zeitgenossen verdient zu haben. Am 25. August 1493 erhielt er vom Konstanzer Weihbischof die Abtsweihe, bei der Zeremonie waren unter anderem Graf Eberhard im Bart und sein Sohn Eitel Heinrich anwesend. Eitel Heinrich - der spätere Herzog Ulrich von Württemberg - wurde zu dieser Gelegenheit die Firmung gespendet, wobei Johannes von Bebenhausen und der Abt von Zwiefalten Firmpaten waren.

Für das Jahr 1494 ist die personelle Stärke Bebenhausens überliefert: Johannes VIII. von Friedingen war der Abt von 46 Chormönchen, vier Laienbrüdern und sechs Chornovizen. Er scheint sich in den Ordensangelegenheiten rege betätigt zu haben und auch in der Landespolitik nahm er bald eine wichtige Position ein. Er wurde von Herzog Eberhard im Bart, dem er zur Herzogserhebung einen vergoldeten Becher mit dem Bebenhausener und Friedinger Wappen geschenkt hatte, ins Regiment für seinen Nachfolger, Herzog Eberhard II., gehoben. Ein Höhepunkt in diesen frühen Jahren seiner Abtstätigkeit war sicherlich der Besuch Kaiser Maximilians in Bebenhausen am 30. Mai 1498. Johannes zog sich nach der Übernahme der württembergischen Herrschaft durch seinen Firmpatensohn Herzog Ulrich jedoch aus der Landespolitik zurück. Einzig in den Geschehnissen rund um die Ermordung des herzoglichen Stallmeisters Hans von Hutten und der Flucht der Herzogin Sabine wird er kurz wieder in den landespolitischen Quellen sichtbar. Auffallend ist, dass er nach der Verbannung Herzogs Ulrich 1519 sofort wieder politisch aktiv wurde. $\mathrm{Zu}$ der habsburgischen Regierung unter Erzherzog Ferdinand hatte Johannes eine gute Beziehung. Er erschien wieder auf den Landtagen und der Erzherzog weilte auch öfters zu Gast in Bebenhausen. Im November 1530 beispielsweise übernachtete der Erzherzog zusammen mit Kaiser Karl V. auf dem Weg vom Augsburger Reichstag zur Königswahl in Köln in Bebenhausen ${ }^{52}$.

Johannes VIII. pflegte auch nach dem Studium noch Beziehungen zur Universität, wie seine Freundschaften zu universitären Gelehrten, darunter die Juristen und Tübinger Professoren Martin Prenninger und Johannes Kingsattler (genannt König), zeigen. Bei Königs zweitem Sohn war er sogar Taufpate ${ }^{53}$. Ebenfalls befreundet war er mit dem Astronomen Johannes Stöffler und mit dem Dichter Heinrich Bebel, Letzterer widmete ihm ein Lobgedicht ${ }^{54}$. Dass Johannes seine Nähe zur Wissenschaft auch als Abt beibehielt, ist zusätzlich aus einem Brief des Abtes von Obermarchtal, Johannes I. Haberkalt, zu entnehmen, in dem er den Abt von Bebenhausen als antiquitatis studiosus ${ }^{55}$ bezeichnet. Johannes liess die Bibliothek in Bebenhausen, in Zusammenhang mit einer grossangelegten, allgemeinen Erneuerung der klösterlichen Gebäude, der das Kloster sein heutiges Erscheinungsbild verdankt, vergrössern.

52 Sydow, Bebenhausen (Anm. 42), S. 243-245.

53 Ebd., S. 246.

54 Das Lobgedicht wurde 1496 von Greyff in Reutlingen gedruckt. Ebd.

55 Hauptstaatsarchiv Stuttgart, A 474 Büschel 10; Sydow, Bebenhausen (Anm. 42), S. 245 
Abt Johannes von Friedingen starb am 21. Dezember 1534 und erlebte die Auflösung seines Klosters im Zuge der Reformation nicht mehr. Er war ein bekennender Gegner der Reformation und konnte den Konvent zusammenhalten ${ }^{56}$. Auf seinem Epitaph wird er mit einem Buch in der Hand haltend dargestellt, die Inschrift bezeichnet ihn als vir magnae doctrinae et maturitatis ${ }^{57}$.

\section{Die Friedinger an der Universität nach 1500}

Insgesamt vier Familienmitglieder immatrikulierten sich zwischen 1500 und 1540 an einer Hohen Schule, davon alle in Tübingen, womit die fortwährende Bindung der Friedinger zum Hause Württemberg illustriert wird. Der erste Friedinger, der sich nach der Jahrhundertwende einem Universitätsbesuch zuwandte, war Johannes IX. Er stammte aus einer Nebenlinie der Friedinger, die aus einer Verbindung zwischen der Bussener und der Krähener Linie hervorgegangen und die um 1500 in Südtirol ansässig war. Der Vater von Johannes IX., Konrad VI., hatte das kaiserliche Pfandlehen Schlanders inne, seine Mutter war Felizitas von Rottenstein ${ }^{58}$. Am 21. August 1504 trug sich Johannes von Friedingen in der Tübinger Rektoratsmatrikel ein. Leider können wie so oft keine näheren Angaben zu seinem Studiumsverlauf und -inhalt gegeben werden. Er ist aber der erste studierte Friedinger, der nicht einen klerikalen Weg einschlug. Nach seinem Studium begab sich Johannes IX. in mehrere verschiedene weltliche Dienstverhältnisse. Dobler meint dazu: «Hans IX. war schon durch die Kargheit des Familienvermögens darauf angewiesen, seinen Lebensunterhalt in fremden Diensten zu suchen. $\rangle^{59}$ Auch wenn Adlige nach wie vor ohne jegliche universitäre Bildung an fürstliche Ämter kamen, so konnte das Studium bereits als zusätzliche Qualifikation helfen ${ }^{60}$. Dies galt insbesondere wenn die Familie keine sonderlich gute Stellung im adligen Gefüge einnahm, wie es am Ende des Mittelalters bei den Friedingern der Fall war. Die Liste der Ämter, die Johannes IX. innehatte, ist beeindruckend. Er war hauptsächlich in österreichischen Diensten tätig: 1519 begann er als Amtmann in Stockach, wurde dann Burgvogt auf

56 Ebd., S. 246; Während seiner Zeit als Abt schloss sich nur ein Mönch aus Bebenhausen der Reformation an. Als das Konvent aber 1535 aufgehoben wurde, bezeichneten sich knapp die Hälfte der Brüder als zum neuen Glauben gehörig. Ebd.

57 Das Epitaph steht in der ehemaligen Klosterkirche Bebenhausen. Eine Abschrift der Inschrift bei ebd., S. 247.

58 Dobler, Hohenkrähen (Anm. 7), S. 276 u. Stammtafel S. 453; Kindler von Knobloch weist Johannes fälschlicherweise der Krähener Linie zu als Sohn von Hans Benedikt, einer jener Friedinger, die den Hohenkrähen 1512 an den Schwäbischen Bund verloren. Kindler von Knobloch, Geschlechterbuch (Anm. 10), Bd. 1, S. 379. Diese Zuweisung kann nicht stimmen, da die Kinder von Hans Benedikt 1520 bei der Aufteilung des friedingischen Besitzes minderjährig waren und Johannes IX. 1519 aber bereits Amtmann in Stockach war. Vgl. Dobler, Hohenkrähen (Anm. 7), S. 271 u. Stammtafeln S. 452-453.

59 Ebd., S. 277; Johannes hatte von seinem Vater nur das kaiserliche Pfandlehen Schlanders geerbt. 1511 ist er in der Tiroler Adelsmatrikel verzeichnet und 1514 bei einem Tiroler Landtag zu fassen. Danach tauchen keine Friedinger mehr in Tirol auf. Es ist möglich, dass Johannes das kaiserliche Pfandlehen ab 1514 nicht mehr besass. Ebd., S. $276-277$.

60 Vgl. Müller, Adel (Anm. 6), S. 163-169. 
dem Hohentwiel - nur ein paar Kilometer vom Hohenkrähen entfernt - und Vogt zu Markdorf. 1527 wurde er sogar Landvogt in Schwaben mit Sitz in Ravensburg ${ }^{61}$. Im Elsass war er Burghauptmann auf der Hohkönigsburg, zu der auch die Vogtei Bergheim gehörte $^{62}$. Zusätzlich zu seinen verschiedenen Tätigkeiten als Amtmann war er seit 1533 königlicher Rat. Neben diesen Ämtern war er seit 1524 Hofmeister des Bischofs von Konstanz.

Am 4. Dezember 1506 findet sich eine weitere Immatrikulation in Tübingen, diesmal gerade von zwei Friedingern, einem Johannes und einem Rüdolffus, beide de Fridingen $^{63}$. Eine eindeutige Zuweisung dieses Johannes ist nicht möglich und wurde in der Forschung unterschiedlich vorgenommen: entweder zum oben besprochenen Johannes IX. oder zu Johannes X., Domherr von Worms ${ }^{64}$. Mit grosser Wahrscheinlichkeit handelt es sich bei der Immatrikulation am 4. Dezember 1506 tatsächlich um jenen Johannes, der am 26. Juli 1513 nochmals als Domherr in Worms in der Matrikel Tübingen inskribiert ist und nicht um Johannes IX. Dafür spricht, dass es sich bei dem Rudolf von Friedingen, der sich zusammen mit Johannes im Dezember 1506 immatrikulierte, um Rudolf XV. handelt, dessen Bruder eben dieser Wormser Domherr Johannes X. war. Wahrscheinlich liess Johannes X. sich zweimal immatrikulieren, weil er für sein Domkanonikat in Worms das Biennium vorzuweisen hatte ${ }^{65}$ er aber bei seinem ersten Universitätsbesuch 1506 nicht zwei Jahre an der Hohen Schule verbracht hatte. Der Onkel der beiden Brüder war Johannes VIII., zu dieser Zeit Abt im nahen Kloster Bebenhausen $^{66}$. Die Nähe eines engen Verwandten war für die Familie sicher beruhigend, wusste man doch, dass die Studienzeit auch zu einigen Umtrieben führen konnte ${ }^{67}$. Ob Rudolf und Johannes von den Kontakten des Onkels zu Tübinger Professoren, vor allem zu den Juristen Martin Prenninger und Johannes Kingsattler, für ihre Studien Gebrauch machten, ist nicht überliefert. Über RudolfXV. ist ausser seiner Immatrikulation 1506 nichts bekannt, wahrscheinlich ist er früh gestorben. Er war der Sohn von jenem bereits besprochenen Martin II., der als Erster der Bussener Linie seit 200 Jahren Ende des 15. Jahrhunderts wieder auf dem Hohenkrähen Fuss fasste. Die Brüder Johannes und Rudolf stammten aus Martins II. erster Ehe, der Name ihrer Mutter ist unbekannt ${ }^{68}$. Als die Brüder sich 1506 in Tübingen immatrikulierten, war ihre familiäre Situation noch

61 Er war der letzte habsburgische Landvogt von Schwaben. Am 28. November wurde die Landvogtei für 50’000 Gulden an den Truchsessen Georg von Waldburg verpfändet. Dobler, Hohenkrähen (Anm. 7), S. 278.

62 Ebd., S. 278-279.

63 Hermelink, Matrikeln Tübingen (Anm. 34), Bd. 1, S. 157, Nr. 93-94.

64 Vgl. ebd. und Dobler, Hohenkrähen (Anm. 7), S. 278 u. 455.

65 Vgl. Burkard Keilmann, Pfründenmarkt und geistlicher Dienst. Wormser Stiftskleriker an der Wende zum 16. Jahrhundert, in: Archiv für mittelrheinische Kirchengeschichte. Nebst Berichten zur kirchlichen Denkmalpflege 51 (1999), S. 93-121, hier: S. 109.

66 Sydow, Bebenhausen (Anm. 42), S. 246.

67 Vgl. Rainer C. Schwinges, Mit Mückensenf und Hellschepoff. Fest und Freizeit in der Universität des Mittelalters (14. bis 16. Jahrhundert), in: Jahrbuch für Universitätsgeschichte 6, Stuttgart 2003, S. 9-27.

68 Dobler, Hohenkrähen (Anm. 7), S. 266. 
stabil. 1513 aber, als sich Johannes X. ein zweites Mal in Tübingen immatrikulierte, hatte der Vater kurz vorher die Burg Hohenkrähen an den Schwäbischen Bund verloren. Die Familie konnte in dieser Situation froh sein, Johannes mit dem Wormser Domkanonikat versorgt zu wissen. Das Wormser Domkapitel gehörte ohne Adelsprüfung zwar nicht zu den exklusivsten des Reiches, dennoch prägte der regionale Niederadel die personelle Zusammensetzung des Domstifts, und die Pfründe erlaubte einen angemessenen Lebensstandard ${ }^{69}$.

Zurück zum Amtmann Johannes IX., der um einiges mehr Einfluss auf die Familiengeschichte hatte, als die gerade erwähnten Brüder. Seit 1530 verfolgte Johannes IX. das Ziel, in den hegauischen Stammlanden Fuss zu fassen ${ }^{70}$. Seine Tätigkeit als Amtmann in dieser Gegend hatte «sicher seine Bindung zu den hegauischen Stammlanden und den dort ansässigen Familienmitgliedern bestärkt» ${ }^{71}$. Zu dieser Zeit genoss Johannes IX. mit Blick auf seine Ämter bestimmt ein gutes Ansehen bei der österreichischen Regierung in Innsbruck. Zur selben Zeit war der bereits erwähnte Rudolf XIV. von Friedingen als Landkomtur der Deutschordensballei Elsass-Burgund für die österreichische Regierung eine wichtige Figur. 1522 war er dem Schwäbischen Bund nach einer längeren Abwesenheit des Deutschordens wieder beigetreten ${ }^{72}$ und im Oktober 1523 stellte Rudolf seine Ordensballei unter österreichische Schutzherrschaft. Die Habsburger hatten mit ihm einen wichtigen Verbündeten in der Region gewonnen. Beide, Johannes IX. und Rudolf XIV., aber auch der Bebenhausener Abt Johannes VIII. haben wohl dafür gesorgt, dass der Name Friedinger nach dem Tiefpunkt von 1512 in den Augen Habsburgs wieder rehabilitiert wurde. Von diesen drei Persönlichkeiten abgesehen, ging es dem Geschlecht der Friedinger jedoch nicht sonderlich gut. Die Krähener Linie war in ihren Besitzungen seit 1512 erheblich beschnitten und die Bussener hatten seit der Abfindung 1521/1522 keine nennenswerten Güter mehr ${ }^{73}$. Es gelang Johannes IX. bis 1534 tatsächlich, die Güter der letzten lebenden Krähener in seiner Hand zu vereinen. Er konnte zudem noch mehrere Güter, die einstmals in friedingischer Hand waren, wieder zurück in den Besitz der Familie bringen. Auf diesem Weg wird der hegauische Familienbesitz auf den Stand von letztmals 1472/1473 zusammengeführt. Der Höhepunkt in der Rückgewinnung der Familiengüter gelang Johannes IX. 1534, als er die Burg Hohenkrähen erlangen konnte. Die Burg wurde aber nicht wieder Eigenbesitz, sondern er erhielt sie lediglich als österreichisches Lehen. Er nannte sich fortan Johannes Friedingen zu Hohenkrähen ${ }^{74}$. Für eine kurze Zeit schien es, als würde die

69 Vgl. Keilmann, Stiftskleriker (Anm. 64), S. 103 u. 111; zusätzlich zum Domkanonikat in Worms hatte Johannes seit 1525 in Dachsel eine Pfarreipfründe inne.

70 Dobler, Hohenkrähen (Anm. 7), S. 279.

71 Ebd., S. 278.

72 Horst Carl, Der Schwäbische Bund 1488-1534. Landfrieden und Genossenschaft im Übergang vom Spätmittelalter zur Reformation (Schriften zur südwestdeutschen Landeskunde 24), Leinfelden-Echterdingen 2000, S. 148

73 Ebd.; Dobler, Hohenkrähen (Anm. 7), S. 278-279.

74 Ebd., S. 279-285 u. 274. 
Familie wieder festen Boden unter den Füssen bekommen. Johannes IX. hatte wieder eine herrschaftliche Basis im Hegau aufgebaut und zwei weitere Familienmitglieder standen in hohen geistlichen Positionen mit Einfluss auf die regionale und überregionale Politik.

Doch der Höhenflug weilte nur für kurze Zeit. Ende 1534 starb Johannes VIII. von Friedingen, Abt von Bebenhausen, und im April 1537 auch sein Bruder, der Landkomtur Rudolf XIV. von Friedingen. Damit hatten die Friedinger ihre mächtigsten und einflussreichsten Familienmitglieder verloren. In den hegauischen Stammlanden brach die neue Herrschaft Hohenkrähen finanziell zusammen. Es war Johannes IX. ab 1536 nicht mehr möglich, für die laufenden Zinsen und Leibrenten aufzukommen. Er verschwand daraufhin für ein paar Jahre aus dem Hegau. Wo er sich in dieser Zeit aufhielt, ist nicht bekannt. Im Frühjahr 1539 musste er dann endgültig seine erworbenen Güter verkaufen, er hatte zu diesem Zeitpunkt insgesamt 20'584 Gulden Schulden. 25 Gläubiger wollten ausbezahlt werden, darunter viele lokale Adelsgeschlechter wie die Reischach, Homburg, Klingenberg und Bodman. Gerade die Reischach und die Klingenberg waren noch vor wenigen Jahrzehnten eng befreundete Standesgenossen der Friedinger gewesen. Johannes IX. von Friedingen starb kurz darauf im Dezember 1540, er hinterliess keine männlichen Nachkommen75.

Für die Friedinger war die Zukunft auch in genealogischen Aspekten schwierig: Die Krähener Linie starb 1539 im Mannesstamm aus ${ }^{76}$. Die Geistlichen Rudolf XV. und Johann X. aus der Bussener Linie hatten zwei Halbbrüder aus der zweiten Ehe ihres Vaters Martins II. mit Margarete von Ehingen. Franz trat wie sein Onkel in die Dienste des Deutschordens und wurde Komtur in Mainau, somit blieb die Aufgabe der dynastischen Kontinuität bei Georg V. Er war 1539 Vogt von Hohengeroldseck bei Lahr in österreichischem Dienst. Er hatte einen Nachkommen, seinen Sohn Hugo. Dieser Hugo aus der Bussener Linie war der letzte Friedinger im Mannesstamm ${ }^{77}$. Es scheint angemessen zu sein, dass dieser letzte Friedinger ebenfalls einen Universitätsbesuch absolvierte. Er schrieb sich am 4. Oktober 1537 aber nicht in Tübingen, sondern an der habsburgischen Universität Freiburg ein, wahrscheinlich wegen der Bindung seines Vaters zu diesem Herrscherhaus. Ganz der Familientradition entsprechend immatrikulierte er sich aber am 10. August 1540 auch noch in Tübingen ${ }^{78}$. Dieser Universitätswechsel war entscheidend für seinen weiteren Lebensweg, denn er blieb in Tübingen und wurde dort württembergischer Hofmeister. Hugo verstarb 1568 ohne männliche Nachkommen, womit er der letzte männliche Friedinger war $^{79}$.

75 Ebd., S. 286-288.

76 Ebd., S. 276.

77 Ebd., S. 266-267.

78 Dieser Universitätswechsel ist aber dahin gehend erstaunlich, weil er damit vom katholischen Freiburg in das reformierte Tübingen wechselte.

79 Ebd., S. 347. 


\section{Einordnung und Zusammenfassung}

In den Jahren 1324 bis 1540 besuchten insgesamt neun Mitglieder der Familie Friedingen eine Universität. Davon stammten sieben aus der Bussener Linie und nur zwei aus der Krähener. Von diesen neun friedingischen Studenten lebten nur zwei im 14. Jahrhundert, die grosse Mehrheit ging zwischen 1469 und 1540 an eine Hohe Schule. Dieser Umstand deckt sich mit der allgemeinen Beobachtung, dass nach 1450 die Zahl der adligen Universitätsbesucher im Reich deutlich anstieg. Die dafür bereits erwähnten Gründe trafen auch auf die Friedinger zu, die innerhalb des Niederadels zunehmend an den unteren sozialen Rand gedrängt wurden. Gegen Ende des Mittelalters und zu Beginn der Frühen Neuzeit waren sie wirtschaftlich und politisch immer wieder in prekären Lagen: Sie verloren den grössten Teil ihrer Besitzungen, hatten sich das Haus Habsburg und den mächtigen Schwäbischen Bund zum Feind gemacht und waren vermehrt auf Einkünfte in fremden Diensten angewiesen. In diesem Kontext wurde der Universitätsbesuch als Strategie in ihre Bemühungen um den Standeserhalt aufgenommen.

Die gewählten Universitäten reflektieren die allgemeinen Tendenzen des Adelsstudiums sowie generell des Studiums im Reich. Ausser dem ersten Universitätsbesucher, dem Konstanzer Domherr Ulrich, ging kein Friedinger mehr für sein Studium über die Reichsgrenzen hinaus, vielmehr besuchten sie Universitäten in ihrer Nähe. Darin zeigt sich die Regionalisierung des Studiums am Ende des Mittelalters ${ }^{80}$ sowie die dann beginnende Vorliebe des Adels für süddeutsche Universitäten ${ }^{81}$. Die eklatant auffällige Bevorzugung der Hohen Schule in Tübingen lässt sich auf die Nähe der Familie zum württembergischen Herrscherhaus zurückführen. Die Bildungsreise, der Besuch mehrerer Universitäten, vor allem im französischen und italienischen Ausland, die als Merkmal adligen Studierverhaltens galt, ${ }^{82}$ unternahm kein Friedinger. Eine solche Universitätstour konnten sich die um ihren Status kämpfenden niederadligen Friedinger finanziell nicht leisten.

Über die Inhalte ihrer Studien sind nur vereinzelt Aussagen möglich. Die gewählten Fachrichtungen können allein bei den zwei promovierten Artisten, ferner bei Johannes VIII., der uns als Kenner der freien Künste überliefert ist, und bei Ulrich, der in Bologna kanonisches Recht studiert hatte, nachvollzogen werden. In der Forschungsliteratur wird davon ausgegangen, dass die Adligen sich hauptsächlich mit der prestigeträchtigen Juristenfakultät assoziierten, in der sie mit anderen Standespersonen verkeh-

80 Zur Regionalisierung des Studiums siehe Immenhauser, Bildungswege (Anm. 35), S. 95-101 u. 108-118.

81 Vgl. Rainer C. Schwinges, Die Universität als sozialer Ort des Adels im deutschen Spätmittelalter, in: Grand Tour. Adeliges Reisen und europäische Kultur vom 14. bis zum 16. Jahrhundert. Akten der internationalen Kolloquien in der Villa Vigoni 1999 und im Deutschen Historischen Institut Paris 2000 (Beihefte der Francia 60), Ostfildern 2005, S. 357-372, hier: S. 366-370.

82 Ebd., S. 366-367; Werner Paravicini, Von der Heidenfahrt zur Kavalierstour. Über Motive und Formen adligen Reisens im Spätmittelalter, in: Wissensliteratur im Mittelalter und in der Frühen Neuzeit, hg. von Horst Brunner und Norbert Richard Wolf, Wiesbaden 1993, S. 91-130, hier: S. 108-111. 
ren konnten ${ }^{83}$. Aus sozialen Gründen sei die Artistenfakultät, in der sich die grosse Masse der Studenten einfand, vom Adel gemieden worden ${ }^{84}$. Dass dies aber hauptsächlich für den höheren Adel galt, lassen regional angelegte Studien wie die von Christian Lackner für den habsburgischen Adel an der Universität Wien vermuten ${ }^{85}$. Mitglieder des niederen Ritteradels wie die Friedinger besuchten durchaus die Artistenfakultät. Die zwei Promovierten in der Familie erwarben entsprechend einen bacc. art. Die niedrige Graduiertenquote ist nicht weiter erstaunlich. Adlige liessen ihr Studium selten durch die Verleihung eines universitären Grades krönen. Den Besitz eines akademischen Titels hielten Adelige, die ja bereits die soziale Spitze der Gesellschaft darstellten, gemeinhin für unnötig ${ }^{86}$.

Die weiteren Lebenswege der Studenten aus dem Haus Friedingen weisen darauf hin, dass das Studium für den Adel nach wie vor hauptsächlich als Vorbereitung für ein klerikales Amt diente. Von neun Studenten besetzten sechs ein klerikales Amt. Von einem ist über die nachuniversitäre Zeit nichts bekannt und nur zwei blieben laikal. Neben den Studenten traten allerdings noch viele weitere Familienmitglieder in die Kirche ein. So waren beispielsweise in der Generation Martins II. und seiner Kinder sieben von 15 Familienmitgliedern in der Kirche ${ }^{87}$. Die wirtschaftliche Situation der Familie im späten Mittelalter ist wohl eine Erklärung dafür. Die Universität war für lange Zeit vor allem eine Ausbildungsstätte für Kleriker, auch wenn diese Tendenz im 15. Jahrhundert abnahm, so war der Anteil der Geistlichen am Universitätsstudium nach wie vor gross ${ }^{88}$. Geistliche hatten es tendenziell leichter als Laikale, ein Studium aufzunehmen, da das Kloster oder die Pfründe für den Aufenthalt an der Universität finanziell aufkam. Auch sozial hatten Kleriker an den Universitäten einen Vorteil: Sie waren bei der Immatrikulation bereits $\langle\text { jemand }\rangle^{89}$. Die klerikale Laufbahn ermöglichte es den niederadligen Friedingern auch an hohe Positionen zu gelangen, nicht umsonst sind die beiden eindrucksvollsten Karrieren aus dem Hause der Friedinger im späten Mittelalter in der Kirche gemacht worden. Weltliche Positionen mit einer vergleichbaren Ausstrahlung lagen hingegen

83 Beispielsweise Schwinges, Universität (Anm. 80), S. 367-368.

84 Wieland, Status (Anm. 6), S. 118.

85 Christian Lackner, Adel und Studium. Adelige Studenten aus den habsburgischen Ländern an der Universität im 15. Jahrhundert, in: Festschrift Heide Dienst zum 65. Geburtstag, hg. von dems. und Willibald Rosner (Forschungen zur Landeskunde von Niederösterreich 30), St. Pölten 2004, S. 71-87, hier: S. 81; eine Studie der Autorin zum Universitätsbesuch des hegauischen und oberschwäbischen Adels ergab ebenfalls, dass viele der untersuchten Adligen nachweislich die Artesfakultät besuchten. Dabei handelte es sich aber ausschliesslich um Niederadlige. Elena Magli, Der Ritter geht studieren. Eine Studie zum Universitätsbesuch des Adels aus dem Raum Hegau-BodenseeAllgäu 1465-1515, Masterarbeit Universität Bern Herbstsemester 2017, S. 51-55.

86 Vgl. Müller, Adel (Anm. 6), S. 159-162.

87 Vgl. Dobler, Hohenkrähen (Anm. 7), Stammtafel S. 455. Von drei Familienmitgliedern ist nichts näher bekannt. Bloss zwei männliche Mitglieder nahmen den weltlichen Weg und hätten die Familie patrilinear weiterführen können, drei der Frauen wurden verheiratet.

88 Rainer C. Schwinges, Pfaffen und Laien in der deutschen Universität des späten Mittelalters, in: Pfaffen und Laien - ein mittelalterlicher Antagonismus? Freiburger Colloquium 1996, hg. von Conrad Lutz und Ernst Tremp, Freiburg/Schweiz 1999, S. 235-249, hier: S. 301-315; Immenhauser, Bildungswege (Anm. 35), S. $153-154$.

89 Ebd., S. 153. 
ausserhalb ihrer Reichweite. Johannes IX. und Hugo, die einzig laikal gebliebenen Universitätsbesucher, haben beide einen Lebensweg als fürstliche Amtsträger eingeschlagen.

Es wäre aber anachronistisch zu behaupten, dass das Studium für diese Karrieren die entscheidende, berufsqualifizierende Ursache gewesen wäre. Die hauptsächliche Funktion des Studiums kann vielmehr in seinem gesellschaftlichen Nutzen für die adligen Universitätsbesucher gefunden werden. Der Universitätsort war ein Begegnungsort, wo Beziehungen zu Gleichaltrigen geknüpft, Verhaltensnormen einstudiert und der Status der Familie gerade auch gegenüber nicht Rangleichen zur Schau gestellt werden konnten ${ }^{90}$. Gerade für die Friedinger wird dieser gesellschaftliche Nutzen ein wichtiger Ansporn gewesen sein. Um ihr konkretes Umfeld an den Universitäten detaillierter einschätzen zu können, wäre es zusätzlich erkenntnisreich, sich mithilfe der Rektoratsmatrikeln weiter in die Besucherklientel einzulesen. Dadurch könnte das Umfeld der adligen Studenten am Universitätsort selbst besser verstanden und der soziale Nutzen des Universitätsbesuchs genauer untersucht werden.

\section{Fazit}

Die studierten Friedinger spielten zunehmend wichtigere Rollen in ihrer Familiengeschichte. Auch wenn sie den Abstieg der Familie nicht aufhalten konnten, so waren es im 16. Jahrhundert ihre Universitätsbesucher, welche die Situation der Friedinger für eine Weile positiv aussehen liessen. Der Anstieg von Studenten um 1500 zeigt, dass die Familie den Universitätsbesuch durchaus als standesgemässes Verhalten akzeptiert hatten: Die Friedinger scheinen das Studium in ihr Erziehungsrepertoire aufgenommen und als mögliches Verhaltensmuster in ihr Selbstverständnis als Adlige integriert zu haben.

Von einer Entklerikalisierung hinsichtlich der betrachteten Adelsstudenten kann nicht gesprochen werden. Die in der Forschung weitverbreitete Ansicht, dass das Adelsstudium gegen Ende des Mittelalters zugenommen habe, weil sich die weltlichen Funktionsträger damit ihre angestammten Positionen am fürstlichen Hof und in der fürstlichen Verwaltung sichern wollten, trifft auf das Studierverhalten der Friedinger nicht zu. Das Studium traten sie vielmehr meistens aus «konservativen〉 Gründen, mit Blick auf eine geistliche Karriere an. Offenbar war hier das Studium - neben dem sozialen Nutzen - nach wie vor hauptsächlich als eine Absicherung für das Erlangen der angestrebten kirchlichen Stelle gedacht.

90 Vgl. beispielsweise Wieland, Status (Anm. 6), S. 135. 


\section{So soll der jung Adel sich auff das Studieren geben: Die Wetterauer Grafen an den Universitäten des Alten Reiches (1450-1550)}

Nachdem Kaiser Karl IV. aus dem Hause Luxemburg 1348 in seiner bevorzugten Residenzstadt Prag die erste Universität Mitteleuropas gegründet hatte, begann eine Welle von Universitätsgründungen im römisch-deutschen Reich. 1365 folgte der Habsburger Rudolf IV. in der Stadt Wien dem Beispiel, 1386 der pfälzische Kurfürst in Heidelberg. In der Formulierung Peter Moraws wurde «die deutsche Universität im Wettbewerb der grossen Dynastien zu einem Prestigeobjekt» ${ }^{1}$. Neben der fürstlichen Trägerschaft begannen weitere politische Mächte sich an dem Gründungsboom zu beteiligen: 1388 beziehungsweise 1389 entstanden die ersten städtischen Universitäten auf dem Boden des Alten Reiches in Köln und Erfurt. Andere Städte und Dynastien folgten. 1477 wurde die von Adolf von Nassau, Erzbischof von Mainz, initiierte Universität Mainz durch dessen Konkurrenten und Nachfolger Diether von Isenburg eröffnet. Unter Landgraf Philipp dem Großmütigen von Hessen erfolgte schliesslich 1527 die erste protestantische Universitätsgründung.

Vom Adel des Reiches wurde das Bildungsangebot dieser neuen Einrichtungen nur sehr verhalten angenommen. Die Forschung hat unlängst konstatiert, dass der Adel zwar ab der zweiten Hälfte des 15. Jahrhunderts vermehrt an die Universitäten strömte, «daß [aber] für die meisten Adeligen noch Mitte des 16. Jahrhunderts, wenn sie nicht eine geistliche Laufbahn anstrebten, ein Universitätsbesuch eher ungewöhnlich war»». Es mangelt daher nicht an zeitgenössischen kritischen Äusserungen über den Bildungsstand des Adels, dessen Erziehungsprogramm problemlos ohne gelehrtes, verstanden als universitäres Wissen auskommen konnte. Diese Einschätzung teilten ab dem 16. Jahrhundert selbst Angehörige des weltlichen Adels 3 .

1 Peter Moraw, Die Universitäten in Europa und in Deutschland. Anfänge und erste Schritte auf einem langen Weg (12.-16. Jahrhundert), in: Gesammelte Beiträge zur Deutschen und Europäischen Universitätsgeschichte, hg. von dems., Leiden/Boston 2008, S. 229-249, hier: S. 242.

2 Ronald G. Asch, Europäischer Adel in der Frühen Neuzeit, Köln 2008, S. 136.

3 Aus der Vielzahl der Literatur, die sich mit dem Themenfeld Bildungskritik am Adel befasst, sei hier exemplarisch verwiesen auf Laetitia Boehm, Konservatismus und Modernität in der Regentenerziehung an deutschen Höfen im 15. und 16. Jahrhundert, in: Humanismus im Bildungswesen des 15. und 16. Jahrhunderts, hg. von Wolfgang Reinhard (Mitteilungen der Kommission für Humanismusforschung 12), Weinheim 1984, S. 61-93, hier: S. 64 f. ; Otto Gerhard Oexle, Aspekte der Geschichte des Adels im Mittelalter und in der Frühen Neuzeit, in: Europäischer Adel 1750-1950, hg. von Hans-Ulrich Wehler, Göttingen 1990, S. 19-56, hier: S. 54-56; Asch, Europäischer Adel (Anm. 2), S. $132-142$. 
In jüngerer Zeit entstanden mehrere Aufsätze, die sich mit dem Studierverhalten des Niederadels beschäftigen ${ }^{4}$. Die Konzentration auf den landsässigen und ritterlichen Adel rührt daher, dass die niederen adeligen Ränge wesentlich präsenter an den Universitäten waren als der gräfliche oder gar fürstliche Hochadel ${ }^{5}$. Da gegen Ende des 15. Jahrhunderts ein Schub ständischer Ausdifferenzierung zu beobachten ist ${ }^{6}$, lassen die Ergebnisse derjenigen Studien nur vorsichtige Rückschlüsse auf die Situation des Hochadels zu. Wie Karl-Heinz Spieß in Bezug auf spätmittelalterliche Adelsreisen betonte, sollten aber auch hier die Unterschiede zwischen Hoch- und Niederadel nicht unterschätzt werden ${ }^{7}$. Die Grafendynastien Nassau, Solms, Sayn und Wittgenstein, Wied-Runkel, LeiningenWesterburg, Isenburg-Grenzau und Isenburg-Büdingen ${ }^{8}$, Hanau, Rieneck, StolbergKönigstein und Waldeck aus den Regionen Wetterau und Westerwald dienen als Beispiel einer hochadeligen Gruppe, deren enge soziale, familiäre und politische Vernetzung sie geeignet macht, für eine vergleichende Perspektive herangezogen zu werden und auf der Ebene des Grafenstandes für das Studierverhalten des Adels weitere Erkenntnisse zu liefern. Da mit den sorgfältig geführten Rektoratsmatrikeln der deutschen Universitäten

4 Vgl. Christian Wieland, Status und Studium. Breisgauischer Adel und Universität im 16. Jahrhundert, in: Zeitschrift für die Geschichte des Oberrheins 148 (2000), S. 97-150; Steffen Arndt, Humanistische Bildung und Adel. Die Löwensteinische Stipendiatenstiftung aus dem Jahr 1536, in: Zeitschrift des Vereins für hessische Geschichte 110 (2005), S. 63-82; Anna-Sophia Fischer, Der Adel an der Universität Rostock in der ersten Hälfte des 15. Jahrhunderts, in: Adel in Mecklenburg. Wissenschaftliche Tagung der Stiftung Mecklenburg in Zusammenarbeit mit der Historischen Kommission für Mecklenburg am 26. und 27.11.2010 in Schwerin, hg. von Wolf Karge, Rostock 2012, S. 50-60; Fanny Münnich, Adel und Bildung, in: Adlige Lebenswelten in Sachsen. Kommentierte Bild- und Schriftquellen, hg. von Martina Schattkowsky, Köln/Wien/Weimar 2013, S. 264-271.

5 Beat Immenhauser hat für adelige Studierende aus dem Bistum Konstanz ein Verhältnis von 402 niederadeligen zu 123 hochadeligen Immatrikulierten herausgearbeitet. Vgl. Beat Immenhauser, Bildungswege - Lebenswege. Universitätsbesucher aus dem Bistum Konstanz im 15. und 16. Jahrhundert (Veröffentlichungen der Gesellschaft für Universitäts- und Wissenschaftsgeschichte 8), Basel 2007, S. 138. Christoph Fuchs zählt für den Zeitraum 1386-1450 lediglich fünf Grafen in der Matrikel der Universität Heidelberg und das, obwohl gerade diese Universität eine vergleichsweise hohe Adelsdichte in Mittelalter und Früher Neuzeit aufwies. Vgl. Christoph Fuchs, Dives, pauper, nobilis, magister, frater, clericus. Sozialgeschichtliche Untersuchungen über Heidelberger Universitätsbesucher des Spätmittelalters 1386-1450 (Education and Society in the Middle Ages and Renaissance 5), Leiden/New York/Köln 1995, S. 30. Die tatsächlichen Zahlen des Niederadels dürften noch weitaus grösser gewesen sein, da die niederen Adelsränge häufig nicht in den Matrikeln als solche markiert sind. Vgl. Rainer Christoph Schwinges, Die Universität als sozialer Ort des Adels im deutschen Spätmittelalter, in: Studenten und Gelehrte. Studien zur Sozial- und Kulturgeschichte deutscher Universitäten im Mittelalter, hg. von dems., Boston/Leiden 2008, S. 317-337, hier: S. 323; zuvor abgedruckt in: Grand Tour. Adeliges Reisen und europäische Kultur vom 14. bis zum 18. Jahrhundert, hg. von Rainer Babel und Werner Paravicini (Akten der internationalen Kolloquien in der Villa Vigoni 1999 und im Deutschen Historischen Institut Paris 2000), Ostfildern 2004, S. 357-372, hier: S. 362 .

6 Vgl. Fritz Wolff, Grafen und Herren in Hessen vom 16. bis zum 18. Jahrhundert, in: Das Werden Hessens, hg. von Walter Heinemeyer, Marburg 1986, S. 333-347, hier: S. 335.

7 Vgl. Karl-Heinz Spieß, Reisen deutscher Fürsten und Grafen im Spätmittelalter, in: Grand Tour, hg. von Babel/Paravicini (Anm. 5), S. 33-54, hier: S. 34.

8 Isenburg-Grenzau und Isenburg-Büdingen werden getrennt abgehandelt, da im Untersuchungszeitraum nicht mehr von einer Dynastie gesprochen werden kann (vgl. Gustav Simon, Die Geschichte des reichsständischen Hauses Ysenburg und Büdingen, Bd. 2, Frankfurt am Main 1865, S. 174 f.). 
eine ausgezeichnete Quellengrundlage zur Verfügung steht ${ }^{9}$, sollen die Universitätsbesuche der im Folgenden als Wetterauer Grafen bezeichneten hochadeligen Gruppe ${ }^{10}$ exemplarisch auf den Gebieten des Alten Reiches untersucht werden: Im Zentrum steht dabei die Frage, inwiefern diese das Bildungsangebot der Universitäten des Reiches, die in grosser Zahl in gut zu erreichender Distanz gegründet wurden, nutzten? Dafür werden die an einer Universität immatrikulierten Wetterauer Grafen zwischen 1450 und 1550 mithilfe des Repertorium Academicum Germanicum, kurz RAG, hinsichtlich der Familienkonstellationen, ihrer Karrierewege und der Wahl der Universitäten analysiert. Daraufhin wird der Befund über die soziale und politische Situation der Wetterauer Grafen im 15. und 16. Jahrhundert kontextualisiert und eine Annäherung an das Verständnis dieser Gruppe über das Verhältnis von Adel zu Bildung unternommen. Als Quellen dienen in erster Linie die Matrikeln der Universitäten des Reiches, auf denen die Datenbank basiert ${ }^{11}$. Für den geistesgeschichtlichen Kontext wird ein solmsisches Adelstraktat des 16. Jahrhunderts herangezogen.

\section{Universitätsstudium als Teil des dynastischen Erziehungsprogramms}

Für den Gesamtadel wurde bereits festgestellt, dass zwar die ersten europäischen Universitäten von adeligen Standespersonen aufgesucht wurden, diese aber für den Zeitraum vom 13. bis Mitte des 15. Jahrhunderts nahezu ausschliesslich dem geistlichen Stand angehörten $^{12}$. Für die Zeit von den Anfängen des〈deutschen〉 Hochschulwesens (ein-

9 Lediglich die Matrikeln der Universitäten Mainz und Trier haben sich nicht erhalten. Aufgrund der Domkapitel, in denen einige Wetterauer Grafen bepfründet waren, ist es gut möglich, dass an diesen Universitäten der ein oder andere Graf aus der Untersuchungsgruppe eingeschrieben war. Jedoch hatten die Betroffenen zumeist ebenso an dem Kölner Domstift oder der Stiftskirche St. Gereon Pfründe inne, weswegen anzunehmen ist, dass sie die renommiertere Universität Köln aufsuchten und der Verlust dieser Matrikeln wenig Auswirkung auf das Ergebnis dieser Untersuchung haben wird.

10 Die Sammelbezeichnung 〈Wetterauer Grafen〉 resultiert aus der Titulatur 〈Wetterauer Grafenverein〉 (bzw. zeitgenössisch (Wetterauische Korrespondenz〉), in dem sich die Grafengeschlechter der Wetterau und des Westerwaldes seit dem 16. Jahrhundert zusammenschlossen.

11 Die folgende Analyse des Studierverhaltens der Wetterauer Grafen basiert auf der Auswertung der Datensammlung des Repertorium Academicum Germanicum, welches Daten zu Leben, Studium und Karriere von mittelalterlichen Gelehrten und adeligen Universitätsbesuchern bereitstellt. Auf einen Nachweis jedes einzelnen Datensatzes wird verzichtet, da diese unter www.rag-online.org nachvollzogen werden können. Es ist anzunehmen, dass die französischen und italienischen Universitäten für diese hochadelige Gruppe eine gewisse Rolle gespielt haben. Da aber an ausländischen Universitäten in der Regel keine Rektoratsmatrikeln geführt wurden, können hierfür keine vergleichbar systematischen Aussagen getroffen werden.

12 Vgl. Werner Paravicini, Von der Heidenfahrt zur Kavalierstour. Über Motive und Formen adeligen Reisens im späten Mittelalter, in: Wissensliteratur im Mittelalter und in der Frühen Neuzeit, hg. von Horst Brunner und Norbert Richard Wolf, Wiesbaden 1993, S. 91-130, hier: S. 146 f.; für die Universität Heidelberg Fuchs, Dives, pauper, nobilis (Anm. 5); Gerhard Fouquet, begehr nit doctor zu werden, und habs Gott seys gedanckht, nit im Sünn. Bemerkungen zu Erziehungsprogrammen ritterschaftlicher Adliger in Südwestdeutschland (14. bis 17. Jahrhundert), in: Wirtschaft, Gesellschaft, Städte. Festschrift für Bernhard Kirchgässner zum 75. Geburtstag, hg. von Hans Peter Becht und Jörg Schadt, Ubstadt-Weiher 1998, S. 95-136, hier: S. 105. 
setzend mit Prag 1348) bis 1450 lassen sich aus den Dynastien Nassau, Solms, Sayn und Wittgenstein, Wied-Runkel, Leiningen-Westerburg, Isenburg-Grenzau und Isenburg-Büdingen, Hanau, Rieneck, Stolberg-Königstein und Waldeck nur 16 Personen ermitteln, die an Universitäten im Reich eingeschrieben waren ${ }^{13}$. Mindestens 13 davon gehörten dem geistlichen Stand $a^{14}{ }^{14}$, womit das Universitätsstudium dieser Wetterauer Grafen in den Kontext einer kirchlichen Karriereplanung einzuordnen ist. Diese Beobachtung deckt sich mit den Ergebnissen der bisherigen Forschung, denn zur Bewältigung von militärischen oder politischen Aufgaben «war für den Adel des Reiches und Europas während des Spätmittelalters [ein Universitätsstudium] weder selbstverständlich noch überhaupt notwendig» ${ }^{15}$.

Gleichwohl ist ab 1450 ein deutlicher Anstieg nicht nur des geistlichen, sondern auch des weltlichen Adels unter den Immatrikulationen zu verzeichnen, was sowohl in Zusammenhang mit dem von Italien her einströmenden Humanismus und der Veränderung des Rechtswesens gebracht werden kann, als auch als Reaktion auf die wachsende gelehrte bürgerliche Konkurrenz in den fürstlichen Kanzleien zu verstehen ist ${ }^{16}$. Auch die Wetterauer Grafen reagierten auf die neuen Herausforderungen. Während in den hundert Jahren zwischen 1350 und 1450 lediglich 16 Grafen an Universitäten des Reiches studierten, waren es zwischen 1450 und 1550 bereits 55: Im Repertorium Academicum Germanicum lassen sich für diesen Zeitraum fünf Grafen von Nassau, acht von Solms, sieben von Sayn und Wittgenstein, fünf von Wied-Runkel, einen von LeiningenWesterburg, acht von Isenburg-Grenzau und fünf von Isenburg-Büdingen, drei von Hanau, einen von Rieneck, einen von Stolberg-Königstein und elf von Waldeck an Universitäten des Reiches nachweisen. Die Zahlen haben sich also mehr als verdreifacht.

Der Anstieg der Anzahl an studierenden Wetterauer Grafen verlief nicht linear. Wie Tabelle 1 ausweist, blieb die Frequentierung der Universitäten des Reiches durch die Wetterauer Grafen von 1450 bis 1520 ziemlich konstant. Darauf folgt ein Anstieg erst ab den 1520 er-Jahren. In den 1540er-Jahren waren bereits 16 Wetterauer Grafen immatrikuliert - in zehn Jahren also ebenso viele wie zwischen 1348 und 1450 in hundert Jahren.

13 In dieser Zeitspanne waren noch nicht alle Geschlechter in den Grafenstand aufgestiegen. Die illegitimen Söhne wurden bei der Zählung nicht berücksichtigt, obwohl einige in der Datenbank zu finden sind.

14 Der Lebenslauf der restlichen drei bleibt unbekannt, jedoch ist auch bei ihnen eine geistliche Laufbahn wahrscheinlich.

15 Schwinges, Die Universität als sozialer Ort des Adels (Anm. 5), S. 323 f. Zahlreiche Überblicksdarstellungen beschäftigen sich mit der Erziehung des Adels an der Schwelle vom Mittelalter zur Frühen Neuzeit. Exemplarisch sei verwiesen auf: Boehm, Konservatismus und Modernität (Anm. 3); Norbert Conrads, Tradition und Modernität im adligen Bildungsprogramm der Frühen Neuzeit, in: Ständische Gesellschaft und soziale Mobilität, hg. von Winfried Schulze (Schriften des Historischen Kollegs 12), München 1988, S. 389-403; Michael Sikora, Der Adel in der Frühen Neuzeit, Darmstadt 2009, S. 106-113; dezidiert nach dem Studierverhalten des Adels fragt Rainer A. Müller, Universität und Adel. Eine soziostrukturelle Studie zur Geschichte der bayrischen Landesuniversität Ingolstadt 1472-1648, Berlin 1974.

16 Schwinges, Die Universität als sozialer Ort des Adels (Anm. 5), S. 332; Boehm, Konservatismus und Modernität (Anm. 3), S. $70 \mathrm{f}$. 
Tab. 1 Aufzählung der zwischen 1450 und 1550 an mind. einer Universität des Reiches immatrikulierten Wetterauer Grafen nach Geschlechtern ${ }^{17}$

\begin{tabular}{|l|l|l|l|}
\hline & $1450-1485$ & $1485-1520$ & $1520-1550$ \\
\hline Nassau: & 1 & 2 & 2 \\
\hline Solms: & 4 & 0 & 4 \\
\hline Sayn-Wittgenstein: & 3 & 2 & 2 \\
\hline Wied-Runkel: & 0 & 4 & 1 \\
\hline Leiningen-Westerburg: & 0 & 1 & 0 \\
\hline Isenburg-Grenzau: & 2 & 1 & 5 \\
\hline Isenburg-Büdingen: & 1 & 0 & 4 \\
\hline Hanau: & 1 & 1 & 1 \\
\hline Rieneck: & 0 & 1 & 0 \\
\hline Stolberg-Königstein: & - & - & 1 \\
\hline Waldeck: & 1 & 4 & 6 \\
\hline Gesamt: & 13 & 16 & 26 \\
\hline
\end{tabular}

Bevor nach den Gründen für den Anstieg der Zahlen gefragt werden soll - der sicherlich nicht allein darauf zurückzuführen ist, dass auf dem Boden des Reiches immer mehr Universitäten entstanden, sondern sich auch ein gewisses Verständnis für die Nützlichkeit oder Notwendigkeit von gelehrtem Wissen in diesen Geschlechtern etabliert haben muss -, wird zunächst das Studierverhalten dieser Geschlechter im Rahmen der Kernfamilien analysiert. Denn lediglich 13 Grafensöhne wurden als einzige ihrer Familien an Universitäten des Reiches geschickt; zwei davon waren die einzigen männlichen Nachkommen des Familienzweiges. Beim überwiegenden Teil fanden sich gleich mehrere Söhne an Universitäten ein; 25 immatrikulierten sich sogar zusammen mit ihren Brüdern an einer oder mehreren Universitäten. Die Ausbildung der jungen Grafen-

17 Die Grafen von Stolberg-Königstein sind von den ersten zwei Zeiträumen ausgenommen. Die Linie bildete sich erst ab 1535, als durch Erbschaft der Eppsteiner Besitz an Ludwig von Stolberg (1505-1574) fiel. 
söhne, sei es zur Vorbereitung auf die Übernahme der Landesherrschaft oder auf eine geistliche oder weltliche Karriere, war von immenser Bedeutung für die Bestandssicherung der Dynastien. Nicht alle Grafensöhne konnten aus dem Land versorgt werden. Gelangten sie aber nicht in Kirchen- und Fürstendienste, drohte Besitzzersplitterung die Dynastie zu gefährden. Daher gilt es, im Folgenden den Fokus auf die Teile der Dynastien zu legen, die ein Universitätsstudium im Reich als sinnvoll für den dynastischen Erhalt angesehen haben.

In der Untersuchungsgruppe befinden sich 60 bis 63 Kernfamilien, die während des festgelegten Zeitraumes Söhne im studierfähigen Alter hatten ${ }^{18}$. Wegen Schwierigkeiten bei der Zeiteinteilung der hypothetischen Immatrikulationsmöglichkeiten können die folgenden Zahlen nur Tendenzen, keine absoluten Grössen darstellen. Insgesamt entschieden sich von den 60 bis 63 Kernfamilien 31 dafür, mindestens einen ihrer Söhne auf eine Universität des Reiches zu schicken. Das sind zwischen $49 \%$ und $52 \%$, also etwa die Hälfte. Acht Kernfamilien schickten ihre Söhne zwischen 1450 und 1485 auf eine Universität des Reiches ( $35 \%$ bis $42 \%$ ), während dies die elf bis 13 zu jener Zeit übrigen Kernfamilien der Region nicht taten ${ }^{19}$. Für den zweiten Zeitraum entschieden sich neun Kernfamilien für ein Universitätsstudium ihrer Söhne im Reich (50 \%), neun dagegen. Und für den dritten Zeitraum 14 dafür (58 \% bis $61 \%$ ), neun bis zehn dagegen.

Mit der Zeit gab es also mehr Kernfamilien aus den Wetterauer Grafengeschlechtern, die ein Universitätsstudium in das Erziehungsprogramm aufnahmen, als Kernfamilien, welche die Ausbildung der Söhne nur an den Höfen stattfinden liessen. Wie bei den absoluten Zahlen der studierenden Grafen ist hier ein Anstieg zu verzeichnen. Betrachtet man die männlichen Geschwister der immatrikulierten Grafensöhne, die zwar ein studierfähiges Alter erreicht haben, für die aber keine Immatrikulationen nachweisbar sind, wird deutlich, dass über die gesamten hundert Jahre hinweg etwa derselbe Prozentsatz an Söhnen ein Studium absolvierte ${ }^{20}$.

18 Klare Zahlen stehen nur für die tatsächlich immatrikulierten Grafen zur Verfügung. Die Aussagekraft dieser Zahlen ist aber abhängig von einer Vergleichsgruppe. Die Vergleichsgruppe besteht in diesem Fall in der Anzahl derjenigen Grafen, die prinzipiell die Möglichkeit gehabt hätten, ein Universitätsstudium im Reich zu absolvieren, diese aber nicht wahrnahmen. Wer zu dieser Gruppe zuzuordnen ist, ist methodisch nicht ganz sauber zu lösen. Aufgenommen wurden alle männlichen Familienangehörigen, die ein studierfähiges Alter erreichten. Da Adelige schon in sehr jungen Jahren eine Universität besuchen konnten, ist hier die Grenze von 18 Jahren gesetzt worden. D.h., wer mindestens 18 Jahre alt geworden ist und keine Universität besucht hatte, ist prinzipiell dieser Gruppe zuzuordnen. In Einzelfällen musste die Schwelle aber auch niedriger angesetzt werden, sofern Geschwister (jünger oder älter) bereits an Universitäten studierten und anzunehmen ist, dass die betreffende Person auch bereits studiert hätte, wäre es vorgesehen gewesen. Natürlich ist nicht auszuschliessen, dass der eine oder andere Grafensohn noch eine deutsche Universität besucht hätte, wenn er älter geworden wäre. Oftmals sind die genauen Lebensdaten besonders der nachgeborenen Grafen nicht bekannt, wodurch auch ihre Studierfähigkeit nicht sicher festgestellt werden kann. Die Verfasserin hat dieses methodische Problem bewusst in Kauf genommen.

19 Die Werte für den ersten und dritten Zeitraum sind schwieriger zu definieren, denn manche der Söhne hätten auch ausserhalb des Zeitraums studieren können.

20 Der Bezugsrahmen ist hier die jeweilige Kernfamilie, die das Universitätsstudium an einer deutschen Universität in ihr Erziehungsprogramm integriert hat. Nicht berücksichtigt werden bei diesem Schritt die Familien, die keine ihrer Söhne nachweisbar an Universitäten im Reich schickten. 
Tab. 2 Vergleich der immatrikulierten Grafensöhne mit ihren nicht immatrikulierten, aber prinzipiell studierfähigen Brüdern

\begin{tabular}{|l|l|l||l|l|}
\hline & $\begin{array}{l}\text { Immatriku- } \\
\text { lierte Grafen } \\
\text { im Reich }\end{array}$ & $\begin{array}{l}\text { Brüder ohne } \\
\text { Immatrikula- } \\
\text { tion im Reich }\end{array}$ & $\begin{array}{l}\text { Erstgeboren } \\
\text { unter den Imma- } \\
\text { trikulierten }\end{array}$ & $\begin{array}{l}\text { Nachgeboren } \\
\text { unter den Imma- } \\
\text { trikulierten }\end{array}$ \\
\hline $1450-1485$ & $13(46-52 \%)$ & $12-15$ & 3 & 10 \\
\hline $1485-1520$ & $16(50-52 \%)$ & $15-16$ & 4 & 12 \\
\hline $1520-1550$ & $26(47-49 \%)$ & $27-29$ & 8 & 18 \\
\hline
\end{tabular}

Interessant ist, dass sich manche Linien dem Studium im Reich ganz verweigerten: Die Linien Nassau-Wiesbaden-Idstein, Nassau-Dillenburg, Nassau-Weilburg und Sayn sind für den festgelegten Zeitraum gar nicht an den deutschen Universitäten vertreten, während die Isenburg-Grenzauer Grafenfamilien alle mindestens einen Sohn studieren liessen. Die Grafen von Waldeck zeigten auch eine überdurchschnittliche Neigung zu einem Studium an den deutschen Universitäten. Fünf der sechs Waldecker Kernfamilien des Zeitraumes schickten ihre Söhne zum Studieren. Die fünf studierfreudigen Kernfamilien schickten sogar rund zwei Drittel ihrer Söhne an deutsche Universitäten. Das Studierverhalten war innerhalb der Wetterauer Grafenhäuser offenbar durchaus unterschiedlich und abhängig von den Voraussetzungen in den einzelnen Grafschaften.

\section{Karrieren}

Es stellt sich nun die Frage, wen die Familien zum Studieren schickten. In der Forschung dominiert die Meinung, dass die nachgeborenen Söhne an die Universitäten geschickt wurden, da sie für den Kirchendienst bestimmt waren. Für die Landesherrschaft war «diese klerikale Erziehungsform» ${ }^{21}$ nicht nötig und galt bis ins 16. Jahrhundert hinein als nicht standesgemäss ${ }^{22}$. Daher mag der Befund zunächst verwundern, dass $27 \%$ der Immatrikulationen von erstgeborenen Wetterauer Grafen stammen ${ }^{23}$. Die Erklärung ist aber denkbar einfach: Bei einigen Geschlechtern aus der Riege der Wetterauer Grafen waren nicht automatisch die ältesten Söhne zur Übernahme der Landesherrschaft sowie die jüngeren zum Kirchendienst vorgesehen. Vielmehr haben nicht selten die Ältesten eine Domherrenstelle bekommen, wie es im Sayn-Wittgensteiner Grafenhaus üblich gewesen zu sein scheint: Unter den Söhnen Georgs I. von Sayn-Wittgenstein (?-1472)

21 Fouquet, begehr nit doctor zu werden (Anm. 12), S. 105.

22 Vgl. Sikora, Der Adel in der Frühen Neuzeit (Anm. 15), S. 110; Asch, Europäischer Adel in der Frühen Neuzeit (Anm. 2), S. 135 .

23 Vgl. Tabelle 2. 
zum Beispiel wurden zunächst die beiden ältesten Werner (?-1484) und Georg (?-1510) mit Domherrenpfründen versorgt, während die dritt- und viertgeborenen für die Landesherrschaft vorbereitet wurden. Der fünfte Sohn wiederum erhielt auch ein Kanonikat in Köln. Die Tradition setzte sich in den folgenden Generationen fort ${ }^{24}$. Die Praxis der Pfründenvergabe in den für den gräflichen Hochadel übrig gebliebenen Stiften gestaltete sich als reine Vetternwirtschaft. In Köln, aber auch in Mainz und Trier, übten die Domherren der Reihe nach das Nominationsrecht aus. Das bedeutete, dass sich die Dynastien regelrecht über Generationen hinweg festsetzen konnten ${ }^{25}$. Mit dieser Praxis wurden häufig schon Kinder zu Domherren, aber es ist nachvollziehbar, dass bei der Ämtervergabe nicht unbedingt der jüngste Vetter ausgewählt wurde. Die Dynastie war im Zweifel über jeden versorgten Sohn froh. Erstgeburt und Kirchendienst schlossen sich also nicht aus und die Primogenitur hatte sich in den Wetterauer Grafschaften längst noch nicht durchgesetzt ${ }^{26}$. Die acht Erstgeborenen im dritten Zeitraum erklären sich zudem dadurch, dass bereits mehr zukünftige Landesherren studierten.

Bei der Erstimmatrikulation waren die meisten Grafen zwischen zwölf und 16 Jahre alt $^{27}$. Drei Grafen besuchten sogar erst im Alter von 25-30 Jahren das erste Mal eine Universität. Der jüngste Student war Bernhard von Solms-Lich, der sich 1540 mit sieben Jahren in Ingolstadt zusammen mit seinen Brüdern (neun und zwölf Jahre) einschrieb. Das errechnete Durchschnittsalter bei der Erstimmatrikulation liegt bei 14,44 Jahren.

In der ersten Zeitspanne 1450-1485 waren elf von 13 immatrikulierten Grafen sicherlich für den geistlichen Stand bestimmt. Nur einer war von vorneherein zur Führung der Landesherrschaft designiert, ein anderer erhielt sie ungeplant nach dem Tod seines älteren Bruders ${ }^{28}$. In der zweiten Zeitspanne 1485-1520 schlugen zwölf der 16 immatrikulierten Grafen eine geistliche Laufbahn ein. Erst zwischen 1520 und 1550 führten die Universitätsstudien stärker auch zu weltlichen Karrieren: 16 der 26 immatrikulierten Grafen waren immer noch für den geistlichen Stand vorgesehen. Die Anzahl der studierten Landesherren nahm in dieser Periode am stärksten zu: 16 regierende Grafen hatten vor der Übernahme der Landesherrschaft mindestens eine Universität besucht.

24 Vgl. die Angaben in den Europäischen Stammtafeln: Europäische Stammtafeln NF 4, hg. von Detlev Schwennicke, 1981, Tafel 122.

25 In Köln und Straßburg konnten die Grafen mit diesem Instrument ihre Stellung festigen, in Mainz und Trier verloren sie den Kampf um die Vorherrschaft im Stift gegen die Reichsritterschaft. Vgl. Wilhelm Kisky, Die Domkapitel der geistlichen Kurfürsten in ihrer persönlichen Zusammensetzung im vierzehnten und fünfzehnten Jahrhundert, Weimar 1906, S. 14.

26 In dieser Hinsicht blieben diese Grafenhäuser noch lange rückständig. Im Haus Solms z.B. existierte auch im 18. Jahrhundert noch kein in den Hausverträgen fixiertes Primogeniturrecht. Vgl. Tobias Busch, Herrschen durch Delegation. Reichsgräfliche Herrschaft Ende des 17. und im 18. Jahrhundert am Beispiel der Grafschaft SolmsRödelheim, Kassel 2007, S. 187.

27 Nur für 24 Grafen der Untersuchungsgruppe lässt sich das Alter bei der Erstimmatrikulation bestimmen.

28 Lediglich der Karriereweg Graf Ludwigs von Hanau-Lichtenberg lässt sich nicht nachvollziehen. Er starb bereits mit 20 Jahren in Trient auf dem Rückweg seiner Pilgerreise nach Jerusalem. Ob ihm sein Studium 1476 den Weg in eine geistliche Laufbahn ebnen sollte, kann nicht mit Bestimmtheit gesagt werden. Pfründenbesitz ist zumindest nicht bekannt. Vgl. Reinhold Röhricht, Die Jerusalemfahrten der Grafen Philipp, Ludwig (1484) und Reinhard von Hanau (1550), in: Zeitschrift des Vereins für hessische Geschichte und Landeskunde 26 (1891), S. 85-188. 
Davon waren sieben zum Zeitpunkt ihres Studiums weder bepfründet, noch sprechen andere Indizien in der Familienkonstellation für eine beabsichtigte geistliche Karriere ${ }^{29}$. Ein Universitätsstudium gewann als Teil der Vorbereitung auf die Übernahme einer Landesherrschaft langsam an Akzeptanz.

Das Übergewicht der geistlichen Karrierewege bei den immatrikulierten Wetterauer Grafen hängt damit zusammen, dass in vielen Dom- und Stiftsstatuten ein Grundstudium der Artes, besser aber noch der Rechte vor oder nach Pfründenerhalt vorgeschrieben war: das sogenannte biennium. Dieses konnte an Universitäten inner- oder ausserhalb des Reiches absolviert werden. Ein Abschluss wurde in der Regel nicht benötigt ${ }^{30}$. Die meisten der 39 (von insgesamt 55) studierten Grafen des gesamten Zeitraumes leisteten daher ihr Pflichtstudium im Rahmen des biennium ab, denn eine Pfründe hatte der Grossteil bereits bei Antritt des Studiums ${ }^{31}$.

Für den gesamten Zeitraum lassen sich aber mindestens 17 Kleriker aus der Riege der Wetterauer Grafen nachweisen, die meistens Kanonikate in Köln, Mainz, Trier und Straßburg besassen, aber keine Universität im Reich besucht hatten ${ }^{32}$. Ein Teil davon hatte möglicherweise ein Studium im Ausland absolviert, wie Engelbert von NassauWiesbaden-Idstein (1448-1508). Dieser erlangte vor 1463 sogar einen Studienabschluss als baccalaureus decretorum an einer ausländischen Universität und wurde Domherr in Köln und Mainz sowie Propst in Frankfurt am Main. Jedoch galt in der Praxis das biennium nicht grundsätzlich als Voraussetzung für das Erlangen eines Kanonikats. Der Adel konnte hiervon nicht nur ausgenommen $\operatorname{sein}^{33}$, auch überwogen familiäre Verbindungen im Zweifel intellektuelle Fähigkeiten. Anhand des Hauses Solms lässt sich plastisch veranschaulichen, wie die einst in 〈Dynastiebesitz〉 gekommenen Kanonikate in Köln innerhalb des Geschlechts weitergegeben und vermehrt wurden: Wolfgang (1480-1511) wurde von seinem Onkel Bernhard von Solms-Braunfels (1436-1503) zur

29 Weitere fünf Grafensöhne waren zunächst für den geistlichen Stand vorgesehen, kehrten aber nach dem Tod der Brüder oder im Falle von deren Kinderlosigkeit zur Fortführung der Dynastie aus dem geistlichen Stand zurück. Dieses Vorgehen war durchaus üblich. In den Domstiften hielten die Geschlechter eine stille Reserve, die zum Dynastieerhalt reaktiviert werden konnte. Selbst der Erzbischof von Köln, Salentin von Isenburg-Grenzau (1532-1610), verliess sein Amt, das ihn in den Rang eines Kurfürsten erhoben hatte, um als letzter Isenburger Graf in den Stand der Ehe zu treten und die Dynastie fortzusetzen. Der Fortbestand der Dynastie hatte oberste Priorität.

30 In den Statuten des Trierer Domkapitels von 1428 wurde festgelegt, dass niemand Aufnahme im Domkapitel finden solle, der nisi prius per integrum biennium in studio generali studendo steterit et sciat ad minus competenter congrue loqui latinum. Auch in Mainz (Michael Hollmann, Das Mainzer Domkapitel im späten Mittelalter, Mainz 1990, S. 19) und Speyer (Gerhard Fouquet, Das Speyerer Domkapitel im späten Mittelalter, ca. 1350-1540. Adlige Freundschaft, fürstliche Patronage und päpstliche Klientel, Bd. 1, Mainz 1997, S. 168-171) wurde das biennium verlangt.

31 Der Pfründenbesitz wurde bei der Immatrikulation in den Matrikelbüchern vermerkt.

32 Der Wert ist ein absoluter Mindestwert. Hierfür wurden die Kapitelmitglieder der Domstifte Mainz und Trier bis etwa 1500 und des Domstifts Köln bis etwa 1560 mithilfe der Listen bei Kisky, Die Domkapitel der geistlichen Kurfürsten (Anm. 25) und Hermann Heinrich Roth, Das kölnische Domkapitel von 1501 bis zu seinem Erlöschen 1803, in: Der Dom zu Köln. Festschrift zur Feier der 50. Wiederkehr des Tages seiner Vollendung am 15. Okt. 1880, hg. von Erich Kuphal, Köln 1930, S. 257-294, ergänzt. Eine gewisse Dunkelziffer derjenigen, die in anderen Dom- und Kollegiatstiften bepfründet waren, muss mit eingerechnet werden.

33 In Speyer galt erst ab 1500 das biennium für ausschliesslich alle als Voraussetzung. Vgl. Fouquet, begehr nit doctor zu werden (Anm. 12), S. 106. 
Präbende des Philipp von Henneberg nominiert und 1501 emanzipiert, während sein Bruder Philipp (1467-1511) Bernhards Präbende nach dessen Tod 1503 erhielt. Das Kanonikat Ottos von Solms-Braunfels (1504-1536), möglicherweise vorher im Besitz seines gleichnamigen Onkels, erhielt 1536 Ernst von Solms-Lich ${ }^{34}$. Lediglich Bernhard und Ernst hatten studiert. Bei den übrigen ist kein Universitätsbesuch nachweisbar. Es ist anzunehmen, dass das biennium nur im Falle einer mangelhaften Vorbildung von den Domkapitularen abverlangt wurde.

Zur Erhaltung von Pfründen oder zum Aufstieg in hohe kirchliche Ämter war für die Grafen ein Universitätsstudium also nicht unbedingt notwendig. Das Studium war für diese hochadelige Gruppe lediglich eine Zusatzqualifikation, keine Voraussetzung für eine kirchliche Karriere ${ }^{35}$. Diese Aussage konnte im Prinzip auch für die höchsten kirchlichen Ämter gelten. Noch Graf Johann von Isenburg-Grenzau (1507-1556), Erzbischof von Trier (1547-1556), galt als mediocriter eruditus und es sind weder Universitätsstudien im Reich noch ausserhalb bekannt ${ }^{36}$. Die Dignitäre der Domstifte Köln, Mainz und Trier aus der Riege der Wetterauer Grafen hatten allerdings nahezu alle studiert $^{37}$. Auffallend ist jedoch, dass in der dritten Zeitspanne ab 1520 deutlich mehr Grafen in den Matrikelbüchern ohne die Nennung einer Pfründe auftauchen. Von der grösser werdenden Zahl studierender zukünftiger Landesherren abgesehen, scheinen die Wetterauer Grafen Probleme bekommen zu haben, ihre Söhne frühzeitig in den Domstiften unterzubringen.

Der Grossteil der Immatrikulationen lässt sich nicht einer bestimmten Fakultät zuordnen. In der Untersuchungsgruppe lassen sich lediglich 14 Grafen an den juristischen Fakultäten verorten. Acht studierten artistische Fächer. Sowohl für die weltlichen als auch für die geistlichen Karrierewege war ein Studium der Rechte am lukrativsten, weswegen der Adel versuchte, möglichst unter Umgehung der artistischen Fakultät die juristischen Vorlesungen zu besuchen ${ }^{38}$. Es ist anzunehmen, dass die meisten Wetterauer Grafen ebenso handelten. Ein Abschluss lässt sich nur für zwei Grafen nachweisen. Graf Bernhard von Solms-Braunfels (1436-1503) erlangte vor 1460 das Licentiat der Leges und Dietrich von Wied-Runkel (?-1507) liess sich 1487 als baccalaureus decretorum in Bologna einschreiben. Vor einem bürgerlichen Professor eine Prüfung abzulegen, galt

34 Vgl. Kisky, Die Domkapitel der geistlichen Kurfürsten (Anm. 25), S. 35 und 81; Roth, Das kölnische Domkapitel (Anm. 32), S. 268. Kisky fasste fälschlicherweise die Grafen Otto von Solms-Braunfels (1504-1536) und Otto von SolmsBraunfels (1474- nach 1498) als eine Person auf.

35 Vgl. Schwinges, Die Universität als sozialer Ort des Adels (Anm. 5), S. 323 f.; Fuchs, Dives, pauper, nobilis (Anm. 5), S. 33

36 Erwin Gatz, Die Bischöfe des Heiligen Römischen Reiches 1448 bis 1648. Ein biographisches Lexikon, Berlin 1996, S. 325. Vgl. darüber hinaus Bernhard Ferdinand Julius Endrulat, 〈Johann V.〉 in: Allgemeine Deutsche Biographie 14 (1881), S. 424-426.

37 Vgl. die Listen bei Kisky, Die Domkapitel der geistlichen Kurfürsten (Anm. 25) und Roth, Das kölnische Domkapitel (Anm. 32).

38 Sikora, Der Adel in der Frühen Neuzeit (Anm. 15), S. 110 f. 
unter Adeligen als nicht standesgemäss und wurde gemeinhin abgelehnt ${ }^{39}$. Hier verhalten sich die Wetterauer Grafen ganz standestypisch. Sie bemühten sich offenbar um die fachlichen Kompetenzen, versperrten sich aber der Bewertung. An die Stelle eines Abschlusszeugnisses trat die Bescheinigung über die Ableistung des bienniums, wie sie etwa von Graf Bernhard von Solms-Braunfels, am 23. August 1451 ausgestellt durch den Vizerektor der Universität Köln, erhalten ist ${ }^{40}$.

\section{Studienorte}

Bei der Wahl der Studienorte im Reich wurde eindeutig die Universität Köln präferiert. Zwischen 1450 und 1550 immatrikulierten sich 33 Wetterauer Grafen an der 1388 gegründeten Universität. Die Attraktivität rührte allerdings weniger vom Renommee der Universität, sondern ist vor allem durch das Domkapitel zu begründen. Der überwiegende Teil der studierten Geistlichen in der Untersuchungsgruppe war am Kölner Domstift bepfründet oder besass Präbenden an der Kölner Stiftskirche St. Gereon. Das biennium leisteten viele einfachheitshalber am Standort der Pfründe. Die Dominanz der Kölner Universität ist ein klares Indiz dafür, dass der Universitätsbesuch der Wetterauer Grafen über den gesamten Untersuchungszeitraum noch eine weitestgehend klerikale Angelegenheit blieb. Ohne das Domstift wäre die städtische Universität Köln sehr viel unattraktiver für diese Adelsgruppe gewesen ${ }^{41}$. Die Universitäten in Prag oder Wien wurden von den Wetterauer Grafen nicht aufgesucht. Die Nähe zum Kaiserhof spielte anscheinend keine Rolle. Attraktiver wurden hingegen die Landesuniversitäten Heidelberg und Ingolstadt. Am zweitstärksten wurden von den Wetterauer Grafen die Universitäten Heidelberg mit sechs und Erfurt mit acht Immatrikulationen frequentiert, wobei auffallend ist, dass Heidelberg 1483 zum letzten Mal in unserer Zeitspanne von einem Wetterauer Grafen besucht wurde. Diese Beobachtung überrascht vor dem Hintergrund, dass Heidelberg die höchste Adelsdichte der Universitäten im Reich aufwies $^{42}$, für die hier untersuchte Adelsgruppe aber die Bedeutung verlor. Erst nach der Einführung der reformierten Konfession in der Kurpfalz und damit auch in der Universität Heidelberg zogen Hof und Universität wieder vermehrt die seit den 1570er-Jahren

39 Der Niederadel zeigte sich wesentlich promotionsfreudiger als der Hochadel. Vgl. Fuchs, Dives, pauper, nobilis (Anm. 5), S. 32; Christian Lackner, Adel und Studium. Adelige Studenten aus den habsburgischen Ländern an der Universität Wien im 15. Jahrhundert, in: Festschrift für Heide Dienst, hg. von Anton Eggendorfer, Christian Lackner und Willibald Rosner (Forschungen zur Landeskunde von Niederösterreich 30), St. Pölten 2004, S. 71-92, hier: S. 82. Erst im 19. Jahrhundert musste sich der Adel dem universitären Prüfungswesen beugen (Peter Moraw, Aspekte und Dimensionen älterer deutscher Universitätsgeschichte, in: Academia Gissensis. Beiträge zur älteren Gießener Universitätsgeschichte, hg. von dems., Marburg 1982, S. 1-43, hier: S. 36).

40 Unter der Bezeichnung 〈Studienzeugnis` abgedruckt in: Hermann Keussen, Studienzeugniss der Universität Köln für den Grafen Bernhard von Solms, Kanonikus am Dom und an S. Gereon zu Köln: 1451 August 23. Köln, in: Quartalblätter des Historischen Vereins für das Großherzogthum Hessen 1 (1884), S. 27 f.

41 Vgl. Schwinges, Die Universität als sozialer Ort des Adels (Anm. 5), S. 335 f.

42 Fuchs, Dives, Paupers, nobilis (Anm. 5), S. 31; Schwinges, Die Universität als sozialer Ort des Adels (Anm. 5), S. 324. 
calvinistisch werdenden Grafen $a^{43}$. Die Nähe zum Hof der bayerischen Herzöge erklärt, dass immerhin vier Grafensöhne 1539-1541 die Universität Ingolstadt aufsuchten. Reinhard von Solms-Lich (1491-1562) stand in diesem Zeitraum in bayerischen Diensten, weswegen drei seiner Söhne und ein Pflegesohn dort zu finden sind ${ }^{44}$.

In Freiburg lassen sich fünf Wetterauer Grafen nachweisen. 1536 schrieben sich die Brüder Johann Ludwig (1524-1542) und Adolph von Nassau-Saarbrücken (1526-1559) zusammen mit Otto von Solms-Braunfels (1504-1536) dort ein und in den 1540er-Jahren zwei Grafen von Isenburg-Büdingen. Letztere zogen daraufhin nach Straßburg weiter. Vermutlich nutzte auch die Dreiergruppe Freiburg als Etappe auf einer grösser angelegten Bildungsreise in das französische oder schweizerische Ausland.

Die Universitäten Leipzig, Basel, Tübingen und Frankfurt an der Oder waren für die Wetterauer Grafen recht unattraktiv. Es immatrikulierten sich lediglich jeweils nur ein oder zwei Wetterauer Grafen über den gesamten Zeitraum.

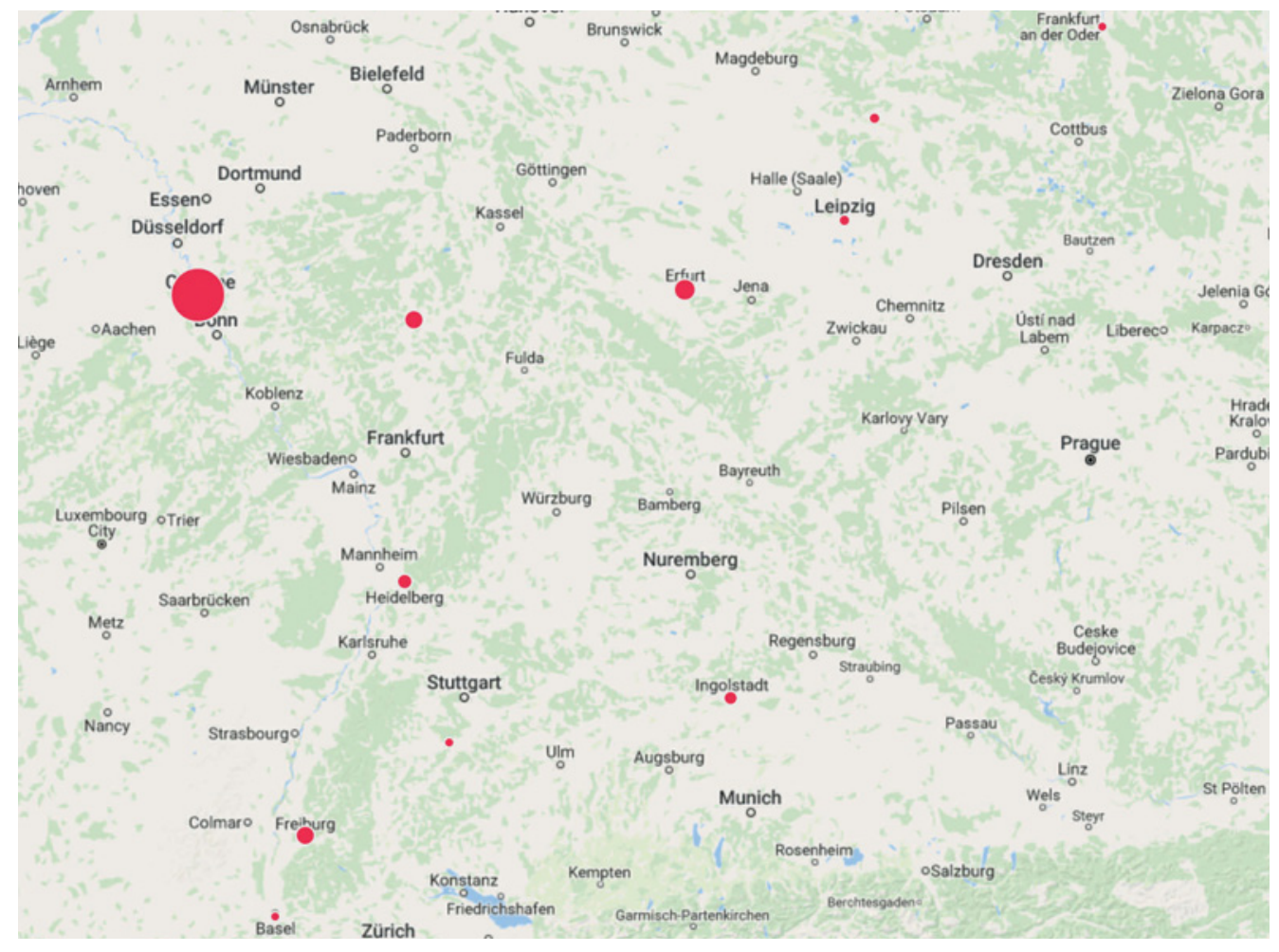

Abb. 1 Studienorte der Wetterauer Grafen 1450-1550

43 Vgl. das Register der Heidelberger Matrikel bei Gustav Toepke, Die Matrikel der Universität Heidelberg von 1386-1870, Bd. 3, Heidelberg 1893.

44 Friedrich Uhlhorn, Reinhard Graf zu Solms und Herr zu Münzenberg 1491-1562, Marburg 1952, S. $49-64$. 
Die Universitäten Wittenberg und Marburg zogen schliesslich die sich langsam dem protestantischen Gedankengut öffnenden Grafen an. In Wittenberg studierten 1520 Graf Ludwig von Stolberg-Königstein (1505-1574) und 1549 Graf Georg von IsenburgBüdingen (1528-1577). In Marburg immatrikulierten sich neben vier Waldecker Grafen die Grafen Philipp (1526-1596), Otto (1533-1553) und Ludwig III. von IsenburgBüdingen (1529-1588). Nach dem frühen Tod ihres Vaters standen die Isenburger Junggrafen unter der Vormundschaft Philipps des Großmütigen von Hessen, was die Wahl der Universität ebenso erklärt wie ihre Neigung zur Reformation ${ }^{45}$.

Philipp, Otto und Ludwig III. von Isenburg-Büdingen besuchten aber nicht allein die Universität Marburg. Ihr Aufenthalt in Marburg war eingebunden in eine grösser angelegte Kavalierstour, die Philipp und Ludwig III. an die Universitäten zu Köln, Marburg und Freiburg und an die Hohe Schule zu Straßburg führte. Ihr Bruder Otto durfte sie immerhin nach Marburg und Straßburg begleiten. Reisen zum Bildungs- und Wissenserwerb war prestigeträchtig und Ausweis des sozialen Ranges. Ab der zweiten Hälfte des 15. Jahrhunderts wurden die Universitäten daher in den Kreis der adeligen Bildungsreisen aufgenommen. Die Bildungsreise der drei Isenburger Grafen wurde standesgemäss absolviert: Kurzes Verweilen und häufige Wechsel der Universität waren typische Merkmale der Kavalierstour ${ }^{46}$.

Vor diesem Massstab zeichnet das Repertorium Academicum Germanicum allerdings ein eher tristes Bild der Wetterauer Grafen. Es dürfte aber wohl nicht nur an der erst allmählich aufkommenden Akzeptanz der Universität als adelige Bildungseinrichtung gelegen haben, dass der Grossteil der studierten Wetterauer Grafen nur eine Universität aufsuchte. Lediglich 18 der 55 im Reich immatrikulierten Grafen studierten an mehr als einer Universität im In- und Ausland, wobei die Hohe Schule zu Straßburg bereits mitgezählt ist. Nur sieben davon besuchten mehr als zwei Universitäten. Auch unter Berücksichtigung von potenziellen, bisher nicht bekannten Studien an ausländischen Universitäten war der Besuch mehrerer Universitäten im Rahmen einer grösser angelegten Bildungsreise bis zur Mitte des 16. Jahrhunderts in den Wetterauer Grafenhäusern noch nicht die Regel ${ }^{47}$. Es liegt nicht fern, einen weiteren Grund für diesen Umstand in den notwendigen Ressourcen zu sehen.

45 Norbert Stieniczka, Philipp der Großmütige und die Reformation in der Grafschaft Ysenburg, in: Büdinger Geschichtsblätter 19 (2006), S. 215-221.

46 Vgl. besonders Paravicini, Von der Heidenfahrt zur Kavalierstour (Anm. 12); vgl. auch Spieß, Reisen deutscher Fürsten und Grafen im Spätmittelalter (Anm. 7).

47 Die Quellenlage ist in diesem Punkt besonders schwierig, da aus Gründen der Sicherheit oder Sparsamkeit der Adel gerne inkognito reiste. Vgl. Norbert Conrads, Das Incognito. Standesreisen ohne Konventionen, in: Grand Tour, hg. von Babel/Paravicini (Anm. 5), S. 591-607. 


\section{Zur soziopolitischen Lage der Wetterauer Grafen im 15. und 16. Jahrhundert}

Weitgreifende gesellschaftliche und politische Wandlungsprozesse im Reich des Spätmittelalters brachten die traditionelle Führungsrolle des Adels in Bedrängnis ${ }^{48}$. Die wetterauischen Reichsgrafen sind zwar dem Hochadel zuzurechnen, gelten aber als mindermächtiger Reichsstand. Im Zuge der allgemeinen herrschaftlichen Verdichtung im 15. Jahrhundert bildeten sich in Wetterau und Westerwald viele kleinräumige Territorien heraus ${ }^{49}$. Direkte Nachbarterritorien der Wetterauer und Westerwälder Grafschaften waren die Erzbistümer von Mainz und Trier, das Hochstift Fulda und die Landgrafschaft Hessen. Der Niederadel der Region gliederte sich in Adel der Reichsritterschaft und landsässigem hessischen $\operatorname{Adel}^{50}$. Von den niederadeligen Nachbarn wurden die Wetterauer Grafen durch ständige Fehden und von den fürstlichen Nachbarn durch deren expansive Territorialisierungsbestrebungen bedroht. Besonders die Landgrafschaft Hessen dehnte ihre Herrschaft immer weiter in gräfliches Gebiet aus. So gingen die Grafschaften Nidda und Ziegenhain 1450, die Grafschaft Katzenelnbogen 1479 und die Hälfte der Herrschaft Eppstein 1492 an Hessen verloren. Im Gegensatz zu Hessen hingen die Wetterauer Grafen in der Arrondierung ihres Herrschaftsbereiches zurück. $\mathrm{Zu}$ Beginn des 16. Jahrhunderts waren die Grenzen der einzelnen Grafschaften noch nicht klar umrissen, stattdessen war das Gebiet durchdrungen von konkurrierenden Herrschaftsrechten und Kondominien. Nicht nur in gemeinsam beherrschtem Gebiet griffen die Landgrafen direkt in die Herrschaftsausübung der Grafen ein. Auch durch Zoll- und Geleitrechte und vor allem die Lehnsabhängigkeit vieler dieser Dynastien zu Hessen wurde trotz ihres reichsunmittelbaren Status nicht nur die Herrschaftsausübung in den Territorien beschnitten, sondern auch der reichspolitische Kurs beeinflusst. In der Reformationszeit begann daher für die Wetterauer Grafen ein vorsichtiges Lavieren zwischen neugläubigem Landgrafen als Lehnsherrn und altgläubigem Kaiser, dessen Unterstützung sie gegen die expansiven fürstlichen Nachbarn nicht verlieren durften. Nichtsdestotrotz tendierten bis in die 1540er-Jahren fast alle Wetterauer Grafen zur lutherischen Lehre ${ }^{51}$.

48 Diese Prozesse werden als Standeskrise oder Adelskrise des Spätmittelalters bezeichnet. Zur Kritik am Krisenbegriff vgl. Heide Wunder und Alexander Jendorff, Einleitung. Adel in Hessen vom 15. bis zum 20. Jahrhundert - Probleme und Perspektiven der Forschung, in: Adel in Hessen. Herrschaft, Selbstverständnis und Lebensführung vom 15. bis ins 20. Jahrhundert, hg. von ders. und Eckart Conze (Veröffentlichungen der Historischen Kommission für Hessen 70), Marburg 2010, S. 13-52, hier: S. 26-32.

49 Vgl. Peter Moraw, Von offener Verfassung zu gestalteter Verdichtung. Das Reich im späten Mittelalter 1250-1490 (Propyläen Geschichte Deutschlands 3), Frankfurt/Berlin 1985, S. 73 f.

50 Vgl. Wunder/Jendorff, Einleitung (Anm. 48), S. 14 f.

51 Vgl. Georg Schmidt, Der Wetterauer Grafenverein, Marburg 1989; ders., Wetterauer Grafenverein, in: Handbuch der hessischen Geschichte, Bd. 3: Ritter, Grafen und Fürsten - weltliche Herrschaften im hessischen Raum ca. 900-1806, hg. von Winfried Speitkamp (Historische Kommission für Hessen), Marburg 2014, S. 327-346. Zur Bindung der Grafen an den Kaiser vgl. Volker Press, Reichsgrafenstand und Reich, in: Adel im Alten Reich. Gesammelte Vorträge und Aufsätze, hg. von dems., Tübingen 1998, S. 113-138, hier: S. 120. 
Während die Fürsten die Grafen in territoriale Bedrängnis brachten und deren Selbstständigkeit bedrohten, drangen der Niederadel und das gebildete und ökonomisch gut gestellte Bürgertum in andere traditionelle Domänen der Grafen vor: die Domkapitel und die fürstliche Zentralverwaltung. Zwar verblieben am Fürstenhof viele Tätigkeitsfelder wie Hofämter, Gesandtschaften und Offiziersstellen in adeliger Hand. Auch die Reichskirche blieb bis zum Ende des Alten Reichs eine Adelskirche. Allerdings verdrängte der Niederadel den Hochadel, v.a. die Grafen, aus wichtigen Dom- und Stiftskapiteln wie Trier und Mainz. Der Grafenstand konnte lediglich seine Stellung in den Dom- und Stiftskapiteln in Köln und Straßburg behaupten, welche sie aber durch das Vordringen der Reformation in den Grafschaften zu verlieren drohten ${ }^{52}$.

Den Wetterauer Grafen gelang es trotzdem, sich an die neuen Herausforderungen anzupassen. Durch ständisch geschlossene Heiratsverbindungen wurde die soziale Abgrenzung nach unten verstärkt. Man ordnete sich dezidiert dem Hochadel zu und konnte eine Abdrängung in die Landsässigkeit verhindern. Erb- und Hausverträge schützten den Besitzstand der Grafenhäuser und stärkten den Familienverband. Ihre Stellung gegenüber den hessischen Landgrafen konnten sie durch den Zusammenschluss im sogenannten Wetterauer Grafenverein stärken, welcher neben der Funktion eines Standesbündnisses auch die einer Reichskorporation hatte. Als solche bekamen die Wetterauer Grafen eine Kuriatstimme im Fürstenrat des Reichstages ${ }^{53}$.

Die traditionelle Bindung zwischen dem Grafenstand und dem Kaiser hatte bereits im 14. und 15. Jahrhundert bestanden, betraf aber eher die habsburgische Klientel. Unter Karl V. intensivierte sich der Kontakt der Wetterauer Grafen zum Kaiser. Allen voran Nassau-Dillenburg und Solms-Lich suchten in der Anlehnung an das Reichsoberhaupt den Schutz vor der landgräflichen Expansion. Universitätsbesuche in der Nähe des Kaiserhofes hatten diese Beziehungen aber nicht zur Folge. Seit etwa 1500 wurden auch die Beziehungen zu den Wittelsbachern und Wettinern ausgebaut, da die grossen Fürstenhöfe den Stiftsverlust ausgleichen mussten - eine Entwicklung, die sich nach der Reformation noch intensivierte ${ }^{54}$. Auf die Professionalisierung der Fürstenkanzlei durch gelehrte bürgerliche Juristen ${ }^{55}$ reagierte man mit Anpassung an die gestiegenen Qualitätsanforderungen: $\mathrm{Ab} 1450$ ist für die Wetterauer Grafen ein intensiverer Besuch der Universitäten des Reichs zu verzeichnen. Zeitgleich wurden die juristischen Fakultäten ausgebaut, die für die Qualifizierung der Grafen für alle Bereiche von grösstem

52 Vgl. Georg Schmidt, Ulrich von Hutten, der Adel und das Reich um 1500, in: Ulrich von Hutten in seiner Zeit, hg. von Johannes Schilling und Ernst Giese (Monographia Hassiae 12), Kassel 1988, S. 19-34.

53 Vgl. Schmidt, Wetterauer Grafenverein (Anm. 51); zu Grafeneinungen im Allgemeinen vgl. Horst Carl, Einungen und Bünde. Zur politischen Formierung des Reichsgrafenstandes im 15. und 16. Jahrhundert, in: Grafen und Herren in Südwestdeutschland vom 12. bis ins 17. Jahrhundert, hg. von Kurt Andermann und Clemens Joos (Kraichtaler Kolloquien 5), Epfendorf 2006, S. 97-118.

54 Vgl. Press, Reichsgrafenstand und Reich (Anm. 51), S. 113-138.

55 Für den Heidelberger Hof konnte Press das Ringen um die Vorherrschaft in der fürstlichen Zentralregierung zwischen bürgerlichen Räten, Niederadel und Grafenstand nachweisen: Volker Press, Calvinismus und Territorialstaat. Regierung und Zentralbehörden der Kurpfalz 1559-1619, Stuttgart 1970. 
Interesse waren ${ }^{56}$. Zunächst blieb das Universitätsstudium lediglich Teil der geistlichen Ausbildung. Erst ab den 1520er-Jahren wurden Universitätsstudien auch in das Ausbildungsprogramm weltlicher Grafensöhne eingebunden. Eingedenk der hohen Anzahl zum Zeitpunkt der Immatrikulation unbepfründeter Wetterauer Grafen in der Periode von 1520 bis 1550 liegt es nahe, dass sich die Situation verschärfte und die Versorgung der nicht für die Landesherrschaft benötigten Söhne prekärer wurde - und das noch unabhängig von der Reformation. Sogar der spätere Erzbischof von Köln, Salentin von Isenburg-Grenzau, war zum Zeitpunkt seines Studiums der Artes in Köln 1547 noch pfründenlos.

In einem letzten Schritt soll nun ein Adelstraktat herangezogen werden, der am Ende der Untersuchungsperiode einen Einblick in die Selbstwahrnehmung der Wetterauer Grafen bezüglich ihrer Lage und der Bedeutung einer sorgfältigen Ausbildung zur Überwindung ebendieser zu geben vermag.

\section{Der Adelstraktat Graf Reinhards von Solms-Lich: Tugendadel $=$ gelehrter Adel?}

Graf Reinhard von Solms-Lich hatte höchstwahrscheinlich kein Universitätsstudium absolviert. Ungebildet war er deswegen aber nicht. Philipp von Solms-Lich (1468-1544) $)^{57}$ hatte seinen Söhnen Reinhard und Otto (1496-1522) eine an humanistischen Idealen orientierte Grunderziehung im Stammschloss in Lich erteilt, welche Reinhard an den Höfen der Kurfürsten Ludwig von der Pfalz und Friedrich von Sachsen fortsetzte. Obwohl sein Vater Philipp als nachgeborener Sohn im Alter von elf Jahren 1479 an der Universität Heidelberg und 1480 an der Universität Erfurt studiert hatte, verzichtete er auf einen universitären Bildungsweg für seine beiden das Erwachsenenalter erreichenden Söhne (zwei weitere verstarben jung). Nichtsdestotrotz darf Graf Reinhard als gelehrt in einem allgemeineren Sinn bezeichnet werden, was seine schriftstellerische Tätigkeit beweist. Er hinterliess der Nachwelt zahlreiche Traktate zu den Themengebieten politisches Zeitgeschehen, Kriegswesen und Adelsstand ${ }^{58}$. Seine Werke sind keine abstrakten theoretischen Schriften, sondern sie vermitteln aus der Erfahrung gewonnenes, praxisorientiertes Wissen. So regt er in seinem 1553 in Köln gedrucktem Traktat Beschreibung vom Ursprung, Anfang und Herkhomen des Adels, adelichen Underhaltungen und aufferlegtem gebürlichem Bevelch, wie sich der Adel seinem Tittel nach halten und herwiderumb solle gehalten werden eine Adelsordnung an, welche den Adelsstand reformieren und auf diese Weise zur Überwindung der Krise des Adels

56 Schwinges, Die Universität als sozialer Ort des Adels (Anm. 5), S. 331.

57 Vgl. zu Philipp von Solms-Lich Friedrich Uhlhorn, Die Geschichte der Grafen von Solms zwischen Reformation und Westfälischem Frieden, Darmstadt/Marburg 2011, S. 179-182.

58 Vgl. zum literarischen Werk Uhlhorn, Reinhard Graf zu Solms (Anm. 44), S. 145-201. 
seiner Zeit führen sollte ${ }^{59}$. In zehn Punkten gibt er seinen Standesgenossen Verhaltensweisen an die Hand, wovon zwei die Ausbildung des jung Adel betreffen: An sechster Stelle werden die Adelssöhne dazu aufgefordert, an fremden Höfen die Kunst der Kriegsführung zu erlernen ${ }^{60}$ und an zehnter, also letzter Stelle geht es um die Ausbildung für die zweite grosse Säule adeliger Zweckbestimmung, das Regieren:

So soll der jung Adel sich auff das Studieren geben, dann es steht einem vom Adel wol an, dass er etwas vor einem andern kann. Dan so einer vom Adel etwas weiß, hat es ein grossers Ansehen dann von einem gemeynen Mann und wird gebraucht von den grossen Hern vor einem Andern, der nichts kann, ob er schon vom Adel sey. ${ }^{61}$

Deutlich zeigt sich hier, dass Reinhard von Solms-Lich die Vorrangstellung des Adels nicht allein in seiner hohen Geburt begründen möchte. Wissen präsentiert er als notwendige und daher qualifizierende Variable in der Konkurrenz zwischen Adel und gelehrtem Bürgertum um Stellungen bei den grossen weltlichen und geistlichen Fürsten. Damit greift er einen Diskurs über das Wesen des Adels auf, der seit dem Spätmittelalter intensiv geführt wurde und sich auf «eine Kombination aus auf Herkunft beruhendem Geburtsadel und durch individuelle Leistung unter Beweis gestellte Tugendhaftigkeit» festlegte $^{62}$. Wissen bestätigt also die Führungsrolle des Standes, während nicht vorhandenes Wissen den adeligen Rat und Diener disqualifiziert.

Reinhard postuliert daraufhin, dass Bildung oder Gelehrtheit die Basis für den regierenden Stand sei und alle Adelsränge umfasse:

Wann sie dann also gelehrt seind, so seind sie auff den hohen Stifften sehr annemlich, werden in Reichssachen gebraucht unnd kommen auff den Stifften zu ehrlichen sehr hohen Wirden unnd Stenden, wie man sieht, als Bischof und Churfürsten, welches den gantzen Geschlechtern zu ehren unnd gutem erreicht. Darumb soll der Adel zu allem gezogen werden, in geystlichen und weltlichen, zu Kriegs- unnd zu friedlichen Regimentssachen. So bekompt er

59 Reinhard von Solms-Lich, Beschreibung vom Ursprung, Anfang und Herkhomen des Adels, adelichen Underhaltungen und aufferlegtem gebürlichem Bevelch, wie sich der Adel seinem Tittel nach halten und herwiderumb solle gehalten werden, Köln 1553 und Frankfurt am Main 1563. Der Traktat beruht auf zum Teil ebenfalls publizierten Vorarbeiten, sodass sich die hier entwickelten Gedanken in die erste Hälfte des 16. Jahrhunderts zurückverfolgen lassen. Eine Inhaltsangabe des Traktats befindet sich in Uhlhorn, Reinhard Graf zu Solms (Anm. 44), S. 153-157. Zu einem weiteren Aspekt des Traktats vgl. Barbara Stollberg-Rilinger, Gut vor Ehre oder Ehre vor Gut? Zur sozialen Distinktion zwischen Adels- und Kaufmannsstand in der Ständeliteratur der Frühen Neuzeit, in: Augsburger Handelshäuser im Wandel des historischen Urteils, hg. von Johannes Burkhardt (Colloquia Augustana 3), Berlin 1996, S. 31-45.

60 Reinhard von Solms-Lich, Beschreibung vom Ursprung, Anfang und Herkhomen des Adels ..., Frankfurt am Main 1563, S. 18.

61 Ebd., S. 19.

62 Vgl. zum Tugenddiskurs die 2016 angenommene Habilitationsschrift von Steffen Krieb, Anfang, Ursprung und Herkommen. Studien zu den Erinnerungskulturen des Adels im späten Mittelalter (unveröffentlichtes Manuskript) und darin besonders das Kapitel: Tugend und Erinnerung - Der ritterschaftliche Adel als Aristokratie. Vgl. auch Boehm, Konservatismus und Modernität (Anm. 3), S. 74 f. 
alle Regierung des Reichs under sich. Aber es ist hiemit nicht der gemeyn Adel alleyn vermeynt, sonder hoch und nieder Adel, als Fürsten, Graven unnd Herren mit zugleich. ${ }^{63}$

Gelehrt zu sein wird hier als Grundvoraussetzung vermittelt, dem eigenen Geschlecht zu Ruhm und Ehre zu verhelfen, verfügte doch gerade der Dienst in der Reichskirche über Mobilitätskanäle, die den sozialen Aufstieg ermöglichten. Obwohl er den geistlichen Karriereweg hervorhebt, bezieht er auch die Anforderungen der weltlichen Laufbahnen im Kriegswesen und der weltlichen Herrschaft mit ein.

Für seine Ausführungen verwendet der Graf die Begriffe 〈studieren〉, 〈wissen〉 und 〈gelehrt sein〉. Unter den Begriff des 〈Studierens〉 fasste er nicht nur die Ausbildung der Adelssöhne an eigenen und fremden Höfen durch universitär gebildete Präzeptoren, sondern schloss das Universitätsstudium mit ein, wie die Erziehung seiner eigenen Söhne nahelegt. Während Reinhard seit 1538 in den Diensten der Herzöge von Bayern stand und mit der Befestigung Ingolstadts beauftragt war, immatrikulierten sich drei seiner Söhne, Ernst (1527-1590), Reinhard (1531-1580) und Bernhard (1533-1553), 1539 und 1540 an der dortigen Universität ${ }^{64}$. Bernhard und Reinhard besassen zum Zeitpunkt des Studiums bereits Pfründen im Kölner Domkapitel. Ihr älterer Bruder Ernst, für den zunächst zwar auch eine geistliche Karriere vorgesehen war, hatte nach dem Tod des ältesten Bruders Wilhelm (1525-1537) seine Domherrenpfründe in Köln resigniert ${ }^{65}$ und sollte seinem Vater in der Landesherrschaft folgen. Wie gezeigt werden konnte, etablierte sich innerhalb der Wetterauer Grafenhäuser gerade erst das Universitätsstudium als Bildungsoption auch ausserhalb des geistlichen Standes. In der Jahrhundertmitte finden wir Graf Reinhard von Solms-Lich in dieser Phase des Übergangs, der mit seiner Bildungsaufforderung an die adeligen Standesgenossen auf die Herausforderungen seiner Zeit reagierte. Ernst wurde nicht nur für seine Aufgabe als Landesherr ausgebildet, sondern wurde auch in Reichssachen gebraucht, als er ab 1546 in kaiserliche Dienste trat. Seit 1552 trug er den Titel eines kaiserlichen Truchsesses. Er beteiligte sich militärisch am Schmalkaldischen Krieg und einem Feldzug gegen Frankreich. Auf diesen Aspekt seines Lebens konnte ihn die Universität nicht vorbereiten, eher dürften ihm auf seiner Bildungsreise durch die Niederlande 1545/46 militärische Fähigkeiten vermittelt worden sein. Auch Bernhard und Reinhard gingen 1548 auf Kavalierstour: In Padua studierten sie die Rechte und zogen daraufhin weiter nach Paris. Während Reinhard bis zu seinem Tod 1580 als Domherr in Köln und Mainz ein aufwendiges Leben führte, resignierte Bernhard 1551 seine Kölner Domherrenstelle, trat 1552 dem Deutschen Orden bei und stand ab Juni 1553 in Diensten des Bischofs von Würzburg. Ein weiterer Sohn Reinhards, Eberhard (1530-1600), hätte bei einer Reise nach Paris im Jahr 1551 die Möglichkeit gehabt, die Universität zu besuchen, was aber nicht nachweisbar ist. Er schlug einen

63 Reinhard von Solms-Lich, Beschreibung vom Ursprung, Anfang und Herkhomen des Adels (Anm. 60), S. 19.

64 Sein Pflegesohn Reinhard von Hanau schloss sich ihnen 1541 an.

65 Sie ist an seinen Bruder Reinhard übergegangen. Vgl. Uhlhorn, Die Geschichte der Grafen von Solms (Anm. 57), S. $187 \mathrm{f}$. 
weltlichen Karriereweg ein und wurde schliesslich Landdrost von Westphalen. Der Nachzögling Hermann Adolf (1545-1613) schliesslich ist wiederum u.a. in den Kapiteln zu Köln und Straßburg zu finden, wo er sich später als Calvinist für die Freistellung der Konfession einsetzte. Er wurde am Kölner Domstift erzogen, ist aber in der Universitätsmatrikel nicht auffindbar ${ }^{66}$.

Nach dieser kurzen Analyse des Studierverhaltens und der Lebensläufe dreier Generationen Solms-Licher Grafen ist zumindest auffällig, dass ein Universitätsstudium in der dritten Generation nicht mehr nur für diejenigen Grafen veranlasst wurde, die in den geistlichen Stand treten sollten, sondern auch der vorgesehene Landesherr an einer Universität nachweisbar ist. In der ersten Generation studierten noch beide nachgeborenen Söhne, vermutlich den geistlichen Stand anstrebend. In der zweiten Generation erfolgte kein Universitätsstudium, wofür in der geringen Anzahl männlicher Nachkommen eine Begründung zu finden sein könnte. Von den zwei das Kindesalter überlebenden Söhnen konnten beide aus den Einkünften der Grafschaft in Kombination mit weltlichen Fürstendiensten versorgt werden. Beide heirateten auch und bekamen noch zu Lebzeiten des Vaters Kinder. Dass ihre Aufgabe in der Fortsetzung der Dynastieerhaltung lag, geht klar hervor.

\section{Die Wetterauer Grafen an den Universitäten des Alten Reiches 1450-1550 - Ein Fazit}

Die Bildungsaufforderung Graf Reinhards von Solms-Lich an seine Standesgenossen legt nahe, dass die steigenden Zahlen an studierenden Wetterauer Grafen als Reaktion auf die 〈Standeskrise〉 des Spätmittelalters zu verstehen sind. Mithilfe des Tugendadelsdiskurses fanden individuelle Leistung und gelehrtes Wissen neben der hohen Geburt ihren Platz in der Legitimation der Wetterauer Grafen. Bildung und Leistung wurden als Mittel akzeptiert, die zu ansehnlichen Karrieren vor allem in der Reichskirche, aber zunehmend auch in weltlichen Diensten führten, was wiederum das Ansehen des gesamten Geschlechts erhöhte.

Die Formulierung So soll derjung Adel sich auff das Studieren geben als Aufforderung bedeutet aber auch, dass es in der Ausbildung des gräflichen Nachwuchses in der Mitte des 16. Jahrhunderts nach wie vor Mängel gab. Im Vergleich zu der Periode von 1348 bis 1450 konnte zwischen 1450 und 1550 zwar ein genereller Anstieg der Anzahl der immatrikulierten Wetterauer Grafen an deutschen Universitäten gezeigt werden. Dieses Ergebnis verwundert nicht und passt zu den Ergebnissen der bisherigen Forschung. Ein deutlicher Schub zeichnet sich ab den 1520er-Jahren ab und besonders in den 1540erJahren stiegen die Immatrikulationszahlen noch, was darauf schliessen lässt, dass in der zweiten Jahrhunderthälfte die Wetterauer Grafen noch intensiver die Universitäten des Reichs aufsuchen werden, auch wenn durch Gründungen von Ritterakademien den

66 Vgl. Uhlhorn, Die Geschichte der Grafen von Solms (Anm. 57), S. 246-248. 
Universitäten Konkurrenz erwuchs ${ }^{67}$. Aber nicht nur die Zahl der studierenden Wetterauer Grafen nahm zu, sondern auch die Zahl der Kernfamilien, die ein Universitätsstudium in das Ausbildungsprogramm ihrer Söhne integrierten. Familien, die sich für eine universitäre Ausbildung entschieden, schickten im Durchschnitt etwa die Hälfte ihrer Söhne zum Studieren. Universitäten wurden in diesem hochadeligen Kreis langsam salonfähig und das Studium Teil der Strategie, sich gegen das gelehrte Bürgertum, aber auch gegen den zunehmend universitätsgebildeten Niederadel im Kirchen- und Fürstendienst zu behaupten sowie eine solide Basis gegen die Landgrafen von Hessen auszubauen. Jedoch spielten auch in der Jahrhundertmitte in immer noch etwa $40 \%$ der Grafenfamilien die deutschen Universitäten für die Ausbildung keine Rolle. Es ist an dieser Stelle allerdings kaum nötig darauf hinzuweisen, dass diese Familien nicht grundsätzlich geistig desinteressiert waren, sondern im Gegenteil sehr viel Wert auf eine sorgfältige Ausbildung ihrer Nachkommenschaft legten, wie an zahlreichen Erziehungsinstruktionen abzulesen ist. Allerdings bedurfte eine Vorbereitung auf höfische oder militärische Aufgaben kaum einer universitären Ausbildung. Adelserziehung fand auch im 15. und 16. Jahrhundert in der Regel noch immer an den Höfen statt.

Das Studium blieb zwischen 1348 und 1520 weitestgehend eine Erziehungsform für den geistlichen Stand. Die meisten studierenden Wetterauer Grafen waren an den grossen Domstiften bepfründet und leisteten bei zu geringer Vorbildung ihr Pflichtstudium im Rahmen des bienniums einfachheitshalber an der Universität Köln ab. Erst ab 1520 lassen sich Tendenzen der Verweltlichung beobachten und gleichzeitig stieg die Zahl der unbepfründeten immatrikulierten Grafen, was ein deutlicher Hinweis auf die aufkommenden Versorgungsprobleme der nicht für die Landesherrschaft vorgesehenen Söhne ist. Das Universitätsstudium begann sich schon vor dem Ausgreifen der Reformation auf die Wetterauer Grafen und Grafschaften von der geistlichen Laufbahn zu lösen.

DerAnstieganImmatrikulationen lässtsichnichtdamiterklären, dass einUniversitätsstudium zur Übernahme von hohen geistlichen oder weltlichen Ämtern grundsätzlich nötig war. Die Universitäten des Reiches wurden für etwa die Hälfte der Wetterauer Grafenfamilien Orte der Aneignung von zusätzlichem gelehrtem Wissen - freilich ohne dabei Abschlüsse zu erwerben -, wenn der Erhalt der Dynastie unsicher erschien. Dass Universitätsbesuche als Stationen der adeligen Bildungsreise bereits vor der zweiten Hälfte des 16. Jahrhunderts zum Standesausweis wurden ${ }^{68}$, spielte auch eine Rolle, wobei die Wetterauer Grafen noch wenigen ihrer Nachkommen ausgedehnte Kavalierstouren ermöglichten. Die hohe Frequentierung der Universitäten in Köln, Erfurt und Heidelberg zeigt aber, dass es dieser Gruppe bei der Wahl der Studienorte zu einem

67 Die zwei folgenden Generationen Solmser Grafen der Linien Solms-Lich und Solms-Braunfels schickten zum Beispiel alle ihre Söhne auf mindestens eine Universität im Reich, zumeist Heidelberg und Basel. Die Akademie in Genf und die Hohen Schulen in Straßburg und Herborn spielten daneben eine wichtige Rolle. Es folgten ausgedehnte Kavalierstouren. Vgl. J. C. Schaum, Das Grafen- und Fürstenhaus Solms ist gleichzeitig mit dem Hause Nassau aus Salischem KönigsStamme erblühet ..., Frankfurt am Main 1828, S. 135-161; Uhlhorn, Die Geschichte der Grafen von Solms (Anm. 57), S. 285 und 331 f. Der im Haus Solms sehr ausgeprägte Studieneifer hängt sicherlich auch mit der Dynastiegrösse zusammen.

68 Grundlegend zur Adelsreise Paravicini, Von der Heidenfahrt zur Kavalierstour (Anm. 12), S. 146 f. 
nicht unbedeutenden Teil um Nähe und Erreichbarkeit ging; die steigenden Zahlen von Immatrikulationen an Universitäten im Reich also aus einer Kombination des wachsenden Angebots universitärer Bildungseinrichtungen in der Nähe und der Einsicht in die Nützlichkeit von gelehrten universitären Wissen resultierte. 


\section{Ladislaus Ulricher, Professor der Theologie}

\section{Ein gelehrter Betrüger an der Universität Basel (um 1500)}

Durch die heute zur Verfügung stehenden technischen Mittel ist es ein Leichtes geworden, Plagiate zu entlarven und vermeintliche Doktoren des Betrugs zu überführen. So manche Personen des öffentlichen Lebens mussten das schmerzlich erfahren, ihnen wurden die akademischen Grade aberkannt und sie mussten von ihren Ämtern zurücktreten. Es ist also kaum mehr möglich, mit einer nicht eigenhändig verfassten Arbeit einen universitären Grad zu erwerben, können doch die eingereichten Arbeiten mittels spezieller Software auf Plagiate geprüft werden.

Selbstredend standen solche Mittel einer mittelalterlichen Universität nicht zur Verfügung. Auch war das Verständnis für Plagiate ein anderes. Eigentlich gab es gar keines, wurden doch Texte einfach abgeschrieben, ohne die Quelle zu nennen. Zur Erlangung der Grade mussten auch keine Qualifikationsarbeiten eingereicht, sondern Prüfungen abgelegt respektive Disputationen abgehalten werden. Von den Dekanen der jeweiligen Fakultäten wurden dann Zeugnisse ausgestellt, die dem Kandidaten seine Studien und Grade bestätigten. Solche Studien- respektive Abschlusszeugnisse waren auch nötig, denn anhand der Daten im RAG lässt sich für rund $11 \%$ der Studenten des Alten Reiches zwischen 1250 und 1550 mindestens ein Universitätswechsel nachweisen ${ }^{1}$. An der neuen hohen Schule angekommen, konnten sich die Studenten mittels Zeugnissen über ihre erworbenen Grade ausweisen. Lange Zeit vor europäischen Austauschprogrammen herrschte also schon eine gewisse Mobilität unter den Studenten. Dabei wird zwischen einer internen und einer externen Mobilität unterschieden, also danach, ob die Studenten eine Universität im eigenen Land oder eine im Ausland besuchten. Die interne Mobilität überwiegt dabei zahlenmässig, konnten sich doch nur Gutbetuchte ein Studium im Ausland leisten. Diese fassten vor allem das Studium der Jurisprudenz ins Auge, während die überwiegende Menge der Studenten im Reichsgebiet an der Artistenfakultät

1 Von insgesamt 57'713 im RAG verzeichneten Immatrikulationen ist bei 6'168 ( 11\%) ein Immatrikulationsgrad verzeichnet und somit ein Universitätswechsel (oder seltener eine erneute Immatrikulation an der gleichen Universität) nachgewiesen. Jedoch konnten mehrmalige Immatrikulationen ohne verzeichneten Immatrikulationsgrad nicht berücksichtigt werden, ebenfalls nicht enthalten sind Wechsel an Universitäten ausserhalb des Reiches, da im RAG in diesen Fällen keine Immatrikulation, sondern ein Studium verzeichnet wird. Repertorium Academicum Germanicum (RAG), [www.rag-online.org], 6.3.2018; Studentische Migration spielte sich grösstenteils zwischen dem Herkunftsund einem Universitätsort ab, nur 10-20\% aller Studenten besuchten je eine zweite Universität, nur 2-5 \% mehr als zwei Universitäten. Rainer C. Schwinges, Migration und Austausch: Studentenwanderungen im Deutschen Reich des späten Mittelalters, in: Studenten und Gelehrte. Studien zur Sozial- und Kulturgeschichte deutscher Universitäten im Mittelalter, hg. von Rainer C. Schwinges (Education and Society in the Middle Ages and Renaissance 32), Boston/ Leiden 2008, S. 119-134, hier S. 122. 
verblieb. Es überrascht also wenig, dass adlige Studenten und Angehörige des städtischen Patriziats sowie Mitglieder aus Dom- und Kanonikerstiften am häufigsten die Universität wechselten. Bezüglich der internen Mobilität lassen sich einige Charakteristika festhalten: Die allermeisten Universitätsbesucher wählten die von ihrem Herkunftsort aus nächstgelegene Hochschule, was dazu führte, dass jede Universität ein räumlich begrenztes Einzugsgebiet hatte. Besonders im Süden des Reiches gestalteten sich die Einzugsräume aufgrund der hohen Universitätsdichte klein, standen doch mit Heidelberg, Freiburg i. Br., Basel, Ingolstadt und Tübingen gleich fünf Universitäten auf engem Raum zur Verfügung, die, mit Ausnahme von Heidelberg, erst noch alle zwischen 1460 und 1477 eröffneten. Für die Wahl der Universität waren vor allem soziale Faktoren ausschlaggebend. Nahgelegene Universitäten wurden nicht zuletzt deswegen frequentiert, weil familiäre und persönliche Bindungen am Studienort bedeutsam waren. So konnte sich ein Student auf ein soziales System verlassen, welches ihm etwa tiefere Lebenshaltungskosten oder Zugang zu einer Pfründe ermöglichte. Diese Beziehungen blieben vielfach auch im späteren Berufsleben erhalten, welches sich ebenfalls oft im gleichen geografischen Raum wie das Studium abspielte. Wechselten nun die Studenten die Universität, so taten sie das ebenfalls meist innerhalb eines begrenzten geografischen Raumes. Typische Stationen sind so beispielsweise Basel und Freiburg i. $\mathrm{Br}^{2}$. Ebenfalls entstanden so Beziehungen zwischen den Herkunfts- und den Universitätsorten, was sich etwa in der Errichtung von Stiftungen und Stipendien ausdrückte, die am Herkunftsort für künftige Studenten eingerichtet wurden ${ }^{3}$. Bei einer erneuten Immatrikulation an einer anderen Universität wurde der mit einem Studienzeugnis belegte Grad oft in die Rektoratsmatrikel eingetragen, auch wurden häufig Rezeptionen in die Fakultäten vorgenommen, meist ab Stufe der baccalaurii ${ }^{4}$. Diese indirekten Belege zeugen von den vielen Studienzeugnissen,

2 Zwischen 1460 und 1550 sind im RAG 240 Personen verzeichnet, die sich sowohl in Freiburg i. Br. und auch in Basel einschrieben. In der gleichen Zeit immatrikulierten sich in Freiburg i. Br. 2'192 Personen, in Basel 1'514. RAG (Anm. 1), 6.3.2018.

3 Hilde de Ridder-Symoens, Mobilität, in: Geschichte der Universität in Europa Bd. 1 Mittelalter, hg. von Walter Rüegg, München 1993, S. 255-273; Rainer C. Schwinges, Akademische Mobilität in der älteren Vormoderne (1350-1550), in: traverse (2018), Nr. 1, S. 27-41; ders., Migration und Austausch (Anm. 1), 119-134.

4 Im RAG sind 4'409 Rezeptionen verzeichnet, davon weisen 2'438 einen Rezeptionsgrad auf, 1'235 auf Baccalarstufe. $R A G$ (Anm. 1), 6.3.2018. Eine Rezeption diente der sogenannten Lozierung, also der Festlegung der Reihenfolge. Dabei wurde überprüft, ob die Neuankömmlinge auch das verlangte Wissen aufweisen konnten und entsprechend dem Abschneiden in der Prüfung wurden sie eingereiht. Doch nicht nur das Wissen spielte eine Rolle, wie immer wurde auch der soziale Status berücksichtigt, sodass Adlige oft auf den vorderen Plätzen zu finden sind. Der Platz in der Lozierung spielte eine wichtige Rolle, etwa wenn es um die Verteilung von lukrativen Vorlesungen ging. Das Vorgehen bei einer Rezeption drückt aus, dass ein Studienzeugnis zwar wichtig war, die Universitäten sich aber auch ihr eigenes Urteil bilden wollten, was bis heute mit Aufnahmeprüfungen und Probevorträgen Bestand hat. Die licentia ubique docendi galt also nicht uneingeschränkt. Vgl. Marian Füssel, Ritus Promotionis. Zeremoniell und Ritual akademischer Graduierungen in der frühen Neuzeit, in: Examen, Titel, Promotionen. Akademisches und staatliches Qualifikationswesen vom 13. bis zum 21. Jahrhundert, hg. von Rainer C. Schwinges (Veröffentlichungen der Gesellschaft für Universitäts- und Wissenschaftsgeschichte 7), Basel 2007, S. 411-450, hier S. $430 \mathrm{f}$. 
die ausgestellt worden sein müssen, heute sind diese aber längst nicht mehr alle erhalten, sodass nicht sicher angenommen werden kann, dass alle bei der Immatrikulation angegebenen Grade auch wirklich erreicht worden waren ${ }^{5}$.

Hier soll mit Ladislaus Ulricher ein Beispiel vorgestellt werden, in welchem es dem Betrüger einige Jahre gelang, trotz erfundener Abschlüsse erfolgreich an der theologischen Fakultät Basels Fuss zu fassen. Dieser Fall zeigt, dass Studienzeugnisse nicht immer vorgelegt wurden, in aller Regel aber schon darauf bestanden wurde. Wie oft keine Beweise für die erworbenen universitären Grade eingereicht wurden, lässt sich nicht quantifizieren, wohl handelte es sich um ein seltenes Vorkommnis. Für den vorliegenden Fall müssen verschiedene Faktoren genauer beleuchtet werden: zum einen Ulrichers Biografie, weiter die Zustände in der theologischen Fakultät Basels in der fraglichen Zeit sowie der Ablauf einer theologischen Doktorpromotion und der Weg dorthin. Ein Augenmerk soll auch auf den nicht universitären Bildungsinstitutionen des Mittelalters liegen, denn Ulricher musste sicherlich vorgebildet sein, sonst wäre sein Betrug bereits viel früher ans Tageslicht gekommen.

\section{Ulrichers Biografie}

Der vermeintliche baccalaureus formatus theologiae und magister artium Ladislaus Ulricher immatrikulierte sich im Wintersemester 1502/03 in Basel. Ulricher stammte aus Veldenz in der Diözese Trier und gab in Basel an, er habe in Köln studiert und dort den Magistergrad sowie auch den Grad eines baccalaureus formatus erworben ${ }^{6}$. Er versäumte es jedoch die ganze Zeit über, dem Dekan und einzigem Doktor der theologischen Fakultät, Mauricius Fininger, die entsprechenden Zeugnisse vorzulegen. So wurde Ulricher ohne die Belege über seine Qualifikationen in die theologische Fakultät rezipiert und sogar am 15. Januar 1504 zum Doktor der Theologie promoviert ${ }^{7}$. Dieser Grad ist denn auch die einzig wirklich erlangte universitäre Qualifikation von Ladislaus Ulricher. Vielfach war die Erlangung eines Doktorgrades aber auch eine hauptsächlich finanzielle Angelegenheit.

5 Ein Beispiel für ein noch erhaltenes Studienzeugnis ist jenes des Grafen Bernhard von Solms, der sich am 20. Oktober 1450 in Köln an der juristischen Fakultät immatrikulierte. Ausgestellt wurde es am 23. August 1451. Der Graf brauchte das Zeugnis nicht, um erworbene Grade zu belegen, er konnte zu diesem Zeitpunkt auch noch keine aufweisen, sondern er benötigte es wahrscheinlich als Nachweis für seine Studienzeit. Das sogenannte biennium (eigentlich war eine zweijährige Studienzeit vorgesehen) war oft eine Voraussetzung für die Aufnahme in einem Domstift. Das Zeugnis liegt im Kölner Stadtarchiv. Hubert Graven, Die Hoheitszeichen der alten Kölner Universität im Zusammenhang mit dem Geistesleben und der Kunst, in: Festschrift zur Erinnerung an die Gründung der alten Universität Köln im Jahre 1388, hg. von Hubert Graven, Köln 1938, S. 384-459, hier S. 425; RAG (Anm. 1), Bernhard von Solms-Braunfels (Graf) - UniquID: ngSI5h779S85dhoKmTLh1QeN, 1.5.2018.

6 Hans-Georg Wackernagel (Hg.), Die Matrikel der Universität Basel, Bd. 1: 1460-1529, Basel 1951, S. 267 , Nr. 9.

7 Wilhelm Vischer, Geschichte der Universität Basel von der Gründung 1460 bis zur Reformation 1529, Basel 1860, S. 223; Staatsarchiv Basel, Sig. Universitätsarchiv O 3, Matricula facultatis theologicae (Matrikel der Theologischen Fakultät), fol. $23 \mathrm{r}, 24 \mathrm{r}$. 
Ladislaus Ulricher wurden aber die Kosten in Anbetracht seiner finanziellen Situation erlassen ${ }^{8}$. Schon vor seiner Promotion nahm Ulrichers scheinbar glanzvolle Karriere ihren Lauf. So wurde er am 8. Juni 1503 von Bürgermeister und Rat Basels auf eine Lektur an der theologischen Fakultät verpflichtet, welche mit einer Chorherrenpfründe zu St. Peter einherging, die der zuvor verstorbene Doktor der Theologie, Michael Wildeck ${ }^{9}$, innegehabt hatte. Ulricher verpflichtete sich bei seiner Bestallung dazu, seine Doktorpromotion abzulegen und jeden Tag Vorlesung zu halten, ansonsten hätte er die Pfründe wieder aufgeben müssen ${ }^{10}$. Ulricher schien auch fachlich zu überzeugen oder aber er verkaufte sich besonders gut. Anders ist es nicht zu erklären, dass Adam von Müllberg ${ }^{11}$, der Rektor der Universität im Wintersemester 1503/04, Ulricher als berühmten Theologen pries, als er nach dem Ende der Pestwelle die Universität wieder eröffnete ${ }^{12}$. Schliesslich wurde Ulricher das höchste Amt der Universität übertragen, im Sommersemester 1504 wurde er Rektor ${ }^{13}$. Sein Rektoratswappen war jedoch genauso erfunden wie seine akademischen Grade. Die Malerei wurde ausserdem nicht eben kunstvoll ausgeführt ${ }^{14}$. Ebenfalls 1504 war er Vizedekan und 1506 auch Dekan der theologischen Fakultät ${ }^{15}$.

Noch im selben Jahr stellte sich heraus, dass Ulricher seine angegebenen Grade gar nie erlangt hatte, er war nie in Köln zum Studium gewesen. Nach der Aufdeckung dieses Skandals zog es Ulricher vor, aus Basel zu verschwinden, seine Spur verliert sich an dieser Stelle. Auch die Quellen geben keine weiteren Auskünfte über den Abgang und den Verbleib Ulrichers. In der Urkunde, in welcher Ulrichers Nachfolger Johannes Gebwiler ${ }^{16}$ sich verpflichtet, die Chorherrenpfründe zu St. Peter, die vorher von Ulricher besetzt war, getreu zu versehen, heisst es lediglich: das Canonicat vnnd pfründ zu der Stifft zu Sannt peter zu Basel So Doctor Ladißlaus Vlricher bißher in besitz gehept hat, vnnd aber die selb pfründ vnnd Canonicatv $\beta$ iedlichen vrsachen [...] ledig worden sind ${ }^{17}$. Um welche Ursachen es sich aber genau handelte, bleibt im Dunkeln, auch im Professorenkatalog steht zu Ulrichers Abgang lediglich: postea cum scandalo

8 Vischer, Universität Basel (Anm. 7), S. 223.

9 RAG (Anm. 1), Michael Wildeck - UniquID: ngLB7S678L74uahPfL8a6JxK, 1.5.2018.

10 Staatsarchiv Basel, Sig. St. Urk. 2584, St. Urk. 2585.

$11 R A G$ (Anm. 1), Adam von Müllberg - UniquID: ngLB2K476K529ahXfLUa8, 1.5.2018.

12 Vischer, Universität Basel (Anm. 7), S. 223.

13 Wackernagel, M Basel Bd. 1 (Anm. 6), S. 273.

14 Das Wappen ist von grünen und roten Randleisten gefasst und wird von einem Löwen getragen. Verwendete Symbole sind ein Herz, ein perspektivisch missglücktes Buch, ein Rad, zwei Schlangen und ein Schwert. Paul Leonhard Ganz, Die Miniaturen der Basler Universitätsmatrikel, Basel/Stuttgart 1960, S.114 f.

15 Wackernagel, M Basel Bd.1 (Anm. 6), S. 369, Nr.28; Vischer, Universität Basel (Anm. 7), S. 223.

$16 R A G$ (Anm. 1), Johannes Gebwiler - UniquID: ngQG0L375QI14fmYkRZfzOcH, 1.5.2018.

17 Staatsarchiv Basel, Sig. St. Urk. 2631. 
a Basilea recessit ${ }^{18}$. Später wurde Ulricher oft mit dem Zusatz Protheus bezeichnet, wohl eine negative Konnotation, die den Betrug Ulrichers mit dem sich wandelnden Gott vergleicht ${ }^{19}$.

\section{Die Situation der Universität Basel mit besonderer Berücksichtigung der theologischen Fakultät}

Die Gründung der Universität Basel war einerseits durch die wirtschaftsgeografisch gute Lage am Rhein wie auch durch das vorangehende Ereignis des Konzils begünstigt. Bereits im zweiten Jahr des Konzils, 1432, entwickelte sich in dessen Umfeld eine Universität. Nicht alle am Konzil Beteiligten waren durch dieses vollständig ausgelastet und konnten so ihre Studien fortsetzen oder ein neues Studium beginnen. Die Konzilsuniversität orientierte sich in ihrer Organisationsform an den Universitäten von Paris und Bologna. Ganze 18 Jahre lang existierte dank dem Konzil in Basel eine Universität. Mit dem Ende der Kirchenversammlung 1449 war jedoch auch das Ende der Lehrinstitution gekommen. Viele, die in der Konzilsuniversität Ämter bekleidet hatten, blieben auch nach dem Ende des Konzils in der Stadt, mit ihnen lebte die Idee der Errichtung einer neuen städtischen Universität weiter. Ein weiterer wichtiger Schritt hin zur Errichtung einer Universität in der Rheinstadt war die Wahl von Enea Silvio Piccolomini ${ }^{20}$ zum Papst Pius II. Er war zur Zeit des Konzils als Sekretär in Basel tätig und behielt die Stadt in guter Erinnerung, ebenfalls war er umgekehrt vielen Bürgern bekannt. Basel schickte seinen Bürgermeister Hans von Flachsland ${ }^{21}$ nach Rom, um dem neuen Papst zu gratulieren und ihn gleichzeitig um die Stiftung einer Universität zu bitten. Der Papst war dem Vorhaben günstig gesinnt und stimmte der entsprechenden Bittschrift mündlich zu.

Die Kosten für die Errichtung der Universität wurden von in Basel ansässigen Universitätsabgängern geschätzt, jedoch schwankten die Schätzungen zwischen 600 und 3000 Gulden. Für die Basler schien es also unumgänglich, sich beim Papst Privilegien für den Pfründenzugang von Universitätsangehörigen sichern zu lassen, sollte doch der grösste Teil der Kosten für das Lehrpersonal von der Kirche getragen werden. Am 12. November 1459 wurde die Stiftungsbulle für die neue Universität ausgestellt, noch im gleichen Jahr inkorporierte der Papst der Universität vier Basler und fünf auswärtige Pfründen. Dennoch gab es in der Bürgerschaft und im Rat Basels Bedenken bezüglich der Finanzierbarkeit der Universität, diese wurden aber bald ausgeräumt, da

18 Johann Werner Herzog, Athenae Rauricae. Sive Catalogus professorum Academiae Basiliensis ab MCCCCLX ad A.MDCCLLXXVIII cum brevi singulorum biographia. Adiecta est recensio omnium eiusdem academiae rectorum, Basel 1778, S. 6, Nr. XI.

19 Ganz, Miniaturen (Anm. 14), S. 114

20 RAG (Anm. 1), Pius (Papst) - UniquID: ngWM3N577V63glsSqV710UiZ, 1.5.2018; Volker Reinhardt, Pius II. Piccolomini. Der Papst, mit dem die Renaissance begann, München 2013.

$21 R A G$ (Anm. 1), Johannes von Flachslanden - UniquID: ngWM6p173VE921sKqXPlgUil, 1.5.2018. 
extra engagierte Sachverständige, ihrerseits Gelehrte von anderen Universitäten, die materiellen Vorteile herausstrichen, die der Bürgerschaft zugutekommen würden. Denn die vielen erwarteten Studenten und ihre Begleiter würden viel Geld in der Stadt ausgeben. Diese Rechnung ging jedoch in vielerlei Hinsicht nicht auf. Die erhofften tausend Personen, die sich auf einmal zu Studienzwecken in der Stadt aufhalten sollten, wurden niemals in solch hoher Zahl angelockt, ebenfalls reiste nicht die gewünschte Klientel nach Basel. Statt der vielen wohlhabenden Juristen wurde die Universität Basel zu rund $80 \%$ von Artisten besucht, von welchen die allerwenigsten über 20 Gulden jährlich verfügen konnten. Zwar passierten durchaus einige Studenten auf ihrem Weg nach Italien die Rheinstadt, jedoch meist ohne sich an der Universität einzuschreiben $^{22}$. Die Universität Basel entwickelte sich also von allem Anfang an nicht zu jenem Gelehrtenhotspot, welchen sich die Stadt versprach. Im ersten Jahrzehnt befanden sich im Schnitt 260 Personen gleichzeitig in Basel, in den beiden folgenden Dekaden sank diese Zahl auf 230 respektive 220. Deutlich ist eine stetige Abnahme, die Frequenz unterliegt jedoch starken Schwankungen ${ }^{23}$. Basel war jedoch die einzige Universität des Reiches, die bis zur Reformation einem stetigen Frequenzrückgang unterworfen war ${ }^{24}$.

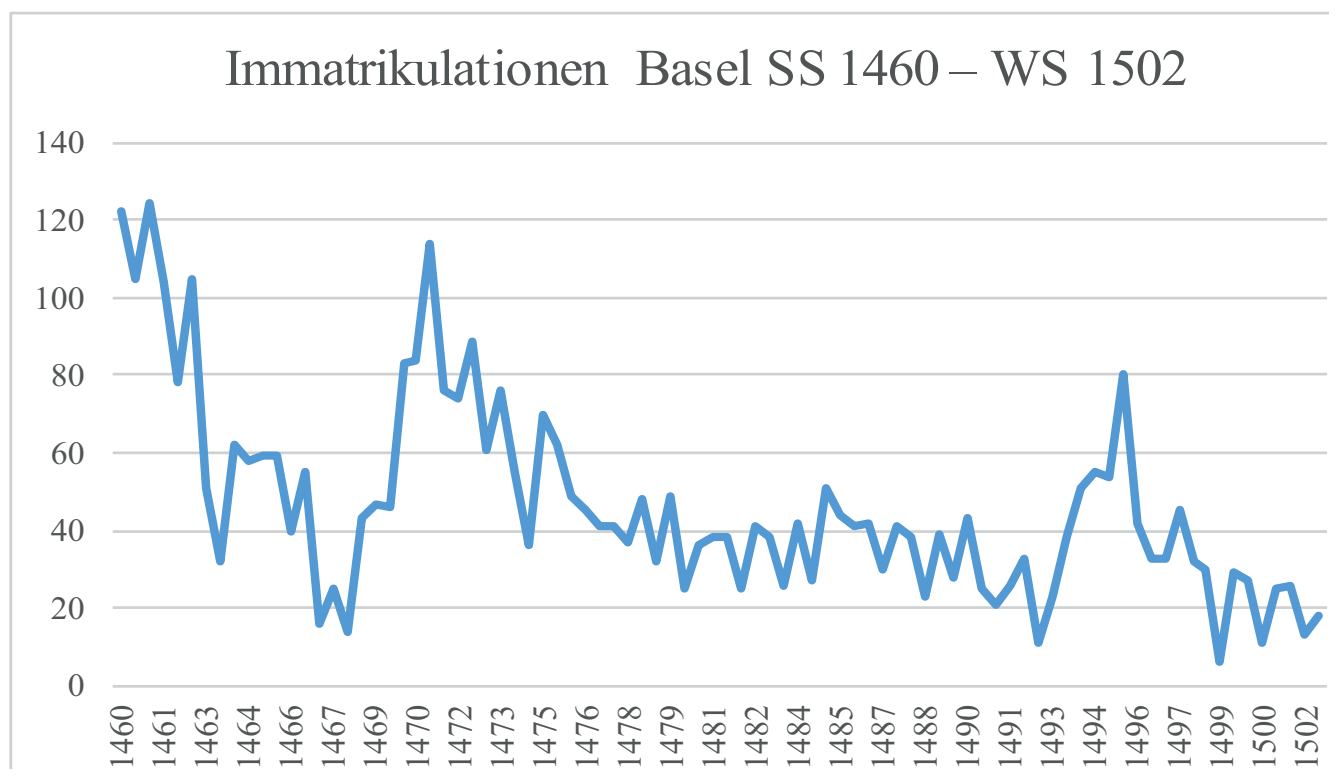

Abb. 1 Die Immatrikulationen der Universität Basel pro Semester von 1460 bis 1502

22 Edgar Bonjour, Die Universität Basel von den Anfängen bis zur Gegenwart. 1460-1960, Basel 1960, S. $21-35$.

23 Wackernagel, M Basel Bd.1 (Anm. 6), S. 3-268.

24 Rainer C. Schwinges, Basel in der europäischen Universitätslandschaft um 1500, in: Gelehrte zwischen Humanismus und Reformation. Kontexte der Universitätsgründung in Basel, hg. von Martin Wallraff (Litterae et Theologia 2), Berlin/ Boston 2011, S. 21-46, hier S. 41. 
Der Frequenzrückgang an der Universität Basel hatte verschiedene Gründe. Gleich nach der Eröffnung wurde die Hohe Schule bereits arg konkurriert. Ebenfalls 1460 nahm die Universität Freiburg i. Br. ihren Betrieb auf, Trier und Ingolstadt folgten 1472, Tübingen und Mainz 1477. Abgesehen von der Eröffnungsklientel, welcher viele Personen nur ehrenhalber angehörten und die gar nie in Basel zu studieren gedachten, blieben die Immatrikulationszahlen in Basel tief. So enttäuschend dieser Verlauf für die Gründer war, kann trotzdem aus dem Vergleich mit anderen Universitäten abgelesen werden, dass rund 100 Neuimmatrikulationen pro Jahr für eine Stadt wie Basel mit 8000 Einwohnern normal waren. Negativ wirkten sich jedoch die Sezessionsbemühungen der Basler Juristenfakultät zwischen 1462 und 1477 aus, die, nach italienischem Vorbild, einen eigenen Rektor aus ihren wohlhabenden und oftmals adligen Reihen bestimmen wollte. Die Stadt liess die Juristen erst gewähren, schliesslich sollte ja gerade diese Klientel die Universität besuchen. Die anderen drei Fakultäten protestierten gegen dieses Vorhaben, allen voran die zahlenmässig bedeutsamen Artisten, deren Professoren nun von der Rektorwürde ausgeschlossen waren. Dieser interne Streit über den Rang der Fakultäten innerhalb einer Universität vom deutschen Vier-Fakultäten-Typ konnte sich nur negativ auf die Frequenz auswirken. 1480/81 griff die Stadt jedoch ein und beendete den Streit mit einer neuen Wahlordnung. Um den Frequenzrückgang zu stoppen, war es aber dann schon zu spät und die Gesamtuniversität konnte, im Gegensatz zur Konkurrentin in Freiburg i. Br., bis zur Reformation nicht mehr neu belebt werden. Bei der Gründung vermochten die Proargumente aber trotzdem zu überzeugen, die Stadt hatte schon einiges investiert und wollte auch ihr Ansehen gegenüber dem Papst wahren, ausserdem waren manche Komplikationen auch nicht vorhersehbar. ${ }^{25}$

Weitere prägende Ereignisse, die zu einem Rückgang führten, waren die Burgunderund Schwabenkriege, wobei sich vor allem Letztere negativ auswirkten, weil viele süddeutsche Studenten der Universität den Rücken kehrten. Auch der Beitritt zur Eidgenossenschaft 1501 hatte ähnliche Folgen, da der Zustrom aus dem Norden merklich abnahm und nicht durch einen solchen aus dem Süden kompensiert wurde ${ }^{26}$. Ereignisse, die alle Bildungsinstitutionen zu spüren bekamen, waren etwa Seuchenausbrüche und die wirtschaftliche Situation. Gegen Ende des 15. Jahrhunderts machte sich ausserdem das Phänomen der ersten Überfüllungskrise an den deutschen Universitäten bemerkbar. Die Bevölkerungszahl im Reich war in den Pestwellen deutlich zurückgegangen, dennoch wurden so viele Universitätsbesucher verzeichnet wie nie zuvor. Doch weder die weltlichen noch die kirchlichen Institutionen vermochten diese auf einmal vorhandene Masse an Gelehrten zu absorbieren. Dieser Umstand führte dazu, dass das Interesse an einer universitären Ausbildung wieder sank und damit auch die Studentenzahlen. Der schlussendlich grösste Einbruch führte die Reformation herbei, das vor allem, weil die Vielzahl an Pfründen wegbrach, die bislang so vielen ein Studium ermöglicht hatte. Erst im 19. Jahrhundert wurde das Ni-

25 Ebd., S. 43-46.

26 Bonjour (Anm. 22), S. 70 f. 
veau der vorreformatorischen Immatrikulationen wieder erreicht ${ }^{27}$. Auch für Basel, welches 1529 zum neuen Glauben übertrat, wirkte sich die Reformation gravierend aus. Im Wintersemester 1528/29 besuchten gerade noch zwei Studenten die Universität ${ }^{28}$. Diese schloss daraufhin ihre Tore und eröffnete erst im Frühling 1532 wieder.

In den letzten zwei Jahrzehnten des 15. Jahrhunderts spielte die theologische Fakultät Basels eine eher untergeordnete Rolle innerhalb der Universität. So war oft nur ein einziger Doktor in der Fakultät, der dann auch gleichzeitig einziger Ordinarius und Dekan der Theologen war. Die anfänglichen Statuten aus dem Jahr 1462 hatten einen solchen Fall gar nicht bedacht ${ }^{29}$. Erst ein späterer Zusatz legte fest, wie die Verwaltung der Fakultät gehandhabt werden sollte, wenn ausser dem Dekan kein anderer Doktor in der Fakultät war. Diese Situation trat häufiger auf. Sie ist einem Abkommen zu verdanken, welches von Rektor Johannes von Berwangen ${ }^{30} 1474$ mit dem Basler Rat geschlossen wurde. Darin verpflichtete sich Letzterer nur zur Besoldung eines einzigen Ordinarius in der theologischen Fakultät. Bei diesem einzigen Professor blieb es dann die meiste Zeit über. Die Liste der städtisch besoldeten Dozenten der Universität Basel gibt Auskunft, welche Theologieprofessoren von der Stadt bezahlt wurden. Nach 1474 sind das lediglich Johannes Heynlin de Lapide ${ }^{31}$ für die Jahre 1477/78, dann Johannes Gebwiler von 1506/07 bis 1522/23 sowie Mauricius Fininger $^{32}$ für die Zeit von $1507 / 08$ bis $1522 / 23$. Zwischen $1477 / 78$ und 1506/07 wurde also gar kein Professor besoldet, folglich mussten diese ihr Einkommen vor allem durch Pfründen bestreiten ${ }^{33}$.

Die Universität Basel erhielt bei ihrer Eröffnung und auch später wiederholt Universitätspfründen durch päpstliche Privilegien zugesichert, was jedoch noch lange nicht bedeutete, dass die Universität die Pfründen auch wirklich mit ihren Leuten besetzen konnte. Die Interessen der Kanoniker- und Domherrenstifte und der Universität differierten zu stark, sodass die Stifte die Pfründen lieber in ihrem Sinn besetzten. Auch waren der Universität zugesprochene Pfründen vielfach noch besetzt oder noch

27 Schwinges, Rainer C., Die Immatrikulationsfrequenz, in: Die Geschichte der Universität in Europa. Bd. 1 Mittelalter, hg. von Walter Rüegg, München 1993, S. 174-179; ders., Universitätsbesuch im Reich vom 14. zum 16. Jahrhundert: Wachstum und Konjunkturen, hg. von Rainer C. Schwinges (Education and Society in the Middle Ages and Renaissance 32), Boston/Leiden 2008, S. 87-118; Beat Immenhauser, Bildungswege-Lebenswege. Universitätsbesucher aus dem Bistum Konstanz im 15. und 16. Jahrhundert (Veröffentlichungen der Gesellschaft für Universitäts- und Wissenschaftsgeschichte 8), Basel 2007. S. 38-71.

28 Wackernagel, M Basel Bd.1 (Anm. 6), S. 364.

29 Staatsarchiv Basel, Sig. Universitätsarchiv O 1, Statutarium facultatis theologicae (Statuten der Theologischen Fakultät; darin: Katalog der doctores promoti 1675-1820).

$30 R A G$ (Anm. 1), Johannes von Berwangen - UniquID: ngEU1D779FM5otayyD9t7CqP, 1.5.2018.

31 Ebd., Johannes Heynlin de Lapide - UniquID: ngSI3p173RK9ehoAmR3h1, 1.5.2018.

32 Ebd., Mauricius Fynnynger - UniquID: ngRH3I072QJ80gnV1SAgdPdQ, 1.5.2018.

33 Josef Rosen, Die Universität Basel im Staatshaushalt 1460 bis 1535. Die Gehälter der Dozenten, in: Finanzgeschichte Basels im späten Mittelalter: gesammelte Beiträge 1971-1978, hg. von Josef Rosen, Stuttgart/Wiesbaden 1989, S. 177-179, 183. Die schon angesprochenen Hieronymus Gebwiler und Mauritius Finninger erhielten 25 respektive 20 Pfund jährlich. Gebwiler erhielt jedoch gleich nach Stellenantritt auch ein Kanonikat an St. Peter. Zum Zeitpunkt der Universitätsgründung 1460 galten 20 Gulden (rund 25 Pfund) als typischer Jahresaufwand für einen Studenten. 
schwerer als ohnehin schon mit Universitätsangehörigen $\mathrm{zu}$ besetzen, weil sie nicht im Einflussgebiets Basels lagen. Das betraf Pfründen in Zürich, Bern, Solothurn und Zofingen. Daran änderte auch der Beitritt Basels zur Eidgenossenschaft 1501 wenig $^{34}$. Innerhalb Basels war die Universität erfolgreicher, wurde doch das Stift St. Peter am 18. Januar 1463 ganz in die Universität inkorporiert. Auch nach diesem Datum wurden die Kandidaten der Universität nicht immer berücksichtigt. Dennoch konnte die Universität ihren Einfluss auf die Investitur der Chorherren stärken. Da die Streitigkeiten über die Besetzung der Pfründen nie ganz beigelegt wurden, liess sich der Rat schlussendlich am 22. Juni 1504 darauf ein, sich pro Kanonikat zu St. Peter zehn Gulden jährlich auszahlen zu lassen und dafür auf die Besetzung der Pfründe mit einem Universitätsangehörigen zu verzichten. In der Zeit von 1507 bis 1531 gelang es der Universität jedoch, rund ein Drittel der Aufwände für den Lehrkörper mit Pfründeneinnahmen zu decken $^{35}$.

In der Zeit von 1474 bis 1523 waren insgesamt 111 Professoren an der Universität Basel tätig, davon jedoch nur 14 Theologen $^{36}$, von denen nur drei jemals eine Besoldung erhielten. Diese neue Situation mag sich verschiedentlich negativ auf die Fakultät ausgewirkt haben, weil zusätzliche Doktoren keine ordentliche Besoldung erhielten. Ein Beispiel dafür ist Johannes Geiler von Kaysersberg ${ }^{37}$, der 1471 als magister artium von Freiburg i. Br. nach Basel kam. Dank mehrerer Dispense wurde er bereits am 11. September 1475 zum Doktor der Theologie promoviert und wurde Professor. Doch er blieb nicht einmal ein Jahr in Basel, sondern ging im Mai 1476 zurück nach Freiburg i. Br. und von da aus als Domprediger nach Strassburg. Geiler von Kaysersberg ist nur ein Beispiel für einen Theologen, der in Basel den Doktorgrad erlangte oder zumindest den cursus begann, jedoch anschliessend nicht länger in der Fakultät verblieb, weil womöglich die finanziellen Anreize fehlten. Von 1478 bis 1491 war Johannes Syber ${ }^{38}$ einziger Ordinarius. Entsprechend wurden in dieser Zeit nur wenige Promotionen vorgenommen, nachzuweisen sind nur gerade sieben baccalaurii. Von diesen wurde Johannes Dieck ${ }^{39}$ zum Lizentiaten promoviert, jedoch ohne später Doktor geworden zu sein. Vom Lizentiaten zum Doktor musste aber vor allem eine finanzielle Hürde genommen werden, sodass die Promotion von Dieck wahrscheinlich an dessen nicht vorhandenen finanziellen Mitteln scheiterte.

34 Schwinges, Basel in der europäischen Universitätslandschaft (Anm. 24), S. 42 f.

35 Guy P. Marchal, Die Statuten des weltlichen Kollegiatsstifts St. Peter in Basel. Beiträge zur Geschichte der Kollegiatsstifte im Spätmittelalter mit kritischer Edition des Statutenbuchs und der verfassungsgeschichtlichen Quellen, 1219-1529 (1709) (Quellen und Forschungen zur Basler Geschichte 4), Basel 1972. S. 87-104; Vischer, Universität Basel (Anm. 7), S. 46-59. Zur wichtigen Bedeutung der Pfründenkirche zur Finanzierung des Lehrkörpers und den Schwierigkeiten, um ans Geld zu kommen vgl. Schwinges, Basel in der europäischen Universitätslandschaft (Anm. 24), S. 30-35.

$36 R A G$ (Anm. 1), 16.4.2018.

37 Ebd., Johannes Geiler - UniquID: ngEU4P375EM1ptaWyD5toCqt, 1.5.2018.

38 Ebd., Johannes Siber - UniquID: ngND7U870OF62cjNhOGc2LzU, 1.5.2018.

39 Ebd., Johannes Dieck - UniquID: ngKA7R577J630zgGeK7z0Iwd, 1.5.2018. 
Einzig der Domprediger Michael Wildeck und Macharius Leopardi ${ }^{40}$ beendeten ihre Kurse und wurden zu Doktoren promoviert ${ }^{41}$. Bei der Promotion Wildecks wurde aus Mangel an eigenen Doktoren ein Ordinarius aus Freiburg i. Br. und der Augustinerprovinzial Basels beigezogen. Auch hier zeigt sich wieder eine Schwierigkeit, mit welcher die Fakultät aufgrund der fehlenden ordinarii zu kämpfen hatte. So war auch die Enttäuschung in der Fakultät gross, als ein weiterer Kandidat, Johannes Textoris oder Mörnach ${ }^{42}$, nach dem Lesen der Sentenzen 1488 heiratete und an der juristischen Fakultät weiter studierte ${ }^{43}$. Erst der Augustinermönch Mauricius Fininger wurde 1501 wieder in Basel zum Doktor der Theologie promoviert. Für kurze Zeit gab es wieder drei Doktoren in der Fakultät, jedoch starben Johannes Syber und Michael Wildeck bereits 1502. Fininger war also wieder der einzige Professor, wie es in den Jahren zuvor schon oft vorgekommen war und was zu einer grossen Unstetigkeit innerhalb der Fakultät führte.

In dieser Situation befand sich also die Fakultät, als 1502 Ladislaus Ulricher bei Mauricius Fininger vorstellig wurde und ihm glaubhaft versichern konnte, er sei in Köln magister und baccalaureus formatus geworden. Fininger war, wie viele seiner Vorgänger, auf sich alleine gestellt und glaubte wohl auch deshalb Ladislaus Ulricher, weil er die Möglichkeit sah, wieder eine Doktorpromotion in Basel vornehmen zu können und nicht mehr alleine die Geschicke der Fakultät lenken zu müssen. Auch dass der im Wintersemester 1503/04 amtierende Rektor, Adam von Müllberg, Ulricher als bekannten Theologen rühmte, spricht für das überzeugende Auftreten Ulrichers, der also nicht nur den Dekan zu täuschen vermochte. Ausserdem gab es zuvor in Basel mindestens zwei Theologen, die ihr Studium in Köln an der theologischen Fakultät begonnen hatten und dieses dann in Basel weiterführten. Zum einen ist das Heinrich Nolt ${ }^{44}$, ein Dominikaner, der am 16. Januar 1471 in Basel zum Doktor promoviert wurde und der zuvor, wie es auch Ulricher angab, in Köln den Grad eines baccalaureus formatus erlangte. Auch Johannes Vredewolt ${ }^{45}$ studierte bis zum vierten Buch der Sentenzen in Köln, wurde aber dann Doktor in Pavia. Er kam 1473 nach Basel, versah seine Professur aber nur für kurze Zeit. Auch Nolt blieb nicht lange im Amt, starb er doch schon 1474. Dennoch könnten die bis anhin guten Erfahrungen der Fakultät mit Theologen aus Köln einen positiven Ausschlag für Ulricher gegeben haben ${ }^{46}$. Für die

40 Ebd., Macharius Leopart - UniquID: ngHX9Y870GP63wdbbH0wsFtY8IK, 1.5.2018.

41 Staatsarchiv Basel, MFTh (Anm. 7), fol. 17v; 19r. Wildeck erlangte den Doktorgrad 1491, Leopardi 1496.

42 RAG (Anm. 1), Johannes Mörnach - UniquID: ngPF2A870OH60elDjPIea, 1.5.2018.

43 Staatsarchiv Basel, MFTh (Anm. 7), fol.15v. Textoris wurde 1508 zum Dr. iur. promoviert und war noch 20 Jahre lang Professor an der juristischen Fakultät.

$44 R A G$ (Anm. 1), Heinrich Nolt (Frater) - UniquID: ngFV1E870GX6rubFzFOu3DrW, 1.5.2018.

45 Ebd., Johannes Vredewolt - UniquID: ngIY7P375H41uxeccJRx8GuT, 1.5.2018.

46 Vischer, Universität Basel (Anm. 7), S. 209-223. Für die Zeit von 1460 bis 1500 sind im RAG 38 Personen verzeichnet, die sich sowohl in Basel wie auch in Köln immatrikulierten. Zwischen den beiden Universitäten gab es also nur einen geringen personellen Austausch, was jedoch nicht ausschliesst, dass die Basler sich an den einen oder anderen Kölner positiv erinnerten. RAG (Anm. 1), 16.4.2018. 
theologische Fakultät blieb der Fall Ulricher wohl nicht ohne Folgen, zumindest lässt sich das aus dem Eintrag zu Ulrichers Nachfolger Johannes Gebwiler im Professorenkatalog schliessen, steht doch da, dass die Richtigkeit seines theologischen Doktorgrades von Zeugen überprüft wurde ${ }^{47}$.

\section{Die theologische Doktorpromotion an der Universität Basel}

An allen mittelalterlichen Universitäten Europas ähnelten sich die Abläufe einer Doktorpromotion mit nur wenigen Abweichungen zwischen den einzelnen Fakultäten. Im Folgenden sind sie Vorgänge zusammengefasst nach Marian Füssel ${ }^{48} . \mathrm{Zu}$ einem ersten Teil gehörten die mündliche Prüfung und die Disputation, wobei Erstere, das sogenannte examen privatum, in einem kleinen Rahmen stattfand, die Disputation oder das examen publicum jedoch in einem öffentlichen und feierlichen Rahmen erfolgte. Die Prüflinge mussten beim examen privatum einen Eid ablegen und eine Gebühr entrichten, danach folgte eine zweistündige Examination, anschliessend musste der Kandidat Wein und Gebäck spendieren. Ein zweiter Teil der Prüfung dauerte vier Stunden, wiederum musste zuvor ein Eid geleistet werden, eine Gebühr bezahlt und Verpflegung bereitgestellt werden. Dieses erste Examen fand entweder in einem Sitzungszimmer oder in der Wohnung des Dekans statt. Ganz im Gegensatz dazu stand die Disputation, die in einer repräsentativen Umgebung, etwa einem geschmückten Auditorium, stattfand. Die Disputation bezweckte die Einübung dialektischer und rhetorischer Fähigkeiten und galt ebenso dem wissenschaftlichen Fortschritt. Nebst dem Erkenntnisgewinn wurde also ein spezifischer Denk- und Kommunikationsstil eingeübt, der dem akademischen Umfeld eigen war. Der zweite Teil einer Doktorpromotion bestand aus der Investitur, bei welcher dem Kandidaten die Doktorinsignien überreicht wurden. Das Ritual lässt sich in drei Abschnitte aufteilen, der Prozession zur Promotionsstätte, oft einer Kirche, dem darin erfolgenden Einsetzungsritual und einem abschliessenden Essen.

Die akademische Gemeinde zog in einer festgelegten Reihenfolge in den Festsaal ein, bevor der Dekan eine Rede hielt. Anschliessend folgte der Doktoreid, welcher der Kandidat dem Kanzler schwor. Danach bat er seinen Promotor um die Verleihung des Titels und der Doktorinsignien, dem Hut, dem Ring und dem Buch. Diese wurden ihm nach einer Ansprache auf der obersten Stufe des Katheders verliehen. Gleich nach seiner Promotion konnte der frischgebackene Doktor seine Fähigkeiten unter Beweis stellen, er hielt im Anschluss eine Lobrede auf die Bibel und leitete eine Disputation. Vor dem wiederum feierlichen Auszug drückte der frisch Promovierte dem Kanzler, dem Dekan und den Professoren seinen Dank aus und es wurde ein Gottesdienst gefeiert. Die Stadtmusiker oder, bei den Theologen, die Kirchenglocken, verkündeten das Ereignis auch der Bürgerschaft. Der finanziell aufwendigste Teil erfolgte am Schluss

47 Herzog, Athenae Rauricae (Anm. 18), S. 7.

48 Füssel, Ritus Promotionis (Anm. 4), S. 140-142. 
mit dem Doktorschmaus, dem prandium doctorale. In gleicher Reihenfolge wie schon zur Kirche zogen die Universitätsangehörigen zu einem Gasthaus. Das Essen hatte einen gemeinschaftsstiftenden Sinn, weiter sollte es Konsum demonstrieren und repräsentierte so den sozialen Aufstieg des neuen Doktors. Die hohen finanziellen Ausgaben stellten einen numerus clausus dar, welcher die Zahl der Graduierungen eindämmen sollte. Ausserdem waren die Gebühren auch eine wichtige Einnahmequelle für die Universität. Das hatte zur Folge, dass einige Studenten unterschiedliche Studien- und Promotionsorte wählten, also ihren Doktorgrad an Universitäten erwarben, an welchen die Gebühren niedriger waren. Die Gebühren und die Aufwände für das Essen waren nicht die einzigen Ausgaben, die auf einen Kandidaten zukamen. Er musste auch Geschenke wie Handschuhe und Gebäck an Professoren, an städtische Räte oder auch landesherrliche Vertreter überreichen. Durch das Ritual der Promotion war der Kandidat öffentlich in den Kreis der Graduierten aufgenommen worden, damit ist nicht nur ein ständischer Aufstieg verbunden, sondern, durch die Aufnahme in die akademische Gemeinschaft, auch ein intellektueller.

Wilhelm Vischer erläutert in seinem Kapitel über die theologische Fakultät Basels die Abläufe einer dort vorgenommenen theologischen Doktorpromotion, die im Folgenden zusammengefasst $\operatorname{sind}^{49}$. Auch an der Universität Basel war es ein langer und kostspieliger Weg, die theologischen Grade zu erlangen. Der Kandidat musste dem Dekan versichern, dass er ehelich geboren sei, die niederen Weihen empfangen habe und frei von körperlichen Gebrechen sei. Ausserdem musste der Grad eines magister artiums erworben worden sein und der Kandidat musste mindestens fünf Jahre an einer theologischen Fakultät studiert haben und mindestens 30 Jahre alt sein. Sollte ein Kandidat alle Anforderungen erfüllt oder aber die Fakultät einen Dispens für die eine oder andere Bedingung ausgestellt haben, wurde der Kandidat einem Magister zugeteilt, dem er in einer Disputation zu antworten hatte. Anschliessend musste er innerhalb eines Monats mit seinem cursus beginnen, wobei er je ein Buch des Neuen und des Alten Testamentes zu erklären hatte. Vor Beginn dieser Vorlesung musste der Kandidat eine Rede halten und ein Mahl für die Doktoren, Lizentiaten und baccalaurii der Fakultät ausgeben. Die Vorlesungen dieser biblici, der Kandidat war durch Aufnahme in den cursus baccalaureus biblicus geworden, fanden jeweils nachmittags statt.

Hatte der Kandidat nun zwei Jahre lang die Bibel erläutert, wurde er zur Erklärung der Sentenzen des Petrus Lombardus zugelassen und war von nun an entsprechend baccalaureus sententiarius. Auch dem Beginn des zweiten cursus ging eine Disputation mit einem Magister voraus, ebenso waren die feierliche Rede und das Festessen wieder ein wichtiger Bestandteil. Mindestens zwei Jahre mussten nun die Sentenzen gelesen werden, diese Vorlesungen fanden nun am Morgen statt. War ein Buch beendet worden, musste bei der Fakultät die Erlaubnis eingeholt werden, mit dem nächsten beginnen zu dürfen. War der Kandidat beim dritten Buch angelangt, war er nun baccalaureus formatus geworden. Nicht nur das Halten der Vorlesung gehörte zum Pflichtprogramm des baccalaureus, sondern auch da regel-

49 Vischer, Universität Basel (Anm. 7), S. 210-215, 220. 
mässige Disputieren mit Magistern aus der Fakultät. Nach dem dritten Buch der Sentenzen musste der Kandidat noch zwei weitere Jahre in Basel bleiben und sich regelmässig bei Disputationen einbringen und Predigten halten. Nach dem Ablauf dieser Zeit meldete sich der Kandidat bei der Fakultät zum Examen der Lizenz an. Anschliessend wurde dieses durch den Kanzler eröffnet und ein Datum für die Prüfung festgesetzt. Vom Kanzler, vom Dekan und zwei weiteren Doktoren der Fakultät wurden für den Prüfling Stellen aus dem Alten und Neuen Testament vorgegeben, welche ihm drei Tage vor dem Examen bekannt gegeben wurden. Wenn nun die Fakultät mit den Erklärungen des Kandidaten zufrieden war, wurde er von den Examinatoren, also Doktoren aus der Fakultät, an den Kanzler empfohlen, der ihm dann die Lizenz erteilte. Vorher musste ein Eid geleistet werden, womit der Kandidat versicherte, mindestens 30 Jahre alt zu sein und keine Ketzereien zu lehren. Weiter sollte er auch innerhalb eines Jahres den Doktorgrad erwerben. Das Annehmen der Doktorinsignien bildete den Abschluss des ganzen Unternehmens, dabei stand vor allem der feierliche Akt im Vordergrund. Begonnen wurde die Verleihung der Doktorwürde mit einer höchstens drei Tage dauernden Disputation, dem sogenannten Vesperieren. Wiederum erfolgte im Anschluss ein Essen, zu welchem alle Doktoren, Lizentiaten und baccalaurii der Fakultät eingeladen waren.

Die eigentliche Feier fand häufig im Basler Münster statt. Nebst den Fakultätsangehörigen musste der Lizentiat auch Vertreter der Stadt einladen. Sie erhielten alle Handschuhe, die beiden Bürgermeister und die Oberzunftmeister zusätzlich noch Barette. Die Doktoren aller Fakultäten, der Dekan der Artisten, der Kanzler und Vizekanzler der Universität erhielten auch Barette, die Magister der Artistenfakultät Handschuhe. Der Pedell erhielt als einziger Stoff für neue Kleider. Mit einer feierlichen Rede übergab schliesslich der Promotor dem Doktoranden die insignia doctoralia, diese umfassten den Katheder, ein geschlossenes Buch, den Doktorhut und schliesslich auch einen Ring, sofern der Empfänger kein Ordensgeistlicher war. Anschliessend hielt der frisch promovierte Doktor eine Lobrede auf die Bibel, gefolgt von einer Disputation mit einem baccalaureus, dann mit den Doktoren. Nachdem der Promovierte allen Anwesenden gedankt hatte, zogen die Beteiligten in einer festlichen Prozession aus dem Münster aus. Laut Statuten waren vom frisch promovierten Doktor zwei Essen auszurichten, ein Mittagessen mit Gästen aus der Fakultät und Vertretern der Stadt sowie ein Abendessen, an welchem nur Mitglieder der theologischen Fakultät teilnahmen. Selbstredend war die ganze Kaskade bis hin zum theologischen Doktorgrad nicht nur mit etlichen Mühen und viel Zeit, sondern auch mit einem erheblichen finanziellen Aufwand verbunden. Bei jeder Zulassung zum Lesen wurden von verschiedenen Stellen der theologischen Fakultät unterschiedliche Gebühren verlangt; ebenso waren die Doktoren bei den Disputationen zu bezahlen. Auch die Examinatoren beim Lizentiatsexamen mussten bezahlt werden, jeder erhielt für gewöhnlich 1 fl. und eine Schachtel Süssigkeiten. Weitere Empfänger waren der Fiskus der Universität und der Fakultät sowie der Notar und der Rektor. Auch die Promotion selbst musste teuer erkauft werden, wieder waren diverse Gebühren an die Fakultät und die Universität fällig. Hinzu kamen noch die Kosten für die verschiedenen Gastmähler und die Kleidungsstücke. 
Es ist daher wenig erstaunlich, dass oftmals die Kandidaten nicht selbst für die gesamten Kosten von rund $50 \mathrm{fl}$. aufzukommen vermochten, vielfach wurden die Kosten gestundet oder aber ganz erlassen, wie es auch bei Ladislaus Ulricher der Fall war. Wollte ein bereits promovierter Theologe in die Fakultät aufgenommen werden, wurden jedoch die gleichen Gebühren verlangt, die fällig geworden wären, hätte er die Doktorpromotion in Basel erworben. Das mag eine Möglichkeit zur Finanzierung der Fakultät gewesen sein, zumal eben nicht alle in Basel promovierten Theologen ihre Gebühren zahlen konnten. Wie schon das Beispiel der beiden aus Köln stammenden Theologen, die nach Basel kamen, gezeigt hat, war es durchaus möglich, auf dem Weg zum Doktorgrad die Universität zu wechseln. Das erstaunt auch kaum, zumal es nach der Erlangung der artistischen Magisterwürde noch zwölf Jahre dauerte, bis der theologische Doktorhut aufgesetzt werden konnte. Oft wurden aber auch Dispense erteilt, so geschehen etwa beim Promotionsverfahren des schon angesprochenen Johannes Geiler von Keysersberg. Als er baccalaureus biblicus geworden war, wurde ihm über die vollen zwei Jahre ein Dispens erteilt und er wurde somit gleich zum Lesen der Sentenzen zugelassen. Auch nachdem er die Sentenzen beendet hatte, wurde ihm wieder ein Dispens erteilt und er wurde gleich zum Lizentiatsexamen zugelassen ${ }^{50}$. Mittels Dispens liess sich also einiges an Zeit einsparen. Noch mehr Zeit auf dem Weg zur Promotion sparte Ladislaus Ulricher, der angab, schon alle Vorstufen abgeschlossen zu haben und bereit für das Lizentiatsexamen zu sein. Ulricher wurde vor dem 21. August 1502 in die theologische Fakultät Basels rezipiert ${ }^{51}$, in der Rekoratsmatrikel ist er jedoch erst im Wintersemester 1502/03 eigetragen ${ }^{52}$. Die Doktorpromotion erfolgte am 15. Januar 1504, also war auch Ulricher nicht volle zwei Jahre als baccalaureus formatus in der theologischen Fakultät. Die lange Dauer und die hohen Kosten einer theologischen Doktorpromotion mögen also Ulrichers grösste Motivation gewesen sein, unwahre Angaben über seine Qualifikationen zu machen.

\section{Bildung an ausseruniversitären Institutionen - Lateinschulen}

Rund drei Viertel der Studenten an mittelalterlichen Universitäten dürften bereits eine Vorbildung genossen haben, diese ist aber nur selten nachzuweisen, auch weil sie ab dem ausgehenden 15. Jahrhundert den Normalfall darstellte und somit keine spezielle Erwähnung fand. Ebenso liegen ausführlichere bibliografische Angaben nur von wenigen Gelehrten vor. Schwierig wird es erst recht, wenn die Vorbildung im privaten Rahmen, beispielsweise durch gelehrte Verwandte, erfolgte. Weiter waren vor allem bürgerliche Schulen noch kaum institutionalisiert, die Schule als Gebäude ist, ebenso

50 Bonjour (Anm. 20), S. 89 f.

51 Staatsarchiv Basel, MFTh (Anm. 7), fol. 23r.

52 Wackernagel, M Basel Bd. 1 (Anm. 6), S. 267, Nr. 9. Zum Ablauf des theologischen Studiums getreu den Statuten vgl. Monika Asztalos, Die theologische Fakultät. Von der Bibelexegese zur scholastischen Theologie, in: Die Geschichte der Universität in Europa Band 1 Mittelalter, hg. von Walter Rüegg, München 1993, S. 359-385, hier S. 365-367. 
wie die Universität als solche, eine spätere Entwicklung. Eine mittelalterliche Schule war vielfach eine Gruppe von Lernwilligen und ihrem Magister, eine räumliche Kontinuität konnte so nicht gewährleistet werden. Ziel des Schulbesuches dürfte in den meisten Fällen das Erlernen der lateinischen Sprache gewesen sein, was die inoffiziell nötige Qualifikation für die Aufnahme an einer Universität war. Eine mittelalterliche Universität war jedoch unabhängig von der Vorbildung für alle Männer mit «guten Sitten〉 und von ehelicher Geburt offen. Für jene ohne Lateinkenntnisse bedeutete das aber, dass diese nebst dem regulären Vorlesungsbetrieb nachgeholt werden mussten. Dafür waren bereits fortgeschrittene Studenten in den Bursen und Pädagogien zuständig ${ }^{53}$. Eine Vorbildung an einer Lateinschule brachte aber erhebliche Vorteile mit sich, so benötigten Abgänger der Lateinschule Freiburgs i. Br. für den Erwerb des Grades eines baccalauerus artium rund die Hälfte der Zeit, die ihre Mitstudenten mit keinen oder wenigen Vorkenntnissen benötigten ${ }^{54}$.

Auch Ladislaus Ulricher muss zwingend eine nicht universitäre Vorbildung genossen haben, sogar eine sehr gute, immerhin vermochte er in Basel ohne Weiteres mit seinen Kollegen, auch wenn diese nicht eben zahlreich waren, in der theologischen Fakultät mitzuhalten. Seine Kenntnisse umfassten auch weitaus mehr als nur das Beherrschen der lateinischen Sprache, dennoch kann er sie an einer guten Lateinschule erworben haben, übertrafen doch manche Schulen die Artistenfakultäten an Bildungsstand und -leistung bei Weitem. Eine Lateinschule war die am häufigsten frequentierte Bildungsinstitution vor dem Universitätsbesuch. Alleine im RAG sind 210 Lateinschulen, grösstenteils über das Reichsgebiet verteilt, verzeichnet. Auch wenn diese Institutionen alle als Lateinschulen bezeichnet werden, so waren dennoch die Unterschiede der vermittelten Bildungsinhalte sehr gross. Ähnlich wie bei den Universitäten besuchten die meisten Schüler eine Schule in ihrem Heimatort oder in der unmittelbaren Nähe. Ein Blick auf die Karte (Abb. 2) zeigt aber, dass in Ulrichers Herkunftsgebiet, dem Moselraum, die Lateinschulen dünn gesät waren, womöglich zog er also an einen anderen Ort, auch mit der Absicht, eine bessere Schule besuchen zu können ${ }^{55}$. Nicht auszuschliessen ist es, dass er in Köln eine Ausbildung genoss, immerhin gab es in der Stadt mehrere Schulen, die verhältnismässig einfach $\mathrm{zu}$ erreichen gewesen wären. Ausserdem stellte Ulricher sich in Basel ja als Abgänger der Kölner Universität vor, gut möglich, dass ihn die Nähe seines Ausbildungsplatzes zur Kölner Hochschule auf diese Idee gebracht hatte. Die andere Möglichkeit ist, dass Ulricher nicht erst für das universitäre Studium, sondern vielleicht schon für seinen Schulbesuch in die Fremde zog. Es stellt sich heraus (Abb. 3),

53 Rainer C. Schwinges, Deutsche Universitätsbesucher im 14. und 15. Jahrhundert. Studien zur Sozialgeschichte des Reiches, (Veröffentlichungen des Instituts für europäische Geschichte Mainz, Abt. Universalgeschichte 123) Wiesbaden, 1986, S. 330-341; Bonjour (Anm. 22), S. 82. Von den im RAG verzeichneten 55'976 Personen ist nur gerade bei 310 ein Schulbesuch nachzuweisen. RAG (Anm. 1), 16.4.2018.

54 Dieter Mertens, Die städtische Lateinschule von der Universitätsgründung bis zum Übergang an Baden, in: Zeitschrift des Breisgau-Geschichtsvereins «Schau ins Land» 120 (2001), S. 153-159, hier S. 153. Schwinges, Universitätsbesucher (Anm. 53), S. 336.

55 Ebd., S. 332. 
dass die bekannten Schulorte von Basler Universitätsbesuchern fast alle in näherer Umgebung der Universität zu finden sind. Womöglich besuchte also auch Ulricher eine Schule im Süden des Reiches.

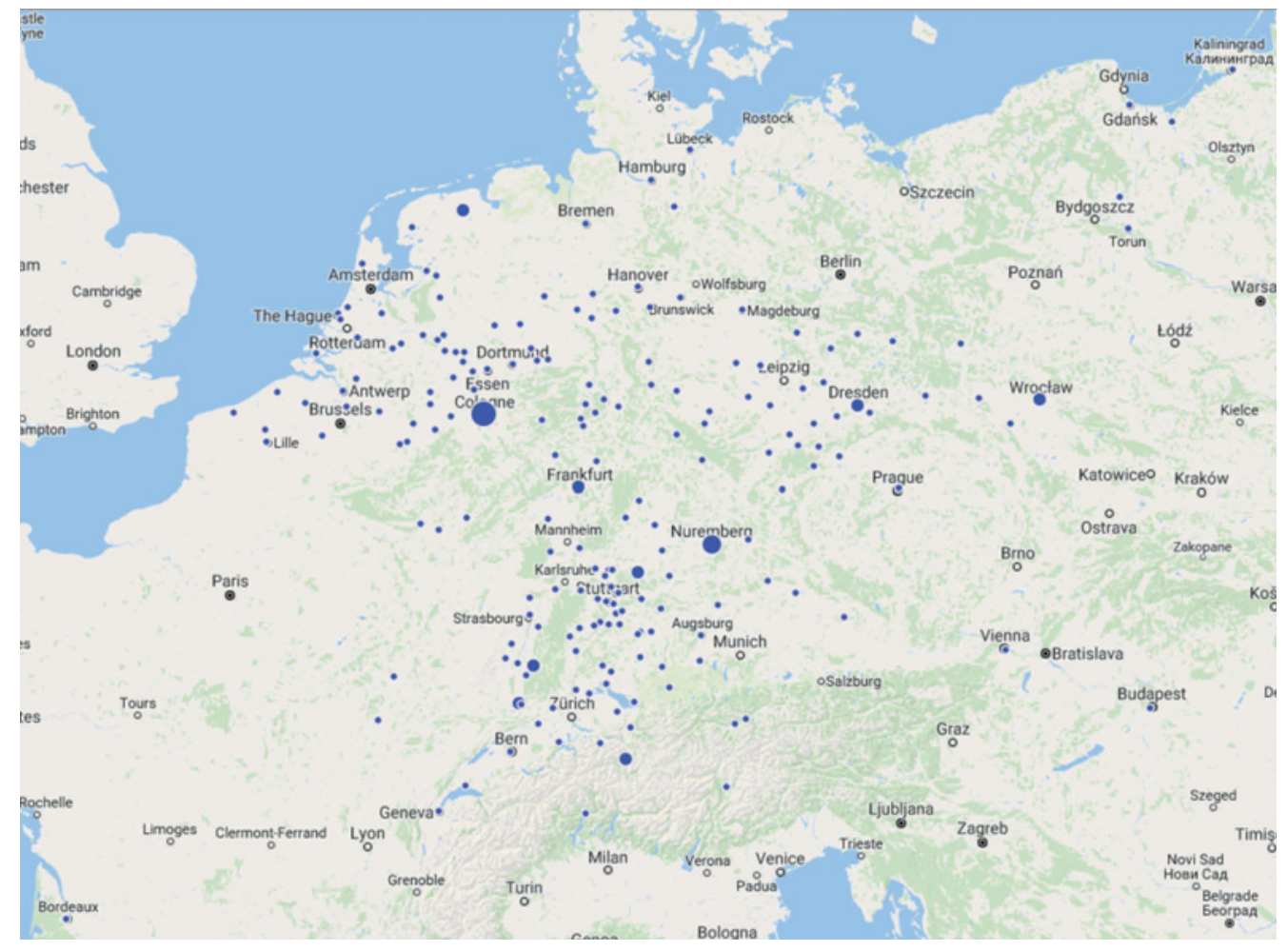

Abb. 2 Die im RAG verzeichneten Lateinschulen im Reich und angrenzenden Gebieten $1250-1550^{56}$

Deutlich heraus sticht die Besucherfrequenz der beiden Schulen in Schlettstadt und in Strassburg, weiter folgen Zürich, Basel, Bern, Augsburg und Pforzheim. Jedoch sollte die Karte nicht überinterpretiert werden, denn es sind lediglich 84 Schulbesuche verzeichnet und das bei 1'422 Immatrikulationen in Basel zwischen 1460-1550. Auf Schlettstadt entfallen 16 Ereignisse und auf Strassburg zwölf. Für Zürich sind es neun, für Basel fünf und für Bern, Augsburg und Pforzheim je vier.

56 Die verzeichneten 210 Lateinschulen sind ein Zufallsprodukt der Arbeit im RAG. Wenn immer es Hinweise auf die ausseruniversitäre Bildung eines Gelehrten gibt, wird die besuchte Schule als Institution verzeichnet. Die Karte erhebt deshalb keinen Anspruch auf Vollständigkeit. RAG (Anm. 1), 16.4.2018. 


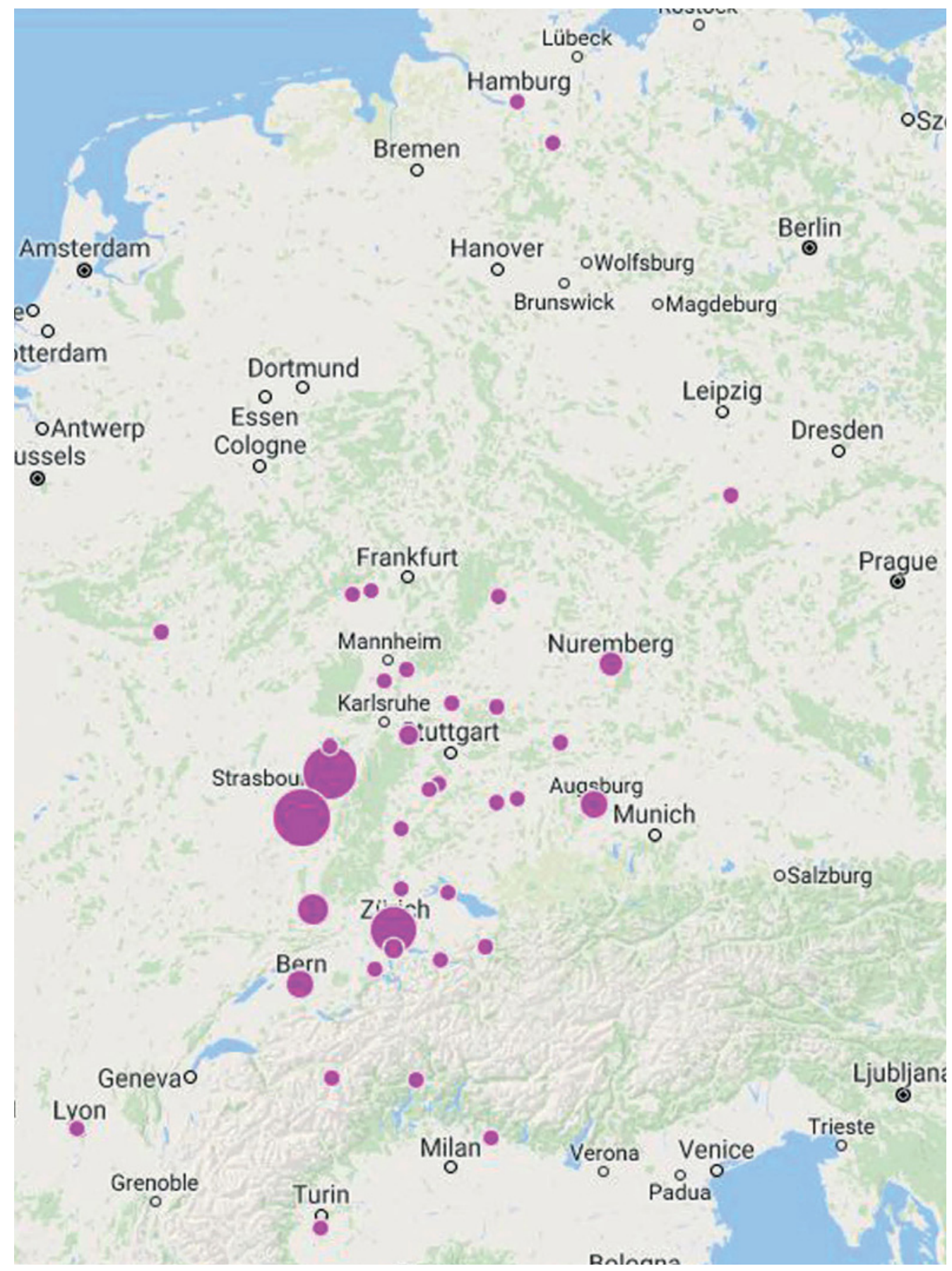

Abb. 3 Von in Basel immatrikulierten Studenten besuchte Schulen 1460-155057 
Aufgrund dieser Zahlen muss ein besonderes Augenmerk auf die Schlettstädter Schule zur Zeit vor Ulrichers Immatrikulation in Basel gelegt werden. Strassburg kommt insofern nicht infrage, weil das dortige Gymnasium, auf welches der allergrösste Teil der oben verzeichneten Schulbesuche entfällt, seine Blütezeit erst nach dem Niedergang der Schlettstädter Schule in den 1520er-Jahren erlebte. Die beiden Schulen stehen aber in direktem Zusammenhang.

Johannes Amerbach ${ }^{58}$ aus Basel, dessen drei Söhne Bruno ${ }^{59}$, Basilius ${ }^{60}$ und Bonifacius ${ }^{61}$ auch die Schlettstädter Schule besuchten und so ihrem Lehrer ebenfalls Bücher zukommen lassen konnten. Hofmans Schulunterricht kann dank zwei erhaltener Schulhefte ein Stück weit rekonstruiert werden, eines der Hefte gehört Beatus Rhenanus ${ }^{62}$ und damit einem berühmten Abgänger der Schule. Hofman hatte ein bestimmtes System, mit den Texten umzugehen. Erst las er den gewählten Abschnitt vor und liess ihn dann sorgfältig übersetzen. Dabei sollten nicht nur die Kenntnisse der Grammatik angewandt werden, sondern auch jene der Rhetorik und der Stilistik. In einem weiteren Schritt wandte sich Hofman dem Inhalt des Textes zu und lehrte seine Schüler in vielfältigen Gebieten, etwa der Geschichte und Geografie oder auch der Mythologie. Einen weiteren Schwerpunkt legte er auf die religiösen Pflichten seiner Schützlinge, sie sollten die Liturgie und die Psalmen durch seine Erläuterungen derselben verstehen. Auch religiöse Lyrik war vorgesehen, um die Frömmigkeit der Knaben zu fördern. Kraft Hofman zog 1501 nach Ulm, jedoch verstarb er schon kurze Zeit später.

Die Nachfolge als Schulmeister trat Hieronymus Gebwiler ${ }^{63}$ an, ein Verwandter wiederum von Ulrichers Nachfolger Johannes Gebwiler als Ordinarius in Basel. Er stand aus pädagogischer Sicht in der Tradition seiner Vorgänger, beschäftigte sich aber vermehrt mit Philosophie und war aufgrund seiner Studienzeit in Paris, die er 1495 mit dem Magistergrad abschloss, von Pariser Theologen und Humanisten beeinflusst. Nebst der Arbeit mit den lateinischen Klassikern bot Gebwiler seinen begabtesten Schülern auch Unterricht in der Dialektik und Ethik und veranstaltete Disputationen. Gebwiler blieb bis 1509 in Schlettstadt, bevor er die Leitung der Strassburger Domschule übernahm. Die Zahl der Schüler bewegte sich in der Amtszeit Gebwilers zwischen 250 und 280. Unter Gebwilers Nachfolger Johannes Witz Sapidus ${ }^{64}$, dem die Schulleitung von 1511-1526 oblag, stieg die Schülerzahl nochmals massiv an ${ }^{65}$. Dieses rund letzte Jahrzehnt der Blütezeit der Schlettstädter Schule ist aber zeitlich ausserhalb des Rahmens, der für Ulrichers Schulbesuch infrage kommt, weshalb nicht weiter darauf eingegangen wird.

58 Ebd., Johannes Amerbach - UniquID: ngCS6F779Ca57ryYwC9roAoJ, 1.5.2018.

59 Ebd., Bruno de Amerbach - UniquID: ngUK0P779Us50jqGoUDjgSgT, 1.5.2018.

60 Ebd., Basilius Amerbach der Ältere - UniquID: ngDT4O274DV04szRxCMs2BpY, 1.5.2018.

61 Ebd., Bonifaz Amerbach - UniquID: ngAQ6D577AI39pwSuBJp5YmR, 1.5.2018.

62 Ebd., Beat Rhenanus - UniquID: ngZP3Q870Z961ovZtZSo2X1G, 1.5.2018.

63 Ebd., Hieronymus Gebwiler - UniquID: ngND0I072M180cjJhMWcwLzA, 1.5.2018.

64 Ebd., Johannes Witz Sapidus - UniquID: ngBR4W072AT83qxJvBUq5ZnM, 1.5.2018.

65 Rapp, Lateinschule von Schlettstadt (Anm. 60), S. 221-230. 
Sollte sich Ulricher wirklich in Schlettstadt aufgehalten haben, könnte es für ihn auch ein gewisses Risiko gewesen sein, an die nahgelegene Universität Basel zu gehen. Denn es besteht die Möglichkeit, dass ihn einer seiner Schlettstädter Mitschüler erkannte und er deshalb 1506 aus Basel verschwand. In der Basler Zeit Ulrichers sind zwar keine Studenten nach Basel gekommen, die nachweislich die Schule besuchten, aus dem Elsass sind aber einige immatrikuliert worden. Auch Studenten aus Köln hätten Ulricher gefährlich werden können, zwischen 1501 und 1506 immatrikulierte sich aber niemand mit entsprechendem Herkunfts- oder Studienort in Basel ${ }^{66}$.

\section{Fazit}

Alleine aus Ulrichers Biografie lassen sich kaum Schlüsse ziehen, wie es ihm gelingen konnte, ohne universitäre Qualifikationen an der theologischen Fakultät Basels Karriere zu machen, jedoch liefert sie wichtige Eckpunkte eines interessanten Lebensabschnittes. Die spezielle, wenn nicht sogar verzweifelte Situation der theologischen Fakultät Basels, die Ulricher vielleicht sogar bekannt war, womöglich hörte er in Schlettstadt davon, spielte ihm aussergewöhnlich in die Hände. Mauricius Fininger war als einziger für die Fakultät zuständig und freute sich über den Zuwachs, vielleicht war für ihn die Erleichterung sogar so gross, dass er es zuerst nicht für wichtig hielt, Ladislaus Ulricher genauer zu überprüfen. Auch andere Stellen hielten das nicht für nötig, sofern überhaupt bekannt war, dass Fininger die Zeugnisse nie gesehen hatte. So erhielt Ulricher die Universitätspfründe an St. Peter und wurde auch Rektor. Auch seine Promotion zum Doktor der Theologie schien ohne grössere Auffälligkeiten vonstatten gegangen zu sein, dafür sprechen zumindest seine Dispense und der Kostenerlass. Für die Fakultät war es also sehr viel wichtiger, endlich wieder eine Promotion durchführen zu können, als damit Geld einzunehmen. Dennoch muss Ulricher auch fachlich überzeugt haben, als Person tat er das ohne Zweifel. Er war verpflichtet, in Basel Vorlesungen zu halten, und musste auch bei Disputationen mithalten können.

Seine Fähigkeiten gingen also weit über das hinaus, was ein durchschnittlicher Abgänger einer beliebigen Lateinschule konnte. Dennoch kann eine Lateinschule bei Ulrichers Ausbildung eine sehr grosse Rolle gespielt haben, erst recht, wenn er eine Schule besuchte, die besondere Fähigkeiten vermittelte, so wie diese in Schlettstadt. Die Humanistenschule sollte aber auch nicht überbewertet werden, ist es doch bei Schülerzahlen von über 200 nicht möglich, dass sämtlichen Schülern ausserordentliche Fähigkeiten vermittelt wurden. Längst nicht jeder brachte das dazu benötigte Talent mit, sodass der lateinische Spracherwerb für die meisten das primäre Ziel blieb. Auch die geografische Nähe zu Basel könnte bei der Schulwahl Ulrichers eine Rolle gespielt haben, zumal in seiner unmittelbaren Heimat kaum Lateinschulen zu finden sind. Auch ein Besuch der Universitäten Trier und Mainz könnte infrage kommen. Es sind jedoch von diesen beiden Hochschulen keine

$66 R A G$ (Anm. 1), 14.5.2018. 
Rektoratsmatrikeln überliefert. In den vorhandenen Quellen finden sich keine Hinweise auf Ladislaus Ulricher. Dass er aber wirklich in Köln an der Universität war, ist mit sehr hoher Wahrscheinlichkeit auszuschliessen, ist doch diese Hochschule mit Rektoratsmatrikel, Promotionslisten und Zeugnissen der Bursen hervorragend dokumentiert. Und dass seine Kölner Abschlüsse erfunden waren, hatte er schlussendlich selber zugeben müssen.

Sollte Ulricher jedoch die Lateinschule in Schlettstadt besucht haben, dann sehr wahrscheinlich unter Kraft Hofman oder auch noch kurze Zeit unter Hieronymus Gebwiler. Über beide Lehrkräfte liegen Quellen vor, die ihren Unterrichtsinhalt dokumentieren. In beiden Fällen wird klar, dass zwar die lateinische Grammatik, Rhetorik und Metrik einen grossen Teil einnahmen, jedoch weit mehr unterrichtet wurde und auch speziell auf besonders begabte Schüler eingegangen wurde. Hofman unterrichtete auch theologische Inhalte, so etwa Erläuterungen zu den Psalmen oder religiöse Lyrik. Auch Gebwiler vermochte als Pariser Magister mit vielen theologischen Inhalten aufzuwarten, für seine besten Schüler veranstaltete er gar Disputationen; es ist gut möglich, dass Ulricher an einer solchen teilgenommen oder zumindest zugehört hat. Weiter ist es sehr wahrscheinlich, dass Ladislaus Ulricher von einem Privatlehrer profitierte, womöglich gar jemand, der in Köln Theologie studierte und er auch daher auf die Idee kam, anzugeben, seine Grade in Köln erworben zu haben, jedoch auch wusste, was ein studierter Theologe können musste. Es sind also sicherlich viele Faktoren, die zusammenkommen mussten, um den Fall Ulricher möglich zu machen, nicht alle konnten abschliessend aufgedeckt werden. Nicht zuletzt deswegen ist es nicht wahrscheinlich, dass Universitätszeugnisse im grossen Stil gefälscht oder, wie bei diesem Beispiel, gar nicht vorgelegt wurden. Ulricher bleibt somit eine unrühmliche Ausnahme. 


\section{Universitas Dolana}

\section{Juristen- und Transituniversität im Land der Legisten (1498-1601)}

Im Vergleich mit den stark frequentierten europäischen Universitäten wirkt die 1423 gegründete Universität Dôle recht bescheiden. Sie steht, quantitativ betrachtet, im Schatten der grossen und bekannten Reichsuniversitäten wie auch der französischen Hochschulen und war in der oberrheinischen Universitätslandschaft im Laufe des 15. Jahrhunderts zunehmend starker regionaler Konkurrenz ausgesetzt durch Gründungen der Universitäten in Freiburg im Breisgau (1457), Basel (1460), Tübingen und Mainz (1477). Dennoch konnte sich die Universität Dôle behaupten und sich in dieser Zeit als Juristenuniversität profilieren, einen Ruf, den die Universität bis zu ihrer Verlegung in die Nachbarstadt Besançon 1691 beibehalten sollte. Im 16. Jahrhundert, mit Erreichen ihres Höhepunktes, setzte zugleich ihr langsamer Abstieg ein, nicht wegen der Anziehungskraft anderer Universitäten, sondern vielmehr durch interne Reformschwierigkeiten und namentlich durch die Konfessionalisierung des Bildungswesens. Die aufstrebenden Jesuiten mit ihren Bildungsreformen errichteten auf Initiative der Stadt Dôle 1582 ein Kolleg mit Gymnasium ebendort, welche aber institutionell getrennt von der Universität betrieben wurden. Auf lange Sicht schwächten diese Einrichtungen die Universität und im 17. und 18. Jahrhundert besuchten führende Familien der Franche-Comté auch die Bildungseinrichtungen der Jesuiten ${ }^{1}$.

Bei der Gründung der ersten burgundischen Universität in Dôle 1423 standen hingegen praktische Erwägungen im Zentrum. Den Kontext erhellt ein Brief, den der Gründer, Herzog Philipp der Gute (1396-1467), an seinen Vertrauten Robert de Baubigny

1 Jacky Theurot, L'Université de Dôle, de sa fondation à son transfert à Besançon (1422-1691), in: Institutions et vie universitaire dans l'Europe d'hier et d'aujourd'hui (Cahiers d'études comtoises, 51), Besançon 1992, S. 25-44, hier: S. 35; Bruno Boute, Universitätsreform und Konfessionalisierungspolitik: das Beispiel der Habsburgischen Niederlanden und Burgund (Dole, Douai, Löwen) 1590-1620, in: Universität - Reform: Ein Spannungsverhältnis von langer Dauer (12.-21. Jahrhundert), hg. von Martin Kintzinger et al. (Veröffentlichungen der Gesellschaft für Universitäts- und Wissenschaftsgeschichte, Band 14), Basel 2018, S. 87-129, hier: S. 89 ff.; Anton Schindling, Die katholische Bildungsreform zwischen Humanismus und Barock. Dillingen, Dôle, Freiburg, Molsheim und Salzburg. Die Vorlande und die benachbarten Universitäten, in: Vorderösterreich in der frühen Neuzeit, hg. von Hans Maier und Volker Press, Sigmaringen 1989, S. 137-176, hier: S. 158-163. Die Jesuiten konnten sich im 16. Jahrhundert bereits in Flandern durchsetzen mit der Gründung der dritten burgundischen Universität nach Dôle und Löwen 1562 in Douai. Diese wurde (wie in Dôle später auch Kolleg und Gymnasium) von Spanien gefördert, allerdings bereits von den Jesuiten geführt, vgl. Matthias Asche, Peregrinatio academica in Europa im konfessionellen Zeitalter. Bestandesaufnahme eines unübersichtlichen Forschungsfeldes und Versuch einer Interpretation unter migrationsgeschichtlichen Aspekten, in: Jahrbuch für Europäische Geschichte 6, 2005, S. 3-33, hier: S. 24. 
gerichtet hatte ${ }^{2}$. Baubigny war Abt von Saint Paul in Besançon und Generalvikar der gleichnamigen Diözese. Der Herzog hatte ihn 1420 zusammen mit einem seiner weiteren Räte, dem Archidiakon von Langres Jehan Jobert (Jean Robert), nach Rom gesandt, um die Gründungsbulle und die Privilegien für die Universität zu erwirken, und nahm wenig später Baubigny in seinen Beraterkreis auf. Baubigny war Doktor des Kirchenrechts und hatte an der Universität Paris gelehrt, bevor er in die Dienste des Herzogs trat $^{3}$. Damit passte sein Profil zum Mitarbeiterstab des Herzogs, denn der Grossteil seiner Räte, Requetenmeister und Sekretäre verfügten über eine universitäre juristische Ausbildung ${ }^{4}$. Baubigny war es auch, der zusammen mit Jehan Jobert, dem Kanzler des Herzogs, Nicolas Rolin, schliesslich die päpstlichen Bullen für die Gründung der Universität überbrachte 5 .

Im erwähnten Brief führt der Herzog die zentralen Argumente für die Notwendigkeit der Universitätsgründung auf. Am Anfang verweist er allgemein auf die Vorteile für die Verwaltung und das Ansehen, welche durch die Studien in kanonischem und zivilem Recht und anderen Studien mit entsprechenden Graden erwachsen, vergleichbar den Studien in den Städten Orléans, Bologna, Toulouse, Montpellier und anderen. Auch die Kirche, so der Herzog weiter, werde durch Anwendung der <justes droiz〉 verteidigt und geschützt. Die erwähnten Städte mit ihren Zentren juristischer Lehre werden vom Herzog mit Absicht erwähnt, um das Hauptargument vorzubereiten: die schwierige Erreichbarkeit dieser Universitäten aufgrund von Krieg und Zwietracht, welche schon seit zwölf Jahre herrschten. Gemeint sind hier unzweifelhaft der Bürgerkrieg der Armagnacs und Bourguignons (1410-1419) sowie auch die zweite Phase des Hundertjährigen Krieges (1415-1435). Im Bürgerkrieg machten die gefürchteten brutalen Söldnerbanden der Armagnaken den burgundischen Raum unsicher, nach der Beilegung des Konflikts durch den Vertrag von Arras 1435 wurden die Banden der Ecorcheurs, die auf eigene Rechnung plünderten, zur Landplage ${ }^{6}$.

Der Herzog fährt weiter, dass aufgrund der kriegerischen Auseinandersetzungen sich Eltern nicht getraut hätten, ihre Kinder an die erwähnten Universitätsorte zum Studium zu schicken, da man vor Feind und Gegner nicht sicher sein konnte, was also

2 Jules Gauthier, L'Université de Dôle au comté de Bourgogne, in: Annales Franc-Comtoise 13, 1870, S. 453-465, hier: S. 458; Jacky Theurot, L'université de Dôle au service de Bourgogne. L'université, les gens de savoir et le prince (1423-début XVIe siècle), in: Hommes d'Église et pouvoirs à l'époque bourguignonne (XIVe-XVIe siècle) Publications du Centre européen d'études bourguignonnes, 38, 1998, S. 263-300, siehe Annexe.

3 Denis de Sainte-Marthe, Gallia christiana in provincias ecclesiasticas distributa; qua Series et Historia archiepiscorum, episcoporum et abbatum franciae vicinarumque ditionum ab origine Ecclesiarum ad nostra tempora deducitur, et probatur ex authenticis Instrumentis ad calcem appositits, Tomus quartus, Paris 1728, Sp. 762.

4 Henri Beaune und Jules D'Arbaumont, Les Universités de Franche-Comté: Gray, Dôle, Besançon, Dijon 1870, p. XVIII; siehe zur Universitätsbildung der Räte Rainer Christoph Schwinges, Im Dienst. Gelehrte im Reich der deutschen Könige und Fürsten des späten Mittelalters, in: König, Reich und Fürsten im Mittelalter, FS Karl-Heinz Spieß, hg. von Oliver Auge, Stuttgart 2007, S. 421-440, hier: S. 427 f.

5 Roman Berger, Nicolas Rolin. Kanzler der Zeitenwende im burgundisch-französischen Konflikt 1422-1461, Freiburg/ Schweiz 1971, S. 69 Anm. 128.

6 Berger, Rolin (Anm. 5), S. 164. 
nicht vorgeschobene Argumentation war, sondern einen realen Hintergrund hatte. Aus diesem Grund hätten die Kinder geringfügigeren Ausbildungen und Tätigkeiten zugeführt werden müssen. Die Folge sei, dass in kurzer Zeit kein «jurist ne clerc souffisant» im burgundischen Land verfügbar sein werde zum grossen Schaden des «bien publique».7 Das gleiche Argument der mangelnden Reisesicherheit aufgrund kriegerischer Auseinandersetzungen wird Philipp der Gute 1437 verwenden, um in Rom die Errichtung einer theologischen Fakultät für Dôle zu erwirken ${ }^{8}$. Vor diesem Hintergrund ist die Standortwahl der Universität, zentral gelegen zwischen der Freigrafschaft und dem Herzogtum Burgund nur folgerichtig. Hier konnte der Herzog einen neuen, gut erreichbaren Bildungsraum schaffen und etablieren. Dazu wurden Lehrkräfte gesucht und verschiedene Städte angeschrieben, die damit zugleich über die Gründung in Kenntnis gesetzt wurden, auch in der Hoffnung auf Studentenzulauf. Adressaten waren Fribourg, Bern, Lausanne, Konstanz, Basel, Utrecht, Trier, Strassburg, Metz, Nancy, Toul, Heidelberg, Köln und Worms ${ }^{9}$.

Am 22. Juni 1423 wurde in Dôle, Hauptstadt der Freigrafschaft Burgund und Sitz des Parlaments der Franche Comté, die Universität errichtet. Kanzler Nicolas Rolin, die rechte Hand Philipps des Guten bei der Universitätsgründung, forderte sogleich Kopien der Privilegien und Statuten der Universitäten Avignon und Montpellier an, die als Vorlage dienen sollten, und es wurde nach geeigneten Gebäuden für den Unterricht gesucht. Eingerichtet wurden die Fakultäten Recht (kirchliches und weltliches), Theologie, Medizin und Artes. Der Lehrbetrieb wurde im November 1423 aufgenommen, wohl auch an der theologischen Fakultät, die aber noch nicht über das Promotionsrecht verfügte ${ }^{10}$.

Während in der Folgezeit unter Philipp dem Guten die Universität aufblühte, brachen nach seinem Tod 1467 unruhige Zeiten an. Zuerst war die Universität unter Karl dem Kühnen finanziell schlechtergestellt, nach seinem Tod 1477 beim Kampf um sein Erbe, bei welchem Dôle zerstört wurde, kam der Universitätsbetrieb von 1479-1484 zum Erliegen. Nach der Wiedereröffnung durch Karl VIII., der trotz möglicher Alternativen am Standort Dôle festgehalten hatte, gelangte 1493 die Freigrafschaft Burgund an das Habsburgerreich. Die Universität war nun Reichsuniversität im französischen

7 Der Herzog argumentierte folglich nicht damit, Eltern sollen ihre Kinder nicht nach ausserhalb zum Studium schicken, so wie es Mertens erwähnt. Sie konnten ihre Kinder nicht auswärts zum Studium schicken, so der Herzog, vgl. Dieter Mertens, Die oberrheinischen Universitäten zwischen Habsburg und Burgund, in: Zwischen Habsburg und Burgund. Der Oberrhein als europäische Landschaft im 15. Jahrhundert, hg. von Konrad Krimm und Rainer Brüning (Oberrheinische Studien 21), Ostfildern 2003, S. 275-287, hier: S. 280.

8 Marcel Fournier, Les statuts et privilèges des Universités françaises depuis leur fondation jusqu' en 1789, Tome III., Paris 1892, Nr. 1623 S. 125.

9 Berger, Rolin (Anm. 5), S. 69 Anm. 128.

10 Jacky Theurot, L’Université de Dôle, de sa fondation à son transfert à Besançon (1422-1691), dans Institutions et vie universitaire dans l'Europe d'hier et d'aujourd'hui (Cahiers d'études comtoises, 51), Besançon 1992, S. 25-44, hier: S. 33-34; Theurot, Service, (Anm. 1) S. 270; Mertens, Habsburg und Burgund (Anm. 7), S. 280; Marie-Thérèse Berthier und John-Thomas Sweeney, Le chancelier Rolin, 1376-1462: ambition, pouvoir et fortune en Bourgogne, Précy-sous-Thil, 1998, S. 81-82. 
Kulturraum, umgeben von vielgestaltigen Kultur- und Herrschaftsräumen, wie dem Herzogtum Burgund, Savoyen, der Eidgenossenschaft und der oberrheinischen Reichslandschaft.

Die Forschung hat die Universität Dôle vor allem punktuell untersucht und dabei auch den Bildungräumen Burgund und Oberrhein in der europäischen Hochschullandschaft eine regionale Bedeutung zugemessen ${ }^{11}$. Eine Matrikeledition, welche für eine vertiefte Analyse der Universität und ihrer Wirkungen Voraussetzung wäre, fehlt. Für die Zeit von 1498-1601 sind Universitätsmatrikeln (mit einigen Lücken), Annalen der Rektoren und weitere universitäre Quellen in ausreichender Dichte für eine entsprechende Auswertung überliefert ${ }^{12}$. Dôle eröffnet vor allem durch die Lage inmitten vielgestaltiger Kultur- und Wissensräume Perspektiven für die Forschung. Betrachtet man Universität, Stadt und Region als Wissensraum, stellen sich Fragen nach Formen und Prozessen inter- und transkultureller Auseinandersetzung, Verflechtung und Angleichung. In weiter gehender Perspektive ist nach Wirkungen und Ausstrahlungen der Prozesse nicht nur für den regionalen, sondern auch für den europäischen Raum zu fragen, besonders hinsichtlich von Gelehrtenmobilität und Wissenszirkulation mittels der Methode einer erweiterten Prosopographie, welche Personen und ihre geistigen Hinterlassenschaften (Texte) beobachtet und beschreibt.

Umgeben von den ganz verschieden geprägten Herrschafts- und Kulturräumen bildete die Universität Dôle in ihrer ursprünglichen wie auch übergeordneten Funktion den südöstlichen Pfeiler akademischer Ausbildung im weitläufigen Burgunderreich vom Juragebirge bis zur Nordsee. Die Universität Löwen, die 1425 nur wenig nach Dôle gegründet worden war, bildete den nordwestlichen Pfeiler. Die Gründung beider Universitäten erscheint damit gleichsam als die Errichtung einer bildungs- und herrschaftspolitischen Klammer. Entsprechend muss die Gründung der Universität Dôle in den Herrschafts- und Verwaltungskontext eingebettet werden, um ihre Funktionen in ihrer Gesamtheit einschätzen zu können. Dadurch wird deutlich, dass die Universität Dôle zentraler Baustein burgundischer Herrschaftspolitik war im Zuge einer grundlegenden Reorganisation der Verwaltung durch Philipp den Guten und seinen Kanzler Nicolas Rolin, der treibenden Kraft bei diesem Unternehmen. Auslöser dieser Reorganisation waren das Fehlen einer Zentralgewalt im Burgunderreich wie auch die Reformbedürftigkeit des Rechtswesens ${ }^{13}$. Philipp der Gute versuchte diese Mängel durch eine Zentralisierung und Professionalisierung der Verwaltung zu beheben unter gleichzeitiger Zurückdrängung des alten Adels. Die Gründung der Landesuniversität in Dôle war entscheidend für die Umsetzung dieser Vorhaben. Sie lieferte das geschulte Personal, die Legisten, den Beamtenadel für die Verwaltung, welcher bei der

11 Mertens, Habsburg und Burgund (Anm. 7), S. 284.

12 Bibliothèque municipale de Besançon, Ms 982-984 (1498-1616), Acta rectorum et matricula Universitatis Dolanae. Der Autor bereitet eine Matrikeledition (1498-1601) vor im Rahmen einer wissensgeschichtlichen Studie zur Universität Dôle.

13 Herta-Florence Pridat, Nicolas Rolin. 1376?-1462 Kanzler von Burgund im Schrifttum von fünf Jahrhunderten (Schriften zur Europäischen Rechts- und Verfassungsgeschichte, Bd. 13), Berlin 1995, S. 39-45. 
Ämterbesetzung den alten Adel verdrängen konnte - wie bei der neu geschaffenen, zentralen Behörde des Grand Conseil, der höchsten Instanz der burgundischen Verwaltung bei Regierungs-, Justiz- und Finanzangelegenheiten. Der Grand Conseil setzte sich ursprünglich aus Hochadel, Juristen und hohen Mitgliedern der Finanzverwaltung zusammen, wobei Kanzler Rolin den Anteil der Legisten auf Kosten des Adels erhöhte. Die Leitung des Grand Conseil oblag Philipp dem Guten und im Fall seiner Abwesenheit, was oft vorgekommen sein dürfte, seinem Kanzler Nicolas Rolin, dem sich dadurch politische Gestaltungsmöglichkeiten eröffneten. Die Bevorzugung der Legisten war nicht auf die höchste Ebene beschränkt, sondern wirkte durch alle Verwaltungsstufen hindurch. Insgesamt konnte der Beamtenadel damit langfristig in die Verwaltung eingebunden werden.

Kanzler Rolin ordnete vor allem die burgundische Justiz- wie die Finanzverwaltung neu, wobei ihm die Verwaltung in Dijon unter anderem als Vorlage diente. Später installierte Rolin mit wenigen Änderungen die neu geschaffene Verwaltungsstruktur auch in den Niederlanden. Bereits am Tag seiner Ernennung zum Kanzler, am 3. Dezember 1422, beorderte Rolin Steuereintreiber und Schatzmeister von Burgund zu sich mit dem Ziel, Ordnung zu schaffen und die Finanzverwaltung zu zentralisieren. Konsequent trieb er nun langausstehende sowie kleinere Schuldbeträge, welche Bürger bei den Herzögen hatten, ein. Bezeichnend für seinen Ordnungssinn und seine initiative Art ist die spätere Zusammenfassung des Verwaltungsschriftgutes in einem dicken Band (1448).

Die Universitätsgründung und ihre Ausrichtung als Juristenuniversität sind somit im Zusammenhang einer grösseren Verwaltungsreform zu sehen. Im Zuge dieser Reform wurde auch das Parlament der Grafschaft in Dôle fest installiert ${ }^{14}$. Die Universität bildete nun das Reservoir an geschultem Personal aus, sei es für weltliche oder kirchliche Administrationseinheiten des burgundischen Staatswesens oder für die Universität selbst, ein Zusammenwirken von Verwaltung und Universität, wie es auch andere Landesherren, die eine Universität gründeten, anstrebten ${ }^{15}$. Die Nähe von Universität, Verwaltung und Parlament sowie die zentrale Erreichbarkeit der Universität, gelegen zwischen Herzogtum und Freigrafschaft Burgund und angrenzenden Räumen, lassen den Universitätsstandort Dôle als ideal erscheinen. Es spielten aber auch machtpolitische Erwägungen mit. Philipp der Gute konnte in Dôle eine stärkere Kontrolle über die Universität ausüben als in anderen, mächtigeren Städten der Region wie Besançon oder Dijon, in denen der Einfluss der Kirche auch grösser war und deren Wirtschaftsleben sich hektischer gestaltete. Dôle war in diesem Punkt vergleichsweise eine ruhige Stadt, was den Studien nur zuträglich sein konnte ${ }^{16}$.

Die Universität Dôle öffnete einen neuen Arbeitsmarkt für soziale Aufsteiger, so wie Nicolas Rolin einer war. Ebenso wie für Kleinadelige und die Aristokratie aus der

14 Theurot, Fondation (Anm. 1), S. 27.

15 Theurot, Service (Anm. 2), S. 264.

16 So Theurot, Service (Anm. 2), S. 266; Theurot, Fondation (Anm. 1), S. 28-30. 
Franche-Comté, was der Absicht des Gründers entsprach ${ }^{17}$. Die Etablierung dieses neuen Ausbildungs- und Arbeitsmarktes wurde durch die fehlende Konkurrenz an Universitäten im benachbarten Umland sicher begünstigt. Nicht zuletzt dürfte auch die Krise der Pariser Universität von 1418-1425 das Gründungsvorhaben begünstigt haben, denn Pariser Studenten gelangten damals an den Herzog von Burgund und den Papst mit der Bitte, ihre Studien ausserhalb von Paris fortführen zu dürfen ${ }^{18}$. Diese Krise kam für Philipp den Guten gelegen, um mit der Gründung der Universität in Dôle und seiner Unterstützung bei der Gründung der Universität Löwen den burgundischen Bildungsund Herrschaftsraum zu stärken. Zehn Jahre nach ihrer Gründung wurde die Universität Dôle bereits als etablierte Grösse in der Juristenausbildung wahrgenommen, wie 1433 die scharfe Intervention der Pariser Universität gegenüber einer Universitätsgründung in Caen zeigt. Die Pariser Universität versuchte namentlich eine Fakultät für weltliches Recht (droit civil) in Caen zu verhindern und führte aus diesem Grund an, dass in Löwen, Dôle und anderswo bereits ausreichend Rechtsstudien betrieben werden könnten «pour fournir ce royaume de legistes \& juristes». ${ }^{19}$

Dôle wurde von Anfang an als Juristenuniversität konzipiert, eine Universität initiiert von Juristen für Juristen, wie Nicolas Rolin einer war, und von Philipp dem Guten als einem ausserordentlich gebildeten Fürsten mit Interesse an römischem Recht und dessen Vermittlung, an historischen Inhalten und Literatur. Philipp der Gute baute seine Bibliothek beständig aus, sammelte Manuskripte in grosser Zahl und förderte den Buchdruck $^{20}$. Er suchte den direkten Kontakt zur Universität und zur Lehre und war bestrebt, die Qualität des Unterrichts hoch zu halten ${ }^{21}$. Er liess italienische Professoren nach Dôle kommen, um das römische Recht zu lehren. Einer von ihnen war Anselmus de Marenches, aus einer noblen Familie stammend, der an der Universität Turin römisches Recht gelehrt hatte. 1452 wurde er Professor in Dôle und verblieb im Amt bis zu seinem Tod $1492^{22}$. Marenches war einer von nicht wenigen Professoren, die in Dôle gelehrt hatten und die zugleich als Conseillers Philippps des Guten tätig waren, wobei der Herzog bei deren Auswahl offenbar mehr auf die Fachkenntnisse als auf die Herkunft abstellte,

17 Sven Stelling-Michaud, Quelques remarques sur l'histoire des universités à l'époque de la Renaissance, in: Les universités européennes du $14 \mathrm{e}$ au $18 \mathrm{e}$ siècle, aspects et problèmes: actes du colloque international à l'occasion du VIe centenaire de l'Université Jagellonne de Cracovie, 6-8 Mai 1964, Genève 1967, S. 71-83, hier: S. 79.

18 Lyse Roy, L'université de Caen aux XVe et XVIe siècles: identité et représentation, Leiden/Bosten 2006, S. 31.

19 Michel Félibien, Histoire de la ville de Paris. Composée par D. Michel Felibien, reveue, augmentée et mise au jour par D. Guy-Alexis Lobineau, tous deux prêtres religieux benedictins, de la Congregation de Saint Maur; justifiée par des preuves autentiques, et enrichie de plans, de figures, et d'une carte topographique. Divisée en cinq volumes in folio, Tome 4, Paris 1725, zit. S. 594; Lyse Roy, Caen (Anm. 18), S. 33.

20 Theurot, Service (Anm. 2), S. 276; Laurent Waelkens, L'influence de la fondation de la Faculté de droit de Louvain (1425) sur la formation des Pays-Bas, in: Science politique et droit public dans les facultés européennes (XIIIe-XVIIIe siècle), hg. von Jaques Krynen und Michael Stolleis, Frankfurt a. M. 2008, S. 251-261, hier: S. 257; Klaus Oschema, Des Fürsten Spiegel? Anmerkungen zu den Bibliotheken der burgundischen Herzöge im 14. und 15. Jahrhundert, in: Buchkultur im Mittelalter: Schrift, Bild, Kommunikation, hg. von Michael Stolz, Berlin [u.a.] 2005, S. 177-192, hier: S. 179, 183 u. 191; Sven Stelling-Michaud, remarques (Anm. 17), S. 79.

21 Theurot, Fondation (Anm. 1), S. 33.

22 Theurot, Service (Anm. 2), S. 276; Henri Beaune und Jules D'Arbaumont, universités (Anm. 4), S. 190. 
denn diese Professorenräte kamen aus Italien wie aus dem burgundischen Raum oder auch aus den nördlichen Gebieten des Burgunderreiches, so wie der Flame Jean de Maldeghem, aus einer alten Adelsfamilie Flanderns. 1429 war er Rektor in Dôle und 1432 Professor im droit civil. Nicht wenige der Rechtsprofessoren waren nebenbei im Parlament von Dôle tätig, womit die mit der Gründung beabsichtigte Wirkungsweise, das Ineinandergreifen von Universität und Verwaltung mit entsprechender Wissenszirkulation, sich erfüllt hatte ${ }^{23}$. Die Professoren konnten durch die Tätigkeit im Parlament vor allem auch ihr Einkommen verbessern, so wie es Professoren in Orléans taten, wo ein Sitz im Parlament weit besser entschädigt wurde als die Professur selbst ${ }^{24}$.

Philipp der Gute umgab sich entsprechend immer mit einem gelehrten Beraterstab und es ist kein Zufall, dass ihm bei der Gründung der Universität Dôle ein in fachlicher und diplomatischer Hinsicht äusserst versierter Rechtsgelehrter zur Seite stand, sein Kanzler burgundischer Herkunft Nicolas Rolin (1376-1462). Rolin hatte bereits unter Philipps Vater, Johann ohne Furcht, gedient. Nicolas Rolin, Lizentiat der Rechte und Bakkalar des Kirchenrechts, studierte zusammen mit seinem Bruder Jean wahrscheinlich in Avignon und beendete um 1401 seine Studien ${ }^{25} .1408$ stand Rolin als Advokat im Parlament in Paris, dem königlichen Gerichtshof, bereits in hohem Ansehen und war auch für die Pariser Universität tätig ${ }^{26} .1420$ erscheint er als deren Advokat im Pariser Parlament ${ }^{27}$. Seinen Erfahrungshorizont aus der praktischen, juristischen Tätigkeit konnte er bei der Gründung der Universität Dôle einbringen. Als Advokat wusste er um den Einfluss der Juristen im Staatsdienst, durch seine burgundische Herkunft, aus Autun, das rund 100 Kilometer entfernt von Dôle liegt, war er mit den geopolitischen Ordnungen und Machtkonstellationen der Region vertraut. Für seine Bestrebungen, die burgundische Unabhängigkeit zu stärken, konnte die Gründung einer Landesuniversität nur folgerichtig sein. Rolin hatte bei der Standortwahl seinen Einfluss mit Bestimmtheit geltend gemacht. Er kannte die Verhältnisse in Dôle bestens. 1413 erscheint er, noch in Diensten am Hof von Johann ohne Furcht, als Conseiller im Parlament von Dôle ${ }^{28} .1422$ wird das Parlament fest in Dôle installiert, 1423 nahm die Universität ihren Betrieb auf und damit war eine Struktur geschaffen, wie sie Rolin von Paris als Advokat vertraut war. Auch bei den Gründungsbestrebungen für die Universität Löwen machte Nicolas Rolin seinen Einfluss sicher geltend, ohnehin hielt er sich damals oft in der Region auf wegen

23 Francis Rapp, Universités et principautés: les Etats bourguignons, in: Milan et les états bourguignons. Deux ensembles politiques princiers entre Moyen Âge et Renaissance (XIVe-XVIe s.). Rencontres de Milan (1-3 oct. 1987), hg. von Jean-Marie Cauchies und Giorgio Chittolini, Basel 1988, S. 115-131, hier: S. 120; Henri Beaune/D'Arbaumont, universités (Anm. 4), S. 189 und passim.

24 In der ersten Hälfte des 16. Jahrhunderts, vgl. Hilde De Ridder-Symoens, Milieu social, études universitaires et carrière des conseillers au conseil de Brabant (1430-1600), in: Recht en instellingen in de oude Nederlanden tijdens de middeleeuwen en de nieuwe tijd. Liber amicorum Jan Buntinx, Louvain 1981, S. 257-301, hier: S. 292.

25 Berthier/Sweeney, Rolin (Anm. 10), S. 29-30.

26 Berger, Rolin (Anm. 5), S. 36.

27 Serge Lusignan, La construction d'une identité universitaire en France (XIIIe-XVe siècle): «vérité garde le roy» (Publications de la Sorbonne), Paris 1999, S. 65 u. 117.

28 Berger, Rolin (Anm. 5), S. 38. 
der Niederlandepolitik von Herzog Philipp dem Guten ${ }^{29}$. Im Gegensatz zu Dôle war der Einfluss der Stadt in Löwen auf die Gründung aber wesentlich grösser ${ }^{30}$. In Rom setzte sich zudem Anselm Fabri von Breda (1379-1449), ein Vertrauter Philipps des Guten, für die Gründung der Universität Löwen ein. Fabri studierte 1412 in Bologna und wurde dort 1415 zum Lizenziat des Kirchenrechts promoviert. Fabri hatte zuvor an der Stiftungsbulle der Universität Rostock mitgearbeitet und konnte seine Erfahrungen nun für Löwen erfolgreich einbringen. Zur Eröffnung der Universität war er als Ehrengast der Stadt geladen. Anselm Fabri war auch in Diensten der Herzöge von Brabant wie auch Philipps des Guten, verschiedentlich wird er in Briefen Philipps des Guten als dessen Rat bezeichnet, so wie auch der Pariser Gelehrte Robert Auclou, ordentlicher Vertreter des Herzogs an der Kurie und sein Gesandter am Basler Konzil ${ }^{31}$. Den beiden Gelehrten gab Philipp der Gute später die Anweisung, seinen Abgesandten, den Lizentiaten der Rechte Jean Ostius, in Rom zu unterstützen, um die Errichtung der theologischen Fakultät in Löwen 1432 zu erreichen, was nach Jahren erfolgloser Versuche dann endlich gelang. Gleichzeitig wurde das studium generale in Löwen zur Universität erhoben ${ }^{32}$.

Wie in Dôle waren in Löwen Universitätsgründung, Zentralisierung der Verwaltung und Förderung der Legisten bzw. des römischen Rechts aufeinander abgestimmt. Die beiden Universitäten erscheinen als vergleichbare Bausteine in einem burgundischen Grossprojekt zur Festigung und Zentralisierung der Herrschaft. Ab 1430 konnte Philipp der Gute seinen Einfluss verstärken, da er ab diesem Zeitpunkt Landesherr beider Universitäten war durch das Erbe des Herzogtums Brabant von seinem Onkel Johann von Burgund. Das Prinzip seiner Herrschaft gründete er nach Waelkens auf dem römischen Recht, auf dessen Vermittlung und Anwendung durch die Legisten. Das römische Recht war Herrschafts- und Machtmittel nach dem Prinzip (gouverner par la jurisprudence). So wurde zum Beispiel durch das römische Recht die Möglichkeit einer Appellation auf Fürstenebene geschaffen, um traditionelle lokale Gerichtsinstanzen zu umgehen und die lokalen Machtträger entsprechend zu schwächen ${ }^{33}$.

29 Berger, Rolin (Anm. 5), S. 69-73.

30 Rainer Christoph Schwinges, Deutsche Universitätsbesucher im 14. und 15. Jahrhundert. Studien zur Sozialgeschichte des Alten Reiches, Stuttgart 1986, S. 137.

31 Brigide Schwarz, Anselmus Fabri (Smit) aus Breda in Brabant (1379-1449), Abbreviator, Referendar, Protonotar und - beinahe - Kardinal : Skizze einer Biographie, in: Quellen und Forschungen aus italienischen Archiven und Bibliotheken, 88, 2008, S. 161-219, hier: S. 192; Thomas Woelki, Lodovico Pontano (ca. 1409-1439). Eine Juristenkarriere an Universität, Fürstenhof, Kurie und Konzil, Leiden 2011, S. 450.

32 Placide Lefèvre, Une lettre de Philipppe le Bon en faveur de la création d'une faculté de théologie à l'université de Louvain, in: Ephemerides theologicae Lovanienses, 40, (1964) S. 491-494.

33 Waelkens, Influences (Anm. 20), S. 252: «En fait le gouvernement par la jurisprudence était la formule du gouvernement selon le droit romain.» 


\section{Eine berühmte Juristenuniversität}

Die Gründung der Universität Dôle war von Beginn an eine Erfolgsgeschichte. Dôle konnte sich innert kurzer Zeit als Juristenuniversität etablieren und war schon bald von grosser Bekanntheit, zog im Laufe der Jahrhunderte viele Gelehrte aus ganz Europa an, so auch einen schillernden Gelehrten wie Heinrich Cornelius Agrippa von Nettesheim, der in Dôle gelehrt hatte ${ }^{34}$.

Berühmtheit erlangte in Dôle nur die juristische Fakultät, vor allem im 16. Jahrhundert und besonders durch die Vermittlung des römischen Rechts. Dôle wird in der Literatur sodann als «Strahlungspunkt römischen Rechts» oder auch als «Tor zu Europa» für die Verbreitung des römischen Rechts bezeichnet und die Franche Comté als Region, von wo aus das «römische Recht Europa erobert hat» ${ }^{35}$. Wobei die Wege und Wirkungen dieser Rechtsinnovationen noch vertieft zu untersuchen wären.

Zeitgenossen berichteten über das hohe Ansehen von Universität und Rechtslehre. Nach dem Mediziner Gervasius Marstaller (1520-1578) blühte 1547 tatsächlich nur das Studium der Rechte ${ }^{36}$. Als sich Lucas Geizkofler (1550-1620) 1574 an der Universität aufhielt, verfügte sie immer noch über einen guten Ruf $^{37}$. Um 1600 schrieb Thomas Platter der Jüngere (1574-1628), der von Paris nach Dôle gereist war, in sein Reisetagebuch, dass Dôle wegen der Rechtslehre weitherum berühmt sei und von etlichen Auswärtigen und Deutschen besucht werde. Der reformierte Platter stellte auch einen Religionseifer als Boden einer scharfen spanischen Inquisition fest, durch welche, so Platter, selbst in dieser Zeit noch viele Reformierte in Dôle verbrannt würden. Platter verglich die Zustände mit den Niederlanden und zweifelte, dass dort mit gleicher Härte in Religionssachen vorgegangen würde ${ }^{38}$.

\section{Im Land der Legisten}

Die Gründung der Universität Dôle war auf fruchtbaren Boden gefallen. Das Konzept einer Juristenuniversität in einem wenig dicht bevölkerten Gebiet schuf einen neuen Wissensraum, gab ihm seine Prägung, eine Identität, füllte ihn mit neuen, rechtlichen Lehren, Anschauungen, Ideen, Texten und Gelehrten. Die Franche Comté wurde zum «Land der

34 RAG (Anm. 80), Heinrich Cornelius - UniquID: ngBR1A476Bz24qxBvBUq7ZnI, 9.7.2018.

35 Rudolf Hoke, Die Freigrafschaft Burgund, Savoyen und die Reichsstadt Besançon im Verbande des mittelalterlichen deutschen Reiches, in: Zeitschrift der Savigny-Stiftung für Rechtsgeschichte, Germanistische Abteilung Bd. 79 (1962) S. 106-194, Zitat S. 186; Andreas Walther, Die Anfänge Karls V., Leipzig 1911, Zitat S. 28.

$36 \mathrm{Zu}$ welchem sich Gelehrte zur selben Zeit vereinzelt kritisch äusserten, vgl. Karl Heinz Burmeister, Das Studium der Rechte im Zeitalter des Humanismus im deutschen Rechtsbereich, Stuttgart 1974, S. 71; RAG (Anm. 80), Gervasius Marstaller - UniquID: ngQG5f577Qo39fmQkQZf0OcB, 9.7.2018.

37 Manfred Linsbauer, Lukas Geizkofler und seine Selbstbiographie, in: Veröffentlichungen des Tiroler Landesmuseums Ferdinandeum 60 (1980), S. 35-84, hier: S. 56.

38 Die Quellenstellen bei Rut Keiser, Akademische Ökumene um 1600 im Spiegel des Reisetagebuches des jüngeren Thomas Platter aus Basel 1595-1600, in: Schaffhauser Beiträge zur Geschichte, 45, 1968, S. 291-315, hier: S. 314-315. 
Legisten». Der Legist, so Walther, suchte «Geld, Ehre, Einfluss auf die Geschäfte», er steht in Konkurrenz zum Adel und unterstützt darum Bestrebungen seines Fürsten, die Herrschaft zu zentralisieren ${ }^{39}$. Dies entspricht dem Profil des Kanzlers Nicolas Rolin, der mit der Universitätsgründung den Boden vorbereiten konnte für Legisten seines Typs, seiner geographischen und bürgerlichen Herkunft, für soziale Aufsteiger, die Karriere machen wollten, was ihnen oft in beindruckender Weise gelang. Gemessen an ihrer vergleichsweise bescheidenen Grösse produzierte die Universität Dôle eine beachtliche Zahl an Gelehrten, die in Spitzenpositionen gelangten. Besonders die burgundischen Gelehrten waren in auffallender Weise erfolgreich, speziell Gelehrte aus der FrancheComté, wobei die burgundischen Gelehrtennetzwerke offenkundig sehr effektiv funktionierten. Neben Nicolas Rolin waren auch die Kanzler Karls des Kühnen (1433-1477) und Philipps des Schönen (1478-1506) Burgunder, wie auch die wichtigen Sekretäre von Margarete von Österreich (1480-1530), Statthalterin der habsburgischen Niederlande. Stark vertreten waren die burgundischen Räte am Hof Karls V. (1500-1558), welche aus der «unbedeutenden Landschaft» der Franche-Comté stammten, einer Landschaft, die einige bedeutende Juristenfamilien hervorbrachte wie die der Carondelet ${ }^{40}$. Die Lage der Franche-Comté, inmitten der französischen, deutschen, eidgenössischen und italienischen Kulturräume sowie die Einflüsse Italiens auf die Universität gaben der FrancheComté einen «internationalen Charakter», welcher der Weltoffenheit der Studenten und Gelehrten förderlich war und den Karrierehorizont erweitern konnte ${ }^{41}$.

\section{Dôle als Drehscheibe für Karrierewege}

Die Vielfalt der Karrierewege von Studenten und Gelehrten, welche die Universität Dôle besuchten, wäre zuerst durch eine systematische Auswertung der Matrikeln gründlich zu quantifizieren. Damit würden sich auch die Transitrouten der Gelehrten, die sich in Dôle kreuzten, deutlicher abzeichnen und einhergehend könnte der gelehrte Wissenstransfer von und nach Dôle erhellt werden. Letzteres vor allem auch durch eine Untersuchung zu Tätigkeiten der Gelehrten in weltlichen und kirchlichen Institutionen sowie zu ihren persönlichen Verbindungen. Diese teils sehr dichten Gelehrtennetzwerke können selbst für die folgenden Gelehrten untereinander bei Weitem nicht aufgezeigt werden, wie auch ihre zahlreichen Karrierestationen nicht. Vorerst sollen deshalb einige Karrierewege nur skizziert werden, angefangen mit Gelehrten aus der Franche-Comté.

39 Walther, Anfänge (Anm. 35), S. 28; John Bartier, Légistes et gens de finances au XVe siècle. Les conseillers des ducs de Bourgogne Philipppe le Bon et Charles le Téméraire, Bruxelles 1955.

40 Zit. nach Walther, Anfänge (Anm. 35), S. 27; Alfred Kohler, Zur Bedeutung der Juristen im Regierungssystem der «Monarchia universalis» Kaiser Karls V., in: Die Rolle der Juristen bei der Entstehung des modernen Staates, hg. von Roman Schnur, Berlin 1986, S. 649-674, hier: S. 658.

41 Walther, Anfänge (Anm. 35), S. 29. 
Nicolas Perrenot de Granvelle (1484-1550) begann seine Karriere an der Universität Dôle. Er wuchs unweit von Besançon in einfachen bürgerlichen Verhältnissen auf, immatrikulierte sich 1504, absolvierte ein Rechtsstudium und wurde ebendort zum Doktor beider Rechte promoviert, später dann auch nobilitiert ${ }^{42}$. Perrenot machte Karriere am Hof Karls V. und folgte 1530 auf den Grosskanzler Gattinara ${ }^{43}$. Der Jurist Jean Matal (um 1517-1597), Vertreter einer humanistischen Jurisprudenz, stammte aus einer eingesessenen Bürgerfamilie aus der Franche-Comté. Matal war wie schon sein Vater, Jean Matal der Ältere, Reich und Kaiser zugewandt. Sein Vater hatte schon verschiedenen Regenten des habsburgischen Hauses gedient, wurde nobilitiert, in den Ritterstand erhoben und in die kaiserliche familia aufgenommen ${ }^{44}$. Jean Matal der Jüngere begann seine Studien an der heimatlichen Universität Dôle, besuchte dann die Universität in Freiburg im Breisgau und verbrachte einen längeren Studienaufenthalt in Italien. Sein weiterer Weg führte ihn über die Niederlande nach Köln ${ }^{45}$. Dort erhielt er einen Ruf an die Universität Löwen für eine Professur in römischem Recht, den er jedoch aus verschiedenen Gründen ablehnte. Matal gehörte dem humanistischen Kreis der Reformjuristen an. Sein Reform- und Gestaltungswille erinnern an andere talentierte Juristen aus der Franche-Comté, wie an einen Gilbert Cousin (1506-1572), Jurist und Theologe, Sekretär des Erasmus von Rotterdam, Studienfreund des erwähnten Jean Matal.

Wenngleich die Juristen aus der Franche-Comté auch in den nördlichen Gebieten der burgundischen Herrschaft Karriere machten, so studierten sie kaum an der Universität Löwen, sondern gingen, wie Jean Matal, nach Italien ${ }^{46}$. So wie Studenten aus den Niederlanden und Belgien, die auf dem Weg nach Italien oft Zwischenhalt in Dôle einlegten. Wie der Jurist Willem Obrecht aus Delft, der sich 1492 in Löwen immatrikulierte, 1505 Rektor in Dôle war, dann nach Bologna zum Studium wechselte und schliesslich in Lüttich Sekretär und Schreiber des Gerichts der 22 wurde ${ }^{47}$. Ebenfalls aus Delft stammte der Jurist Joost (oder Josse) Sasbout, der in Dôle 1512 Rektor war $^{48}$. Auch er kehrte Richtung Norden zurück, wurde Rat im Hof von Holland, hatte verschiedene bedeutende Ämter inne und brachte es zum Kanzler Karls V. Sasbout wurde unter anderem damit beauftragt, in den neuen niederländisch-habsburgischen Gebieten Gerichtshöfe

42 Hoke, Burgund (Anm. 35), S. 176.

43 Kohler, Juristen (Anm. 40), S. 663-666.

44 Matal der Ältere diente unter anderem Maximilian I., König Philippp I. von Spanien, Margarethe von Österreich und Kaiser Karl V., siehe Peter Arnold Heuser, Jean Matal. Humanistischer Jurist und europäischer Friedensdenker (um 1517-1597), Köln 2003, S. 34.

45 Heuser, Matal (Anm. 44), S. 162 u. 442.

46 RAG (Anm. 80), Gilbert Cousin - UniquID: ngHX2K072GP80wdPbGgw1Fta, 9.7.2018; siehe zu den burgundischen Studenten in Bologna Sven Stelling-Michaud, La «nation» de Bourgogne à l'université de Bologne du XIIIe au XVIe siècle, in: Mémoires de la Société pour l'histoire du droit et des institutions des anciens pays bourguignons Bd. 18 (1956) S. 8-43.

47 RAG (Anm. 80), Wilhelm Obrecht - UniquID: ngPF8W072QX80elfjOYebNbK, 9.7.2018; Bibliothèque et Archives Municipales Besançon, Ms 982, fol. 51: Giullaume Obrecht.

48 Bibliothèque et Archives Municipales Besançon, Ms 982, fol. 86: Josse Sasbout. 
einzurichten. ${ }^{49}$ Bei den Gelehrten aus den nördlichen Gebieten des Burgunderreiches gilt es jedoch zu differenzieren, dass gelehrte Räte im Rat von Brabant die Universität Dôle durchgehend nicht besuchten, was erklärungsbedürftig ist, aber Studenten aus den südlichen Niederlanden durchaus, vor allem auf dem Weg nach Italien ${ }^{50}$.

In anderer Richtung, auf der Achse von Italien Richtung Norden, war Dôle nicht nur Transitort, sondern konnte, durch Tätigkeiten in der burgundischen Verwaltung oder an der Universität, Sprungbrett für die weitere Karriere werden ${ }^{51}$. Beispielhaft ist Raimondo de Marliano (um 1410-1475) aus einer bedeutenden Mailänder Familie, deren Mitglieder im Dienste der Herzöge von Mailand standen und die einige Gelehrte hervorbrachte, die beachtliche Karrieren hinlegten, vor allem in Italien, aber als Ausnahme auch auswärts ${ }^{52}$. So wie Raimondo Marliano, der seine Karriere im burgundischen Herrschaftsbereich machte, wo er sich auch niederliess und nur bei diplomatischen Angelegenheiten nach Italien zurückkehrte. Seine universitäre Ausbildung hatte er in Italien absolviert. 1436 wurde Marliano in Pavia zum Doktor beider Rechte promoviert, er trat zwei Jahre später ins Mailänder Juristenkolleg ein und lehrte 1441 an der Universität Dôle die Rechte. 1443 wird er als Rat Philipps des Guten im burgundischen Parlament erwähnt. Naheliegend ist es, dass ihn der Herzog an die Universität Dôle gerufen hatte, denkbar ist es auch, dass die Mailänder Herzöge ihn zugleich empfohlen oder gar entsandt hatten, um ihn auch als Mittelsmann zwischen den Herzogtümern Mailand und Burgund zu installieren. Marliano blieb längere Zeit in Dôle und trug mit seiner Lehrtätigkeit sicherlich zum guten Ruf als Juristenuniversität bei. 1460 wollte ihn die Stadt Basel mit Unterstützung des Grafen Ulrich von Württemberg als Professor für die eben gegründete Universität gewinnen, doch Marlianos Gehaltsvorstellungen überstiegen die Erwartungen des Basler Rats ganz offensichtlich ${ }^{53}$. Nur wenig später kam der Ruf aus Löwen, wohl nicht zufällig, denn Marlianos Marktwert war durch die Gründung der Universität Basel, die gezielt italienische Professoren suchte, sowie auch durch die Gründung der Universität Freiburg im Breisgau gestiegen. Marliano entschied sich jedoch für Löwen, ausschlaggebend dürfte neben dem deutlich höheren Gehalt als in Basel der Verbleib im burgundischen Herrschaftsbereich mit den Vorteilen seines ausgezeichneten politischen Netzwerkes den Ausschlag gegeben haben ${ }^{54}$. Marliano lehrte in Löwen

49 Serge ter Braake, Met recht en rekenschap: de ambtenaren bij het Hof van Holland en de Haagse Rekenkamer in de Habsburgse Tijd (1483-1558), Hilversum Verloren 2007, S. 159 ff.

50 De Ridder-Symoens, Conseillers (Anm. 24), S. 287; siehe auch Ad Teervort, The iter Italicum and the Northern Netherlands: Dutch students at Italian universities and their role in the Netherlands' society (1426-1575), Leiden 2005.

51 Hoke, Burgund (Anm. 35), S. 179.

52 Siehe eingehend zu Marliano und zum Folgenden: Werner Paravicini, Raimondo de Marliano. Ein Schicksal des Quattrocento zwischen Italien und Burgund, in: Revue belge de philologie et d'histoire, tome 89, fasc. 3-4, 2011, S. $1075-1164$.

53 Guido Kisch, Die Anfänge der Juristischen Fakultät der Universität Basel 1459-1526, Basel 1962, S. 47.

54 Paravicini, Marliano (Anm. 52); Wilhelm Vischer, Geschichte der Universität Basel. Von der Gründung 1460 bis zur Reformation 1529, Basel 1860, S. 67-69. In Löwen wurden Marliano 1461400 Rheinische Gulden geboten, was das Basler Angebot, dessen Höhe wir nur indirekt durch andere Saläre für italienische Rechtsprofessoren zur selben Zeit abschätzen können, sicher deutlich übertraf. 
seit 1461 Kirchenrecht, so wie er es vorher in Dôle getan hatte ${ }^{55}$. In Löwen gewann Marliano weiter an Ansehen und wurde $\mathrm{zu}$ einem gefragten Rechtsexperten, einem $\langle\text { Starjuristen }\rangle^{56}$. Marliano war darüber hinaus Domherr in Lüttich und Besançon und Rat im Dienst von Philipp dem Guten und Karl dem Kühnen, von welchen er mit diplomatischen Aufgaben betraut wurde. In diesem Kontext erscheint Marliano als Bindeglied zwischen den Burgunder und Mailänder Herzögen, für die Marliano parallel tätig war und dabei sein ausgezeichnetes Netzwerk spielen lassen konnte, so wie bei einer Besprechung mit Kardinal Jean Rolin, Sohn des Kanzlers Nicolas Rolin, 1452 in Mailand. Rolin berichtete Marliano über einen Vertrag Philipps des Guten, welcher die Informationen an den Mailänder Herzog weitergab. Die Funktion des Ratgebers zweier Seiten hatte nicht zufällig ein späteres Mitglied der Familie, der Arzt und Rat Luigi de Marliano in der habsburgisch-burgundischen Zeit ${ }^{57}$. Freundschaftliche Verbindungen und der Austausch zwischen Mailand und Burgund zeigen sich ebenso bei der Berufung Raimondos an die Universität Löwen. Francesco Sforza bezeichnete die Berufung in einem Schreiben an Philipp den Guten und seinen Rat Jean de Croy, aus dem französisch-burgundischen Adelsgeschlecht der Croy, als Ehrenerweis an Marliano und er würdigte seine Verdienste ${ }^{58}$. Die Besonderheit der Quellenüberlieferung zur Person Marlianos ist sein Testament, welches ein Licht auf den Erkenntnisgewinn aus der Verbindung von Personen und ihren schriftlichen Wissensbeständen wirft, erhellt doch erst sein Testament den Lebensweg dieses Gelehrten, reichert ihn an mit bemerkenswerten Beobachtungen zu seinen Lebensstationen, so auch eine umfangreiche Studienstiftung für ärmere Studenten und die Errichtung des Collegoium Marlianorum in Pavia für elf Studenten. Auch Stadt und Universität in Löwen wie Dôle wurden im Testament bedacht und ermächtigt, Studenten auszuwählen, die durch die Stiftung begünstigt wurden $^{59}$. Jean Carondelet, einer der Testamentsexekutoren und Kanzler Maximilians, stammte aus der erwähnten Juristenfamilie aus Dôle, wo er auch seine Rechtsstudien absolviert hatte ${ }^{60}$.

Im Unterschied zu den Burgundern war für französische Studenten Dôle, angesichts der Universitätsdichte im eigenen Land, hingegen bei Weitem nicht erste Wahl für den

55 Paravicini, Marliano (Anm. 52), S. 1097-1098.

56 So die Bezeichnung von Paravicini, Marliano (Anm. 52), S. 1116.

57 Paravicini (Anm. 52), S. 1108 Anm. 175; Andreas Walther, Anfänge (Anm. 35) S. 29. Luigi (Ludovico/Ludovicus/ Louis/Aloisius) de Marliano war Leibarzt der Herzöge von Mailand wie auch Karls V., dessen Rat er ebenso war wie derjenige Phillips des Schönen und Margaretes von Österreich.

58 Paravicini, Marliano (Anm. 52), S. 1104 u. S. 1120: Marlianos juristische Brillanz zog naturgemäss auch den Neid an. In einer Auseinandersetzung zwischen Bischof und Stadt Lüttich vertrat Marliano erfolgreich den Bischof. Er konterte in beeindruckender Art und Weise die Argumentation dreier Kölner Universitätsjuristen, welche die Stadt für den Streitfall eigens angestellt hatte. Anerkennend rühmte der Geistliche, der 1462 darüber berichtet hatte, die Literaturkenntnisse Marlianos - mit den Sitten und Leuten des Landes sei er als Italiener hingegen nicht vertraut, so werde berichtet.

59 Paravicini, Marliano (Anm. 52), S. 1082.

60 Kohler, Karl V. 1500-1558. Eine Biographie, 3. Auflage, München 2014, S. 123. 
Besuch einer Reichsuniversität. Sie gingen in erster Linie nach Löwen oder Köln ${ }^{61}$. In anderer Richtung, für Studenten aus dem Reich, war Dôle attraktiver. Eine Auszählung von Stammbucheinträgen deutscher Studenten an italienischen und französischen Universitäten im 16. Jahrhundert enthält bei den französischen Universitäten für Dôle die meisten Einträge, noch vor Paris und Orléans ${ }^{62}$. Besonders für Adelige aus dem Reich war Dôle wichtiger Transitort auf dem Weg nach Italien oder Frankreich, wobei solche Bildungsreisen auf den Adel oder sozial höhergestellte Studenten begrenzt waren und entsprechend eine Ausnahme darstellten hinsichtlich studentischer Mobilität ${ }^{63}$. Die viel begangene Adelsroute via Dôle nach Frankreich hatte aber immerhin Eingang gefunden in den Adelsspiegel von Cyriacus Spangenberg (1528-1604), dem wichtigen Nachschlagwerk der Frühen Neuzeit zur vorbildlichen adeligen Lebensweise. Den massgebenden juristischen Studienweg stellt Spangenberg am Beispiel des Georg von Crailsheim dar, der Lust am Rechtsstudium bekommen habe, woraufhin Freunde ihm die Universität Ingolstadt empfohlen hätten, die damals den besten Ruf bezüglich des Rechtsstudiums in Deutschland gehabt habe. Crailsheim immatrikulierte sich somit 1544 in Ingolstadt ${ }^{64}$. Nach einigen Studien in Ingolstadt, so Spangenberg weiter, habe er die Universitäten Dôle, Orléans und Paris besucht, die französische Sprache gelernt und so gut wie das Deutsche beherrscht ${ }^{65}$.

Der französische Kulturraum hatte Anziehungskraft für den Adel, und Dôle bot eine gute Möglichkeit, im geschützten Herrschaftsbereich des Reiches einen fremden Kulturkreis $\mathrm{zu}$ betreten und sich mit ihm vertraut $\mathrm{zu}$ machen. Idealtypisch hierzu ist das Beispiel des vielseitig begabten Rechtsgelehrten Johann Wolff (1537-1600) aus Bergzabern $^{66}$. Seine Ausbildung begann mit dem Besuch des Gymnasiums in Strassburg. Dann studierte Wolff an den Universitäten Wittenberg und Tübingen und wandte sich schliesslich juristischen Studien in Frankreich zu an den Universitäten Bourges, Angers und Dôle. Nachfolgend bereiste er Frankreich sowie Burgund und erwarb profunde Kenntnisse des Französischen. Zurück im Reich wurden die Herzöge von Pommern-Stettin, die Brüder Ernst Ludwig (1545-1592) und Barnim (1549-1603), auf ihn aufmerksam, nicht zuletzt aufgrund seiner sehr guten Kenntnisse der französischen Sprache. Die Brüder hatten zuvor in Wittenberg gemeinsam studiert, 1563 bekleidete Ernst Ludwig das Amt des Ehrenrektors der Universität und im darauffolgenden Jahr

61 Rainer Christoph Schwinges, Studenten und Gelehrte. Studien zur Sozial- und Kulturgeschichte deutscher Universitäten im Mittelalter, Leiden/Boston 2008, S. 147.

62 Wolfang Klose, Stammbucheinträger an italienischen und französischen Universitäten im 16. Jahrhundert, in: Dona Melanchthoniana. Festgabe für Heinz Scheible zum 70. Geburtstag, hg. von Johanna Loehr, 2. Aufl. Stuttgart/ Bad Cannstatt 2005, S. 211-215, hier: S. 213.

63 Vgl. Schwinges, Studenten und Gelehrte (Anm. 61), S. 592.

64 RAG (Anm. 80), Georg von Crailsheim - UniquID: ngDT1C678EV4pszLxCcs1Bps, 9.7.2018.

65 Cyriacus Spangenberg, Adels-Spiegel (Band 2): Was Adel mache, befördere, ziere, vermehre [...], Schmalkalden 1594, fol. 194r: Als er nun seine fundamenta nach notdurfft gelegt / und lust ad Iurisprudentiam gewonnen / ist er auff seiner Freunde rhat gen Ingolstadt (welche Academia damals des Studij Iruis halben den groesten beruff in Deutschland gehabt) verschickt worden...

66 Wolfgang Irtenkauf, Johann Wolff, in: Lebensbilder aus Schwaben und Franken, 13, 1977, S. 73-83. 
war die Reihe an Barnim ${ }^{67}$. Die protestantischen Herzöge wählten nun Dôle als weiteren Studienort, was exemplarisch die interkonfessionelle Offenheit, die an dieser katholischen Universität gepflegt wurde, bezeugt. Johann Wolff begleitete die Herzöge nach Dôle, wo er am 29. Januar 1568 zum Dr. jur. promoviert wurde. Die Kosten für die Promotion übernahmen die Herzöge. Nach dem Aufenthalt in Dôle begann Wolff eine Juristenlaufbahn am Reichskammergericht in Speyer, wo er nach zweijähriger Tätigkeit Beisitzer wurde. Weiter war Wolff auch als Übersetzer und Historiker tätig und in diplomatischen Missionen gefragt. Eine solche führte ihn, seiner Sprach- und Landeskenntnisse wegen, nach Frankreich. Wolff begleitete den protestantischen Pfalzgrafen Wolfgang von Pfalz-Zweibrücken (1526-1569) nach Frankreich in einem Feldzug zur Unterstützung der Hugenotten, auf welchem der Pfalzgraf erkrankte und verstarb, jedoch nicht rückgeführt wurde. Wolff wurde zwei Jahre nach dem Hinschied damit beauftragt, den verdeckten Rücktransport des Leichnams aus Frankreich durchzuführen. Da sich der Landweg als zu gefährlich erwiesen hatte, musste Wolff den Seeweg wählen und brachte, trotz Piratengefahr, den Leichnam sicher zurück ${ }^{68}$.

Der Spracherwerb war neben der juristischen Ausbildung für Studenten aus dem Reich, nicht nur für Adelige, in Dôle von grosser Bedeutung ${ }^{69}$. Da aber viele Deutschsprachige die Universität in Dôle besuchten, konnte dies den Lerneffekt behindern. In Dôle sei viel deutscher Geschäfft beklagte sich Graf Eberhard von Erbach (1511-1564), der 1528 in Dôle war, um die französische Sprache zu lernen ${ }^{70}$. Andere Studenten waren mehr an den französischen Töchtern interessiert als an deren Sprachunterricht ${ }^{71}$.

Sprachkenntnisse waren in der Gelehrtenwelt von wichtigster Bedeutung, gerade für eine Karriere in diplomatischen Diensten, sie waren im Laufe des 15. Jahrhunderts je länger je mehr unabdingbar. Johann von Lannoy (1410-1493), ein westflämischer Adeliger, war im 15. Jahrhundert für die burgundischen Herzöge tätig, so auch für Philipp den Guten, der ihn 1448 zum Statthalter von Holland und Zeeland ernannte. Lannoy bedauerte als Rat des Herzogs, nicht mehr Sprachen gelernt zu haben, und riet deshalb seinem Sohn Louis in einem Schreiben, er solle die Lateinschulen in Löwen, Köln oder Paris besuchen zusammen mit einem deutschsprachigen Priester, um dessen Sprache zu lernen. Kaiser Maximilian I. unterstützte zu Beginn des 16. Jahrhunderts Studenten, die in Paris oder Löwen Sprachen lernten. In seiner Kanzlei war mit Johannes Collauer ein Doktor beider Rechte zuständig für lateinische und französische

67 Universitäts- und Landesbibliothek Sachsen-Anhalt, Halle, Saale, Wittenberger Matrikel, Bd. 3, fol. 151r u. 160r.

68 Julius Ney, Pfalzgraf Wolfgang. Herzog von Zweibrücken und Neuburg, in: Schriften des Vereins für Reformationsgeschichte, 29, Nr. 106/107, Leipzig 1912, S. 1-124, hier: S. 93 ff.

69 Burmeister, Studium der Rechte (Anm. 36), S. 59-60.

$70 R A G$ (Anm. 80), Eberhard von Erbach - UniquID: ngWM3N577V63glsWqW716UiJ, 9.7.2018.

71 Linsbauer, Geizkofler (Anm. 37), S. 57. 
Korrespondenzen ${ }^{72}$. Der berühmte Legist aus Savoyen, Mercurino Arborio di Gattinara (1465-1530), seit 1518 Grosskanzler am Hof Karls V., war seiner breiten Sprachkenntnisse wegen gefragt ${ }^{73}$.

Neben dem Spracherwerb galt es vor allem für die Adeligen aus dem Reich, sich mit dem französischen Kulturraum vertraut zu machen. Ausritte in die Gegend von Dôle, wie sie die Grafen von Castell unternommen hatten, verschafften einen ersten Überblick. Zudem liess sich Konrad von Castell (1519-1577) von Stadtpfeifern in Dôle das welsch Tanzen beibringen, wie aus seinem Rechnungsbuch hervorgeht ${ }^{74}$. Es konnten auch Einblicke in das lokale Rechtswesen gewonnen werden. Lucas Geizkofler durfte im Parlament in Dôle einen Kriminalprozess mitverfolgen und pflegte einen juristischen Austausch mit dem bekannten Rechtsprofessor und 1574 zum Rektor in Dôle gewählten Viglius von Zwichem (1507-1577) ${ }^{75}$. Auch im 17. Jahrhundert blieb Dôle für die adelige Ausbildung eine wichtige Referenzgrösse. Gemäss den Vorgaben des Vormunds von Graf Ferdinand Bonaventura von Harrach (1637-1706) sollte dieser das Rechtsstudium ergreifen und mit dem Doktorat abschliessen. Er sollte Sprachen lernen, Französisch und welsche, in Wort und Schrift und sich in Reiten, Fechten, Tanzen und Voltegieren üben, ohne das Studium zu vernachlässigen. Der Graf studierte sodann, wie andere österreichische Adelige dies auch taten, in Dôle. In Brüssel erhielt er zudem Unterricht von einem «renommierten Rechtslehrer» und wurde während der Reisen «intensivst» in römischem Recht, in erster Linie in den Institutionen, geschult ${ }^{76}$. Der Unterricht brachte den angestrebten Erfolg. Von Harrach gelangte in verschiedene Führungspositionen, war in diplomatischen Diensten tätig und wurde Berater von Kaiser Leopold I. (1640-1705).

\section{Kulturelle Reichweiten der Universität Dôle - erste Zuweisungen}

Die kulturellen Reichweiten der Universität Dôle können vorerst nur skizziert werden. Zusätzlich zur Analyse der Karrierewege wären besonders die Texte der Gelehrten, die in Dôle studierten und lehrten, einzubeziehen, um die Ausstrahlung dieser Universität hinsichtlich der Zirkulation des gelehrten Wissens in europäischer Perspektive zu

72 Stelling-Michaud, Remarques (Anm. 17), S. 79; Burmeister, Studium der Rechte (Anm. 36), S. 60.

73 Walther, Anfänge (Anm. 35), S. 29 Anm. 1: 1518 zählte ein Gesandter die Sprachkenntnisse Gattinaras mit Bewunderung auf, neben der Muttersprache (Italienisch), beherrsche er Latein, Spanisch, Französisch und Deutsch.

74 Stephan Sauthoff, Adliges Studentenleben und Universitätsstudium zu Beginn des 16. Jahrhunderts. Darstellung anhand des Ausgabenbüchleins von Conrad zu Castell (= Europäische Hochschulschriften, Reihe 3, 367), Frankfurt am Main 1988, S. 101.

75 Linsbauer, Geizkofler (Anm. 37), S. 56 u. 75.

76 Gernot Heiss, Bildungs- und Reiseziele österreichischer Adeliger in der Frühen Neuzeit, in: Grand Tour. Adeliges Reisen und Europäische Kultur vom 14. bis zum 18. Jahrhundert. Akten der internationalen Kolloquien in der Villa Vigoni 1999 und im Deutschen Historischen Institut in Paris 2000, hg. von Rainer Babel und Werner Paravicini, Ostfildern 2005, S. 217-235, hier: S. 223, vgl. auch das Beispiel S. 22: Maximilian von Lichtenstein, Studium der Rechte 1659 in Dôle und Löwen mit dem Ziel des Doktorats. 
erschliessen, was gerade wegen der Lage dieser Institution im transkulturellen Raum mit den sich daraus ergebenden Verflechtungen von besonderem Interesse ist.

Die Universität Dôle war eine «université de passage» ${ }^{77}$. Sie kann darüber hinaus als eine 〈université de qualité〉 gesehen werden, was die juristische Fakultät anbelangt. Beide Aspekte wären in transkultureller wie wissensgeschichtlicher Perspektive zu untersuchen, auch um Wirkungen und Ausstrahlung, die von einer kleineren Universität ausgehen konnten, besser einschätzen zu können. Es waren nur ausnahmsweise mehr als 100 Studenten, welche die Universität Dôle in einem Jahr besuchten. Für das 15. Jahrhundert sind aufgrund fehlender Matrikeln nur noch rund 70 Studierende bekannt, im 16. Jahrhundert, mit dem Einsetzen der Matrikel 1498, dürften es im Jahresschnitt um die 70 gewesen $\operatorname{sein}^{78}$. Die Universität Löwen, in einem ungleich dichter bevölkerten Raum gelegen, zog im 15. Jahrhundert in Spitzenzeiten über 500 Studenten im Jahr $\mathrm{an}^{79}$. Gemessen an solch hohen Werten sind aber die zahlreichen Führungsfunktionen und leitenden Positionen von Gelehrten, welche die Universität Dôle besucht hatten, doch beeindruckend, namentlich von der Gruppe mit Herkunft aus der FrancheComté.

Einen ersten Eindruck zu den kulturellen Reichweiten gibt aus deutscher Perspektive das Repertorium Academicum Germanicum $(\mathrm{RAG})^{80}$. Die Universität Dôle ist die einzige Reichsuniversität, die das RAG noch nicht vollständig erfasst hat. Sie ist daher vergleichbar mit den Universitäten ausserhalb des Reiches, deren deutsche Universitätsbesucher grundsätzlich nur in die Datenbank aufgenommen wurden, falls sie zusätzlich zum Auslandsstudium eine deutsche Universität besucht hatten. Die systematische Erfassung der deutschen Universitätsbesucher an Universitäten ausserhalb des Reiches durch das RAG steht damit noch an. Sie wird auch im Hinblick auf eine Wissenszirkulation im europäischen Gelehrtenraum neue Perspektiven eröffnen. Somit können für Dôle bestenfalls erste Zuweisungen zu den kulturellen Funktionen und Reichweiten der Universität vorgenommen werden. Bislang wurden 45 Gelehrte gemäss der RAG-Definition für die Datenaufnahme mit Bezug zur Universität Dôle erfasst. Voraussetzung für die Aufnahme eines Gelehrten sind: Magistergrad oder ein Studium an einer höheren Fakultät (Jus, Theologie, Medizin) oder adelige Herkunft, wobei ein Gelehrter mindestens eine deutsche Universität in der Zeit von 1250-1550 besucht haben musste. Die Daten zu den Gelehrten mit einem Besuch der Universität Dôle reichen von 1440 bis 1590. Sie steigen gegen Ende des 15. Jahrhunderts kräftig an und verteilen sich klar auf das 16. Jahrhundert. 34 dieser Gelehrten waren, wie zu erwarten, Juristen, nur je drei waren promovierte Theologen oder Mediziner, die übrigen Artisten. Gut ein Drittel der Gelehrten (17) war adeliger Herkunft.

77 De Ridder-Symones, Conseillers (Anm. 24), S. 287.

78 Theurot, Fondation (Anm. 1), S. 35-38.

79 Schwinges, Universitätsbesucher (Anm. 30), S. 144.

80 Repertorium Academicum Germanicum (RAG), [www.rag-online.org]. 
Bei der geographischen Herkunft der Studenten deckt das RAG die Stadt und Region Dôle kaum ab, wie dies aufgrund der Erfassungskriterien zu erwarten ist. Aus diesem Gebiet kamen aber im 15. Jahrhundert nicht wenige der nachweisbaren Studenten, was wiederum zu erwarten ist, da aus dem näheren Raum einer Universität jeweils die meisten Studenten kamen, was sich für Dôle auch im 16. und 17. Jahrhundert bestätigen wird, wie eine kursorische Durchsicht der Matrikel bereits zeigte ${ }^{81}$. Die Herkunftsorte der Studenten, die im RAG verzeichnet sind, stehen somit für Studenten, die mindestens eine Reichsuniversität besucht hatten, vor oder nach dem Aufenthalt in Dôle.

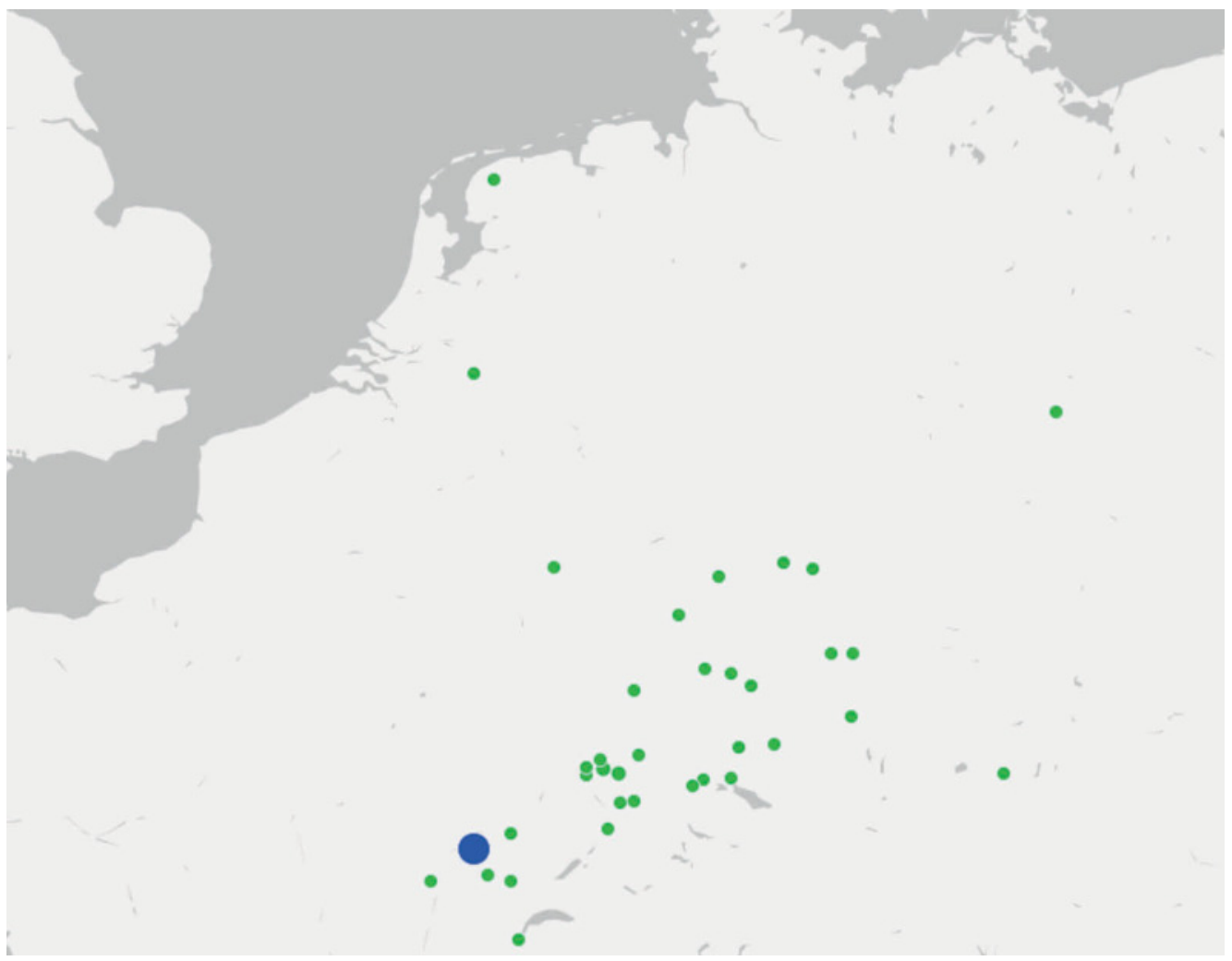

Abb. 1 Geographische Herkunft (grün) der Gelehrten im RAG mit einem Studienaufenthalt in Dôle (blau)

Die geographische Herkunft der Gelehrten (Abb. 1) zeigt deutlich die Verdichtung des Herkunftsraumes im Südwesten des Reiches und wenige im burgundischen und savoyischen Raum wie in den Niederlanden. Wie erwähnt, lassen sich die Daten deutlich eingrenzen, denn erst um die Wende zum 15. Jahrhundert nehmen sie zu, dann aber

81 Vgl. die Karte bei Jacky Theurot, Fondation (Anm. 1), S. 37; ders., Service (Anm. 2), S. 277. 
kontinuierlich, was die steigende Attraktivität des Studiums in Dôle für Studenten aus dem Reich im 16. Jahrhundert bestätigt.

Aus dem Südwesten des Reiches kamen die Adeligen wie die sozialen Aufsteiger bürgerlicher Herkunft, die Karriere machten als Juristen. Auch hier widerspiegelt sich die Konkurrenzsituation zwischen altem Adel und aufstrebenden Juristen geringerer sozialer Herkunft, wie sie in der Franche-Comté durch die Errichtung der Universität mit Absicht geschaffen wurde. Nördlichster Herkunftsort ist Leuvaarden in den Niederlanden, von hier kam einer der bekanntesten Gelehrten, welche die Universität Dôle besucht hatten, der erwähnte Rechtsgelehrte Viglius van Zwichem (Aytta) ${ }^{82}$. Nach ersten juristischen Studien an der Universität Löwen wechselt Viglius nach Dôle, wo er sich 1526-1529 aufhielt und Kontakt zu Anton Fugger (1493-1560) knüpfte. Viglius wird später das Rechtsstudium in Dôle als für Anfänger ungeeignet bezeichnen ${ }^{83}$. Im März 1529 wechselte Viglius an die Universität Avignon und wurde Schüler des grossen Juristen Andreas Alciatus ${ }^{84}$. Am 8. Mai 1529 wurde Viglius an der benachbarten Universität in Valence zum Doktor beider Rechte promoviert und folgte im Juni 1529 seinem Lehrer Alciatus nach Bourges, wo Viglius zwei Jahre blieb und während dieses Aufenthalts Alciatus zeitweise vertrat. Um 1531 verliess er Bourges und ging via Orléans, Paris, Basel und Freiburg im Breisgau nach Augsburg, um bei den Fuggern Zwischenhalt einzulegen. Anschliessend machte er sich nach Italien auf und lehrte in Padua 1532 römisches Recht. 1534 kehrte Viglius an die Universität Freiburg zurück, wo er Erasmus von Rotterdam (1466-1536) und den Rechtsgelehrten Ulrich Zasius (1461-1535) traf, der ihm seinen Lehrstuhl angeboten hatte. Viglius verzichtete aber auf das grosszügige Angebot, um in der Praxis bleiben zu können ${ }^{85} .1537$ immatrikulierte er sich an der Universität Ingolstadt, wo er Dekan der juristischen Fakultät wurde und Rechtsprofessor. Er bekleidete in der Folge mehrere hohe Ämter und wurde 1559 zum Vorsteher der Burgunder Bibliothek ernannt.

Die Karte 2 zeigt die Studienorte der Gelehrten mit einem Besuch an der Universität Dôle. Im Vergleich mit den begrenzten Herkunftsräumen fällt die hohe Mobilität der Gelehrten auf. Erkennbar werden dabei die Zieluniversitäten in Frankreich und Italien wie auch die Transitrouten, von und nach Italien, Frankreich und den Niederlanden. Diese Transitrouten, von Nordosten nach Südwesten wie von Ost nach West, waren zugleich wichtige Handelswege mit viel Verkehr, Absicherungen und Infrastruktur, was das Reisen der Studenten vereinfachte und entsprechend den Studienaufenthalt ausserhalb des heimatlichen Herrschaftsbereiches begünstigte. Das Beispiel einer oft begangenen Adelsroute, vom Reich via Dôle nach Italien, knüpft wieder an Viglius an.

82 RAG (Anm. 80), Viglius van Zwichem - UniquID: ngLB5a072KT80ahHfMUawJxa, 9.7.2018; ebd., Anton Fugger UniquID: ngGW4R577G638vceaGfv8EsN, 9.7.2018.

83 Burmeister, Studium der Rechte (Anm. 36), S. 71.

$84 R A G$ (Anm. 80), Andreas Alciatus - UniquID: ngHX7O274Gf0qwdVbIAwtFtO, 9.7.2018.

85 RAG (Anm. 80), Ulrich Zasius - UniquID: ngGW9X779Fe5pvcCaG9v1EsF7FT, 9.7.2018; ebd. Erasmus von Rotterdam - UniquID: ngVL0U870UN6ekrHpVOk3ThQ, 9.7.2018. 


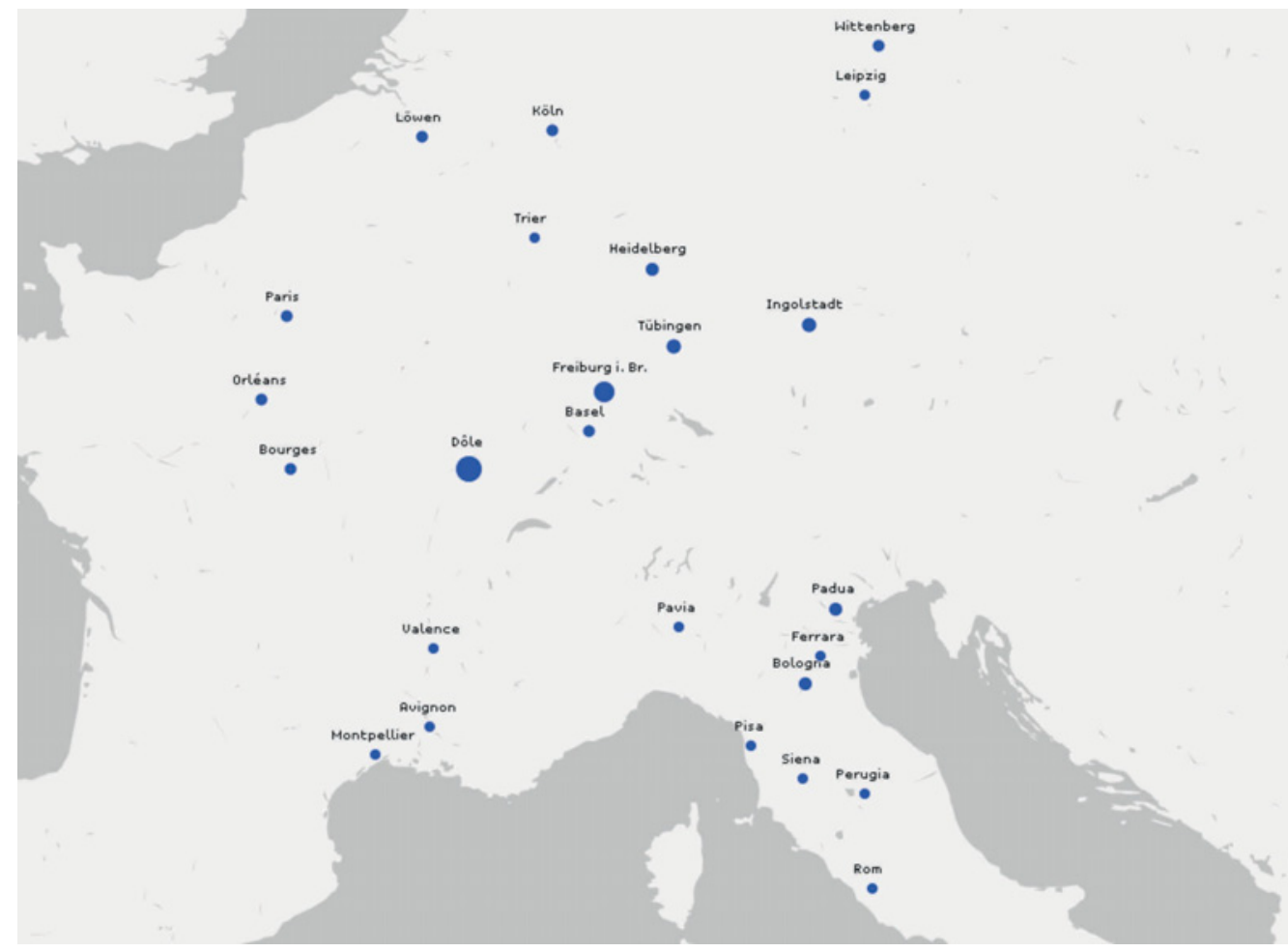

Abb. 2 Studienorte der Gelehrten im RAG mit einem Studienaufenthalt in Dôle

Unter ihm studierte 1527-1530 der Lehrer (Präzeptor) Lukas Landstrasser aus Salzburg. Landstrasser wurde in Dôle oder später in Padua zum Doktor beider Rechte promoviert. Er immatrikulierte sich 1521 an der Universität Tübingen und wurde der erste Lehrer des Freiherrn Wilhelm Truchsess von Waldburg (1518-1566). Landstrasser begleitete ihn und seinen Bruder Otto (1514-1573) zum Studium in Tübingen, wo sich Otto 1524 und Wilhelm 1526 immatrikulierten. Von Tübingen aus begab sich die Gruppe nach Dôle, wo sie von 1527 bis 1530 unter Viglius studierte und ihm 1531 nach Padua folgte, um die Studien fortzusetzen. 1532 begab sich die Gruppe auf Bildungsreise nach Venedig, danach zum Studium nach Pavia, wo Otto 1535 Rektor der Universität wurde, wie es schon sein Vater gewesen war. Im selben Jahr wurde Otto von Waldburg in Bologna zum Dr. iur. promoviert, während der letzte Studienhinweis von Wilhelm 1534 das gemeinsame Rechtsstudium in Pavia ist. Otto von Waldburg wird eine geistliche Karriere machen und unter anderem als Bischof von Augsburg und Kardinalbischof amtieren. In Dôle hatte sich der Gruppe der spätere Jurist Joachim Münsinger angeschlossen. Münsinger besuchte zuerst die Lateinschule in Stuttgart (1521-1527). Er kehrte 1531 aus Dôle nach Stuttgart zurück. Sein Vater schickte ihn dann, entgegen den Absichten Münsingers, zum Studium nach Padua. Münsinger schloss sich erneut der Gruppe an, verliess diese aber nach der Bildungsreise nach Venedig, kehrte nach Stuttgart zurück, 
immatrikulierte sich an der Universität Tübingen 1533, wechselte nach Freiburg im Breisgau, wo er 1536 zum Doktor beider Rechte promoviert wurde und anschliessend die Institutionen ebendort lehrte. Einer seiner Schüler war der bereits erwähnte Graf Konrad von Castell, der bei Münsinger Unterkunft hatte und Kostgeld bezahlte. Später wurde Münsinger Dekan der juristischen Fakultät in Freiburg wie auch Rektor. 1548 ernannte ihn der Kaiser zum Beisitzer am Reichskammergericht für den oberrheinischen Kreis.

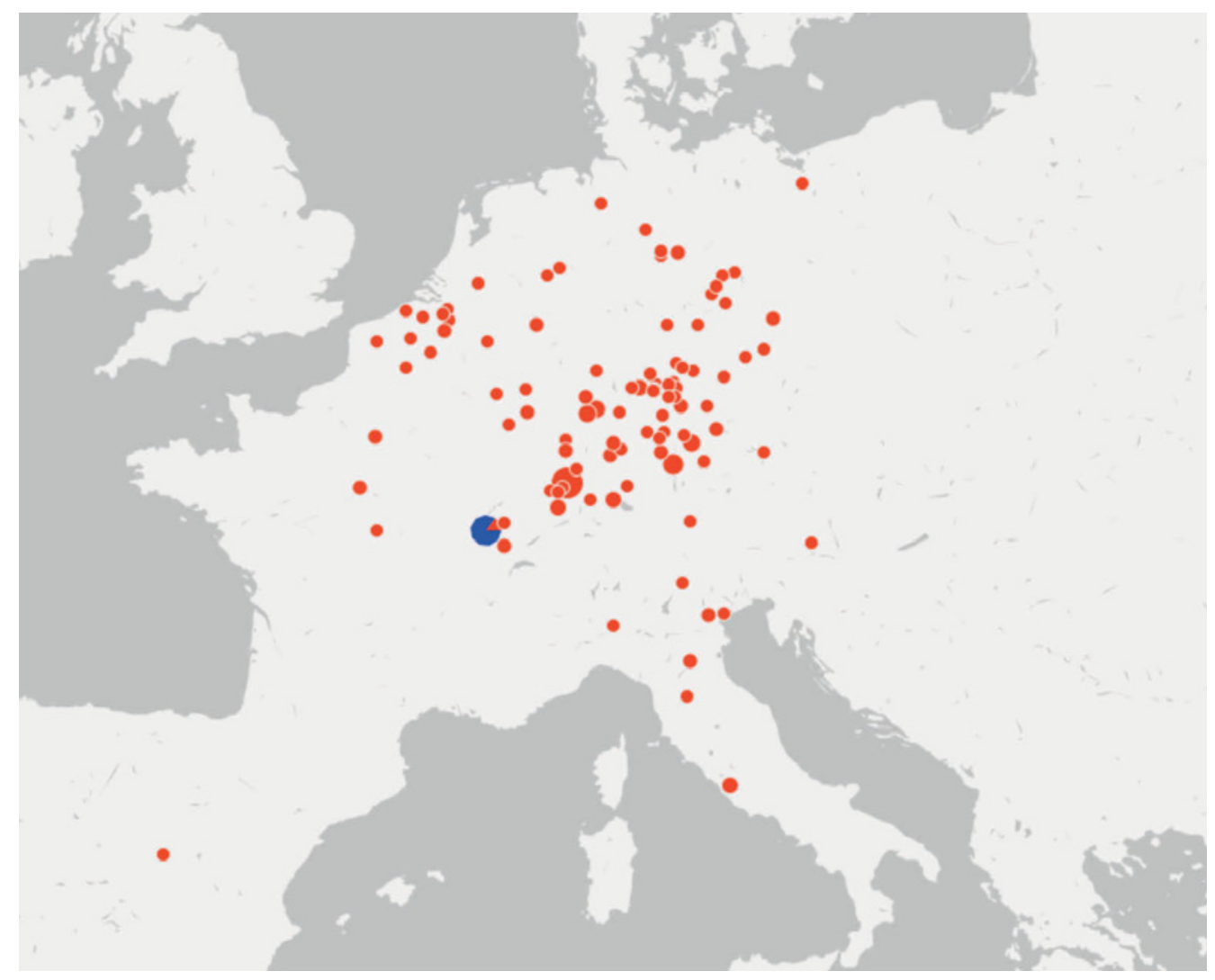

Abb. 3 Tätigkeitsorte (orange) der Gelehrten im RAG mit einem Studienaufenthalt in Dôle (blau)

Die Tätigkeitsorte (Abb. 3) der Gelehrten mit einem Studienaufenthalt in Dôle zeigen, was erwartet werden kann, da viele von ihnen in ihre Herkunftsräume zurückkehrten, wie dies auch für andere Universitäten zu beobachten ist. Wieder lassen sich aber die Verbindungen nach Italien und den Niederlanden erkennen, die durch Einbeziehung sämtlicher Studenten in Dôle entsprechend stärker hervortreten würden. Im Einzelnen betrachtet, zeigen sich Häufungen von Tätigkeiten an den Universitäten Basel, Freiburg im Breisgau und Ingolstadt, einerseits durch die Adelsrouten, vor allem zur katholischen Adelsuniversität Ingolstadt, andererseits weisen sie aber bei Basel und Freiburg auch auf die Netzwerke der Gelehrten. Einen weiteren Schwerpunkt bilden kirchliche Ämter in den Domstädten Augsburg und Speyer, was auf die adeligen Gelehrten verweist, sowie 
die Tätigkeiten am Reichskammergericht in Speyer. Zu erwarten ist unter Einbeziehung sämtlicher Studenten, die Dôle besucht hatten, eine Verdichtung der Tätigkeitsorte westlich und nordwestlich des Reiches im burgundischen Herrschaftsbereich sowie ein stärkeres Hervortreten der Transitwege von den Niederlanden nach Italien.

Es muss vorerst bei diesen skizzenhaften Betrachtungen bleiben. Stellung, Funktionen und Wirkungen der Universität Dôle in der europäischen Wissenslandschaft werden sich erst durch eine umfassende kombinierte Analyse von Matrikeln, Karrierewegen, Netzwerken und Texten der Gelehrten erschliessen lassen. Der Lebensweg des Raimondo Marliano erschliesst sich nach Paravicini nur durch eine «Zusammenschau von Nord und Süd», welche durch den Text seines Testaments erst möglich wird ${ }^{86} . \mathrm{Zu}$ beiden Aspekten kann eine Untersuchung zur Universität Dôle ihren Beitrag leisten. Dôle erweitert die Zusammenschau auch Richtung Ost und West und eröffnet damit eine breite europäische Perspektive. Sie ist im Hinblick auf die Gelehrten mit ihren Netzwerken und Texten als eine Art Drehscheibe der Wissenszirkulation im transkulturellen Raum anzusehen mit vielfältigen Wirkungen und Einflüssen auf die Gelehrtenwelt und Gesellschaft, konkret auch auf Verbreitung und Rezeption des römischen Rechts nördlich der Alpen. 


\title{
Gelehrte Mediziner am Niederrhein
}

\author{
Das Italienstudium der Ärzte am Hof Wilhelms V. von \\ Jülich-Kleve-Berg (1539-1592)
}

Die seit 1521 unter Johann III. (1490-1539) vereinigten Herzogtümer Jülich-Kleve-Berg, denen bis zum Aussterben des Hauses Mark 1609 eine bedeutende Stellung im Nordwesten des Heiligen Römischen Reiches zukam, waren lange geprägt durch eine besonnene und konfessionell auf Ausgleich bedachte Politik. Humanistisch gesinnte Räte aus dem Kreise des Erasmus hatten sowohl unter Johann III. als auch unter dessen Nachfolger Wilhelm V. (1516-1592), dessen Erzieher der Erasmianer Konrad Heresbach gewesen war, beträchtlichen Einfluss auf die politische und konfessionelle Ausrichtung des Herzogtums ${ }^{1}$. Zahlreiche der herzoglichen Räte hatten eine juristische Ausbildung an italienischen Universitäten genossen ${ }^{2}$. In diesem Beitrag sollen hingegen die Leibärzte des Düsseldorfer Hofes in den Blick genommen werden, von denen ebenfalls viele einen iter italicum unternahmen. Wie viele andere ultramontane Medizinstudenten zog es sie an die italienischen Universitäten, die die Schauplätze der drei grossen Felder medizinischer Innovation im 16. Jahrhundert waren: die Entwicklung der Botanik zum festen Bestandteil eines Medizinstudiums in Padua, Pisa und Bologna, einhergehend mit der Errichtung öffentlicher botanischer Gärten, die Begründung der klinischen Lehre durch Giovanni Battista da Monte in Padua, die zur Emanzipation der Praktiker von den

1 Vgl. für die Geschichte der Herzogtümer im 16. Jh. sowie den niederrheinischen Humanismus insbesondere Martin Szameitat, Konrad Heresbach - Ein niederrheinischer Humanist zwischen Politik und Gelehrsamkeit (Schriftenreihe des Vereins für rheinische Kirchengeschichte 177), Bonn 2010; Elisabeth M. Kloosterhuis, Erasmusjünger als politische Reformer. Humanismusideal als Herrschaftspraxis am Niederrhein im 16. Jahrhundert (Rheinisches Archiv 148), Köln/Weimar/Wien 2006; Meinhard Pohl (Hg.), Der Niederrhein im Zeitalter des Humanismus. Konrad Heresbach und sein Kreis. Referate der 9. Niederrhein-Tagung des Arbeitskreises niederrheinischer Kommunalarchive für Regionalgeschichte (Schriften der Heresbach-Stiftung Kalkar 5), Bielefeld 1997; Christian Schulte, Versuchte konfessionelle Neutralität im Reformationszeitalter. Die Herzogtümer Jülich-Kleve-Berg unter Johann III. und Wilhelm V. und das Fürstbistum Münster unter Wilhelm von Ketteler (Geschichte 9), Münster 1995.

2 Kloosterhuis, Erasmusjünger (Anm. 1), S. 457-471. 
Theoretikern beitrug, sowie die Aufwertung der Anatomie, die durch Infragestellung der antiken Autoritäten und Einführung des experimentellen Ansatzes eine grundsätzliche methodische Neuerung darstellte ${ }^{3}$.

Es soll untersucht werden, welchen Platz das Medizinstudium an den italienischen Universitäten für die Ausbildung der späteren Leibärzte am niederrheinischen Hof einnahm. Neben den Studienwegen, besuchten Universitäten und erzielten Abschlüssen sollen insbesondere die Kontakte während des Studiums, die Verflechtungen der Leibärzte untereinander sowie deren familiäre Ausbildungsstrategien betrachtet werden. Einleitend wird der Personenkreis der Ärzte am Düsseldorfer Hof skizziert, bevor anschliessend in drei Abschnitten näher auf deren Medizinstudium, die nachfolgenden Karrieren und Kontakte sowie die Studientradition der Familien eingegangen wird.

In den 1530er-Jahren, noch unter Johann III., waren die Ärzte Andreas Leenius, Simon Reichwein, Wilhelm von Grevenbroich und Johannes Isenburg am Hof tätig. Für diese Generation von Leibärzten war das Italienstudium noch kein prägendes Merkmal. Nur Grevenbroich hatte sich nach dem Artes-Studium in Köln (1511-1514) 4 in den 1520er-Jahren zum Studium in Italien aufgehalten ${ }^{5}$. Gemeinsam ist den Ärzten, lässt man Andreas Leenius aussen vor ${ }^{6}$, vielmehr das Studium in Köln sowie die Zugehörigkeit zum Kreise der 〈Erasmusjünger〉. Wilhelm von Grevenbroich war Erasmusanhänger,

3 Vgl. zu den Entwicklungen in der Medizin Claudia Zonta, Schlesische Studenten an italienischen Universitäten. Eine prosopographische Studie zur frühneuzeitlichen Bildungsgeschichte (Neue Forschungen zur schlesischen Geschichte 10), Köln 2004, S. 46-51; Ian Maclean, Trois facultés de médecine au XVIe siècle: Padoue, Bâle, Montpellier, in: Les échanges entre les universités européennes à la Renaissance, hg. v. Michel Bideaux und Marie-Madeleine Fragonard (Travaux d'Humanisme et Renaissance 384), Genf 2003, S. 349-358; Paul F. Grendler, The Universities of the Italian Renaissance, Baltimore 2002, S. 328-352; Giuseppe Ongaro, Medicina, in: L'Università di Padova. Otto secoli di storia, hg. v. Piero Del Negro, Padua 2001, S. 153-193; Jerome J. Bylebyl, The School of Padua: Humanistic Medicine in the Sixteenth Century, in: Health, Medicine, and Mortality in the Sixteenth Century, hg. v. Charles Webster (Cambridge Monographs on the History of Medicine), Cambridge/New York 1979, S. 335-370.

4 Hermann Keussen (Hg.), Matrikel der Universität Köln, Bd. 1-3 (Publikationen der Gesellschaft für Rheinische Geschichtskunde 8), Bonn 1919-1931 [Nachdr. Düsseldorf 1979], hier: Bd. 2, Nr. 489,30; Repertorium Academicum Germanicum (RAG), [www.rag-online.org], Wilhelm Insulanus Menapius - UniquID: ngHX4S678H748wdfbGgwrFtK, 3.5.2018.

5 Er soll 1524 in Padua, ausserdem in Bologna und Rom gewesen sein. In Rom war er zeitweise als Sekretär des Kardinals Raymundus Vick tätig, Kloosterhuis, Erasmusjünger (Anm. 1), Nr. 73; Keussen, Köln (Anm. 4), Bd. 2, Nr. 489,30. In den Acta graduum Paduas taucht er nicht auf. Über den Ort seiner medizinischen Doktorpromotion ist nichts Näheres bekannt. Möglicherweise ist er mit M. Gulielmus Germanus zu identifizieren, der im Oktober 1525 in Bologna seine Prüfung zum dr. med. ablegte, Giovanni Bronzino (Hg.), Notitia doctorum sive Catalogus doctorum qui in collegiis philosophiae et medicinae Bononiae laureati fuerunt ab anno 1480 usque ad annum 1800 (Universitatis Bononiensis Monumenta 4), Mailand 1962, S. 21.

6 Über Leenius ist mir, abgesehen vom Einstellungsdatum bei den Herzögen von Berg 1531, nichts weiter bekannt. Haberling und Schadewaldt nennen ihn als dr. med., Wilhelm Haberling, Die Geschichte der Düsseldorfer Ärzte und Krankenhäuser bis zum Jahre 1907, in: Düsseldorfer Jahrbuch 38 (1936), S. 1-141, hier: Nr. 69; Hans Schadewaldt, Die Medizin in Düsseldorf, in: Düsseldorf und seine Krankenanstalten, hg. v. dems. und Irmgard Müller (Historia hospitalium. Sonderheft), Düsseldorf 1969, S. 5-108, hier: S. 22. Kloosterhuis erwähnt ihn nicht, auch im RAG finden sich keine Studiendaten. 
Verfasser zahlreicher humanistischer Schriften ${ }^{7}$ und bereits seit dem Studium in Köln eng verbunden mit den humanistisch gesinnten herzoglichen Räten ${ }^{8}$, insbesondere mit Konrad Heresbach ${ }^{9}$ - seit 1523 Privatlehrer des herzoglichen Erbprinzen und nach dessen Volljährigkeit 1534 herzoglicher Rat ${ }^{10}$ - und Johannes Gogreve ${ }^{11}$, der seit 1528 jülichbergischer und schliesslich Kanzler der gesamten herzoglichen Territorien war ${ }^{12}$. Simon Reichwein aus Montabaur, ein Freund des Erasmus und Hermanns von Neuenahr ${ }^{13}$, hatte das Artes-Studium ebenfalls in Köln, das Medizinstudium hingegen in Löwen absolviert $^{14}$. Der Kölner Johannes Isenburg verbrachte sein Studium vollständig an der Kölner Universität, an der er anschliessend Professor war. Auch er lernte bereits im Studium Wilhelm von Grevenbroich und Johannes Gogreve kennen ${ }^{15}$.

Die Leibärzte hingegen, die während der langen Regierungszeit Wilhelms V. (1539-1592) eingestellt wurden, hatten zum Grossteil eine peregrinatio medica an die italienischen Universitäten unternommen. Nicht mehr in die Betrachtung einbezogen

7 So verfasste er etwa 1536 eine «Oratio funebris in obitum D. Erasmi Roterodami` und warb 1533 für Köln als Austragungsort eines Konzils, Carl Krafft (Hg.), Aufzeichnungen des schweizerischen Reformators Heinrich Bullinger über sein Studium zu Emmerich und Köln (1516-1522) und dessen Briefwechsel mit Freunden in Köln, Erzbischof Hermann von Wied etc. Ein Beitrag zur niederrheinisch-westfälischen Kirchen-, Schul- und Gelehrtengeschichte, Elberfeld 1870, S. 111-113. Siehe zu seiner Biografie auch Kloosterhuis, Erasmusjünger (Anm. 1), Nr. 73.

8 Auch Heinrich Bars gen. Olisleger studierte dort zur selben Zeit Recht und trat 1529 im gleichen Jahr wie Grevenbroich in herzogliche Dienste, Keussen, Köln (Anm. 4), Bd. 2, Nr. 492,29; RAG (Anm. 4), Heinrich Olisleger - UniquID: ngZP6C476Y529ovVtAIo8X1U, 3.5.2018; Kloosterhuis, Erasmusjünger (Anm. 1), Nr. 10.

9 Dieser studierte dort Artes von Oktober 1512 bis Juli 1515, Keussen, Köln (Anm. 4), Bd. 2, Nr. 496,5; RAG (Anm. 4), Konrad Heresbach - UniquID: ngUK8L577TM37jqkoUtj5Sgr5TX, 3.5.2018.

10 Kloosterhuis, Erasmusjünger (Anm. 1), Nr. 97; Franz Irsigler, Konrad Heresbach. Leben und Werk eines grossen rheinischen Humanisten, in: Der Niederrhein im Zeitalter des Humanismus, hg. v. Meinhard Pohl (Anm. 1), S. 93-110, hier: S. 99.

11 Johannes Gogreve nahm sein Studium in Köln im April 1514 auf, als Grevenbroich dort ebenfalls noch Student war, Keussen, Köln (Anm. 4), Bd. 2, Nr. 502,15; RAG (Anm. 4), Johannes Gogreff - UniquID: ngPF2A870QX6zelHjQIe0, 3.5.2018.

12 Kloosterhuis, Erasmusjünger (Anm. 1), Nr. 70; Detlef Illmer, Cornelia M. Ridderikhoff und Hilde de RidderSymoens (Hg.), Premier livre des procurateurs de la nation germanique de l'ancienne Université d'Orléans, T1. 2, Bd. 2: Biographies des étudiants, 1516-1546 (Les livres des procurateurs de la nation germanique de l'ancienne Université d'Orléans 1), Leiden/Boston 1971-1985, Nr. 582.

13 Kloosterhuis, Erasmusjünger (Anm. 1), S. 495, 515.

14 Die Magisterprüfung legte er 1522 in Köln als pauper ab. Bevor er sich 1527 in Löwen einschrieb, war er zunächst einige Jahre als Präzeptor der Grafen von Isenburg und als Rektor der Lateinschule in Diest tätig. 1529 erscheint er als dr. med. Für Johann III. war er in den 1530er-Jahren als Leibarzt tätig, später für den Erzbischof von Trier, RAG (Anm. 4), Simon Reichwein Dythemius - UniquID: ngZP6C476Y529ovVtASo8X1K, 3.5.2018; Keussen, Köln (Anm. 4), Bd. 2, Nr. 524,50; Arnold Schillings (Hg.), Matricule de l'Université de Louvain, Bd. 3: 31 août 1485-31 août 1527, Brüssel 1958, S. 778,88; Kloosterhuis, Erasmusjünger (Anm. 1), S. 404, 435; Haberling, Düsseldorfer Ärzte (Anm. 6), Nr. 96.

$15 R A G$ (Anm. 4), Johannes Ysenborch - UniquID: ngYO3P779Y850nuwsX9n1WkB, 3.5.2018; Keussen, Köln (Anm. 4), Bd. 2, Nr. 502,92; Kloosterhuis, Erasmusjünger (Anm. 1), Nr. 103 und S. 404, 434. 
werden Lambertus Wolf ${ }^{16}$ und Heinrich Botter ${ }^{17}$, die erst gegen Ende der Regierungszeit Wilhelms V. angestellt wurden (1585 und ca. 1590) und Leibärzte dessen Sohnes Johann Wilhelm (1562-1609) waren - in einer Zeit, in der die Erasmusanhänger am Hof ihren Einfluss verloren hatten und sich die künftige tiefe Krise des Herrscherhauses abzeichnete $^{18}$. Nur am Rande berücksichtigt wird ausserdem Johann Weyer, der nicht in Italien studiert hatte, aber für die familiären Strategien von Interesse ist. In Grave geboren und aus einer Kaufmannsfamilie stammend, war er zunächst Schüler des Cornelius Agrippa von Nettesheim. Im Anschluss konnte sein Vater ihm ein Medizinstudium in Frankreich ermöglichen, seine Promotion ist allerdings umstritten ${ }^{19}$. Nachdem er zunächst als Arzt

16 Lambertus Wolf stammte aus Grave und studierte in Löwen. 1579-1581 war er als dr. med. Medizinprofessor in Köln, seit 1581 Leibarzt in Münster und seit 1585 Leibarzt am Düsseldorfer Hof, wo er von 1589 bis 1602 an verschiedenen consilia zu Johann Wilhelms Gesundheitszustand beteiligt war. Wo er seinen Doktortitel erwarb, ist mir nicht bekannt, vgl. dazu Uta Müller, Leben und Wirken des niederrheinischen Arztes Galenus Weyer (1547-1619), Leibarzt der Herzöge Wilhelm III. und Johann Wilhelm von Jülich, Kleve und Berg, Inaugural-Diss., vorgelegt der Hohen Med. Fakultät der Ruhr-Universität Bochum 2000, S. 12, Anm. 32 und S. 44-46; Arnold Schillings (Hg.), Matricule de l’Université de Louvain, Bd. 4: Février 1528-Février 1569, Brüssel 1961, S. 471,51; Hermann Keussen, Ulrike Nyassi und Mechtild Wilkes (Hg.), Die Matrikel der Universität Köln, Bd. 4: 1559-1675 (Publikationen der Gesellschaft für Rheinische Geschichtskunde 8), Düsseldorf 1981, Nr. 701,240; Haberling, Düsseldorfer Ärzte (Anm. 6), Nr. 128; Erich Meuthen, Die Alte Universität (Kölner Universitätsgeschichte 1), Köln/Wien 1988, S. 394; Hermann Keussen, Die alte Universität Köln. Grundzüge ihrer Verfassung und Geschichte. Festschrift zum Einzug in die neue Universität Köln (Veröffentlichungen des Kölnischen Geschichtsvereins e. V. 10), Köln 1934, S. 484, Nr. 122.

17 Heinrich Botter stammte aus Amersfoort, hatte in Köln, Löwen, Paris und Bologna studiert und wurde 1570 in Padua promoviert. Anschliessend war er 1576/77 Medizinprofessor in Marburg, Leibarzt der Landgrafen von Hessen und des Erzbischofs von Köln, seit 1598 bis zu seinem Tod schliesslich Medizinprofessor in Köln. Als Leibarzt von Johann Wilhelm war er mind. seit 1590 tätig, Elda Martellozzo Forin (Hg.), Acta graduum academicorum Gymnasii Patavini, T1. 4: Ab anno 1566 ad annum 1600, Bd. 2: 1566-1575 (Fonti per la storia dell'Università di Padova 20), Rom/Padua 2008, Nr. 517; Keussen/Nyassi/Wilkes, Köln (Anm. 16), Bd. 4, Nr. 684,25; Keussen, Die alte Universität (Anm. 16), S. 484 f., Nr. 125; Schillings, Louvain, Bd. 4 (Anm. 16), S. 674,49; Meuthen, Alte Universität (Anm. 16), S. 393, 397; Ad Tervoort, The Iter Italicum and the Northern Netherlands. Dutch Students at Italian Universities and their Role in the Netherlands' Society (1426-1575). Biographies of Students (Education and Society in the Middle Ages and Renaissance 21), Leiden/Boston 2005 Nr. 196; Müller, Galenus Weyer (Anm. 16), S. 12, Anm. 33 und S. 44-46.

18 Vgl. etwa Schulte, Versuchte konfessionelle Neutralität (Anm. 1), S. 229 f., 245.

19 In der Literatur findet sich häufig eine Promotion zum dr. med. 1537 in Orléans, etwa Rudolf van Nahl, Zauberglaube und Hexenwahn im Gebiet von Rhein und Maas. Spätmittelalterlicher Volksglaube im Werk Johan Weyers (1515-1588) (Rheinisches Archiv 116), Bonn 1983, S. 38; Heinrich Eschbach, Dr. med. Johannes Wier, der Leibarzt Herzog Wilhelm III. von Kleve-Jülich-Berg, in: Beiträge zur Geschichte des Niederrheins. Jahrbuch des Düsseldorfer Geschichtsvereins 1 (1886), S. 58-174, hier: S. 84 f.; Kloosterhuis, Erasmusjünger (Anm. 1), Nr. 220; Michaela Valente, Johann Wier. Agli albori della critica razionale dell'occulto e del demoniaco nell'Europa del Cinquecento (Studi per la Storia religiosa del Cinquecento 12), Florenz 2003, S. 50 f. Diese hat aber wohl nie stattgefunden. In Orléans existierte noch keine med. Fakultät und Weyer selbst führte den Titel nicht. Er könnte von den Verlegern seiner Werke eigenmächtig hinzugefügt worden sein, vgl. dazu die Ausführungen von Christoph Kaltscheuer, Johann Weyer (1515/1516-1588), Gegner der Hexenverfolger, in: Portal Rheinische Geschichte [http://www.rheinischegeschichte.lvr.de/persoenlichkeiten/W/Seiten/JohannWeyer.aspx], 3.5.2018, sowie Thomas Meyer, Weyer, Johann, in: Biographisch-Bibliographisches Kirchenlexikon 20 (2002), Sp. 1537-1544. Ob graduiert oder nicht, er wurde jedenfalls als Doktor bezeichnet, etwa bei der Promotion des Sohnes Dietrich 1564 in Pisa: Pat. Iohannes doctor, Rodolfo Del Gratta (Hg.), Acta graduum academiae Pisanae, Bd. 1: 1543-1599, Pisa 1980, S. 72, Nr. 00632. 
in seiner Heimat tätig war, bekam er 1545 die Stelle als Stadtarzt in Arnhem und stieg 1557 zum Leibarzt des Herzogs auf. Er wurde vor allem als Gegner der Hexenverfolgung bekannt ${ }^{20}$.

Sechs weitere Ärzte, die für Wilhelm V. tätig waren, haben hingegen ein italienisches Medizinstudium aufgenommen. Es handelt sich um Johannes Bachofen von Echt (1515-1576), Theodor Birckmann (um 1536/37-1586), Johannes Lithodius (Lebensdaten nicht bekannt), Reiner Solenander (1524-1601), Johannes Solenander (?-1605) und Galenus Weyer (1547-1619), deren Werdegänge im Folgenden im Mittelpunkt stehen sollen.

\section{Das Medizinstudium}

Johannes Bachofen von Echt absolvierte sein Artes-Studium in Köln und erreichte dort die akademischen Grade baccalarius artium (1531) und licentiatus artium (1533), nicht aber den Magistergrad ${ }^{21}$. Er hat wohl auf diesen verzichtet, da das Lizentiat für das medizinische Fachstudium ausreichte und der Magistergrad ohnehin nicht der höchste Abschluss hätte bleiben sollen. Anschliessend studierte er in Bologna Medizin $^{22}$, wo er sich 1538/39 durch eine Tätigkeit als Lektor für Rhetorik finanzierte ${ }^{23}$ und am 10. Februar 1539 zum dr. phil. et med. promoviert wurde ${ }^{24}$. Dadurch, dass er den Magistergrad nicht wie sonst bei den ultramontanen Studenten noch üblich bereits vor

20 Sein Hauptwerk 〈De praestigiis Daemonum〉 von 1563 fand weite Verbreitung. Vgl. Anm. 19 sowie RAG (Anm. 4), Johannes Weyer Piscinarius - UniquID: ngDT4O274C305szVxCMsnBpw, 3.5.2018. Leben und Lebenswerk Johann Weyers haben viel Beachtung gefunden; s. für einen Forschungsüberblick Sonja Kinzler, Johann Weyer (Kurzbiographie und Forschungsbericht), in: Lexikon zur Geschichte der Hexenverfolgung, hg. v. Gudrun Gersmann, Katrin Moeller und Jürgen-Michael Schmidt, [https://www.historicum.net/purl/jdzva/], 3.5.2018. Für eine ausführliche Weyerbibliografie s. ebd., [https:/www.historicum.net/de/themen/hexenforschung/bibliographien/ weyerbibliographie/chronologisch/], 3.5.2018.

21 Bei seiner Immatrikulation in Köln übernahm der Rektor einen Teil seiner Gebühr: Joh. de Echt, Col.; art.; i. et s. 4 a., reliquos 3 d. rector donavit, quia parrochianus eius, Keussen, Köln (Anm. 4), Bd. 2, Nr. 559,17; RAG (Anm. 4), Johannes von Echt Echtius - UniquID: ngVL0U870UN6fkrZpUOk9ThG, 3.5.2018. Kloosterhuis erwähnt irrig einen Kölner Magistergrad, Kloosterhuis, Erasmusjünger (Anm. 1), Nr. 7.

22 Adam gibt ein vorangegangenes Studium in Wittenberg an, das wohl auf einer Verwechslung mit einem Verwandten beruht, Melchior Adam, Vitae Germanorum medicorum, Frankfurt a. M. 1620, S. 72, ebenso in der Anm. bei Keussen, Köln (Anm. 4), Bd. 2, Nr. 559,17 und bei Kloosterhuis, Erasmusjünger (Anm. 1), Nr. 7. Johannes findet sich in der Wittenberger Matrikel nicht, wie schon Husemann feststellte, Theodor Husemann, Die Kölnischen Pharmakopöen und ihre Verfasser, in: Apotheker-Zeitung 14 (1899), Nr. 54-64, S. 403-480, hier: S. 419, Anm. 21.

23 Umberto Dallari (Hg.), I rotuli dei lettori legisti e artisti dello Studio bolognese dal 1384 al 1799, Bd. 2 (Dei monumenti istorici pertinenti alle provincie della Romagna 2), Bologna 1889, S. 89; Amore Scientiae Facti Sunt Exules (ASFE), [http://asfe.unibo.it], Johann Bachofen, [http://asfe.unibo.it/it/persona/BR0614], 3.5.2018.

24 Bronzino, Notitia doctorum (Anm. 5), S. 29. Hier wird er fälschlicherweise zweimal aufgeführt, als Iohannes Bacconius ex Colonia und als Iohannes Barconius Germanus, daher auch im ASFE doppelt, ASFE (Anm. 23), Johann Bachofen, [http://asfe.unibo.it/it/persona/BR0614], 3.5.2018, und ebd., Iohannes Barconius, [http://asfe.unibo.it/it/ persona/BR0616], 3.5.2018. Es handelt sich mit Sicherheit um die gleiche Person. Die Promotion ist lediglich doppelt überliefert, sowohl durch das Liber Secretus als auch durch die Akten des Kollegiums, Datum und Gruppenpromotion stimmen überein, Archivio di Stato di Bologna, Fondo Studio, Libri actorum utriusque collegii 1481-1604, Ms. 191, fol. 56r, sowie ebd., Liber secretus 1504-1575, Ms. 217, fol. 70r. 
Antritt des iter italicum an einer heimischen Universität erwarb, ist er ein frühes Beispiel für den bei den italienischen Studiengenossen verbreiteten kombinierten medizinischphilosophischen Abschlussgrad ${ }^{25}$. In Bologna hielt er sich zur selben Zeit (1538/39) wie die Rechtsstudenten und späteren herzoglichen Räte Philipp Grün (1537-1540) ${ }^{26}$ und Wilhelm von Ketteler (1539) ${ }^{27}$ auf. $\mathrm{Zu}$ Wilhelm von Ketteler, der zeitweise Bischof von Münster war, stand er auch später in persönlichem Kontakt ${ }^{28}$.

Reiner Solenander, geboren als Reinhard Gathmann, stammte aus einer Bürgerfamilie aus Büderich. Seine Ausbildung wurde durch den Landesherrn ermöglicht ${ }^{29}$. Am Hof war Johannes Bachofen sein Fürsprecher, er setzte sich 1539 unter dem neuen Herzog Wilhelm V. für die Weiterfinanzierung der Studien Solenanders ein und dieser widmete ihm später sein Erstlingswerk ${ }^{30}$. Nach dem Besuch des humanistischen Gymnasiums in Wesel nahm Solenander anders als die meisten seiner rheinischen Landsleute sein Studium nicht an der Universität Köln auf, sondern in Löwen. Die Immatrikulation im Mai 1548 an der Universität ist wohl Indiz für den Beginn des Medizinstudiums ${ }^{31}$, während er zuvor zum Studium der alten Sprachen das Collegium Trilingue besucht hatte ${ }^{32}$. Mit Johannes Sohetius aus Lüttich, einem Studienfreund aus

25 Kloosterhuis missversteht wohl die Angabe 1549 dr. med. bei Keussen, die m. E. lediglich auf ein Auftauchen als dr. med. 1549 hinweist, und gibt eine Promotion in Köln 1549 an, Kloosterhuis, Erasmusjünger (Anm. 1), Nr. 7; Keussen, Köln (Anm. 4), Bd. 2, Nr. 559,17.

26 Ernst Friedländer und Carlo Malagola (Hg.), Acta Nationis Germanicae Universitatis Bononiensis ex archetypis tabularii Malvezziani, Berlin 1887 [Nachdr. Bologna 1988], S. 314,19; Gustav Knod, Deutsche Studenten in Bologna (1289-1562). Biographischer Index zu den Acta nationis Germanicae Universitatis Bononiensis, Berlin 1899 [Nachdr. Aalen 1970], Nr. 1241; RAG (Anm. 4), Philipp de Groen - UniquID: ngAQ9R173ZI9mpwuuAzpkYmx1Zt, 3.5.2018.

27 Friedländer/Malagola, Acta Nationis (Anm. 26), S. 318,32; Knod, Bologna (Anm. 26), Nr. 1710; RAG (Anm. 4), Wilhelm von Ketteler - UniquID: ngUK0P779Us50jqYoTtj7SgL, 3.5.2018.

28 In Bachofens Testament von 1564 wird ein vergoldeter Silberkelch erwähnt, der ein Geschenk von Wilhelm von Ketteler an ihn gewesen war, Kaspar Keller (Hg.), Urkunden zur Geschichte der Familie Bachoven von Echt, Bonn 1907, S. 118 f., Nr. 212.

29 Kloosterhuis, Erasmusjünger (Anm. 1), Nr. 195; Arnold Wackerbauer, Reiner Solenander (Reinhard Gathmann), ein niederrheinischer Arzt, Leibarzt am Düsseldorfer Hofe (1524-1601), in: Düsseldorfer Jahrbuch 37 (1933), S. 95-140, hier: S. 102; Haberling, Düsseldorfer Ärzte (Anm. 6), Nr. 110.

30 Maurits Biesbrouck, Theodoor Goddeeris und Omer Steeno, Reiner Solenander (1524-1601): An Important 16th Century Medical Practitioner and his Original Report of Vesalius' Death in 1564, in: Acta medico-historica Adriatica 13 (2015), Nr. 2, S. 265-286, hier: S. 268, 274; Wackerbauer, Solenander (Anm. 29), S. 106.

31 Schillings, Louvain, Bd. 4 (Anm. 16), S. 366,66; RAG (Anm. 4), Reiner Solenander - UniquID: ngVL6o072Ut8hkrHpVOk3ThY, 3.5.2018.

32 Laut Henry de Vocht war er zwischen 1545 und 1550 in Löwen, Henry de Vocht, History of the Foundation and the Rise of the Collegium Trilingue Lovaniense 1517-1550 (Humanistica Lovaniensia 13), Bd. 4: Strengthened Maturity, Löwen 1955, S. 415 f. 
Löwen, setzte er auch in Italien das Studium gemeinsam fort $\mathrm{t}^{33}$. Vor der Promotion zum dr. phil. et med. 1551 (Pisa) studierte er in Bologna und Pisa ${ }^{34}$. Er war dort Schüler des Kritikers der Lehren Galens Giovanni Argenterio - eine Verteidigungsrede für diesen gegen die Angriffe des Galenisten Giulio Alessandrini von 1552 wurde Solenanders erste Veröffentlichung ${ }^{35}$ - und Luca Ghinis, der der erste Botanikprofessor sowohl Bolognas als auch Pisas sowie der Gründer des botanischen Gartens in Pisa war ${ }^{36}$. In Bologna war Solenander wahrscheinlich zur gleichen Zeit (Herbst 1550) wie der jüngere Bruder Friedrich seines Fürsprechers am herzoglichen Hof Johannes Bachofen ${ }^{37}$. Auch Eberhard von Schöler, der ab 1551 adeliger Rat des jülich-klevischen Herzogs wurde, war 1550 zum Rechtsstudium in Bologna ${ }^{38}$. In Pisa hielt sich Solenander wohl noch bis

33 Im Dez. 1552 waren sie in Pisa gemeinsam Zeugen bei der Promotion des Gervasius Marstaller, Del Gratta, Acta graduum (Anm. 19), S. 329, Nr. 00088. Auch Sohetius war noch 1553 in Pisa, im Juni war er Zeuge bei der Prüfung von Heinrich Reck, ebd., S. 333, Nr. 00100. In seinen 1558 veröffentlichten 〈Consilia〉 schreibt Solenander selbst über das gemeinsame Studium in Löwen und Italien [...] olim in communibus studiis Louanii incaepta primum, postea in Italia confirmata est nobis amicitia, immortalis existat, Reineri Solenandri Budericensis Medici Consiliorum Medicinalium, Sectio prima, Lyon 1558, S. 15. Vgl. auch Wackerbauer, Solenander (Anm. 29), S. 103 und Iwan Bloch, Der rheinische Arzt Solenander und die Geisteskrankheit des Herzogs Albrecht Friedrich von Preußen, in: Klinischtherapeutische Wochenschrift 29 (1922), Sp. 147-162, hier: Sp. 150. In der Löwener Matrikel ist allerdings 1549 nur ein Gerardus Sohetius Leodiensis zu finden, Schillings, Louvain, Bd. 4 (Anm. 16), S. 389,110.

34 Im Promotionsprotokoll in Pisa werden die Studienorte Löwen, Bologna und Pisa genannt: Lovanii, Bononiae et Pisis sexennio, Del Gratta, Acta graduum (Anm. 19), S. 329, Nr. 00069. Weigle gibt eine Promotion in Pisa zum dr. med. an, vorangegangene artistische Grade sind jedoch nicht bekannt, Fritz Weigle, Deutsche Studenten in Italien. T1. 4: Deutsche Studenten in Pisa, in: Quellen und Forschungen aus italienischen Archiven und Bibliotheken (QFIAB) 39 (1959), S. 173-221, hier: Nr. 362.

35 Solenandri Apologia, qua Julio Alexandrino respondetur pro Argenterio, Florenz 1556; Haberling, Düsseldorfer Ärzte (Anm. 6), Nr. 110; Wackerbauer, Solenander (Anm. 29), S. 104, 106; Biesbrouck/Goddeeris/Steeno, Solenander (Anm. 30), S. 274 f. Zur Vita Argenterios vgl. Felice Mondella, Argenterio, Giovanni, in: Dizionario Biografico degli Italiani 4 (1962), [http://www.treccani.it/enciclopedia/giovanni-argenterio_(Dizionario-Biografico)/], 3.5.2018.

36 Ghini war bei der Promotion in Pisa einer seiner promotores, Del Gratta, Acta graduum (Anm. 19), S. 329 , Nr. 00069. Solenander hatte zudem offenbar im Hause Ghinis gewohnt. In seiner Schrift von 1558 bezeichnete er Ghini als olim praeceptor et hospes meus observandus und nach dessen Tod 1556 schrieb er in einem Brief an den Botaniker Ulisse Aldrovandi in Bologna, ebenfalls ein Schüler Ghinis: Credetti molto à m. Lucha padre mio, pie memorie, per la molta esperientia, acquistata in longa età, il quale havendo le invidiose parcae tolto di questa vita, zit. nach Peter Arnold Heuser, Gicht und Syphilistherapie in Köln um 1560. Ein Beitrag zur Frühgeschichte der Sarsaparillakur in Europa, in: Rheinisch-westfälische Zeitschrift für Volkskunde 46 (2001), S. 67-197, hier: S. 187 f., Anm. 398; vgl. auch Haberling, Düsseldorfer Ärzte (Anm. 6), Nr. 110. Vgl. zu Ghinis akademischer Karriere und seiner Bedeutung für die universitäre Botanik Grendler, The Universities (Anm. 3), S. 74, 346 f.; Franco Aurelio Meschini, Ghini, Luca, in: Dizionario Biografico degli Italiani 53 (2000), [http://www.treccani.it/enciclopedia/luca-ghini_\%28DizionarioBiografico\%29/], 3.5.2018.

37 Friedrich graduierte in Bologna am 30. Okt. 1550, Maria Teresa Guerrini, "Qui voluerit in iure promoveri ...» I dottori in diritto nello Studio di Bologna (1501-1796) (Voci di Clio 2), Bologna 2005, Nr. 1274; ASFE (Anm. 23), Federicus Bacchonus, [http://asfe.unibo.it/it/persona/LL1280], 3.5.2018. Am 18. Aug. 1550 war er noch in Padua, Elda Martellozzo Forin (Hg.), Acta graduum academicorum Gymnasii Patavini, T1. 3: Ab anno 1500 ad annum 1550, Bd. 3: $\mathrm{Ab}$ anno 1538 ad annum 1550 (Fonti per la storia dell'Università di Padova 7), Padua 1971, Nr. 3861.

38 Friedländer/Malagola, Acta Nationis (Anm. 26), S. 332,7; Knod, Bologna (Anm. 26), Nr. 3365; ASFE (Anm. 23), Eberhardus a Schöler, [http://asfe.unibo.it/it/persona/MF0781], 3.5.2018; Kloosterhuis, Erasmusjünger (Anm. 1), Nr. 183. 
1553 auf; er taucht dort im Dezember 1552 und Ende April 1553 als Zeuge bei Doktorprüfungen auf ${ }^{39}$. In den folgenden Jahren war er als Badearzt in Lucca (etwa 1553-1556) und anschliessend noch am Ospedale Santo Spirito in Rom ${ }^{40}$.

Johannes Lithodius stammte aus der Diözese Lüttich und war zum Artes-Studium in Wittenberg, wo er am 3. Februar 1545 magister artium wurde ${ }^{41}$. Im Zeitraum von 1545 bis 1548 war er als Magister Rektor des Weseler Gymnasiums ${ }^{42}$. Anschliessend konnte er sich offenbar das Medizinstudium in Bologna leisten, wo er im April 1553 zum dr. med. promoviert wurde ${ }^{43}$. Wenn auch nicht festzustellen ist, seit wann Lithodius in Bologna war, so ist es doch möglich, dass er in Italien auf Reiner Solenander traf, der um 1550/51 ebenfalls in Bologna studierte und anschliessend von Pisa und Lucca aus noch Kontakte dorthin unterhiel $t^{44}$.

Theodor Birckmann besuchte zunächst die Universität Köln und wurde dort sehr bald zum artistischen Bakkalaren ${ }^{45}$. Wo er einen Magistergrad erwarb, ist nicht bekannt. Die Stationen seiner peregrinatio academica in Frankreich und Italien sind hingegen im Detail nachvollziehbar. Im Juli 1555 schrieb er sich zum Medizinstudium in Montpellier ein ${ }^{46}$, wo er Schüler des Guillaume Rondelet war $^{47}$. Er verbrachte dort noch eineinhalb Jahre und reiste schliesslich Ende Februar 1557 mit seinem Studienfreund, dem Basler Felix Platter, über Narbonne, Carcassone, Toulouse, Bordeaux, Poitiers und

39 Del Gratta, Acta graduum (Anm. 19), S. 331, Nr. 00088 und S. 332, Nr. 00096.

$40 \mathrm{Zu}$ den Stationen vgl. Heuser, Gicht (Anm. 36), S. 187 f. Neapel erwähnt Heuser allerdings nicht. In der Literatur wird meist ohne weitere Differenzierung von einem siebenjährigen Studium an den Universitäten Bologna, Pisa, Rom und Neapel gesprochen. Das Studium selbst kann aber mit der Promotion 1551 als abgeschlossen betrachtet werden. Rom und Neapel waren demnach keine Studienorte im engeren Sinne. Als gesichert kann hingegen gelten, dass er sich in der Tat etwa sieben Jahre in Italien aufhielt (1550-1557), vgl. Kloosterhuis, Erasmusjünger (Anm. 1), Nr. 195; Wackerbauer, Solenander (Anm. 29), S. 104; Biesbrouck/Goddeeris/Steeno, Solenander (Anm. 30), S. 269 f.

41 RAG (Anm. 4), Johannes Lithodius - UniquID: ngWM3N577WE371sIqV71iUip, 3.5.2018; Karl Eduard Förstemann (Hg.), Album Academiae Vitebergensis, Bd. 1: Ab A. CH. MDII usque ad A. MDLX, Leipzig 1841, S. 214b; Julius Köstlin (Hg.), Die Baccalaurei und Magistri der Wittenberger philosophischen Fakultät, Bd. 3: 1538-1546, Halle 1890, S. 17,7 .

42 Konrad-Duden-Gymnasium (Hg.), 650 Jahre Konrad-Duden-Gymnasium, Wesel 1992, S. 119.

43 Bronzino, Notitia doctorum (Anm. 5), S. 56; ASFE (Anm. 23), Iohannes Lithodius, [http://asfe.unibo.it/it/persona/ BR0905], 3.5.2018.

44 Er schrieb am 5. Juli 1556 an Ulisse Aldrovandi in Bologna, Heuser, Gicht (Anm. 36), S. 188, Anm. 398.

45 Immatrikuliert am 14. März 1551, wurde er am 9. Juni 1551 zum bacc. art., Keussen, Köln (Anm. 4), Bd. 2, Nr. 645,194.

46 Marcel Gouron (Hg.), Matricule de l'Université de Médecine de Montpellier (1503-1599) (Travaux d'Humanisme et Renaissance 25), Genf 1957, Nr. 2090. Er war offenbar schon seit Mai in Montpellier, wie Felix Platter in seiner Lebensbeschreibung vermerkt: Es kam den tag [9. Mai] auch Theodorus Birckmannus von Cöln, ein glerter gsel und guter instrumentist, zu uns, der hernoch mit mir durch Franckreich gereißt, Valentin Lötscher (Hg.), Felix Platter. Tagebuch. Lebensbeschreibung, 1536-1567 (Basler Chroniken 10), Basel/Stuttgart 1976, S. 218 f. Er erwähnt ihn noch einmal im Juli sowie im November 1556, ebd., S. 248, $257 \mathrm{f}$.

47 Heuser, Gicht (Anm. 36), S. 167, Anm. 329 und Husemann, Pharmakopöen (Anm. 22), S. 418. 
Orléans nach Paris, wie in dessen Aufzeichnungen zu lesen ist ${ }^{48}$. Von April $1557^{49}$ bis Ende April 1558 verweilte Theodor in Paris bzw. Chartres ${ }^{50}$. Über Basel reiste er nach Bologna, wo er im September 1558 die medizinische Doktorprüfung ablegte ${ }^{51}$. Nach seiner Promotion in Bologna schrieb er sich im Dezember 1558 noch in Padua ein ${ }^{52}$, wo er 1560 der deutschen Nation zum Abschied ein chirurgisches Buch schenkte ${ }^{53}$ und sich demnach trotz abgeschlossenem Studium noch über ein Jahr lang aufhielt. Bei dieser Gelegenheit wird er als in anatomicis sectionibus exercitatissimus iuvenis bezeichnet. Es ist anzunehmen, dass er wie viele ultramontane Studenten der Anatomiestudien wegen in Padua war, für die das studium einen ausgezeichneten Ruf hatte. Seit 1551 lehrte dort der berühmte Anatomist Gabriele Falloppio, dessen «Observationes anatomicae` im Jahr nach Birckmanns Abreise erschienen ${ }^{54}$. In Padua muss er zudem den Basler Theodor

48 Zur Abreise aus Montpellier schrieb Felix Platter: Ich rust mich uf die reiß mit Theodoro Birckmanno von Cöln, der mein gespan wardt, ein glerter junger man, des elteren buchdrucker zu Cöln verriempt gewesen, der nit allein uf den instrumenten, sunder auch uf der pfiffen wol geiebt war und deßenthalben uf der reis, wo gelegenheit, uns belustigen konten. [...] Den 27 februarii, so der letst on einen war, gnodet ich meinem herren Catalano, [...], und kamen die Teutschen, die uns gleiten wolten, mit dem Birckman, [...], Lötscher, Felix Platter (Anm. 46), S. 263. Zu den Reisestationen vgl. ebd., S. 264-278. Vgl. auch Heuser, Gicht (Anm. 36), S. 189, Anm. 367.

49 Der Reisegefährte Felix Platter hingegen brach noch im April 1557 den Heimweg Richtung Basel an, Ich hette gern gferten kan, heim zu zien, wil Birckmannus zu Paris blyben wolt und ich mein roß noch ieder zeit auf hielt, Lötscher, Felix Platter (Anm. 46), S. 284.

50 Birckmanns Abreisedatum aus Paris ist durch einen Brief des Basilius Amerbach von dort an seinen Vater belegt, der zudem zeigt, dass er über Basel gereist sein muss. Amerbach schrieb Ende April 1558: Birckmannus enim, tipographi Coloniensis filius, optimus iunenis et, ut audio, in re medica ualde doctus, ad uos proficiscitur, Alfred Hartmann und Beat Rudolf Jenny (Hg.), Die Amerbachkorrespondenz, Bd. 10: Die Briefe aus den Jahren 1556-1558, Halbbd. 2: 1. Juli 1557-Ende 1558, Basel 1995, Nr. 4307, S. 697. Siehe ebd. zur Datierung des Briefes auf den 29. April, S. 696 f. Birckmanns zwischenzeitlicher Aufenthalt in Chartres geht aus seinen Briefen an Felix Platter hervor, er schrieb diesem am 6. Juni, 25. Juni und 18. Aug. 1557 aus Paris, am 18. Nov. 1557 aus Chartres, s. ebd., Nr. 4307, S. 697-701, Anm. 6. Die Briefe werden dort z. T. paraphrasiert, z. T. im Wortlaut wiedergegeben.

51 ASFE (Anm. 23), Theodor Birckmann, [http://asfe.unibo.it/it/persona/BR1045], 3.5.2018; Bronzino, Notitia doctorum (Anm. 5), S. 55.

52 Lucia Rossetti (Hg.), Matricula nationis Germanicae artistarum in Gymnasio Patavino (1553-1721). Con la collaborazione di Giorgetta Bonfiglio Dosio (Fonti per la storia dell’Università di Padova 10), Padua 1986, Nr. 92; Gustav Knod, Rheinländische Studenten im 16. und 17. Jahrhundert auf der Universität Padua, in: Annalen des historischen Vereins für den Niederrhein 68 (1899), Padua 1986, S. 168, Nr. 4.

53 Theodorus Birckmannus Coloniensis, in anatomicis sectionibus exercitatissimus iuvenis, mense iunio [1560] discedens in patriam amore ac benevolentia singulari erga Nationem ductus, Librum Chirurgicum Germanicum Gualtheri Riffi, quam Chirurgiam Magnam vocat, Nationi dono Consiliariis quotannis usui reliquit, Antonio Favaro (Hg.), Atti della nazione Germanica artista nello Studio di Padova, Bd. 1 (Monumenti storici pubblicati dalla R. Deputazione Veneta di Storia Patria 19), Venedig 1911, S. 32.

54 Bartolo Bertolaso, Ricerche d'archivio su alcuni aspetti dell'insegnamento medico presso la Università di Padova nel Cinque- e Seicento, in: Acta medicae historiae Patavina 6 (1959/60), S. 17-38, hier: S. 30; Klaus Bergdolt, Medicina a Padova tra XVI e il XVII secolo, in: Il teatro anatomico. Storia e restauri, hg. v. Camillo Semenzato, Limena 1994, S. 37-54, hier: S. 45; Grendler, The Universities (Anm. 3), S. 334 f.; Ongaro, Medicina (Anm. 3), S. 169. 
Zwinger kennengelernt haben, der im Januar 1559 promoviert wurde ${ }^{55}$ und mit dem er noch Jahre später in Briefkontakt stand ${ }^{56}$.

Galenus Weyer, Sohn des berühmteren Johann Weyer, begann sein Studium der Artes 1567 in Köln, hielt sich seit April 1571 in Orléans und seit August 1571 in Montpellier auf. ${ }^{57} \mathrm{Ab}$ November 1572 befand er sich in Padua ${ }^{58}$. Dort trug er sich gemeinsam mit Friedrich Bachofen, Sohn des Johannes Bachofen, und den beiden Augsburgern Gregorius Laub und Felix Manlich in die Artistenmatrikel ein ${ }^{59}$. Da die drei ebenfalls zuvor in Montpellier studiert hatten, machten sie sich wahrscheinlich gemeinsam auf die Reise nach Padua ${ }^{60}$. In Padua nahmen sie mit Sicherheit an den Anatomien des renommierten und langjährigen Chirurgie- und Anatomieprofessors Girolamo Fabrici d'Acquapendente teil, die - wie in den Nationsakten ausdrücklich erwähnt wird - in diesem Jahr ordnungsgemäss stattfanden ${ }^{61} .1573$ wurde Weyer zum consiliarius gewählt, trat jedoch von dem Amt zurück, um nach Rom zu reisen. $\mathrm{Zu}$ Beginn des akademischen Jahres war er im November 1573 aber zurück in Padua ${ }^{62}$. Anfang März 1575 taucht er schliesslich als promovierter dr. art. et med. als Zeuge in Pisa bei der Promotion des Gregorius Laub auf ${ }^{63}$. Auch Felix Manlich graduierte im Oktober 1575 in $\mathrm{Pisa}^{64}$, weswegen von einer gemeinsamen Reisegruppe ausgegangen werden kann. Wo Galenus selbst seinen Doktorgrad erwarb, ist leider nicht bekannt.

55 Elisabetta Dalla Francesca und Emilia Veronese (Hg.), Acta graduum academicorum Gymnasii Patavini, Tl. 4, Bd. 1: Ab anno 1551 ad annum 1565 (Fonti per la storia dell'Università di Padova 16), Rom/Padua 2001, Nr. 859; ASFE (Anm. 23), Theodor Zwinger, [http://asfe.unibo.it/it/persona/AP0038], 3.5.2018.

56 Zwei Briefe von Birckmann aus Köln an Zwinger in Basel vom 7. Sept. 1561 und 24. März 1577 werden wiedergegeben bei Hartmann/Jenny, Amerbachkorrespondenz, Bd. 10,2 (Anm. 50), Nr. 4307, Anm. 6, S. 701.

57 Cornelia M. Ridderikhoff, Hilde de Ridder-Symoens und Chris L. Heesakkers (Hg.), Les livres des procurateurs de la nation germanique de l'ancienne Université d'Orléans: 1444-1602, T1. 3: Troisième livre des procurateurs de la nation germanique de l'ancienne Université d'Orléans 1567-1587. Texte des rapports des procurateurs (Education and Society in the Middle Ages and Renaissance 45), Leiden/Boston 2013, S. 157; Gouron, Montpellier (Anm. 46), Nr. 2690. Er erlebte dort die Bartholomäusnacht. Laut Haberling befand er sich während dieser sogar in Paris, Haberling, Düsseldorfer Ärzte (Anm. 6), Nr. 124. Student war er dort aber nicht, vgl. Müller, Galenus Weyer (Anm. 16), S. 19.

58 Rossetti, Matricula (Anm. 52), Nr. 277; Knod, Padua (Anm. 52), S. 169 f., Nr. 10.

59 Rossetti, Matricula (Anm. 52), Nr. 275 (Bachofen), 278 (Manlich) und 279 (Laub); Knod, Padua (Anm. 52), S. 169, Nr. 9 (Bachofen).

60 Gouron, Montpellier (Anm. 46), Nr. 2726 (30. Juni 1572, Bachofen), 2718 (21. Mai 1572, Manlich) und 2719 (21. Mai 1572, Laubius).

61 Favaro, Atti, Bd. 1 (Anm. 53), S. 88 f. Der Anatomieunterricht in Padua war für die ultramontanen Studenten der vielleicht wichtigste Grund dorthin zu kommen. Dementsprechend häufig wird dieser in den Acta erwähnt und Abwesenheiten des zuständigen Professors beklagt, vgl. dazu Bylebyl, The School of Padua (Anm. 3), S. 351 f.

62 Hierüber geben die Nationsakten Auskunft, Favaro, Atti, Bd. 1 (Anm. 53), S. 89-92. Anders als die der Edition angefügten Jahreszahlen angeben, handelt es sich hier um das Jahr 1573/74, wie die Überschrift des Textes für das Jahr auch mitteilt, nicht 1572/73. Auch Uta Müller, die mit dem Original gearbeitet hat, gibt 1573/74 an, vgl. Müller, Galenus Weyer (Anm. 16), S. 23 f.

63 Del Gratta, Acta graduum (Anm. 19), S. 364, Nr. 00389.

64 Ebd., Nr. 00392. 
Da er im Rahmen seines iter italicum (ebenso wie Laub ${ }^{65}$ ) auch in Florenz gewesen sein soll, könnte das dortige studium Ort seiner Promotion gewesen sein ${ }^{66}$.

Auch Johannes Solenander muss er während seines Studiums begegnet sein. Dessen ausgedehnte peregrinatio führte ihn im August 1569 zunächst nach Heidelberg - die Universität Köln mied er wohl aus konfessionellen Gründen ${ }^{67}$. In Heidelberg wird er bereits Friedrich Bachofen, den Sohn von Johannes Bachofen, kennengelernt haben, der sich im gleichen Monat dort immatrikulierte ${ }^{68}$ und den er später in Montpellier wiedertreffen sollte. Seine Studienreise führte ihn zuvor noch nach Wittenberg (1570) und Basel $(1571 / 72)^{69}$. Im Mai 1572 immatrikulierte er sich schliesslich gemeinsam mit Gregorius Laub und Felix Manlich in Montpellier ${ }^{70}$ und wird dort Friedrich Bachofen wieder- und Galenus Weyer angetroffen haben ${ }^{71}$. Anders als die beiden Augsburger und Friedrich Bachofen schloss er sich im August 1572 noch nicht der Reise Weyers nach Padua an, sondern blieb in Montpellier und wandte sich anschliessend nach Pisa, wo er sich am 20. Juni 1573 einschrieb und im Februar 1574 seinen Doktorgrad erreichte ${ }^{72}$. Direkt im Anschluss (März 1574) schrieb er sich in die natio germanica artistarum in Padua ein ${ }^{73}$. Ob er dort die Studienkollegen aus Montpellier wiedertraf und wie lange er sich vor der Rückkehr in Padua aufhielt, ist nicht festzustellen.

65 So schreibt Adam in seiner Vita über Laub, Adam, Vitae (Anm. 22), S. 343.

66 Auch Müller hält eine Promotion in Florenz für wahrscheinlich, Müller, Galenus Weyer (Anm. 16), S. 14 f. Für das Studium in Florenz s. auch Kloosterhuis, Erasmusjünger (Anm. 1), Nr. 221 und Haberling, Düsseldorfer Ärzte (Anm. 6), Nr. 124. Alle drei erwähnen hingegen den Aufenthalt in Pisa nicht. Müller zufolge war er 1574/75 bereits als Armenarzt in Kleve tätig, das kann aber erst nach dem 4. März 1575 gewesen sein, Müller, Galenus Weyer (Anm. 16), S. $25 \mathrm{f}$.

67 Da Reiner Solenander, sein älterer Bruder, reformiert war (er wurde in der reformierten Kirche St. Willibrord in Wesel bestattet, Wackerbauer, Solenander (Anm. 29), S. 122; Kloosterhuis, Erasmusjünger (Anm. 1), Nr. 195) und angesichts der besuchten Universitäten Heidelberg und Basel, wird auch er reformierten Glaubens gewesen sein. Offenbar waren die Studienverläufe 1570 (noch) nicht so weit durch die Konfession determiniert, dass für einen Reformierten ein Aufenthalt in Wittenberg nicht infrage kam.

68 Gustav Toepke (Hg.), Die Matrikel der Universität Heidelberg von 1386 bis 1662, Bd. 2: 1554-1662, Heidelberg 1886 [Nachdr. Heidelberg 1976], S. 52,91 (Bachofen) und 52,99 (Solenander); Rossetti, Matricula (Anm. 52), Nr. 275; Knod, Padua (Anm. 52), S. 169, Nr. 9; Gouron, Montpellier (Anm. 46), Nr. 2726.

69 Hans Wackernagel (Hg.), Die Matrikel der Universität Basel, Bd. 2: 1532/33-1600/01, Basel 1956, S. 205,39; Karl Eduard Förstemann und Otto Hartwig (Hg.), Album Academiae Vitebergensis, Bd. 2: Ab A. CH. MDII usque ad A. MDCII, Halle 1894, S. 180b,1.

70 Gouron, Montpellier (Anm. 46), Nr. 2717 (Solenander), 2718 (Manlich) und 2719 (Laubius). Er konnte sich offenbar trotz der Hugenottenkriege zum Studium in Montpellier aufhalten.

71 Galenus hielt sich bereits seit August 1571 dort auf und Bachofen traf im Monat nach Solenander in Montpellier ein, Gouron, Montpellier (Anm. 46), Nr. 2690 (Aug. 1571, Weyer) und 2726 (30. Juni 1572, Bachofen).

72 Weigle, Pisa (Anm. 34), Nr. 361; Rodolfo Del Gratta (Hg.), Libri matricularum studii Pisani 1543-1737, Bd. 1: 1543-1609, Pisa 1983, S. 73, Nr. 1864. Weitere Zwischenstationen wird es nicht gegeben haben, da in Pisa die besuchten Universitäten aufgezählt sind, Del Gratta, Acta graduum (Anm. 19), S. 363, Nr. 00378.

73 Knod, Padua (Anm. 52), S. 170, Nr. 11; Rossetti, Matricula (Anm. 52), Nr. 299. Er könnte dort noch Albertus Echtius aus Köln angetroffen haben, der sich im folgenden Monat am 10. Mai 1574 einschrieb, Rossetti, Matricula (Anm. 52), Nr. 303; Knod, Padua (Anm. 52), S. 170, Nr. 12. 
Die Aufenthaltszeiten an den ausländischen Universitäten sind im Einzelnen zwar nur annähernd zu bestimmen, insgesamt verbrachten aber alle sechs späteren Leibärzte mehrere Jahre mit ihrem iter italicum. Ihre Italienreise war eindeutig vorwiegend dem medizinischen Fachstudium gewidmet und wurde mit der Promotion an einer italienischen Universität abgeschlossen. Vor allem die späteren Studenten integrierten auch die französische Universität Montpellier in ihre Studienreise.

Für das Artes-Studium wurde in der Regel die nahegelegene Kölner Universität bevorzugt. Drei der sechs späteren Leibärzte begannen ihr Studium in Köln, nur Lithodius und die beiden Solenander studierten, wohl konfessionell motiviert, nicht in Köln. Die bei den späteren Leibärzten beliebteste Universität während des iter italicum war sowohl für die Promotion als auch für das Studium Bologna, dicht gefolgt von Pisa sowie Padua und Montpellier. Während das gute Abschneiden der beiden grossen Universitäten Bologna und Padua nicht verwundert, war die Universität Pisa erstaunlich beliebt. Das studium in Pisa war nach den Kriegswirren in der ersten Jahrhunderthälfte erst 1543 endgültig wiedereröffnet worden ${ }^{74}$. In den folgenden Jahrzehnten aber erlebte die Universität ihre Blütezeit und hatte vor allem einige bekannte Artes- und Medizinprofessoren vorzuweisen ${ }^{75}$. Zeitgleich mit Padua wurde dort erstmals ein universitärer botanischer Garten angelegt ${ }^{76}$. Durch den Ausbau der Botanik für die ultramontanen Medizinstudenten zunächst besonders von Interesse, wurde die von den Medici favorisierte Ausbildungsstätte seit den 1570er-Jahren zunehmend gemieden ${ }^{77}$.

\section{Die Karrieren}

Johannes Bachofen (auch Dr. Echtius) war seit den 1550er-Jahren einer der Leibärzte des Herzogs Wilhelm V., wurde aber auch am Kölner erzbischöflichen Hof konsultiert ${ }^{78}$. In den Jahren 1571 und 1573 sollte er als Leibarzt an den kaiserlichen Hof Maximilians II.

74 Rodolfo Del Gratta, L'età della dominazione fiorentina (1406-1543), in: Storia dell'Università di Pisa, Bd. 1: 1343-1737, hg. v. Elena Amatori, Ospedaletto 1993, S. 33-78, hier: S. 37-43; Danilo Marrara, L'età medicea, in: Storia dell'Università di Pisa, Bd. 1: 1343-1737, hg. v. Elena Amatori, Ospedaletto 1993, S. 79-187, hier: S. 79; Zonta, Schlesische Studenten (Anm. 3), S. 68; Grendler, The Universities (Anm. 3), S. 72 f.

75 Grendler, The Universities (Anm. 3), S. 75 f.; Zonta, Schlesische Studenten (Anm. 3), S. 68 f.

76 Fabio Garbari, Lucia Tongiorgi Tomasi und Alessandro Tosi, Giardino dei Semplici/ Garden of Simples, Pisa 2002, S. 363; Grendler, The Universities (Anm. 3), S. 73.

77 So wurde etwa die professio fidei tridentina in Pisa schon bald konsequent durchgesetzt, Marrara, L'età medicea (Anm. 74), S. 174; Grendler, The Universities (Anm. 3), S. 75. Für die Gesamtfrequenz durch Studenten aus dem Reich stellte bereits Weigle eine Hochzeit für den Zeitraum von 1543 bis 1570 fest, Weigle, Pisa (Anm. 34), S. 194 f.

78 Heuser, Gicht (Anm. 36), S. 170 f. Weinsberg schrieb über ihn, er werde im hoff von Coln und Gulch und sunst beim adel hoich gehalten, Die autobiographischen Aufzeichnungen Hermann Weinsbergs - Digitale Gesamtausgabe, Liber Decrepitudinis, fol. 179r, [http://weinsberg.uni-bonn.de/Edition/Liber_Decrepitudinis/ld4.htm], 3.5.2018. 1552 etwa weilte er am Totenbett des abgesetzten Kurfürsten Hermann von Wied, Meuthen, Alte Universität (Anm. 16), S. 399 und Heuser, Gicht (Anm. 36), S. 171, Anm. 338. 
geholt werden, lehnte die Gesuche jedoch mit Verweis auf sein Alter $\mathrm{ab}^{79}$. Auch für die Stadt Köln machte er sich als Arzt verdient. Er war einer der Verfasser der Pharmakopöe von 1565, das 〈Dispensarium usuale〉 für die Kölner Apotheker, welches der Kölner Rat in Auftrag gegeben hatte ${ }^{80}$. Zudem legte er den ersten botanischen Garten Kölns an ${ }^{81}$. Der Mitverfasser des 〈Dispensarium〉 Bernhard Dessen von Cronenburg, ebenfalls ein in Bologna promovierter Doktor der Medizin ${ }^{82}$, äusserte sich 1555 lobend über den Garten:

Quod haud segniter, sed bene feliciter facit d. Ioannes Echtius medicus eximius, apparato destinatoque ad huiusmodi institutum horto spacioso, quem exoticis elegantibusque herbis iamdudum Coloniae instruxit. ${ }^{83}$

Da Bachofen sich in eben jenem Jahrzehnt zum Studium in Bologna befunden hatte, in welchem dort die Botanik Aufnahme in das universitäre Medizinstudium fand ${ }^{84}$, kann festgehalten werden, dass sein Studium in Italien konkrete Auswirkungen auf seine spätere ärztliche Praxis hatte ${ }^{85}$. Er war in Köln zudem an den Leprauntersuchungen der 1560er-Jahre beteiligt und Mitglied der Kölner Medizinerfakultät, wenn auch kein ordentlicher Professor ${ }^{86}$. Bekannt ist er ausserdem als Verfasser einer Schrift über Skorbut $^{87}$ und Besitzer einer Privatbibliothek mit wertvollen Handschriften ${ }^{88}$.

Mit zahlreichen rheinischen Gelehrten stand er in engem Kontakt und nicht wenige dieser Kontakte bestanden bereits seit dem Studium in Bologna. So lernte er den Mediziner Bernhard Dessen in Bologna kennen und veranlasste ihn, wie dieser in einem Schreiben von 1560 selbst berichtet, nach Köln zu ziehen:

79 Keller, Urkunden (Anm. 28), S. 157 f., Nr. 270; Heuser, Gicht (Anm. 36), S. 171; Kloosterhuis, Erasmusjünger (Anm. 1), Nr. 7; Husemann, Pharmakopöen (Anm. 22), S. 425; Keussen, Köln (Anm. 4), Bd. 2, Nr. 559, 17.

80 Heuser, Gicht (Anm. 36), S. 168, 182 f.; Husemann, Pharmakopöen (Anm. 22), S. 403-406, 412 f.; Meuthen, Alte Universität (Anm. 16), S. 398 f.; Wolfgang Herborn, Der Graduierte Ratsherr. Zur Entwicklung einer neuen Elite im Kölner Rat der frühen Neuzeit, in: Bürgerliche Eliten in den Niederlanden und in Nordwestdeutschland, hg. v. Heinz Schilling und Herman Diederiks (Städteforschung. Reihe A, Darstellungen 23), Köln 1985, S. 337-400, hier: S. 359 f.

81 Heuser, Gicht (Anm. 36), S. 172; Husemann, Pharmakopöen (Anm. 22), S. 425.

82 Bronzino, Notitia doctorum (Anm. 5), S. 28; ASFE (Anm. 23), Bernhard Dessen van Kronenburg, [http://asfe.unibo. it/it/persona/BR0590], 3.5.2018; RAG (Anm. 4), Bernhard Dessenius Cronenburg - UniquID: ngFV4Q476FX2rubXzEYu8DrS, 3.5.2018.

83 Zit. nach Heuser, Gicht (Anm. 36), S. 172, Anm. 342.

84 Vgl. Grendler, The Universities (Anm. 3), S. 346.

85 An Universitäten im Reich gab es ab 1580 die ersten botanischen Gärten; die Universität Köln hatte auch im 17. Jh. noch keinen, Meuthen, Alte Universität (Anm. 16), S. 400.

86 Meuthen, Alte Universität (Anm. 16), S. 399; Keussen, Köln (Anm. 4), Bd. 2, Nr. 559,17 und Bd. 1, S. *93, Nr. 114 sowie Keussen, Die alte Universität (Anm. 16), S. 484, Nr. 114.

87 Heuser, Gicht (Anm. 36), S. 169, s. dort auch Anm. 335; Husemann, Pharmakopöen (Anm. 22), S. 419.

88 Er besass eine karolingische Handschrift des «Corpus agrimensorum Romanorum», die sich heute unter den Beständen der Bibliotheca Palatina in Rom befindet, Heuser, Gicht (Anm. 36), S. 177; Peter Arnold Heuser, Jean Matal. Humanistischer Jurist und europäischer Friedensdenker (um 1517-1597), Wien/Köln/Weimar 2003, S. 256 f. 
Hic annis novem commoratus multis equidem dolentibus, Coloniam Agrippinam perveni, adiuvante tunc institutum nostrum clarissimo medico Ioanne Echtio, amico meo charissimo, studiorumque meorum per Italiam sodali coniunctissimo. ${ }^{89}$

Nicht nur Dessen befand sich 1538 zum Medizinstudium in Bologna, auch der Humanist Justus Velsius, ebenfalls ein Freund von Bachofen ${ }^{90}$, wurde dort am 8. Februar 1538 zum dr. med. promoviert ${ }^{91}$. Und nicht zuletzt hielt sich auch Jean Matal, dieser zum Studium der Rechte, 1538 und 1539 in Bologna auf ${ }^{92}$. Auch der Jurist Jean Matal, der seit 1563 in Köln lebte, stand in engem Kontakt mit Bachofen ${ }^{93}$. Beide gehörten zum Freundeskreis des irenischen Theologen Georg Cassander ${ }^{94}$.

Auch mit Melanchthon soll Bachofen korrespondiert haben ${ }^{95}$, interessanter für seine Bedeutung als Arzt und die italienischen Einflüsse auf seinen Werdegang ist aber, dass er offenbar auch mit Andreas Vesalius bekannt war ${ }^{96}$. Möglicherweise hatte er diesen, der von 1537 bis 1543 in Padua gelehrt und während dieser Zeit auch in Bologna und Pisa öffentliche Anatomien durchgeführt hatte ${ }^{97}$, in Italien sogar persönlich kennengelernt.

Reiner Solenander ging nach seiner ausgedehnten Italienreise 1557 zunächst nach Frankreich, wo er in Lyon als Arzt praktizierte und an der Universität dozierte ${ }^{98}$. Schon 1559 wurde er an den herzoglichen Hof berufen, wo er bis 1595 Leibarzt des Herzogs Wilhelm V. und dessen Nachfolgers Johann Wilhelm war. Wie seiner Bestallungsurkunde $\mathrm{zu}$ entnehmen ist ${ }^{99}$, wechselte er sich im Hofdienst mit Johann Weyer im Dreimonatsrhythmus ab, während Johannes Lithodius, der seit 1554 im herzoglichen Dienst stand, für die Gesundheit der herzoglichen Kinder verantwortlich war. Solenander

89 Zit. nach Heuser, Gicht (Anm. 36), S. 168, Anm. 333, vgl. ebd., S. 167, Anm. 329. Auch Jahre später in einem Brief im Jahr 1573 erwähnt Dessen erneut die langjährige Freundschaft mit Bachofen: Ioannes Echtius (cuius industri medicatione C. T. subinde utitur) mihi multis retro annis indissolubili amicitiae nexu copulatus, zit. nach Heuser, Gicht (Anm. 36), S. 173, Anm. 342.

90 Kloosterhuis, Erasmusjünger (Anm. 1), Nr. 7; Meuthen, Alte Universität (Anm. 16), S. 399. Im Sept. 1555 wurde Johannes Bachofen vom Rat ermahnt, weil er den inhaftierten Velsius besucht hatte, Keller, Urkunden (Anm. 28), S. 90, Nr. 164.

91 Bronzino, Notitia doctorum (Anm. 5), S. 28; ASFE (Anm. 23), Joost Welsens, [http://asfe.unibo.it/it/persona/BR0587], 3.5.2018; RAG (Anm. 4), Justus Velsius - UniquID: ngXN8O870WP62mtFrWQmiVjE8Wq, 3.5.2018.

92 Er schrieb von dort aus mehrere Briefe, Heuser, Jean Matal (Anm. 88), S. 49 f.

93 Heuser, Jean Matal (Anm. 88), S. 223, 240, 297, 398; Heuser, Gicht (Anm. 36), S. 172-177.

94 Heuser, Gicht (Anm. 36), S. 173-176; Kloosterhuis, Erasmusjünger (Anm. 1), Nr. 7; Meuthen, Alte Universität (Anm. 16), S. 399.

95 Kloosterhuis, Erasmusjünger (Anm. 1), Nr. 7.

96 Vesalius bezeichnet Bachofen in einem Brief an Joachim Roelants, veröffentlicht 1546, als gemeinsamen Freund, Heuser, Gicht (Anm. 36), S. 171, Anm. 340.

97 Vgl. z. B. Grendler, The Universities (Anm. 3), S. 331; Bertolaso, Ricerche (Anm. 54), S. 30.

98 Heuser, Gicht (Anm. 36), S. 188; Haberling, Düsseldorfer Ärzte (Anm. 6), Nr. 110; Wackerbauer, Solenander (Anm. 29), S. 104.

99 Diese wird bei Wackerbauer wiedergegeben, Wackerbauer, Solenander (Anm. 29), S. 105. Siehe auch Haberling, Düsseldorfer Ärzte (Anm. 6), S. 8. 
heiratete dessen Tochter Maria und wohnte während seiner Dienstzeiten in Düsseldorf vermutlich im Haus von Lithodius ${ }^{100}$.

Solenander begleitete den Herzog auf zahlreichen Reisen ${ }^{101}$, so etwa 1566 zum Augsburger Reichstag, wo der Herzog einen ersten Schlaganfall erlitt ${ }^{102}$, und 1573 nach Königsberg zur Hochzeit der Herzogstochter Maria Eleonore mit Albrecht Friedrich von Preußen, über dessen Gesundheitszustand er ausführlich Bericht erstattete ${ }^{103}$. Gemeinsam mit den beiden Kollegen Galenus Weyer und Lambert Wolf schrieb er 1589 ein ärztliches Gutachten über den Geisteszustand des Herzogssohnes Johann Wilhelm, in dem sie dessen Regierungsunfähigkeit feststellten ${ }^{104}$. Konsultiert wurde er für ärztliche Ratschläge auch von anderen niederrheinischen Gelehrten, so von Georg Cassander ${ }^{105}$ und dem Duisburger Geografen Gerhard Mercator, mit dem er befreundet war ${ }^{106}$. Er war zudem als Medizinprofessor für die geplante Duisburger Universität vorgesehen ${ }^{107}$.

Nach der bereits erwähnten Verteidigungsschrift für Argenterio veröffentlichte er noch von Lyon aus 1558 zwei weitere Schriften. Zum einen verarbeitete er seine geologisch-mineralogischen Studien sowie seine praktische Erfahrung aus Lucca in einem balneologischen Werk ${ }^{108}$. Zum anderen gab er die «Consultationes medicinales〉 des Giovanni Battista da Monte, Begründer der klinischen Medizin, der von spätestens

100 Haberling, Düsseldorfer Ärzte (Anm. 6), S. 8 und Nr. 72 (Lithodius) sowie Nr. 110 (Solenander); Wackerbauer, Solenander (Anm. 29), S. 111; Biesbrouck/Goddeeris/Steeno, Solenander (Anm. 30), S. 271 f.

101 Bei Wackerbauer, Solenander (Anm. 29), S. 110 findet sich eine Chronologie der Aufenthaltsorte für die Jahre 1560-1594.

102 Kloosterhuis, Erasmusjünger (Anm. 1), Nr. 195; Bloch, Der rheinische Arzt (Anm. 33), Sp. 156; Wackerbauer, Solenander (Anm. 29), S. 112; Haberling, Düsseldorfer Ärzte (Anm. 6), Nr. 110.

103 Bloch, Der rheinische Arzt (Anm. 33), Sp. 156-158. Er schrieb von Königsberg aus drei Briefe an Herzog Wilhelm V. über den Gesundheitszustand des Bräutigams, die bei Bloch, ebd., Sp. 160-162, und - sprachlich angepasst - bei Wackerbauer, Solenander (Anm. 29), S. 133-135 wiedergegeben sind. Midelfort zufolge beschönigte er Albrecht Friedrichs Zustand aus dem Wunsch heraus, in die Heimat zurückkehren zu können, Hans C. Erik Midelfort, Verrückte Hoheit. Wahn und Kummer in deutschen Fürstenhäusern, Stuttgart 1996, S. 107 f.

104 Ausführlich zum Krankheitsbild Johann Wilhelms und zu den Therapieversuchen, Midelfort, Verrückte Hoheit (Anm. 103), S. 138-170.

105 Er erteilte Cassander im Mai 1563 Auskunft über die Sarsaparillawurzel. Der Brief mit der Anfrage Cassanders sowie das Antwortschreiben, welches Solenander auch selbst in seinen «Consilia` 1596 veröffentlichte, sind ediert bei Heuser, Gicht (Anm. 36), S. 187-191.

106 Auch die Schreiben an Mercator von Dez. 1590 und Jan. 1594 sind Teil seiner 1596 veröffentlichten 〈Consilia), vollständig wiedergegeben von Wackerbauer, Solenander (Anm. 29), S. 127-133; s. auch Biesbrouck/ Goddeeris/Steeno, Solenander (Anm. 30), 273 f.; Bloch, Der rheinische Arzt (Anm. 33), Sp. 159.

107 Wackerbauer, Solenander (Anm. 29), S. 109. Zu den Planungen für die Duisburger Universität s. Clemens v. Looz-Corswarem, Das Monheimsche Gymnasium in Düsseldorf und die geplante Universität zu Duisburg im 16. Jahrhundert, in: Der Niederrhein im Zeitalter des Humanismus, hg. v. Meinhard Pohl (Anm. 1), S. 167-186; Hubert Jedin, Der Plan einer Universitätsgründung in Duisburg, in: Die Universität Duisburg. Mit einem Beitrag von Hubert Jedin, hg. v. Günter v. Roden (Duisburger Forschungen 12), Duisburg 1968, S. 1-32.

108 Reineri Solenandri Budericensis medici, De caloris fontium medicatorum causa, eorumque temperatione, libri duo, et Philosophis et Medicis perutiles, Lyon 1558; Biesbrouck/Goddeeris/Steeno, Solenander (Anm. 30), S. 275; Bloch, Der rheinische Arzt (Anm. 33), Sp. 151, 154; Haberling, Düsseldorfer Ärzte (Anm. 6), Nr. 110; Wackerbauer, Solenander (Anm. 29), S. 106 f. 
1539 bis 1551 in Padua lehrte ${ }^{109}$, mit Ergänzung eigener «Consilia〉 heraus ${ }^{110}$. Hier ist besonders die Vorrede von Interesse, in der er sich mit Nachdruck für die praktische Ausbildung an der Seite eines erfahrenen Arztes sowie bei einem Chirurgen aussprach ${ }^{111}$. Zuletzt lobte er explizit die italienische Praxis der Lehre am Krankenbett, wie sie da Monte etabliert hatte:

Quae in prima parte secundi tomi sunt, non simpliciter consilia medica sunt: sed de aegrotis confabulationes quaedam, quales in visendis aegrotis solent inter medicum \& discipulos haberi: qui Italiam vidit, nouit morem hunc laudatissimum, quo sane cunctas alias nationes in studio medico antecedit. ${ }^{112}$

Seine eigenen «Consilia〉 fanden schliesslich eine Fortsetzung, als er sich 1595 ins Privatleben nach Büderich zurückzog ${ }^{113}$. 1596 erschien die Gesamtausgabe ${ }^{114}$. Er schrieb ausserdem einen kurzen Bericht über die Todesumstände des Andreas Vesalius ${ }^{115}$, mit dem er selbst aber wohl nicht bekannt war ${ }^{116}$. Die Arbeiten des Vesalius kannte er jedoch mit Sicherheit, schon in der ersten Schrift von 1556 nahm er Bezug auf diese ${ }^{117}$.

Theodor Birckmann öffnete nach der Rückkehr aus Italien eine gut gehende Praxis in Köln und wurde wohlhabender Arzt ${ }^{118}$. Weinsberg schrieb zu Birckmanns Tod 1586:

A. 1586 den 15. sept. starb doctor Birckman in sinem eigen haus zur Cronen am Haiffe, hat ein gutte weil krank gelegen, war ein weitberoimter medicus, der bei fursten, herrn und burgern kostlich gehalten wart, kunt vil leuten helfen,

109 Ongaro, Medicina (Anm. 3), S. 174; Grendler, The Universities (Anm. 3), S. 341 f.; Bertolaso, Ricerche (Anm. 54), S. $23 \mathrm{f}$.

110 Biesbrouck/Goddeeris/Steeno, Solenander (Anm. 30), S. 275 f.; Bloch, Der rheinische Arzt (Anm. 33), Sp. 152-154; Wackerbauer, Solenander (Anm. 29), S. 108.

111 Reineri Solenandri Budericensis Medici Consiliorum Medicinalium, Sectio prima, Lyon 1558, S. 3 und 7 f. der Vorrede (nicht paginiert). Eine deutsche Übersetzung der Vorrede findet sich bei Wackerbauer, Solenander (Anm. 29), S. 123-127, eine verkürzte inhaltliche Wiedergabe bei Bloch, Der rheinische Arzt (Anm. 33), Sp. 152 f.

112 Reineri Solenandri Consiliorum (Anm. 111), S. 10 der Vorrede.

113 Laut Haberling handelt es sich bei dem vielzitierten Antwortschreiben von Solenander auf die Anfrage des Hofmarschalls, die Herzogin Jakobe zu vergiften, um eine Fälschung, Haberling, Düsseldorfer Ärzte (Anm. 6), Nr. 110. Der Brief samt Antwort wird wiedergegeben bei Wackerbauer, Solenander (Anm. 29), S. 117-121, s. auch Bloch, Der rheinische Arzt (Anm. 33), Sp. 158 f.; Biesbrouck/Goddeeris/Steeno, Solenander (Anm. 30), S. 272 f.; Kloosterhuis, Erasmusjünger (Anm. 1), Nr. 195.

114 Biesbrouck/Goddeeris/Steeno, Solenander (Anm. 30), S. 276 f.; Bloch, Der rheinische Arzt (Anm. 33 ), Sp. 159.

115 Der Bericht «Historia de Obitu Andreae Vesalii〉 ist im Mai 1566 in Augsburg entstanden und in einer Schrift von Theodor Crusius von 1722 überliefert, Biesbrouck/Goddeeris/Steeno, Solenander (Anm. 30), S. 278-280. Dort finden sich sowohl das lateinische Original als auch eine englische Übersetzung, ebd., S. 280-284.

116 Auch wenn er da Monte und Vesalius rezipierte, war er wohl selbst nie in Padua, dazu Biesbrouck/Goddeeris/Steeno, Solenander (Anm. 30), S. 279.

117 Biesbrouck/Goddeeris/Steeno, Solenander (Anm. 30), S. 275.

118 Heuser, Gicht (Anm. 36), S. 180 f.; Hartmann/Jenny, Amerbachkorrespondenz, Bd. 10,2 (Anm. 50), Nr. 4307, S. 698, Anm. 6. 


\section{[...]. Hat vil leut doit uffgesneiden, exemptereirt und gebalsamet. [...] Die me-} dicin hatt in reich gemacht, das er vom haus Brabant das haus zur Cronen am Haif erlangte, [...]. ${ }^{119}$

Nebenbei war er als jülich-klevischer Leibarzt tätig ${ }^{120}$. Er war nie Mitglied des Kölner Professorenkollegiums, war aber wie Bachofen an der Kölner Pharmakopöe beteiligt, die 1565 in der Birckmannschen Offizin erschien. Als einziger Kölner Arzt verfocht er die Lehren des Paracelsus und verlegte dessen Werke, die in der Pharmakopöe allerdings wohl aus Dissens mit den anderen Verfassern keine Aufnahme fan$\operatorname{den}^{121}$. Heuser hat auf die Ähnlichkeit seiner ausgleichenden Haltung zwischen Tradition und Paracelsismus mit jener seiner Studienfreunde Felix Platter und Theodor Zwinger, beide Professoren der Medizin in Basel, hingewiesen. Wenn seine chemischen Kenntnisse zwar in den akademischen Kreisen Kölns keinen Anklang fanden, brachten sie ihm doch anderenorts Bekanntheit ${ }^{122}$.

Das väterliche Druckgeschäft, an dem er «stiller Teilhaber» war, führten derweil seine Brüder fort ${ }^{123}$. Nach deren Tod erbte er das Unternehmen 1582 gemeinsam mit seiner Schwester Barbara, der er 1585 seinen Anteil übertrug. Ihr Mann Arnold Mylius, ebenfalls Buchdrucker, führte die Birckmannsche Offizin weiter ${ }^{124}$. Diese verlegte auch weiterhin medizinische und pharmazeutische Schriften. Die zweite, überarbeitete Ausgabe der Kölner Pharmakopöe, die die Kölner Professoren Peter Holtzemius und Johannes Bachofen d. J. (Sohn des gleichnamigen Jülicher Leibarztes) verfassten, erschien 1627 ebenfalls dort ${ }^{125}$.

119 Die autobiographischen Aufzeichnungen Hermann Weinsbergs - Digitale Gesamtausgabe, Liber Senectutis, fol. 605v, [http://www.weinsberg.uni-bonn.de/Edition/Liber_Senectutis/1s10.htm\#605], 3.5.2018.

120 Heuser, Gicht (Anm. 36), S. 181; Hartmann/Jenny, Amerbachkorrespondenz, Bd. 10,2 (Anm. 50), Nr. 4307, S. 698, Anm. 6; Keussen, Köln (Anm. 4), Bd. 2, Nr. 645,194.

121 Isabel Heitjan, Die Stellung der Buchgewerbetreibenden in der Stadt Köln und zu ihrer Universität (15. bis 18. Jahrhundert), in: Archiv für Geschichte des Buchwesens 11 (1971), Sp. 1129-1358, hier: Sp. 1255; Herborn, Ratsherr (Anm. 80), S. 359 f.; Husemann, Pharmakopöen (Anm. 22), S. 418; Meuthen, Alte Universität (Anm. 16), S. 399.

122 Heuser, Gicht (Anm. 36), S. 181, dort auch Anm. 371. Interessant sind in dem Zusammenhang auch die Briefe aus Köln an Theodor Zwinger. Am 7. Sept. 1561 schrieb er diesem, er würde Köln verlassen, wenn er dort nicht Eltern und Verwandtschaft hätte. Im Brief vom 24. März 1577 erwähnt er seine chemischen Experimente und schickt Rezepte, die Zwinger angefragt hatte, Hartmann/Jenny, Amerbachkorrespondenz, Bd. 10,2 (Anm. 50), Nr. 4307, S. 701, Anm. 6. Zur Rezeption des Paracelsus in Basel s. auch Maclean, Trois facultés (Anm. 3), S. 355 f.

123 Es handelt sich um die Brüder Arnold, Johann und Gottfried, wobei Gottfried nur bei Heuser erwähnt wird, Heuser, Jean Matal (Anm. 88), S. 136, Anm. 8; Severin Corsten, Unter dem Zeichen der 〈Fetten Henne〉. Franz Birckmann und Nachfolger, in: Gutenberg-Jahrbuch 37 (1962), S. 267-272, hier: S. 272; Christoph Reske, Die Buchdrucker des 16. und 17. Jahrhunderts im deutschen Sprachgebiet. Auf der Grundlage des gleichnamigen Werkes von Josef Benzing (Beiträge zum Buch- und Bibliothekswesen 51), Wiesbaden 22015, S. $471 \mathrm{f}$.

124 Heitjan, Stellung der Buchgewerbetreibenden (Anm. 121), Sp. 1255; Reske, Buchdrucker (Anm. 123), S. 472; Corsten, Unter dem Zeichen (Anm. 123), S. 272; Wolfgang Reuter, Zur Wirtschafts- und Sozialgeschichte des Buchdruckergewerbes im Rheinland bis 1800, in: Börsenblatt des deutschen Buchhandels 14 (1958), S. 139 f. (Eintrag zu Arnold Mylius).

125 Heitjan, Stellung der Buchgewerbetreibenden (Anm. 121), Sp. 1255; Husemann, Pharmakopöen (Anm. 22), S. 474; Meuthen, Alte Universität (Anm. 16), S. 399. 
Galenus Weyer löste seinen Vater 1578 als Leibarzt des Herzogs Wilhelm V. ab und blieb auch der Leibarzt dessen Nachfolgers Johann Wilhelm, bis dieser 1609 starb und damit das Herrscherhaus erlosch ${ }^{126}$. Seine Anstellung schrieb vor, dass er in Düsseldorf zu wohnen hatte, was als Wendepunkt für die medizinische Versorgung der Stadt interpretiert wird ${ }^{127}$. Zusätzlich war er offenbar dennoch für den Trierer Kurfürsten als Leibarzt tätig ${ }^{128}$. 1589 schrieb er gemeinsam mit Reiner Solenander und Lambert Wolf das Gutachten über den Gesundheitszustand Johann Wilhelms, 1597 führte er mit einem Wundarzt die Obduktion der wahrscheinlich ermordeten Herzogin Jakobe von Baden durch und 1609 untersuchte er den Leichnam des verstorbenen Herzogs gemeinsam mit Heinrich Botter und Arnold Birckmann ${ }^{129}$. Wissenschaftlich trat er nicht in Erscheinung.

Über den jüngeren Bruder des Reiner Solenander, Johannes Solenander, ist mir nur wenig bekannt ${ }^{130}$. Aus einer Anmerkung zu seinem Eintrag in der Nationsmatrikel Paduas geht hervor, dass auch er Medicus principis Clivi ${ }^{131}$ wurde. Zusätzlich (oder anschliessend?) war er für die Grafen zur Lippe tätig (Medicus comitis de Lippia), bevor er, wie ebenfalls der Nationsmatrikel zu entnehmen, im November 1605 verstarb $^{132}$. Vorstellbar ist, dass er in Anbetracht der inzwischen katholischen Ausrichtung des Herzogtums aus konfessionellen Gründen nach Lippe wechselte ${ }^{133}$.

126 Müller, Galenus Weyer (Anm. 16), S. 39-74; Kloosterhuis, Erasmusjünger (Anm. 1), Nr. 221; Haberling, Düsseldorfer Ärzte (Anm. 6), Nr. 124.

127 Seine Bestallungsurkunde schreibt ausdrücklich vor, er habe nicht nur die Hofgesellschaft ärztlich zu versorgen, sondern gegen Bezahlung auch der Bevölkerung zur Verfügung zu stehen, Haberling, Düsseldorfer Ärzte (Anm. 6), S. 8 und Nr. 124; Müller, Galenus Weyer (Anm. 16), S. 38-41.

128 So wurde in der Nationsmatrikel Paduas vermerkt: Medicus illustrissimi Iuliae Cliviae agri Montensis ducis, nec non principis electoris Trevirensis archiater, Rossetti, Matricula (Anm. 52), Nr. 277. In der Nationsmatrikel von Orléans hiess es knapper medicus ducis Clivensis, Ridderikhoff/Ridder-Symoens/Heesakkers, Troisième livre (Anm. 57), S. 157. Müller nennt zudem Belege für die Position als Leibarzt des Kurfürsten von Trier für die Jahre 1602 und 1607 , Müller, Galenus Weyer (Anm. 16), S. 88

$129 \mathrm{Zu}$ den Behandlungsmethoden und verschiedenen Gutachten und consilia vgl. Müller, Galenus Weyer (Anm. 16), S. 41-74, 130-175. Zur Ermordung Jacobes von Baden und zu Weyers Obduktionsbericht, in dem er die sichtbaren äusseren Anzeichen der Erdrosselung unerwähnt lässt, vgl. ebd., S. 74-83.

130 Heuser, Bloch und Wackerbauer erwähnen den jüngeren Bruder, der ebenfalls dr. med. war und den Reiner Solenander in seinen «Consilia) einige Male nennt, über seinen Werdegang ist ihnen jedoch nichts bekannt, Heuser, Gicht (Anm. 36), S. 187, Anm. 396; Bloch, Der rheinische Arzt (Anm. 33), Sp. 149; Wackerbauer, Solenander (Anm. 29), S. 103.

131 Rossetti, Matricula (Anm. 52), Nr. 299; Knod, Padua (Anm. 52), Nr. 11; Josef Giesen, Kölner, Rheinländer und Westfalen auf der alten Universität Pisa, in: Jahrbuch des Kölnischen Geschichtsvereins 41 (1967), S. 197-201, hier: Nr. 9.

132 Rossetti, Matricula (Anm. 52), Nr. 299. Bei Knod und Giesen fehlen diese Informationen.

133 Die katholische Partei setzte sich in den 1580er-Jahren durch, Schulte, Versuchte konfessionelle Neutralität (Anm. 1), S. 226-230, 245. 


\section{Familiäre Studientraditionen}

Alle hier untersuchten Leibärzte haben im näheren familiären Umfeld ebenfalls in Italien ausgebildete Gelehrte. Johannes Bachofen entstammte der Kölner Linie der Rats- und Kaufmannsfamilie Bachofen von Echt. Bereits sein Vater Friedrich ${ }^{134}$ war Doktor beider Rechte und Syndikus der Stadt Köln ${ }^{135}$. Während dessen ältester Sohn Heinrich Kaufmann war, wurde den übrigen Söhnen Johannes, Friedrich und Reinhard ein Studium ermöglicht. Johannes ging zum Medizinstudium nach Italien, Friedrich und Reinhard hingegen schlugen - dem Vater folgend - den juristischen Ausbildungsweg ein. Friedrich war von 1546 bis 1549 in Orléans, wo sich während seiner Amtszeit als Prokurator der deutschen Nation 1549 auch der Bruder Reinhard gemeinsam mit dem Neffen Friedrich, ein Sohn des älteren Bruders Heinrich, einschrieb ${ }^{136}$. Reinhard verstarb allerdings kurz darauf in Paris ${ }^{137}$. Friedrich (d. Ä.) hingegen setzte sein Jurastudium in Padua und Bologna fort, wo er im Oktober 1550 zum Doktor des kanonischen Rechts promoviert wurde ${ }^{138}$. Johannes Bachofen kam also aus einer Familie, die bereits Juristen hervorgebracht hatte und nun durch ihn auch das Medizinstudium in die Familienstrategie aufnahm.

134 Dieser hatte gemeinsam mit dem Bruder Arnold 1532 von Karl V. einen Wappenbrief erhalten, Keller, Urkunden (Anm. 28), S. 52-54, Nr. 86.

135 Bei Arnold Fahne, Geschichte der Kölnischen, Jülichschen und Bergischen Geschlechter in Stammtafeln, Waffen, Siegeln und Urkunden, Bd. 1: Stammfolge und Wappenbuch (A-Z), Osnabrück 1848, S. 17 werden zwei verschiedene dr. med. Johann Bachovens aufgeführt, ein Bruder von Arnold und dem Kölner Ratsherren Friedrich sowie ein Sohn des Friedrich, Ersterer mit Katharina Herl, Zweiterer mit Gertrud von Mühlheim verheiratet. Es handelt sich jedoch um nur eine Person (Sohn Friedrichs) mit zwei Ehen, wie mehrere Dokumente bei Keller deutlich machen, insbesondere das Testament Johannes Bachofens vom 4. Juni 1575, welches die Erbschaft klären sollte, sowie der Vergleich vom 17. April 1576 über seine Erbschaft zwischen den Kindern aus erster und den noch minderjährigen Kindern aus zweiter Ehe, Keller, Urkunden (Anm. 28), S. 166-174, Nr. 289 und S. 175-178, Nr. 294. So auch bei Kloosterhuis, Erasmusjünger (Anm. 1), Nr. 7 und Husemann, Pharmakopöen (Anm. 22), S. 426 (die Angaben zu den Kindern sind dort allerdings unvollständig).

136 Illmer/Ridderikhoff/Ridder-Symoens, Premier livre, T1. 2, Bd. 2 (Anm. 12), Nr. 1226; Cornelia M. Ridderikhoff und Hilde de Ridder-Symoens (Hg.), Premier livre des procurateurs de la nation germanique de l'ancienne Université d'Orléans, 1444-1546, T1. 1: Texte des rapports des procurateurs (Les livres des proc. de la nation germ. de l'ancienne Univ. d'Orléans 1), Leiden 1971, S. 385,37 und 40; Cornelia M. Ridderikhoff und Chris L. Heesakkers (Hg.), Deuxième livre des procurateurs de la nation germanique de l'ancienne Université d'Orléans ,1546-1567, T1. 1: Texte des rapports des procurateurs, Bd. 1 Texte des rapports 1546-1560 (Les livres des proc. de la nation germ. de l'ancienne Univ. d'Orléans 2), Leiden et al. 1988, S. 94.

137 So wurde zu seinem Eintrag in Orléans notiert obiit Lutecie anno 1550, mense julio, Ridderikhoff/Heesakkers, Deuxième livre, Bd. 1 (Anm. 136), S. 94.

138 Guerrini, I dottori (Anm. 37), Nr. 1274; ASFE (Anm. 23), Federicus Bacchonus (Anm. 37). Obwohl er zum dr. iur. can. promoviert wurde, findet sich seine Promotion in den Akten des zivilrechtlichen Doktorenkollegiums, nicht in denen des kirchenrechtlichen, Archivio di Stato di Bologna, Registri d'atti del collegio civile. Prima serie, segnata B, Ms. 31, fol. 193v. In Padua taucht er am 18. Aug. 1550 als Zeuge der Promotion von Hupertus Faber auf, Martellozzo Forin, Acta graduum, T1. 3, Bd. 3 (Anm. 37), Nr. 3861. 
Drei seiner vier Söhne, Friedrich, Johannes und Albert, wurden ebenfalls in Italien in Medizin ausgebildet. Friedrich Bachofen, Sohn der ersten Ehefrau Katharina Herl ${ }^{139}$, studierte in Heidelberg (Aug. 1569), Montpellier (Juni 1572) und Padua (Nov. 1572) ${ }^{140}$. Da er später Arzt in Köln wurde ${ }^{141}$ und als dr. med. genannt wird ${ }^{142}$, kann angenommen werden, dass er während seines iter italicum einen Doktortitel erwarb, auch wenn der Promotionsort nicht bekannt ist. Sein Bruder Johannes schrieb sich bereits als Medizinstudent in Ingolstadt ein. Seine peregrinatio führte ihn über Padua, wo er Prokurator der natio germanica artistarum war und sich zwei Jahre (Nov. 1588 bis Okt. 1590) aufhielt ${ }^{143}$, und Siena (Nov. 1590) nach Bologna, wo er im April 1591 zum dr. med. promoviert wurde ${ }^{144}$. Johannes war seit 1606 Professor der Kölner medizinischen Fakultät ${ }^{145}$. Ausserdem war er Leibarzt des Kurfürsten von Trier ${ }^{146}$ und wurde 1621 nach Theodor Birckmann d. J. der zweite promovierte Mediziner und der erste Medizinprofessor im Rat der Stadt Köln. Er wurde zwar nicht aufgrund seiner medizinischen Qualifikation gewählt, sondern als Nachfolger seines Bruders Caspar, der der einzige der Brüder war, der kein Mediziner wurde. In der Folge setzte ihn der Rat jedoch als medizinischen Sachverständigen ein ${ }^{147}$. Da Theodor Birckmann 1623 verstarb - seine letzte Amtsperiode war 1621 -, kann Johannes Bachofen als der Nachfolger für medizinische Fragen im Rat gelten ${ }^{148}$.

139 Vgl. das Testament Johannes Bachofens vom 9. Sept. 1564, Keller, Urkunden (Anm. 28), S. 116-125, Nr. 212; s. auch Husemann, Pharmakopöen (Anm. 22), S. 426.

140 Rossetti, Matricula (Anm. 52), Nr. 275; Knod, Padua (Anm. 52), S. 169, Nr. 9; Gouron, Montpellier (Anm. 46), Nr. 2726; Toepke, Heidelberg, Bd. 2 (Anm. 68), S. 52,91. Möglicherweise ist er auch identisch mit Fridericus Bachhoffius Echtius, der 1567 mit Thomas, einem Cousin, und Albert, seinem Halbbruder, in Orléans war. Für wahrscheinlicher halte ich aber, dass es sich bei diesem um den gleichnamigen Bruder von Thomas handelt, der bereits 1549 minderjährig mit dem Onkel Reinhard in Orléans gewesen und vermutlich den Frankreichaufenthalt nach dessen Tod abgebrochen hatte, Ridderikhoff/Ridder-Symoens/Heesakkers, Troisième livre (Anm. 57), S. 119; vgl. Anm. 137.

141 Spätere Notiz zu seinem Eintrag in der Artistenmatrikel Paduas: Medicus Coloniae, Rossetti, Matricula (Anm. 52), Nr. 275; Knod, Padua (Anm. 52), S. 169, Nr. 9.

142 Etwa in seinem Testament von 1597, als er an der Pest erkrankt war, Keller, Urkunden (Anm. 28), S. 257 , Nr. 465.

143 Rossetti, Matricula (Anm. 52), Nr. 641; Martellozzo Forin, Acta graduum, T1. 4 (Anm. 17), Bd. 3: 1576-1590, Nr. 2474 (Zeuge) und S. 80 (Prokurator); Knod, Padua (Anm. 52), S. 171, Nr. 21.

144 Bronzino, Notitia doctorum (Anm. 5), S. 99; Maria Luisa Accorsi (Hg.), Natio germanica Bononiae, Bd. 1: La matricola/Die Matrikel, 1573-1602, 1707-1727, Bologna 1999, Nr. 1677; Fritz Weigle (Hg.), Die Matrikel der Deutschen Nation in Siena (1573-1738), Bd. 1 (Bibliothek des Deutschen Historischen Instituts in Rom 22), Tübingen 1962, Nr. 1975; Götz von Pölnitz (Hg.), Die Matrikel der Ludwig-Maximilians-Universität Ingolstadt-LandshutMünchen, Tl. 1: Ingolstadt, Bd. 1: 1472-1600, München 1937, S. 1159,18.

145 Keussen, Die alte Universität (Anm. 16), S. 485, Nr. 128.

146 Als solcher wird er im Juli 1606 genannt, Keller, Urkunden (Anm. 28), S. 268 f., Nr. 507.

147 Herborn, Ratsherr (Anm. 80), S. 359 f.

148 Er wurde von 1621 bis zu seinem Tod 1651 elfmal über das Gebrech in den Rat gewählt, Herborn, Ratsherr (Anm. 80), Nr. 45; Herbert M. Schleicher, Ratsherrenverzeichnis von Köln zu reichsstädtischer Zeit von 1396-1796 (Veröffentlichungen der Westdeutschen Gesellschaft für Familienkunde N. F. 19), Köln 1982, Nr. 941. 
Neben Friedrich, Johannes und Caspar hatte Johannes Bachofen noch einen unehelichen Sohn Albert ${ }^{149}$. Dieser war im Mai 1574 ebenfalls zum Medizinstudium in Padua und legte im August des folgenden Jahres in Bologna die medizinische Doktorprüfung $\mathrm{ab}^{150}$. Anschliessend war er als Arzt in Köln tätig, wo Weinsberg 1585 seinen Tod dokumentierte $^{151}$. Eine seiner Töchter, Margarete, verheiratete Johannes Bachofen zudem mit dem Sohn seines Kollegen Johann Weyer, Heinrich Weyer - ebenfalls Mediziner ${ }^{152}$. Johannes etablierte also nicht nur einen Medizinerzweig in seiner Familie, sondern versippte diese auch mit der anderen Leibarztfamilie am herzoglichen Hof. Auch einer seiner Neffen, Hermann Echt, Sohn des ältesten Bruders Heinrich, schrieb sich 1561 in Padua bei den Artisten ein, verstarb aber ebendort vor Abschluss des Studiums ${ }^{153}$.

Idealtypisch ist die Ausbildungsstrategie der Familie Weyer. Johann Weyer, selbst Leibarzt am herzoglichen Hof, aber noch ohne einen iter italicum, hatte vier Söhne, die er alle zum Studium nach Italien schickte ${ }^{154}$. Der Studienverlauf von Galenus, der seinem Vater in der Leibarztposition am jülich-klevischen Hof folgte, wurde oben dargelegt. Seine älteren Brüder Heinrich und Dietrich begannen ihre Artes-Ausbildung

149 Im Testament Johannes Bachofens vom 9. Sept. 1564 werden ihm die Studienkosten zugesprochen sowie die Dubletten aus der medizinischen Bibliothek des Vaters, die an den Halbbruder Dr. med. Friedrich gehen sollte, Keller, Urkunden (Anm. 28), S. 118 f., Nr. 212.

150 Rossetti, Matricula (Anm. 52), Nr. 303; Bronzino, Notitia doctorum (Anm. 5), S. 80; Knod, Padua (Anm. 52), S. 170, Nr. 12. 1567 war er bereits in Orléans, Ridderikhoff/Ridder-Symoens/Heesakkers, Troisième livre (Anm. 57), S. 119.

151 Item den 18 janvarii starb doctor Acht medicus vor den Crutzbrodern ein naturlichs sohn doctors Johans Acht medici, Die autobiographischen Aufzeichnungen Hermann Weinsbergs - Digitale Gesamtausgabe, Liber Senectutis, fol. 487v, [http://www.weinsberg.uni-bonn.de/Edition/Liber_Senectutis/ls9.htm\#487], 3.5.2018. Auch die Nationsmatrikel Paduas vermerkt seinen Tod (obiit anno 1585) und bezeichnet ihn als Coloniae medicus, Rossetti, Matricula (Anm. 52), Nr. 303. Siehe auch Keller, Urkunden (Anm. 28), S. 211, Nr. 372.

152 Die anderen Töchter ehelichten Juristen, Clara den Syndikus Dr. Werner Schenck, Anna Lic. Philipp von Brachell, Keller, Urkunden (Anm. 28), S. 166-174, Nr. 289, S. 175-178, Nr. 294, S. 185 f., Nr. 309, S. 200, Nr. 345, S. 231 f., Nr. 414, S. 236, Nr. 424.

153 In der Matrikel erscheint folgender Hinweis: Obiit 29 augusti 1561 Patavii, sepultus in Monasterio S. Antonii, Archivio antico dell'Università di Padova, Matricola dei Teologi, medici e filosofi della Naz. Germ. Art., Ms. 465, fol. 8v. Rossetti und Knod geben das Jahr 1564 an, im Original ist jedoch zweifelsfrei 1561 zu lesen, Rossetti, Matricula (Anm. 52), Nr. 128; Knod, Padua (Anm. 52), S. 168, Nr. 5. Auch in den Acta der Nation wird sein Tod im Jahr 1561 erwähnt, Favaro, Atti, Bd. 1 (Anm. 53), S. 41 f. Interessant ist zudem, dass der Student, der ein Wittenberger Magister und wie seine fünf Brüder protestantisch war, im Kloster bestattet wurde, Förstemann, Album, Bd. 1 (Anm. 41), S. 315b; Julius Köstlin (Hg.), Die Baccalaurei und Magistri der Wittenberger philosophischen Fakultät, Bd. 4: 1548-1560, Halle 1891, S. 21,5; Keller, Urkunden (Anm. 28), S. XIV. Auffallend ausdrücklich wird wohl gerade deswegen betont: funus docti et optime de religione sentientis iuvenis M. Hermanni Echtii Coloniensis, Favaro, Atti, Bd. 1 (Anm. 53), S. 41.

154 Ein Stammbaum der Familie findet sich bei Müller, Galenus Weyer (Anm. 16), S. 13. 
gemeinsam in Genf und Paris ${ }^{155}$. Heinrich ging daraufhin zum Medizinstudium zunächst nach Montpellier (Sept. 1561), im folgenden Jahr nach Padua (Nov. 1562) ${ }^{156}$ und wurde im Juli 1564 in Bologna zum dr. phil. et med. promoviert ${ }^{157}$. Sein Bruder Dietrich hingegen wandte sich zum Rechtsstudium an die französischen Universitäten mit rechtlichem Schwerpunkt, Bourges und Orléans, und anschliessend ebenfalls nach Italien, wo er sich 1562 in Padua in die Nationsmatrikel der Juristen einschrieb und nach einer weiteren Station in Bologna schliesslich im Mai 1564 in Pisa Doktor beider Rechte wurde. ${ }^{158}$ Er war damit der erste Jurist in der Medizinerfamilie.

Nicht nur Galenus, der seinen Vater im Herzogtum Jülich-Kleve-Berg beerbte, auch seine beiden Brüder stiegen in höfische Positionen auf. Dietrich wurde kurpfälzischer Rat $^{159}$. Das war wohl der Grund, weswegen der vierte und jüngste der Brüder, Johannes Wierus, zum Rechtsstudium nach Heidelberg ging ${ }^{160}$. Auch er ist später noch in der Nationsmatrikel Paduas zu finden ${ }^{161}$, war aber der einzige der Brüder, der sein Studium nicht mit einer italienischen Promotion abschloss. Für ihn reichte wohl die juristische Ausbildung und der bereits bestehende Kontakt an den Hof durch den Bruder, um ebenfalls in pfälzische Dienste treten zu können ${ }^{162}$.

155 Für Heinrich gibt Kloosterhuis wohl fälschlicherweise ein vorangegangenes Artes-Studium in Köln an, dort immatrikuliert er sich jedoch erst als Professor am 11. Aug. 1565, Keussen/Nyassi/Wilkes, Köln (Anm. 16), Bd. 4, Nr. 687,58; Kloosterhuis, Erasmusjünger (Anm. 1), Nr. 219. Knod gibt für die Einschreibung in Köln irrig das Jahr 1564 an, Knod, Padua (Anm. 52), S. 169, Nr. 6. Knod wiederum gibt für Dietrich ein vorangegangenes Artes-Studium in Köln an, wohl weil er die Jahreszahl der Einschreibung in Köln - 1566 als Professor - mit einer 1556 vertauschte, was dann vor dem weiteren Studium gewesen wäre, Keussen/Nyassi/Wilkes, Köln (Anm. 16), Bd. 4, Nr. 689,81 und Knod, Padua (Anm. 52), S. 148, Nr. 27.

156 Kloosterhuis nennt ihn einen Schüler von Vesalius, dieser lehrte jedoch nur von 1537 bis 1543 in Padua, Bertolaso, Ricerche (Anm. 54), S. 30; Grendler, The Universities (Anm. 3), S. 331. Sein Nachfolger auf dem Lehrstuhl für Anatomie und Chirurgie war Gabriele Falloppio, ebenfalls ein berühmter Anatomist, s. ebd.

157 Gouron, Montpellier (Anm. 46), Nr. 2390; ASFE (Anm. 23), Heinrich von Weyer, [http://asfe.unibo.it/it/persona/ BR1215], 3.5.2018; Bronzino, Notitia doctorum (Anm. 5), S. 65; Rossetti, Matricula (Anm. 52), Nr. 147; Knod, Padua (Anm. 52), S. 169, Nr. 6.

158 ASFE (Anm. 23), Dietrich von Weyer, [http://asfe.unibo.it/it/persona/WE02743], 3.5.2018; Elisabetta Dalla Francesca Hellmann (Hg.), Matricula nationis Germanicae iuristarum in Gymnasio Patavino (Fonti per la storia dell'Università di Padova 19), Rom/Padua 2008, Nr. 1477; Weigle, Pisa (Anm. 34), Nr. 419; Del Gratta, Acta graduum (Anm. 19), S. 72, Nr. 00632; Knod, Padua (Anm. 52), S. 148, Nr. 27. Im 〈Livre des procurateurs〉 in Orléans ist er nicht zu finden, aber Orléans, Bourges und Bologna werden neben Padua und Paris bei der Promotion in Pisa als Studienorte genannt.

159 In der Nationsmatrikel Paduas ist zu seiner Person von späterer Hand vermerkt: Archisatrapa nobilis electoris Palatini, rei militaris peritissimus, Hellmann, Matricula (Anm. 158), Nr. 1477. Als solcher war er auch als Gesandter tätig; seit 1575 war er Gouverneur von Kaiserslautern, Müller, Galenus Weyer (Anm. 16), S. 9, Anm. 14. Vgl. auch Kloosterhuis, Erasmusjünger (Anm. 1), Nr. 222.

160 Toepke, Heidelberg, Bd. 2 (Anm. 68), S. 65,13 und S. 498.

161 Hellmann, Matricula (Anm. 158), Nr. 3077.

162 Er wurde Archipraefectus in der Oberpfalz, Müller, Galenus Weyer (Anm. 16), S. 9, 13. 
Heinrich bekam 1565 zunächst eine Lehrerlaubnis an der medizinischen Fakultät in Köln ${ }^{163}$, die ihm jedoch bald darauf wieder entzogen wurde, da er - ganz der Schüler Paduas - von den Lehren Galens und Hippokrates' abwich ${ }^{164}$. Für die italienischen Innovationen in der medizinischen Lehre war man in Köln offenbar nicht empfäng$\operatorname{lich}^{165}$. Nachdem Galenus zunächst eine Zeit lang als Arzt in Köln und als Stadtarzt in Lemgo tätig war, wurde er Leibarzt des Trierer Kurfürsten ${ }^{166}$. Alle drei Söhne kamen folglich an Fürstenhöfen unter und nutzten somit ein mehrjähriges Fachstudium an den italienischen Universitäten, um die durch den Vater erreichte soziale Stellung der Familie zu konsolidieren. Heinrich heiratete zudem Margarete, die Tochter des Johannes Bachofen von Echt ${ }^{167}$.

Auch in der nächsten Generation gab es noch einen Italienreisenden. Galenus Weyer hatte einen Sohn, Johannes, der sein Studium 1601 in Marburg begann, zum Medizinstudium im April 1602 dann zunächst nach Basel und anschliessend nach Padua (Aug. 1605) zog ${ }^{168}$. Dort dürfte er wie sein Vater Schüler des Girolamo Fabrici d'Acquapendente gewesen und in den Genuss des 1594 eingeweihten anatomischen Theaters gekommen $\operatorname{sein}^{169}$. In Padua war er 1606 (ca. Juli bis Oktober) noch Prokurator der deutschen Artistennation, bevor er 1607 für die Promotion nach Basel zurückkehrte ${ }^{170}$. In der Zeit nach Einführung der professio fidei tridentina zur Erlangung akademischer Grade an katholischen Universitäten durch Papst Pius IV. 1564 und vor Einrichtung des Collegium Venetum artistarum in Padua 1616 war eine Promotion in Basel eine beliebte Option für Medizinstudenten nicht katholischer Konfession,

163 Keussen/Nyassi/Wilkes, Köln (Anm. 16), Bd. 4, Nr. 687,58 und Keussen, Die alte Universität (Anm. 16), S. 484, Nr. 116.

164 Meuthen, Alte Universität (Anm. 16), S. 397; Müller, Galenus Weyer (Anm. 16), S. 9, Anm. 15.

165 Auch ein Jahrhundert später trat die med. Fakultät in Köln noch für die Lehren Galens ein, s. Meuthen, Alte Universität (Anm. 16), S. 397.

166 Kloosterhuis, Erasmusjünger (Anm. 1), Nr. 219; Müller, Galenus Weyer (Anm. 16), S. 9, Anm. 15. In der Nationsmatrikel Paduas steht zu seiner Person folgender Vermerk: Medicus principis electoris Trevirensis, Rossetti, Matricula (Anm. 52), Nr. 147.

167 Kloosterhuis, Erasmusjünger (Anm. 1), Nr. 219; Müller, Galenus Weyer (Anm. 16), S. 9, Anm. 15; Fahne, Geschlechter (Anm. 135), S. 17; Knod, Padua (Anm. 52), S. 169, Nr. 6.

168 Rossetti, Matricula (Anm. 52), Nr. 1124; Hans Wackernagel (Hg.), Die Matrikel der Universität Basel, Bd. 3: 1601/02-1665/66, Basel 1962, S. 9,84; Julius Caesar (Hg.), Catalogus studiosorum scholae Marpurgensis, Bd. 3: A medio anno MDLXXI usque ad extremum annum MDCIV pertinens, Marburg 1882, S. 139.

169 Bertolaso, Ricerche (Anm. 54), S. 30; Ongaro, Medicina (Anm. 3), S. 169-171; Grendler, The Universities (Anm. 3), S. 335, 340; Bergdolt, Medicina (Anm. 54), S. 45; Klaus Bergdolt, L'Aquapendente e la Natio Germanica di Padova, in: Il teatro dei corpi, hg. v. Maurizio Rippa Bonati und José Pardo-Tomás, Mailand 2004, S. 228-234, hier: S. 228, 231.

170 Rossetti, Matricula (Anm. 52), S. 137; Antonio Favaro (Hg.), Atti della nazione Germanica artista nello Studio di Padova, Bd. 2 (Monumenti storici pubblicati dalla R. Deputazione Veneta di Storia Patria 20), Venedig 1912, S. 252, 255 f., 259 f., 265, 267; Wackernagel, Basel, Bd. 3 (Anm. 168), S. 9,84. In Basel trug er sich am 27. März 1607 als dr. med. in das Stammbuch des Caspar Bauhin ein. 
ihren iter italicum dennoch mit einem Doktorgrad abzuschliessen ${ }^{171}$. Der Rechtsstudent Franciscus Weier, wahrscheinlich ein Bruder von Johannes, wurde hingegen wohl ohne vorheriges Studium in Italien im Juli 1605 in Basel zum Lizentiaten beider Rechte ${ }^{172}$.

Die Studienverläufe der beiden Solenanders, Reiner und Johannes, wurden bereits vorgestellt. Der Aufstieg Reiner Solenanders, der aus bürgerlichen Verhältnissen kam ${ }^{173}$, bis zum Leibarzt am herzoglichen Hof ist vergleichbar mit dem des Johann Weyer. Trotz des beträchtlichen Altersunterschiedes handelt es sich bei Reiner und Johannes Solenander um Brüder. Reiner hatte nur einen Sohn namens Reinhard, weswegen Knod in Johannes einen Neffen vermutete ${ }^{174}$. Da in Pisa aber Ameldongus ${ }^{175}$ als Name des Vaters angegeben ist, auch Reiner der Sohn eines Amelongus ${ }^{176}$ war und Reiner zudem einen Bruder namens Johannes hatte, der ebenfalls Arzt gewesen sein soll ${ }^{177}$, muss es sich um den Bruder handeln ${ }^{178}$. Ob es sein älterer Bruder war, der das Medizinstudium in Italien unterstützte, lässt sich hingegen nur vermuten.

Johannes Solenander, der, wie bereits dargelegt, später für die lippischen Grafen tätig war, hatte offenbar einen Sohn namens Hermannus Solenander - dieser jetzt ein Westphalus beziehungsweise Lemgoviensis. Er studierte in Wittenberg (1601) und Helmstedt $(1604 / 5)^{179}$, bevor er sein Medizinstudium in Padua fortsetzte, wo er zeitweise Prokurator und consiliarius der deutschen Nation war und Johannes Weier noch

171 Matschinegg hat dieses Phänomen für die österreichischen Studenten festgestellt, Ingrid Matschinegg, Österreicher als Universitätsbesucher in Italien (1500-1630). Regionale und soziale Herkunft - Karrieren - Prosopographie, Diss. eingereicht 1999 an der Geisteswiss. Fak. der Karl-Franzens-Universität Graz, S. 87. Siehe auch Edgar Bonjour, Die Universität Basel. Von den Anfängen bis zur Gegenwart, 1460-1960, Basel 1960, S. 222; Maclean, Trois facultés (Anm. 3), S. 355. Zur Einführung der professio fidei sowie zum Collegium Venetum in Padua, an dem eine Promotion ohne Ablegung des Eides möglich war, s. Zonta, Schlesische Studenten (Anm. 3), S. 71-75; Guerrini, I dottori (Anm. 37), S. 17 f.; Grendler, The Universities (Anm. 3), S. 190-193; Fritz Weigle, Die deutschen Doktorpromotionen in Philosophie und Medizin an der Universität Padua von 1616 bis 1663, in: QFIAB 45 (1965), S. 329-333.

172 Wackernagel, Basel, Bd. 3 (Anm. 168), S. 50,125. Im Stammbaum bei Müller taucht er nicht namentlich auf; er wird aber wohl einer der drei weiteren Söhne «NN» von Galenus Weyer sein, Müller, Galenus Weyer (Anm. 16), S. 13.

173 Kloosterhuis, Erasmusjünger (Anm. 1), Nr. 195; Biesbrouck/Goddeeris/Steeno, Solenander (Anm. 30 ), S. 268.

174 Knod, Padua (Anm. 52), S. 170, Nr. 11. Was aus jenem Reinhard geworden ist, ist mir nicht bekannt.

175 Del Gratta, Acta graduum (Anm. 19), S. 363, Nr. 00378.

176 Ebd., S. 329, Nr. 00069.

177 Wackerbauer, Solenander (Anm. 29), S. 103; Biesbrouck/Goddeeris/Steeno, Solenander (Anm. 30), S. 268; Bloch, Der rheinische Arzt (Anm. 33), Sp. 149.

178 So auch Heuser, Gicht (Anm. 36), S. 187, Anm. 396.

179 In Helmstedt schrieb er sich am 21. Juni 1601 ein, war aber bereits am 10. Juli 1601 in Wittenberg und kehrte dann nach Helmstedt zurück, wo er sich 1604 an der medizinischen Fakultät einschrieb, Paul Zimmermann (Hg.), Album Academiae Helmstadiensis, Bd. 1: Album Academiae Juliae (Veröff. der Hist. Komm. für Hannover, Oldenburg, Braunschweig, Schaumburg-Lippe und Bremen 9), Hannover 1926, S. 156,11 und 174,3; Förstemann, Album, Bd. 2 (Anm. 69), S. 481. 
begegnet sein könnte ${ }^{180}$. Wie jener schloss er aus offensichtlich konfessionellen Gründen sein Studium in Basel ab, nämlich mit der Promotion zum dr. med. bei Felix Platter $1610^{181}$.

Über die Familienverhältnisse des Johannes Lithodius ist mir, abgesehen von der Tochter Maria, die Reiner Solenander heiratete, wenig bekannt. Bei Guilielmus Lithodius Montensis, der sich im September 1583 in Orléans einschrieb, könnte es sich um einen Sohn handeln ${ }^{182}$.

Theodor Birckmann wiederum, Sohn des Kölner Druckers Arnold Birckmann, hatte einen gleichnamigen Neffen, der in seine Fussstapfen trat und ebenfalls in Padua und Bologna Medizin studierte. Im Vergleich zur ausgiebigen Studienzeit seines Onkels an den dortigen Universitäten war die seine allerdings merklich kürzer. Nach dem Artes-Studium in Köln war er im Juni 1587 in Padua und legte seine Doktorprüfung im März 1588 in Bologna $\mathrm{ab}^{183}$. Allzu intensiv kann sein Medizinstudium demnach weder in Padua noch in Bologna gewesen sein, er hatte es wohl zum Grossteil bereits in Köln oder an einer anderen Universität absolviert. In Köln hatte er sich 1581 eingeschrieben und somit sicherlich vor 1587 mit dem Medizinstudium bereits begonnen $^{184}$. Theodor, der wie sein Onkel kein Mitglied der medizinischen Fakultät war, wurde der erste Mediziner im Rat der Stadt Köln ${ }^{185}$.

Nicht nur der Neffe unternahm einen iter italicum zum Studium der Medizin, auch zwei Söhne Theodors, Arnold und Hermann ${ }^{186}$, waren Ende des 16. Jahrhunderts für ein Medizinstudium an italienischen Universitäten. Beide besuchten wie der Vater die Universitäten Padua und Bologna. Arnold Birckmann studierte nach einem Artes-Studium in Köln ${ }^{187}$ eineinhalb Jahre in Padua, bevor er nach Bologna weiterzog. Er schrieb sich in Padua im April 1592 ein, wo er sich im November noch in das Liber amicorum des Wolfgang Kern von Obervilslern eintrug, sowie in Bologna im November 1593. Dort legte er im September 1594 die Prüfung zum dr. med. ab, übernahm bis 1595 aber

180 Er schrieb sich am 21. Dez. 1606 dort ein, war ab Sept./Okt. 1607 für ein Quartal Prokurator und von Juli/Aug. 1608 bis Febr. 1609 Consiliarius, Rossetti, Matricula (Anm. 52), Nr. 1160, S. 140, 142, 145. Johannes Weier war bis Sept./ Okt. 1606 dort Prokurator, war aber erst 1607 mit Sicherheit wieder in Basel (s. Anm. 170).

181 Er schrieb sich am 2. März 1610 in Basel ein und wurde am 8. Mai dr. med., Wackernagel, Basel, Bd. 3 (Anm. 168), S. 111,85. Dass er bei Platter promoviert wurde, ist einer Notiz in der Nationsmatrikel in Padua zu entnehmen: Doctor proclamatus Basileae a Felice Platero, Rossetti, Matricula (Anm. 52), Nr. 1160.

182 Ridderikhoff/Ridder-Symoens/Heesakkers, Troisième livre (Anm. 57), S. 514.

183 ASFE (Anm. 23), Theodor Birckmann, [http://asfe.unibo.it/it/persona/BR1684], 3.5.2018; Bronzino, Notitia doctorum (Anm. 5), S. 95; Knod, Padua (Anm. 52), S. 171, Nr. 20; Rossetti, Matricula (Anm. 52), Nr. 597.

184 Er immatrikulierte sich in Köln am 29. Okt. 1581 zum Studium der Artes. Beim Wechsel der Fakultät trugen die Studenten sich nicht ein weiteres Mal in der Matrikel ein, möglich ist also ein Medizinstudium in Köln, Keussen/ Nyassi/Wilkes, Köln (Anm. 16), Bd. 4, Nr. 703,69.

185 Er wurde seit 1609 für die Gaffel Windeck im üblichen Dreijahresrhythmus fünfmal in den Rat gewählt, Herborn, Ratsherr (Anm. 80), Nr. 30; Schleicher, Ratsherrenverzeichnis (Anm. 148), Nr. 344.

186 Stammbaum (ohne Gottfried, s. Anm. 123) der Birckmanns im 16. Jh. bei Corsten, Unter dem Zeichen (Anm. 123), S. 272.

187 Keussen/Nyassi/Wilkes, Köln (Anm. 16), Bd. 4, Nr. 708,81. 
noch das Amt des consiliarius der natio anglorum ${ }^{188}$. Hermann kam im März 1598 als bacc. art. nach Ingolstadt ${ }^{189}$. Dort studierte er vermutlich ein Semester, bevor er nach Padua weiterreiste, wo er sich von November 1598 bis mindestens Juli 1600 aufhielt. Zum dr. phil. et med. promoviert wurde er schliesslich im Mai 1601 in Bologna ${ }^{190}$. Hermann war anschliessend in Würzburg als herzoglicher Oberarzt und Professor der dortigen Universität tätig ${ }^{191}$.

Theodor Birckmann d. Ä., der erste Doktor der Familie, stieg also nicht nur selbst aus dem Familienunternehmen aus, sondern begründete eine Gelehrtenfamilie. Neben den drei Medizinern Arnold, Hermann und Theodor d. J. gab es in der nachfolgenden Generation auch zwei erste Juristen, die meines Wissens allerdings nicht an italienischen Universitäten ausgebildet wurden. Der zweite Neffe und Bruder von Theodor d. J., Johann, wurde lic. iur. und der dritte Sohn Theodors d. Ä., Gerwin, dr. iur. und Kölner Schöffe ${ }^{192}$. Auch die Tochter Theodors d. Ä., Katharina, wurde mit einem Juristen, dem städtischen Syndikus Winold Kyver, verheiratet ${ }^{193}$. Die Drucker- bzw. dann Medizinerfamilie integrierte sich so auch in die «regionale Juristenelite» ${ }^{194}$.

Bei den Familienangehörigen der Leibärzte verschob sich die Beliebtheit der besuchten italienischen Universitäten insgesamt deutlich zugunsten von Padua und Bologna. Es lässt sich ein Generationenunterschied feststellen. Nach Pisa ging der Medizinernachwuchs nach den 1570er-Jahren nicht mehr. Auch an der Universität in Montpellier, die zuvor dank ihrer praktischen Ausrichtung beliebt war, jetzt jedoch durch die Religionskriege an Attraktivität einbüsste ${ }^{195}$, sind nur die älteren unter den Verwandten noch anzutreffen: Heinrich Weyer, der Bruder des Galenus, 1562 und

188 ASFE (Anm. 23), Arnold Birckmann, [http://asfe.unibo.it/it/persona/BR1786], 3.5.2018; Bronzino, Notitia doctorum (Anm. 5), S. 102; Accorsi, La matricola (Anm. 144), Nr. 1856; Rossetti, Matricula (Anm. 52), Nr. 749; Knod, Padua (Anm. 52), S. 171, Nr. 25.

189 Pölnitz, Ingolstadt, Bd. 1 (Anm. 144), S. 1371,27. In Köln ist er im Gegensatz zu zahlreichen Familienmitgliedern nicht zu finden.

190 ASFE (Anm. 23), Hermann Birckmann, [http://asfe.unibo.it/it/persona/NG2567], 3.5.2018; Bronzino, Notitia doctorum (Anm. 5), S. 107; Knod, Padua (Anm. 52), S. 172, Nr. 28; Rossetti, Matricula (Anm. 52), Nr. 943; Accorsi, La matricola (Anm. 144), Nr. 2567; Martellozzo Forin, Acta graduum, T1. 4 (Anm. 17), Bd. 4: 1591-1600, Nr. 3527, 3531, 3532; Favaro, Atti, Bd. 2 (Anm. 170), S. 174.

191 In der Nationsmatrikel Paduas wurde notiert: Illustrissimi principis Herbipolensis Franconiae ducis archiater et in Academia Herbipolensi professor, Rossetti, Matricula (Anm. 52), Nr. 943; Sebastian Merkle (Hg.), Die Matrikel der Universität Würzburg, Bd. 1 (Veröff. der Ges. für Fränkische Geschichte, Reihe 4, Matrikeln fränkischer Schulen 5), München/Leipzig 1922, Nr. 1311; Knod, Padua (Anm. 52), S. 172, Nr. 28.

192 Beide schrieben sich 1587 bzw. 1590 zum Artes-Studium in Köln ein, möglicherweise absolvierten sie dort auch das Rechtsstudium, Keussen/Nyassi/Wilkes, Köln (Anm. 16), Bd. 4, Nr. 707,101 und 710,68. Vgl. zu den Familienverhältnissen den Stammbaum bei Corsten, Unter dem Zeichen (Anm. 123), S. 272.

193 Corsten, Unter dem Zeichen (Anm. 123), S. 270.

194 Wolfgang Herborn und Peter Arnold Heuser, Vom Geburtsstand zur regionalen Juristenelite. Greven und Schöffen des kurfürstlichen Hochgerichts in Köln von 1448 bis 1798, in: Rheinische Vierteljahrsblätter 62 (1998), S. 59-160, hier: S. 107, zu Gerwin Birckmann ebd., Nr. 91.

195 Maclean, Trois facultés (Anm. 3), S. 356 f. 
Friedrich Bachofen 1572. In Bologna waren sechs der zehn untersuchten Familienangehörigen. Die beiden Bachofens Hermann und Friedrich sind während ihres iter italicum in den 1560er-Jahren und Anfang der 1570er als zwei der früheren nicht hier gewesen. ${ }^{196}$ Die jüngsten der Familie Weyer und Solenander haben ihr Studium offensichtlich aus konfessionellen Gründen in Basel abgeschlossen. In Padua waren hingegen ausnahmslos alle. Auffällig ist, dass an der für hohe Promotionsgebühren bekannten Universität ${ }^{197}$ niemand seinen Doktorgrad erlangte. Diesen erwarben alle erst anschliessend in Bologna bzw. Basel.

\section{Fazit}

Es konnte gezeigt werden, dass die Leibarztpositionen am jülich-klevischen Hof in der zweiten Hälfte des 16. Jahrhunderts durch an italienischen Universitäten promovierte niederrheinische Mediziner besetzt wurden. Bis in die 1570er-Jahre besuchten die späteren Ärzte am Düsseldorfer Hof neben den Universitäten Bologna und Padua auch die studia in Pisa und Montpellier, wobei der Abschlussgrad in Pisa oder Bologna erreicht wurde. Ihre Nachkommen besuchten seit den 1570er-Jahren ausnahmslos die Universität Padua und je nach Konfession auch jene in Bologna (Birckmann und Bachofen) oder Basel (Weyer und Solenander), wo das Studium mit der Promotion abgeschlossen wurde.

An den ausländischen Universitäten knüpften die Mediziner Kontakte, die sie auch nach dem Studium beibehielten. So entstand in und um Köln ein enger Zirkel aus Gelehrten, die sich alle um 1538/39 in Bologna aufgehalten hatten und denen Johannes Bachofen angehörte. Anfang der 1570er-Jahre findet sich mit dessen Sohn Friedrich Bachofen sowie Johannes Solenander und Galenus Weyer hingegen eine Gruppe des leibärztlichen Nachwuchses gemeinsam an den Universitäten Montpellier, Padua und Pisa.

Bei einigen machten sich die Lehrjahre bei den berühmten italienischen Botanikund Anatomieprofessoren auch inhaltlich in ihrer späteren medizinischen Praxis bemerkbar. Johannes Bachofen, Absolvent Bolognas, legte gar den ersten botanischen Garten in Köln an. Auch beim Verfassen der kölnischen Pharmakopöe werden seine botanischen Kenntnisse Anwendung gefunden haben, ebenso wie jene Theodor Birckmanns. Ihre Mitverfasser Bernhard Dessen von Cronenburg und Hubert Faber hatten ihre medizinischen Doktorgrade ebenfalls an italienischen Universitäten erreicht. Die Lehren Paracelsus hingegen, die etwa in Padua kaum rezipiert wurden ${ }^{198}$, fanden in der Pharmakopöe keinen Niederschlag. Dass Birckmann ein Verfechter von Paracelus war, ist weniger auf seinen Aufenthalt in Italien als vielmehr auf das Studium in Montpellier sowie seine engen Kontakte nach Basel zurückzuführen. Für seine

196 Hermann könnte jedoch auch durch seinen Tod in Padua an weiteren universitären Stationen gehindert worden sein.

197 Richard Palmer, The Studio of Venice and its Graduates in the Sixteenth Century (Contributi alla storia dell’Università di Padova 12), Sarmeola di Rubano 1983, S. 31-33.

198 Maclean, Trois facultés (Anm. 3), S. 358. 
anatomische Ausbildung wird wiederum neben dem Professor Guillaume Rondelet in Montpellier auch der Aufenthalt unter Gabriele Falloppio in Padua eine Rolle gespielt haben. Die zahlreichen niederrheinischen Studenten, die seit den 1560er-Jahren in Padua studierten, können wiederum als Schüler von dessen Nachfolger Girolamo Fabrici d'Acquapendente betrachtet werden, so neben Johannes Solenander und Galenus Weyer auch deren Söhne Hermann Solenander und Johannes Weyer, die drei Söhne von Johannes Bachofen Friedrich, Albert und Johannes sowie die Söhne und der Neffe von Theodor Birckmann, Arnold, Hermann und Theodor. Ein besonders produktiver Rezipient der italienischen Medizin war Reiner Solenander - wenn auch vor allem im Vorfeld und im Anschluss an seine Anstellung am Düsseldorfer Hof. Er bezog nicht nur schon früh Stellung gegen die Verteidiger Galens und rezipierte Vesalius, sondern bewarb auch die klinische Medizin, wie sie da Monte in Padua praktiziert hatte.

Festzustellen war, dass die Leibärzte, die zumeist selbst noch nicht aus Gelehrtenfamilien stammten, auch ihre Söhne zum Medizinstudium nach Italien schickten. Auch die studierten Söhne, jüngeren Brüder und Neffen der Leibärzte erreichten oftmals Leibarztpositionen - wenn nicht am jülich-klevischen Hof, so an anderen Höfen. Die personelle Verflechtung mit der in diesem Zeitraum sehr überschaubaren medizinischen Fakultät in Köln hielt sich hingegen in Grenzen ${ }^{199}$. Standen genug Söhne zur Verfügung, wurde zusätzlich auf juristische Ausbildung gesetzt, diese wiederum nicht unbedingt in Italien, und die Töchter wurden mit Juristen verheiratet. Auch untereinander gingen die Familien enge Verbindungen ein. Johannes Bachofen verheiratete seine Tochter mit Heinrich Weyer und unterstützte die Ausbildung Reiner Solenanders, der wiederum die Tochter von Johannes Lithodius ehelichte. Anders als Bachofen, der den irenischen Kreisen am Hof zugeneigt war, hielt sich Theodor Birckmann für seine familiäre Heiratsstrategie an die katholische Kölner Stadtelite und war damit erfolgreich: Sein Sohn wurde der erste Ratsherr der Familie. Bachofen stammte allerdings selbst bereits aus einer Ratsfamilie. Im Unterschied zu den Familien Weyer, Solenander und Birckmann, die sich über eine erste französische und italienische Medizinerausbildung einen Aufstieg in die regionale Gelehrtenelite ermöglichten und erst in den folgenden Generationen ihre Söhne auch zu Juristen ausbilden liessen, kam er aus einer Familie, die bereits Juristen hervorgebracht hatte und nun auch das Medizinstudium in die Familienstrategie aufnahm. Der praktische Teil dieses Medizinstudiums war es, der die niederrheinischen Studenten wie so viele andere Ende des 16. Jahrhunderts an die italienischen Universitäten, insbesondere nach Padua, führte:

\section{[...]; paucos enim vel nullos potius ex nostris lectionum tantum gratia huc ad- ventasse, omnes autem praxis: non deesse nobis nec in patria aut alibi lectores, nec domi libros, quorum opera aeque uti hic uti queamus: praxis studium illud esse quod tot montes conscendere, tot nummos consumere nos invitet; [...] ${ }^{200}$}

199 Vgl. Meuthen, Alte Universität (Anm. 16), S. 392 f.

200 Favaro, Atti, Bd. 2 (Anm. 170), S. 77. 


\section{Der Humanistenkreis in Erfurt und die Reformation in Hessen (ca. 1500-1550)}

Bis zur Gründung der Universität Marburg ging die Mehrzahl der Hessen zum Studium ins benachbarte Erfurt, das im frühen 16. Jahrhundert eine Hochburg des Humanismus war ${ }^{1}$. Es fällt auf, dass die meisten frühen evangelischen Prediger in Hessen bei ihrem Studium in Erfurt in Kontakt mit dem dortigen Humanistenkreis gestanden hatten $^{2}$. So sind aus diesem Kreis auch einige bedeutende Reformatoren hervorgegangen, wie etwa Georg Spalatin, Johannes Lang oder Justus Jonas ${ }^{3}$. Philipp Melanchthon war zwar kein festes Mitglied, stand aber in enger freundschaftlicher Verbindung zu diesem Kreis ${ }^{4}$. In diesem Beitrag sollen die Wechselwirkungen zwischen dem Humanistenkreis in Erfurt und der Reformation in Hessen genauer betrachtet werden. Ausgangspunkt ist dabei zunächst die Frage, warum gerade viele Mitglieder des Humanistenkreises der Reformation aufgeschlossen gegenüberstanden. Anschliessend wird das reformatorische Wirken einiger Mitglieder oder Freunde des Kreises, die in der Landgrafschaft Hessen geboren wurden und/oder dort in besonderem Masse gewirkt haben, exemplarisch analysiert. $\mathrm{Zu}$ diesen Personen zählen insbesondere Adam Krafft (1493-1558), Johannes Feige (1482-1543), Eobanus Hessus (1488-1540), Johannes Draconites (1494-1566), Euricius Cordus (1486-1535), Erhard Schnepf (1495-1558) und Tilmann Schnabel (um 1475-1559). Schnabel war zwar ebenfalls kein Mitglied des Humanistenkreises, freundete sich aber in Erfurt mit Johannes Lang an, der dem Humanistenkreis angehörte ${ }^{5}$. Der Schwerpunkt der folgenden Analyse liegt auf den Personenverbindungen zwischen den genannten Personen des Humanistenkreises und deren Beziehungen zu den Wittenberger Reformatoren Martin Luther und Philipp Melanchthon. Die

1 Walter Heinemeyer, Johann Feige von Lichtenau. Kanzler des Landgrafen Philipp - Kanzler der Philipps-Universität Marburg, in: Zeitschrift des Vereins für hessische Geschichte und Landeskunde 97 (1992), S. 25-39, hier: S. 26.

2 Hans Schneider, Der hessische Augustiner Tilemann Schnabel und sein Orden, in: Jahrbuch der Hessischen Kirchengeschichtlichen Vereinigung 51 (2000), S. 143-179, hier: S. 147.

3 Dieter Stievermann, Marschalk (ca. 1470-1525), Spalatin (1484-1545), Mutian (ca. 1470-1526), Hessus (1488-1540) und die Erfurter Humanisten, in: Große Denker Erfurts und der Erfurter Universität, hg. von Dietmar von der Pfordten, Göttingen 2002, S. 118-142, hier: S. 137 f.

4 Eckhard Bernstein, Der Erfurter Humanistenkreis am Schnittpunkt von Humanismus und Reformation. Das Rektoratsblatt des Crotus Rubianus, in: Der polnische Humanismus und die europäischen Sodalitäten. Akten des polnischdeutschen Symposions vom 15.-19. Mai 1996 im Collegium Maius der Universität Krakau, hg. von Stephan Füssel und Jan Pirożyński (Pirckheimer Jahrbuch für Renaissance- und Humanismusforschung 12), Wiesbaden 1997, S. 137-165, hier: S. 146.

5 Schneider, Der hessische Augustiner Tilemann Schnabel (Anm. 2), S. 147. 
Datenbank des RAG liefert dazu wichtige Aufschlüsse über gemeinsame Studienzeiten, Lehrer-Schüler-Verhältnisse oder Freundschaften etc. Es wird dabei besonders danach gefragt, welche Rolle diese persönlichen Verbindungen bei der Durchführung der Reformation in Hessen gespielt haben.

\section{Der Charakter des Erfurter Humanistenkreises und die Anfänge der Reformation}

Der Humanistenkreis, der zunächst von dem Gothaer Stiftsherrn Konrad Muth (genannt Mutianus Rufus) geleitet wurde, war ausseruniversitär. Das heisst, dass der gebürtige Hesse und ehemalige Student der Erfurter Universität nicht selbst an der Hierana lehrte, aber in seinem Haus trafen sich humanistisch gesinnte Professoren und Studenten zum Gedankenaustausch ${ }^{6}$. Mutian hielt seine Freunde und Schüler zum Studium der antiken Literatur an und korrigierte ihre Briefe und Arbeiten ${ }^{7}$. Er unterstützte sie auch tatkräftig, indem er ihnen beispielsweise Arbeitsstellen verschaffte oder Empfehlungsschreiben für sie schrieb ${ }^{8}$. So hatte Mutian etwa 1508 die später für die Reformation von zentraler Bedeutung werdende Anstellung Spalatins am kurfürstlichen Hof Friedrichs des Weisen arrangiert ${ }^{9}$.

Die Mitglieder des Humanistenkreises hegten ein grosses Gefühl der Verbundenheit untereinander und unterstützten sich bei ihren schriftstellerischen Tätigkeiten, wie etwa bei gegenseitigen Korrekturen oder durch Hilfe bei der Beschaffung von Handschriften ${ }^{10}$. Eobanus Hessus kam immer wieder zurück nach Erfurt und schrieb während seiner Abwesenheit an Mutian:

Vivite, delitiae nostrae, dum vester amicus longius a vobis, quam decuisset, abest! Qui tamen, ut vultis, vivitque valetque videtque; quam non vobiscum vivere triste nihil. Quem precor, ut solita semper virtute colatis; ipse sub hoc etiam sydere vester erit. ${ }^{11}$

Auch Crotus Rubeanus beklagte während seiner Fuldaer Zeit als Leiter der dortigen Klosterschule die Abwesenheit von den anderen Humanisten:

Vivere absque ullo consorte morum et studii sors mihi videtur beluarum inferior, quas natura similitudine genuina conciliat [...]. ${ }^{12}$

6 Heinemeyer, Johann Feige von Lichtenau (Anm. 1), S. 26.

7 Bernstein, Der Erfurter Humanistenkreis (Anm. 4), S. 142.

8 Eckhard Bernstein, Mutianus Rufus und sein humanistischer Freundeskreis in Gotha (Quellen und Forschungen zu Thüringen im Zeitalter der Reformation 2), Köln/Weimar/Wien 2014, S. 157.

9 Wolfgang Breul-Kunkel, Fulda und Erfurt. Der Einfluss des Humanismus auf die Reichsabtei Fulda am Vorabend der Reformation, in: Fuldaer Geschichtsblätter 75 (1999), S. 71-131, hier: S. 95.

10 Bernstein, Der Erfurter Humanistenkreis (Anm. 4), S. 151.

11 Zit. nach Walther Ludwig, Eobanus Hessus in Erfurt. Ein Beitrag zum Verhältnis von Humanismus und Protestantismus, in: Mittellateinisches Jahrbuch 33/1 (1998), S. 155-170, hier: S. 162.

12 Zit. nach Breul-Kunkel, Fulda und Erfurt (Anm. 9), S. 84. 
Wie anhand von Mutians Briefwechsel aufgezeigt werden kann, fand innerhalb des freundschaftlichen Kreises ein sehr offener und freier Gedankenaustausch statt. So übte Mutian in seinen Briefen hemmungslose und massive Kritik an der zeitgenössischen Kirche. Seine Kritik äusserte er auf eine sehr direkte, spöttische und satirische Art und Weise. Theologen bezeichnete er etwa als Theoligen (= Theolügen). Er lehnte die kirchlichen Zeremonien, den Reliquienkult und die Ohrenbeichte ab. Über die Beichte schrieb er:

Nos Christiani apud Deum iudicem (nam auriculariam confessionem improbo) fatemur peccata et utimur non purgacione criminis, sed deprecacione et, quia culpam defendere non possumus, precamur, ut ignoscat. ${ }^{13}$

Das Leben der Mönche sei von Scheinheiligkeit und sexuellen Ausschweifungen geprägt:

Sed quid dicam de monachis, qui, quum mendicos se dicant, ipsi nihil non possident, quin affluunt diviciis et mollibus illecebris, revera spurcum animal et est lupus oppidicus sub agni nocens vellere. Sacratas Deo virgines adit buccis rubentibus Tunc dicimus nos creduli: >De Deo pater loquitur et pravos mores corrigit. Sed quid penis protuberat arctis compressiunculis raptisque turget basiis? ${ }^{14}$

Vor allem widerstrebte ihm die mangelnde Bildung der Geistlichen, über deren «Verhunzung» der lateinischen Sprache er sich brüskierte. Sein Spott galt zudem besonders den scholastischen Theologen. Aus der Kritik des Augustinerchorherrn lässt sich allerdings nicht nur ein starker Antiklerikalismus herauslesen, sondern teilweise auch eine generelle Geringschätzung des christlichen Glaubens. Mutian zögerte auch das Halten seiner ersten Messe bis zum elften Jahr hinaus ${ }^{15}$ und ärgerte sich über die Verpflichtung zu den Chorgebeten:

Distinet me chorus et otiosorum preces. Totos dies superstitio sibi vendicat. Trahor ad aras veluti victima immolanda. ${ }^{16}$

Ebenso widerstrebte ihm auch das Fasten:

Sum enim piger et tardus. In causa est cibus stultorum, ne quid gravius dicam. Stulti, certe stulti, qui preteritis lautis edundis obsoniis raphanum et stockfisch devorant. ${ }^{17}$

13 Fidel Rädle, Mutianus Rufus (1470/1-1526). Ein Lebensentwurf gegen die Realität, in: Humanistica Lovaniensia. Journal of Neo-Latin Studies 60 (2011), S. 3-33, hier: S. 25 ff.

14 Zit. nach Fidel Rädle, Mutians Briefwechsel und der Erfurter Humanismus, in: Humanismus in Erfurt, hg. von Gerlinde Huber-Rebenich und Walther Ludwig (Acta Academiae Scientiarum 7, Humanismusstudien 1), Rudolstadt/Jena 2002, S. 111-129, hier: S. 122 f.

15 Rädle, Mutianus Rufus (Anm.13), S. 25 ff.

16 Zit. nach Rädle, Mutians Briefwechsel (Anm. 14), S. 123.

17 Zit. nach ebd., S. 124. 
Die Erfurter Humanisten teilten die Kirchenkritik ihres Oberhauptes und übernahmen auch dessen Spottlust. So herrschte auch innerhalb des Humanistenkreises eine ablehnende Haltung gegenüber der Scholastik vor. Der Einfluss Mutians zeigt sich etwa an den sogenannten Dunkelmännerbriefen, die im Kreise der Erfurter Humanisten entstanden und in ihrer bissigen Kritik ganz im Stil Mutians gehalten $\operatorname{sind}^{18}$. Als Verfasser können namentlich Ulrich von Hutten und Crotus Rubeanus ausgemacht werden ${ }^{19}$. In den Briefen wurden die Skrupellosigkeit der Kirche und die Weltlichkeit, Lustorientierung und mangelnde Bildung des Klerus herausgestellt und der Lächerlichkeit preisgegeben $^{20}$. Die als scholastische Theologen dargestellten fiktiven Absender der Briefe erzählen etwa von ihren Besäufnissen und sexuellen Fehltritten ${ }^{21}$. Die Briefe wurden absichtlich in einem äusserst schlechten Latein verfasst (durch Germanismen und eine deutsche Wortfolge), um auf die mangelnde Beherrschung der lateinischen Sprache und Halbbildung in der Scholastik aufmerksam zu machen ${ }^{22}$.

Vor diesem Hintergrund wird verständlich, warum sich der Humanistenkreis anfangs stark mit Luther solidarisierte, der mit seiner Kirchenkritik und Ablehnung der Scholastik den Humanisten ähnelte. Johannes Lang, der seit 1511 mit Martin Luther befreundet war, stellte die Verbindung zwischen dem Erfurter Humanistenkreis und Luther her ${ }^{23}$. Den Erfurter Humanisten ist es auch gelungen, Erasmus von Rotterdam zumindest kurzzeitig für Luther zu gewinnen $(1518 / 19)^{24}$. So stellte sich Erasmus 1518 in einem Brief an Johannes Lang auf die Seite Luthers. In diesem übte er scharfe Kritik am Papsttum. Der Brief verbreitete sich schnell unter den Humanisten, die nunmehr Luthers Werke durch die Brille des Erasmus lasen ${ }^{25}$. Am Anfang befürworteten und förderten viele Humanisten die evangelische Bewegung in Erfurt und nahmen die Lehrunterschiede zwischen Luther und Erasmus nicht wahr, da sie Luther als einen Weggefährten ansahen $^{26}$. Von vornherein nahmen sie etwa in der Auseinandersetzung zwischen Luther und Eck Partei für Luther, da Eck sich kritisch gegenüber Erasmus und gegenüber den

18 Ludwig, Eobanus Hessus in Erfurt (Anm. 11), S. 162.

19 Bernstein, Der Erfurter Humanistenkreis (Anm. 4), S. 145.

20 Alexander Thumfart, Ulrich von Hutten (1488-1523) und Crotus Rubianus (ca. 1480-1545). Die Verfasser der Dunkelmännerbriefe, in: Große Denker Erfurts und der Erfurter Universität, hg. von Dietmar von der Pfordten, Göttingen 2002, S. 184-220, hier: S. 202.

21 Gerlinde Huber-Rebenich, Epistolae obscurorum virorum (EOV, Dunkelmännerbriefe), in: Deutscher Humanismus 1480-1520. Verfasserlexikon 1 (2008), S. 646-658, hier: S. 652.

22 Reinhard Hahn, Die «Dunkelmännerbriefe» und der Erfurter Humanismus, in: Beiträge zur Geschichte der Literatur in Thüringen. Mit 28 Abbildungen und einem Faksimile, hg. von Detlef Ignasiak (Palmbaum-Studien 1), Rudolstadt/Jena 1995, S. 53-66, hier: S. 63.

23 Bernstein, Der Erfurter Humanistenkreis (Anm. 4), S. 147.

24 Horst Rudolf Abe, Euricius Cordus (1486-1535) und die Universität Erfurt, in: Erfurt 742-1992. Stadtgeschichte, Universitätsgeschichte, hg. von Ulman Weiß, Weimar 1992, S. 277-294, hier: S. 290.

25 Bernstein, Der Erfurter Humanistenkreis (Anm. 4), S. 160.

26 Bob Scribner, Die Eigentümlichkeit der Erfurter Reformation, in: Erfurt 742-1992. Stadtgeschichte, Universitätsgeschichte, hg. von Ulman Weiß, Weimar 1992, S. 241-254, hier: S. 241. 
humanistischen Studien geäussert hatte. Im Sommer 1520 erschien in Erfurt die anonyme Schmähschrift 〈eccius dedolatus ${ }^{27}$.

Erasmus' Schriften hatten den Erfurter Humanistenkreis zur Auseinandersetzung mit theologischen Fragen angeregt. Dieser kritisierte in seinen Werken einige kirchliche Zeremonien, den Wunder- und Heiligenglauben, die Sittenlosigkeit vieler Geistlicher und die scholastische Theologie scharf ${ }^{28}$. Theologische Themen trafen bei den Erfurter Humanisten auf grosses Interesse. Einige von ihnen, wie etwa Crotus Rubianus, Justus Jonas, Johannes Lang und Johannes Draconites, waren selbst Theologen. Zunächst war Erasmus ihr theologisches Vorbild. Mit der Zeit wandten sich einige jedoch zunehmend von Erasmus ab und stellten sich ganz auf die Seite Luthers ${ }^{29}$. Die Erfurter Humanisten konnten durch ihren Einfluss verhindern, dass Luther von der Universität, die zu der Zeit zu den angesehensten Universitäten im Reich gehörte, öffentlich der Ketzerei beschuldigt wurde ${ }^{30}$.

Als Rektor der Universität fügte Crotus Rubeanus im Mai 1521, zum Ende seiner Amtszeit, eine Wappentafel in die Universitätsmatrikel ein. Um sein Wappen herum liess er in die Ecken die Wappen von Martin Luther, Erasmus von Rotterdam, Johannes Reuchlin und Mutianus Rufus zeichnen. Zwischen diese Wappen fügte er die Wappen von anderen Humanisten ein, und zwar von Ulrich von Hutten, Philipp Melanchthon, Joachim Camerarius, Eobanus Hessus, Justus Jonas, Johannes Lang, Peter Eberbach, Georg Forchheim, Heinrich Urban, Johannes Draconites, Adam Krafft und Justus Menius $^{31}$. Die Inschrift berichtet vom Reichstag in Worms, auf dem Martin Luther primus post saecula ausus fuit gladio sacrae scripturae Rhomanam licentiam iugulare. ${ }^{32}$ Crotus und Luther hatten sich bereits in ihrer Erfurter Studienzeit angefreundet ${ }^{33}$. Aus Bologna schrieb Crotus am 16. Oktober 1519 an Luther:

Duo, Martine venerande idemque mihi charissime, firmum in te amorem meum custodiunt: quod summa familiaritate Erffordiae bonis artibus simul operam dedimus aetate iuvenili, quod tempus inter similes mores arctissima fundamenta amicitiae collocat, deinde quod te habemus tam egregium defensorem rectae pietatis. ${ }^{34}$

Crotus hatte als Rektor der Universität auch dafür gesorgt, dass Luther auf seinem Weg zum Wormser Reichstag in Erfurt einen triumphalen Empfang erhielt ${ }^{35}$. Er zog

27 Breul-Kunkel, Fulda und Erfurt (Anm. 9), S. 120 f.

28 Wolfgang Breul-Kunkel, Herrschaftskrise und Reformation. Die Reichsabteien Fulda und Hersfeld ca. 1500-1525 (Quellen und Forschungen zur Reformationsgeschichte 71), Gütersloh 2000, S. 210 f.

29 Bernstein, Der Erfurter Humanistenkreis (Anm. 4), S. 159.

30 Abe, Euricius Cordus und die Universität Erfurt (Anm. 24), S. 290.

31 Scribner, Die Eigentümlichkeit der Erfurter Reformation (Anm. 26), S. 241.

32 Zit. nach Bernstein, Der Erfurter Humanistenkreis (Anm. 4), S. 162.

33 Breul-Kunkel, Fulda und Erfurt (Anm. 9), S. 81.

34 Zit. nach ebd., S. 120.

35 Breul-Kunkel, Herrschaftskrise und Reformation (Anm. 28), S. 212. 
Luther mit 40 berittenen Universitätsmitgliedern entgegen ${ }^{36}$. Bob Scribner weist darauf hin, dass sich der Erfurter Humanistenkreis gegenüber anderen Humanistengruppen Deutschlands (übertroffen nur von den Wittenbergern) durch ein besonders stark ausgeprägtes Solidaritätsgefühl und kollektive Zielstrebigkeit im Einsatz für die beginnende Reformation auszeichnete ${ }^{37}$.

Wenn die Humanisten auch zu grossen Teilen mit den Reformideen Luthers sympathisierten, wurden viele Luther positiv gesonnenen Humanisten durch die Erfurter Pfaffenstürme am 11. und 12. Juni 1521 abgeschreckt, da sie sich eine sanftere und intellektuellere Reform wünschten ${ }^{38}$. Unter den Hochschullehrern, die häufig Kanoniker waren, gab es einige, die Opfer der Pfaffenstürme wurden ${ }^{39}$. Es folgte der Bauernkrieg, weshalb die Humanisten Erfurt in Scharen verliessen. Nur Hessus blieb noch eine ganze Weile länger in Erfurt ${ }^{40}$. Die Konflikte der 1520er-Jahre schadeten der Universität enorm, was sich an einem drastischen Rückgang der Immatrikulationszahlen bemerkbar machte ${ }^{41}$. Die Universität wurde nach Juli 1522 wieder verstärkt von den Altgläubigen geleitet ${ }^{42}$, weshalb auch Johannes Lang aus der theologischen Fakultät ausgeschlossen wurde ${ }^{43}$. Der Humanistenkreis zerfiel nicht nur, da die meisten Humanisten Erfurt verliessen. Der Kreis spaltete sich nun auch in Befürworter und Gegner Luthers ${ }^{44}$. Einige Humanisten, die zuvor glühende Erasmusanhänger gewesen waren, wandten sich von ihm ab, weil er sich nicht Luther anschloss ${ }^{45}$.

Eobanus Hessus war 1518 noch zu Erasmus von Rotterdam nach Löwen gereist, um seine tiefe Verehrung zu bekunden. Zudem lobte er Erasmus in zahlreichen Gedichten. Ab 1521 jedoch wurde der Dichter Anhänger Luthers. Die Stimmung in Erfurt beim triumphalen Empfang von Martin Luther hielt er in vier Preiselegien auf den grossen Reformator fest. Seine Lutheranhängerschaft gab er auch in weiteren Publikationen kund, in denen er die Reformation begrüsste und die Papstkirche kritisierte ${ }^{46}$. Seit 1518 hatte Johannes Draconites mit Erasmus von Rotterdam im Briefwechsel gestanden und

36 Ludwig, Eobanus Hessus in Erfurt (Anm. 11), S. 164.

37 Scribner, Die Eigentümlichkeit der Erfurter Reformation (Anm. 26), S. 243.

38 Ebd., S. 244.

39 Christian Peters, Erfurt ist Erfurt, wird's bleiben und ist's immer gewesen. Luthers Einwirkungen auf die Erfurter Reformation, in: Erfurt 742-1992. Stadtgeschichte, Universitätsgeschichte, hg. von Ulman Weiß, Weimar 1992, S. 255-276, hier: S. 261.

40 Stefan Rhein, Philipp Melanchthon und Eobanus Hessus. Wittenberger Reformation und Erfurter «Poetenburg», in: Erfurt. Geschichte und Gegenwart, hg. von Ulman Weiß (Schriften des Vereins für die Geschichte und Altertumskunde von Erfurt 2), Weimar 1995, S. 283-295, hier: S. 288.

41 Stievermann, Marschalk, Spalatin, Mutian, Hessus und die Erfurter Humanisten (Anm. 3), S. 135.

42 Rhein, Philipp Melanchthon und Eobanus Hessus (Anm. 40), S. 289.

43 Bernstein, Der Erfurter Humanistenkreis (Anm. 4), S. 164.

44 Breul-Kunkel, Herrschaftskrise und Reformation (Anm. 28), S. 212.

45 Gerlinde Huber-Rebenich und Sabine Lütkemeyer, Hessus (Koch; Coci), Helius Eobanus, in: Deutscher Humanismus 1480-1520. Verfasserlexikon 1 (2008), S. 1066-1122, hier: S. 1071.

46 Ebd., S. 1069-1072. 
ihn 1520 mit anderen Erfurtern zusammen in Löwen besucht. Ab 1521 stellte aber auch er sich ganz auf die Seite Luthers ${ }^{47}$. Erhard Schnepf nahm 1518 an der Heidelberger Disputation teil und liess sich für die reformatorische Lehre gewinnen. Zusammen mit anderen jungen Zuhörern, wie etwa Martin Bucer, kam der gebürtige Heilbronner nach der Disputation mit Luther persönlich ins Gespräch ${ }^{48}$. Adam Krafft hatte 1519 zusammen mit Johannes Lang an der Leipziger Disputation teilgenommen ${ }^{49}$. Er schloss sich Luthers Lehrmeinung, wie einige andere Erfurter, im Jahr 1521 an, als er Luthers Predigt am 7. April im Erfurter Augustinerkloster hörte. Danach trat er selbst als evangelischer Prediger in Erfurt und Fulda auf ${ }^{50}$. Ebenso wurde Euricius Cordus entschiedener Anhänger Luthers. Der in Simtshausen geborene Hesse hatte 1521 am Wormser Reichstag teilgenommen und hielt seine Eindrücke in einer noch im selben Jahr publizierten Lobschrift auf Luther fest ${ }^{51}$. Offenbar sprachen die Erfurter Luther eine grössere Wirkmacht als Erasmus zu. So äusserte Crotus:

Beide [Erasmus und Luther] haben der Welt den Weg zu reinerer Frömmigkeit gezeigt; Luther aber hat diesen Weg nicht nur gezeigt, sondern auch betreten; er hat die Hacke zur Hand genommen, um den Weinberg Christi zu roden, darum ist er größer als Erasmus. ${ }^{52}$

Eckhard Bernstein macht darauf aufmerksam, dass es auch eine Frage der Generationszugehörigkeit gewesen sei, welche Humanisten sich Luther anschlossen. Der jüngeren Generation fiel scheinbar ein radikaler Bruch mit der Kirche leichter als der älteren. So ist es auffällig, dass sich viele junge Humanisten Luther anschlossen, während ältere wie Erasmus, Mutian und Reuchlin Luther gegenüber kritisch blieben ${ }^{53}$. Mutian geriet durch die Radikalisierung der reformatorischen Bewegung in gravierende materielle Sorgen. Trotz seiner Kritik am Kirchenwesen schloss er sich nicht der Reformation an, was allerdings dazu führte, dass er den Kontakt zu vielen seiner ehemaligen Weggefährten, Freunde und Schüler verlor ${ }^{54}$. Mit Johannes Lang war er etwa eng befreundet, bis dieser aufgrund seiner Lutheranhängerschaft den Kontakt zu Mutian abbrach. In einem Brief an Lang versuchte Mutian seine Stellung zu verteidigen:

Mihi belle convenit cum Lutheranis. Nomina tu mihi duos, quos habeam cordi pro Iona, Croto absentibus. Draco, Petreius iam diu sunt in meo calendario. [...]

47 Repertorium Academicum Germanicum (RAG), [www.rag-online.org], Johannes Drach Draconites - UniquID: ngND0I072M18ycjdhOGcwLzA, 2.5.2018.

48 Karl-Heinz zur Mühlen, Reformatorisches Profil. Studien zum Weg Martin Luthers und der Reformation, Göttingen 1995, S. 186.

49 RAG, (Anm. 47), Adam Krafft Vegetius Crato - UniquID: ngPF5e476PX2aeljjOYezNbW, 2.5.2018.

50 Johannes Schilling, Adam Krafft, der erste hessische Landesbischof, in: Fuldaer Geschichtsblätter 70 (1994), S. 87- 100, hier: S. 92.

$51 R A G$, (Anm. 47), Euricius Cordus - UniquID: ngVL8M678UN40krVpWEkfThk6UI, 2.5.2018.

52 Zit. nach Bernstein, Der Erfurter Humanistenkreis (Anm. 4), S. 162.

53 Ebd., S. 163.

54 Stievermann, Marschalk, Spalatin, Mutian, Hessus und die Erfurter Humanisten (Anm. 3), S. 132. 
Ianue saxis ceduntur, fenestre deturbantur. Spiramus in media barbarie. Stultus sim, si profitear hic me sentire cum sevientibus Lutheranis. Interim erent illico sancti patres iniuria affecti nocturna. Quare mihi ignoscant boni Lutherani. ${ }^{55}$

Hessus, der seit 1514 Mutian als Oberhaupt des Kreises ersetzt hatte und in dessen Haus in Erfurt, der sogenannten Engelsburg, sich die Humanisten seitdem versammelten ${ }^{56}$, blieb im Gegensatz zu den anderen Humanisten trotz der unterschiedlichen Haltung gegenüber der neuen Lehre weiterhin Mutians Freund ${ }^{57}$. An Spalatin schrieb er 1521:

Mutiano pene sum iratus, quod Martinum impugnat in omnibus, quas ad amicos scribit, epistolis. [...] Sed ignoscimus bono patri in sua insula tranquillitati magis quam istis turbis assueto. ${ }^{58}$

So verfasste Hessus später auch eine Totenklage auf Mutian ${ }^{59}$. Crotus war einige Jahre begeisterter Anhänger der Reformation, distanzierte sich dann allerdings wieder von der neuen Lehre ${ }^{60}$, was ihm ebenfalls die Feindschaft mit den ehemaligen Freunden, wie etwa mit Luther selbst, einbrachte ${ }^{61}$.

\section{Der frühe Einsatz für die Ausbreitung der Reformation in Hessen}

Bereits vor der Konversion des Landgrafen traten im hessischen Raum evangelische Prediger auf, die grossen Rückhalt in der hessischen Bevölkerung erzielten. Zu ihnen gehörte Tilmann Schnabel, der in Alsfeld wirkte. Er ist der vermutlich einzige Mönch, der vor 1525 in Hessen evangelisch predigte ${ }^{62}$. Schnabel wurde 1521 trotz seiner Doktorpromotion unter dem im selben Jahr gebannten und geächteten Luther Provinzial der sächsisch-thüringischen Provinz der Augustiner-Eremiten und damit zum Oberen der grössten Provinz in Deutschland. In einem Brief vom 13. November 1521 an seinen Freund Johannes Lang schrieb er:

[...] Reverendus ille pater et praeceptor M. Martinus Luder, quem Deus beatum faciat in terra et non tradat cum in manum inimicorum eius, a cuius doctrina, si Christianus sum, absit, ut aliquando desciscam. ${ }^{63}$

55 Zit. nach Rädle, Mutianus Rufus (Anm. 13), S. 23 f.

56 Huber-Rebenich/Lütkemeyer, Hessus (Anm. 45), S. 1068.

57 Bernstein, Mutianus Rufus und sein humanistischer Freundeskreis in Gotha (Anm. 8), S. 173.

58 Zit. nach Rädle, Mutianus Rufus (Anm. 13), S. 31.

$59 R A G$, (Anm. 47), Helius Eoban Hessus - UniquID: ngIY4T779JQ5txeEcHhx7GuZ, 2.5.2018.

60 Stievermann, Marschalk, Spalatin, Mutian, Hessus und die Erfurter Humanisten (Anm. 3), S. 137 f.

61 Huber-Rebenich/Lütkemeyer, Hessus (Anm. 45), S. 1072. Vgl. auch RAG, (Anm. 47), Crotus Rubeanus - UniquID: ngHX4S678Hf4qwdHbH8wtFtK, 2.5.2018.

62 Schneider, Der hessische Augustiner Tilemann Schnabel (Anm. 2), S. $143 \mathrm{ff}$.

63 Zit. nach ebd., S. $160 \mathrm{f}$. 
Trotz seiner hohen Position und der Exkommunikation Luthers war er also entschiedener Lutheranhänger. Er nutzte seine Position als Provinzial dazu, den evangelischen Glauben weiterzutragen, indem er Mönche zum Studium nach Wittenberg - der Hochburg des Luthertums - schickte. So verfuhr er noch im Herbst 1522, womit er sich im Grunde offiziell zum evangelischen Glauben bekannte ${ }^{64}$. Seine evangelischen Predigten in Alsfeld stiessen im Jahr 1523 noch auf die Missbilligung des hessischen Landgrafen Philipp des Großmütigen, weshalb sich Schnabel nach einer Zurechtweisung durch den Landgrafen zum Fortgang aus Alsfeld und damit zugleich zum Austritt aus dem Kloster entschloss $^{65} .1525$ kehrte Schnabel allerdings nach Alsfeld zurück, und zwar nicht nur aufgrund der Konversion Philipps, sondern weil die Alsfelder forderten, dass Schnabel als Prediger zurückkommen solle ${ }^{66}$. Der gebürtige Alsfelder blieb dort bis zu seinem Tod im Jahre $1559^{67}$.

Auch am landgräflichen Hof in Kassel gab es unter den Kanzleischreibern bereits im Frühjahr 1521 viele Lutheranhänger. Die Altgläubigen stellten daher die Vermutung auf, dass Philipp durch seine Umgebung im Jahre 1524 zum Konfessionswechsel veranlasst wurde. Über den genauen Zeitpunkt der Konversion des hessischen Kanzlers Johannes Feige können nur Vermutungen angestellt werden. Allerdings sandte Feige im Frühjahr 1521 einen Brief an Luther, in dem er sich für eine von ihm übersandte Schrift bedankte. Beide hatten sich zum selben Zeitpunkt in Erfurt immatrikuliert (1501), weshalb es möglich ist, dass sie seit der Studienzeit in persönlichem Kontakt standen ${ }^{68}$.

\section{Die Zusammenarbeit mit dem Landgrafen}

Philipp von Hessen gehörte zu den ersten Reichsfürsten, die sich Luther anschlossen ${ }^{69}$. Um 1524 verfasste Feige nach dem Konfessionswechsel seines Herrn die neue Landesordnung. Diese bezog den üblichen Anspruch der Obrigkeit, über das sittliche Verhalten der Untertanen wachen zu dürfen, nun auch auf die kirchlichen Angelegenheiten, um der Reformation Vorschub zu leisten. Johannes Feige galt als besonders geschickter und geduldiger Verhandlungspartner und gelangte an die Spitze der landgräflichen Berater. Der in Lichtenau geborene Hesse war an allen politischen Entscheidungen Philipps unmittelbar beteiligt und trat etwa auf der Homberger Synode (1526) und dem Marbur-

64 Ebd.

65 Ebd., S. $172 \mathrm{ff}$.

66 Artur Rühl, Tilemann Schnabel und die evangelische Bewegung in Alsfeld, in: Jahrbuch der Hessischen Kirchengeschichtlichen Vereinigung 30 (1979), S. 253-259, hier: S. 257.

67 RAG, (Anm. 47), Tilmann Schnabel (Frater) - UniquID: ngOE7Z971NG7xdkGiN1d0Mah, 2.5.2018.

68 Heinemeyer, Johann Feige von Lichtenau (Anm. 1), S. 28.

69 Wolfgang Breul-Kunkel, Marburg und die Reformation in Hessen, in: Hessen. Geschichte und Politik, hg. von Bernd Heidenreich und Klaus Böhme (Schriften zur politischen Landeskunde Hessens 5), Stuttgart/Berlin/Köln 2000, S. 163-181, hier: S. 163. 
ger Religionsgespräch (1529) als Redner und Vertreter des Landgrafen auf ${ }^{70}$. Auch am Augsburger Reichstag von 1530 nahm Feige im Gefolge des Landgrafen teil ${ }^{71}$.

Die der Reformation zuneigenden Landesherren interpretierten die Formel des Reichstagsabschiedes von 1526, nach der jeder Landesherr mit dem Wormser Edikt gegen Luther und seine Anhänger bis zu einem Konzil oder einer Nationalversammlung so verfahren solle, wie er es gegenüber Gott und Kaiser glaube verantworten zu können, als Erlaubnis zur Einführung der Reformation in ihren Territorien. Auf der Homberger Synode wurde nun über die Neuordnung des Kirchenwesens der Landgrafschaft beratschlagt ${ }^{72}$.

Adam Krafft und Philipp von Hessen lernten sich in den Wochen des Bauernkrieges in Hersfeld kennen. Krafft predigte dort gegen die Unruhen. Nachdem der Landgraf Fulda eingenommen hatte, liess er den in Fulda geborenen Krafft eine an die Aufständischen gerichtete mahnende Predigt halten und nahm ihn als Feldprediger nach Mühlhausen mit. Auch ernannte er ihn zu seinem Hofprediger ${ }^{73}$. Im Gefolge des hessischen Landgrafen nahm Krafft 1526 am Reichstag in Speyer teil. Ebenso war er Teilnehmer der Homberger Synode ${ }^{74}$.

1527 wurde Krafft vom Landgrafen mit der Visitation der Kirchen in der Landgrafschaft betraut. Die Visitation beinhaltete vor allem die Sicherstellung der evangelischen Predigt $^{75}$. Deshalb wird Adam Krafft als der erste hessische Landesbischof bezeichnet ${ }^{76}$. Krafft war es auch, der am Himmelfahrtstag 1527 in der Pfarrkirche zu Marburg den evangelischen Gottesdienst einführte. Als Generalsuperintendent war er für die Prüfung und Absetzung von altgläubigen Pfarrern und die entsprechende Neubesetzung mit evangelisch gesinnten Geistlichen zuständig. Somit wirkte er in hohem Masse am Aufbau der evangelischen Kirche in Hessen mit. Die Visitation lag zunächst hauptsächlich in den Händen Kraffts ${ }^{77}$. Erst 1531 wurde die Landgrafschaft dann in sechs Superintendenturbezirke eingeteilt: Marburg, Kassel, Alsfeld, Rotenburg/Fulda, Darmstadt und St. Goar. Krafft blieb für Marburg zuständig ${ }^{78}$. Die Superintendenten stellten also die Führungsschicht der Geistlichen im evangelischen Kirchenwesen dar ${ }^{79}$.

Tilmann Schnabel war von 1530 bis 1541 Superintendent des Bezirks Alsfeld ${ }^{80}$. Er gehörte zu den Geistlichen, die sich dem Interim Karls V. von 1548, welches bestimmte, dass bis zu einem allgemeinen Konzil, mit Ausnahme von Laienkelch und Priesterehe,

70 Heinemeyer, Johann Feige von Lichtenau (Anm. 1), S. 29 ff.

$71 R A G$, (Anm. 47), Johannes Feige Ficinus - UniquID: ngSI0N577SK39hoAmTLhbQeR, 2.5.2018.

72 Breul-Kunkel, Marburg und die Reformation in Hessen (Anm. 69), S. 170.

73 Schilling, Adam Krafft, der erste hessische Landesbischof (Anm. 50), S. 92 f.

$74 R A G$, (Anm. 47), Adam Krafft Vegetius Crato - UniquID: ngPF5e476PX2aeljjOYezNbW, 2.5.2018.

75 Schilling, Adam Krafft, der erste hessische Landesbischof (Anm. 50), S. 93 ff.

76 Ebd., S. 87.

77 Ebd., S. 94 f.

78 Johannes Schilling, Klöster und Mönche in der hessischen Reformation (Quellen und Forschungen zur Reformationsgeschichte 67), Gütersloh 1997, S. 174.

79 Schneider, Der hessische Augustiner Tilemann Schnabel (Anm. 2), S. 143.

80 RAG, (Anm. 47), Tilmann Schnabel (Frater) - UniquID: ngOE7Z971NG7xdkGiN1d0Mah, 2.5.2018. 
die katholischen Zeremonien, insbesondere die Messe, wieder einzuführen seien, hartnäckig widersetzten. Der Widerstand gegen das Interim wurde allerdings von der breiten Masse der hessischen Bevölkerung befürwortet, sodass Befürworter des Interims es schwer hatten, sich gegen ihre Pfarrgemeinden durchzusetzen. Dass das Interim kaum Einfluss auf die Predigt, Lehre und die neue Gottesdienstordnung in Hessen ausübte, ist also nicht allein dem Widerstand einzelner leitender Geistlicher der evangelischen Kirche zuzuschreiben $^{81}$. Adam Krafft beteiligte sich ebenfalls am Widerstand gegen das Interim $^{82}$. Auch die Gründung der Universität Marburg sollte zur Ausbreitung der Reformation dienen. Der Landgraf verfolgte mit der Gründung das Ziel, Beamte und Pfarrer für das Land auszubilden, die sowohl humanistisch gesinnt als auch dem evangelischen Glauben zugehörig sein würden. Es fällt daher auf, dass insbesondere diejenigen an die Marburger Universität berufen wurden, die den Wittenberger Reformatoren nahestanden. Das gilt aber nicht für alle Berufungen, denn es wurden durchaus auch Altgläubige an der Universität aufgenommen ${ }^{83}$.

Johannes Feige war an der Universitätsgründung massgeblich beteiligt. Insbesondere die am 16. Juli 1541 durch Kaiser Karl V. erfolgte Bestätigung der Universität geht auf ihn zurück, denn er war dazu nach Regensburg gereist. Erst durch die Bestätigung des Kaisers erhielt die Marburger Universität alle Rechte einer Universität, darunter vor allem die Anerkennung der akademischen Grade. Am 1. Juli 1527 eröffnete Feige die Universität und wurde ihr erster Kanzler ${ }^{84}$.

Auch an der Universität hatte Adam Krafft eine zentrale Stellung. Er war 1536 Dekan der theologischen Fakultät und dreimal Rektor $(1529,1540,1553)$. Von der Gründung der Universität 1527 bis zu seinem Tod im Jahre 1558 war er als Theologieprofessor in Marburg angestellt. Er nahm auch am Marburger Religionsgespräch (1529) und den Religionsgesprächen in Worms (1540) und Regensburg (1541) teil. Für den Landgrafen übersetzte er das Regensburger Buch ins Deutsche. Zudem gab er 1549 das Marburger Gesangbuch heraus ${ }^{85}$.

Landgraf Philipp lernte Erhard Schnepf auf der Homberger Synode kennen und berief ihn als Hofprediger und Theologieprofessor nach Marburg ${ }^{86}$. Zweimal hatte Schnepf das Rektorat inne. Zudem war er als Prediger und Superintendent in Marburg tätig. Im Gefolge des Landgrafen nahm er am Reichstag in Speyer und Augsburg teil. Darüber hinaus wirkte er an sämtlichen Religionsgesprächen mit, so 1539 in Nürnberg, 1540/41 in Hagenau und Worms, 1546 in Regensburg und 1557 in Worms ${ }^{87}$. Im Auftrag

81 Rühl, Tilemann Schnabel und die evangelische Bewegung in Alsfeld (Anm. 66), S. 258 f.

82 Schilling, Adam Krafft, der erste hessische Landesbischof (Anm. 50), S. 95 f.

83 Heinemeyer, Johann Feige von Lichtenau (Anm. 1), S. 32 ff.

84 Ebd.

$85 R A G$, (Anm. 47), Adam Krafft Vegetius Crato - UniquID: ngPF5e476PX2aeljjOYezNbW, 2.5.2018.

86 Robert Stupperich, Reformatorenlexikon, Gütersloh 1984, S. 190.

$87 R A G,($ Anm. 47), Erhard Schnepf - UniquID: ngZP9Q072YH8kovVtY2olX1K0Zi, 2.5.2018. 
des Landgrafen verfasste Schnepf eine Grundschrift für Heinrich VIII. von England, in der er die evangelische Position darlegte ${ }^{88}$.

Johannes Draconites wurde 1534 als Theologieprofessor nach Marburg berufen, wo er auch als Pfarrer tätig war. Hier lehrte er bis 1547 und war einmal Rektor (SoSe 1544) und Dekan der theologischen Fakultät (SoSe 1545). In Marburg war er schriftstellerisch sehr aktiv und veröffentlichte theologische Gutachten, Auslegungen biblischer Bücher und Predigten ${ }^{89}$.

\section{Reformatorisches Wirken ausserhalb der Landgrafschaft}

Adam Kraffts bedeutende Stellung bezüglich der Durchführung der Reformation wird auch an seinem Wirken über die Landgrafschaft hinaus ersichtlich. Im Auftrag des hessischen Landgrafen Philipp half er bei der Einführung der Reformation in Korbach, Waldeck, Höxter, Göttingen, Frankfurt am Main und in der Grafschaft Wittgenstein mit $^{90}$.

Johannes Draconites konnte ab 1522 als Pfarrer in Miltenberg seine Kirchengemeinde für den evangelischen Glauben gewinnen. Doch der in Karlstadt geborene Prediger wurde bereits im September 1523 exkommuniziert und musste fliehen. An seine Gemeinde schrieb er weiterhin Trostbriefe ${ }^{91}$. Von Miltenberg aus war er an der Universität Wittenberg zum Doktor der Theologie promoviert worden. Im Auftrag des Landgrafen nahm Draconites 1541 am Religionsgespräch in Regensburg teil ${ }^{92}$. Dort überreichte er dem Rat seine Auslegung des 117. Psalms und forderte die Annahme der lutherischen Lehre, woraufhin er allerdings Regensburg verlassen musste ${ }^{93}$. Später ging er als Theologieprofessor nach Rostock und war dort von 1557 bis 1560 Superintendent. 1560 wurde er Präsident (Bezeichnung des Vorstehers eines evangelischen Bistums) des Bistums Pomesanien ${ }^{94}$.

Erhard Schnepf trat nach seiner Konversion in Württemberg in verschiedenen Orten (Weinsberg, Neckarmühlbach, Wimpfen) als evangelischer Prediger auf ${ }^{95}$. Graf Philipp III. von Nassau-Weilburg berief Schnepf 1525 als Pfarrer und Superintendent nach Weilburg, wo Schnepf die Reformation einführte. 1534 gab er seine Professur in Marburg auf, um wieder nach Württemberg zu gehen. Herzog Ulrich von Württemberg hatte Schnepf als Reformator zu sich berufen, nachdem er mithilfe des hessischen Landgrafen sein

88 Stupperich, Reformatorenlexikon (Anm. 86), S. 190.

89 RAG, (Anm. 47), Johannes Drach Draconites - UniquID: ngND0I072M18ycjdhOGcwLzA, 2.5.2018.

90 Schilling, Adam Krafft, der erste hessische Landesbischof (Anm. 50), S. 95. Vgl. auch RAG, (Anm. 47), Adam Krafft Vegetius Crato - UniquID: ngPF5e476PX2aeljjOYezNbW, 2.5.2018.

91 Stupperich, Reformatorenlexikon (Anm. 86), S. 69.

92 RAG, (Anm. 47), Johannes Drach Draconites - UniquID: ngND0I072Ml8ycjdhOGcwLzA, 2.5.2018.

93 Stupperich, Reformatorenlexikon (Anm. 86), S. 69.

94 RAG, (Anm. 47), Johannes Drach Draconites - UniquID: ngND0I072M18ycjdhOGcwLzA, 2.5.2018.

95 Volker Leppin, Schnepf, Erhard (1495-1558), in: Theologische Realenzyklopädie 30 (1999), S. 233-235, hier: S. 233. 
Territorium zurückgewonnen hatte. Ab 1544 wirkte Schnepf als Theologieprofessor, Pfarrer und Superintendent in Tübingen ${ }^{96}$. Tübingen musste er 1548 aufgrund des Interims, gegen das er sich gestellt hatte, wieder verlassen ${ }^{97}$. In Jena fand er eine neue Anstellung als Pfarrer, Superintendent und Lektor für Hebräisch am Pädagogium. Nach der Gründung der Universität Jena im Jahr 1558 wurde er dort der erste Dekan. Hier lehrte er als Theologieprofessor bis zu seinem Lebensende ${ }^{98}$.

\section{Soziale Verflechtungen}

Tilmann Schnabel hat um 1500 zeitgleich mit Johannes Lang und Martin Luther in Erfurt studiert. Da alle drei dem Orden der Augustiner-Eremiten angehörten, kannten sie sich also bereits seit ihrer Erfurter Studienzeit. Schnabel und Lang freundeten sich schon in Erfurt an und blieben auch nach dem gemeinsamen Studium in Briefkontakt. Alle drei wechselten innerhalb kurzer Zeitabstände (Luther 1508, Lang 1511, Schnabel 1512) an die Universität Wittenberg, wo Lang auch mit Luther eine lebenslange Freundschaft schloss. Hier studierte Schnabel bei Luther ${ }^{99}$ und wurde dessen erster Doktorand ${ }^{100}$. $\mathrm{Zu}$ diesem Zeitpunkt waren neben Lang noch weitere Mitglieder des Humanistenkreises in Wittenberg anwesend. Justus Jonas hatte sich, ebenso wie Lang, im Jahre 1511 immatrikuliert. Georg Spalatin kam 1512 an die Universität Wittenberg, um dort die Stelle des Bibliothekars anzutreten. Beide wurden enge Freunde Luthers. Nach seiner Doktorpromotion im Jahre 1515 wurde Tilmann Schnabel als Theologieprofessor in Wittenberg angestellt, lebte aber bereits 1518 wieder als Prior im Alsfelder Konvent. Luther verschaffte Schnabel, als dieser 1523 aufgrund seiner evangelischen Predigten Alsfeld verlassen musste, eine Stelle als evangelischer Prediger in Leisnig ${ }^{101}$.

Euricius und Hessus haben sich wohl schon während ihrer gemeinsamen Schulzeit an der Lateinschule in Frankenberg angefreundet ${ }^{102}$ und dann in den Folgejahren (mit Unterbrechungen) relativ zeitgleich an der Universität Erfurt studiert. Beide waren seit ihrer Studienzeit wiederum mit Johannes Feige und auch Martin Luther

$96 R A G$, (Anm. 47), Erhard Schnepf - UniquID: ngZP9Q072YH8kovVtY2olX1K0Zi, 2.5.2018.

97 Stupperich, Reformatorenlexikon (Anm. 86), S. 190.

$98 R A G$, (Anm. 47), Erhard Schnepf - UniquID: ngZP9Q072YH8kovVtY2olX1K0Zi, 2.5.2018.

99 RAG, (Anm. 47), Tilmann Schnabel (Frater) - UniquID: ngOE7Z971NG7xdkGiN1d0Mah, 2.5.2018; ebd., Johannes Lang - UniquID: ngOE2V779OG50dkmiPHda, 2.5.2018; ebd., Martin Luther - UniquID: ngXN3O678XP4gmtrr XGm9Vju, 2.5.2018.

100 Schneider, Der hessische Augustiner Tilemann Schnabel (Anm. 2), S. 148.

101 RAG, (Anm. 47), Johannes Lang - UniquID: ngOE2V779OG50dkmiPHda, 2.5.2018; ebd., Justus Jonas der Ältere - UniquID: ngZP1Y274YH05ovptZIo5Xlo, 2.5.2018; ebd., Georg Spalatin - UniquID: ngFV9W678EN48ubvZ EOupDrI6GI, 2.5.2018; ebd., Martin Luther - UniquID: ngXN3O678XP4gmtrrXGm9Vju, 2.5.2018; ebd., Tilmann Schnabel (Frater) - UniquID: ngOE7Z971NG7xdkGiN1d0Mah, 2.5.2018.

102 Peter Dilg, Cordus, Euricius, in: Deutscher Humanismus 1480-1520. Verfasserlexikon 1 (2008), S. 470-496, hier: S. 471 . 
befreundet ${ }^{103}$. Feige stimmte als Mitbegründer der Universität dem Vorschlag der Wittenberger Reformatoren, seine ehemaligen Studienfreunde aus Erfurt, Eobanus Hessus und Euricius Cordus, an die Universität Marburg zu berufen, $\mathrm{zu}^{104}$. Als Arzt in Braunschweig konnte sich Cordus aufgrund seiner Lutheranhängerschaft nicht halten, weshalb ihm der Ruf an die Universität Marburg im Jahr 1527 an den Lehrstuhl für Medizin zugutekam ${ }^{105}$. Beim Landgrafen setzte sich Feige auch für die finanziellen Nöte der Marburger Professoren ein, so auch konkret für seinen Freund Eobanus Hessus. Aus Dankbarkeit schrieb Hessus Distichen für ihn ${ }^{106}$.

Der Dichter und Arzt Euricius Cordus war mit weiteren Mitgliedern des Humanistenkreises befreundet, so mit Erhard Schnepf, Justus Jonas, Johannes Lang, Georg Spalatin, Adam Krafft, Johannes Drach und Joachim Camerarius. Auch mit Crotus Rubeanus und Mutianus Rufus war er eng vertraut, bevor er impulsiver Lutheranhänger wurde. Da auch Krafft an der neu gegründeten Universität Marburg lehrte, trafen sich die Erfurter Freunde dort als Kollegen wieder. Die Studienzeiten von Cordus und Schnepf decken sich hingegen nicht, weshalb sie vermutlich erst in Marburg Freundschaft schlossen. Cordus verfasste nicht nur für seine Freunde Epigramme, sondern widmete einige auch Philipp Melanchthon ${ }^{107}$.

Eobanus Hessus war neben Cordus, Luther und Feige mit den Verfassern der Dunkelmännerbriefe Ulrich von Hutten und Crotus Rubeanus sowie mit Mutianus Rufus, Johannes Draconites, Justus Jonas, Georg Spalatin, Johannes Lang und Joachim Camerarius $^{108}$, dem engsten Freund Melanchthons, und auch mit Melanchthon selbst befreundet ${ }^{109}$.

Hessus setzte sich gegen die radikalen evangelischen Prediger in Erfurt ein, die die humanistischen Studien für unnötig hielten und damit einen eklatanten Schwund des Interesses an diesen auslösten, was sich durch eine rapide Abnahme der Neuimmatrikulationen und Besucher der humanistischen Kurse äusserte. Luther, Melanchthon und Hessus waren sich einig, dass das Studium der alten Sprachen Voraussetzung für das Bibelstudium sei, da die Bibel auf diese Weise im Urtext gelesen werden könne und so das Textverständnis vertieft werde. Hessus publizierte 1523 einige Briefe anderer Lutheraner, um seine Meinung zu unterstützen, so unter anderem Briefe von Melanchthon, Justus Jonas, Draconites und von Luther selbst. Hessus gab seine freundschaftlichen Beziehungen zu altgläubigen Kollegen aus der theologischen Fakultät nicht auf. Er war der Einzige der Lutheranhänger im Humanistenkreis, der die Freundschaft zu Crotus

103 RAG, (Anm. 47), Euricius Cordus - UniquID: ngVL8M678UN40krVpWEkfThk6UI, 2.5.2018; ebd., Helius Eoban Hessus - UniquID: ngIY4T779JQ5txeEcHhx7GuZ, 2.5.2018.

104 Heinemeyer, Johann Feige von Lichtenau (Anm. 1), S. 33.

105 Bernstein, Mutianus Rufus und sein humanistischer Freundeskreis in Gotha (Anm. 8), S. 204.

106 Heinemeyer, Johann Feige von Lichtenau (Anm. 1), S. 36.

107RAG, (Anm. 47), Euricius Cordus - UniquID: ngVL8M678UN40krVpWEkfThk6UI, 2.5.2018; ebd., Adam Krafft

Vegetius Crato - UniquID: ngPF5e476PX2aeljjOYezNbW, 2.5.2018; ebd., Erhard Schnepf - UniquID: ngZP9Q072

YH8kovVtY2olX1K0Zi, 2.5.2018.

108 Ebd., Helius Eoban Hessus - UniquID: ngIY4T779JQ5txeEcHhx7GuZ, 2.5.2018.

109 Rhein, Philipp Melanchthon und Eobanus Hessus (Anm. 40), S. 286. 
Rubeanus nicht beendete, als dieser sich wieder von der neuen Lehre abwandte ${ }^{110}$. Seine Kontakte zu Altgläubigen und sein Auftreten gegen die radikal gesinnten Prediger in Erfurt führten allerdings in reformatorischen Kreisen zu Verdächtigungen, dass er nicht mehr der lutherischen Lehre anhängig sei ${ }^{111}$. Insbesondere Johannes Lang, sein Erfurter Griechischlehrer und Freund ${ }^{112}$, beschuldigte Hessus antireformatorischer Umtriebe. So dachte auch Mutian, dass Hessus wieder zur Alten Kirche zurückgekehrt sei, wie er in einem Brief an Erasmus berichtete. Auch Melanchthon beklagte den Bildungsverfall und die Verachtung der humanistischen Studien und nahm Hessus daher gegen die Anschuldigungen Langs in den Schutz. ${ }^{113}$ Hessus schrieb vergeblich zahlreiche Briefe an Lang, in denen er seine Freundschaft $\mathrm{zu}$ ihm und seine Befürwortung der reformatorischen Bewegung herausstellte. Er blieb aber unabhängig seiner Kritik oder Freundschaft zu Altgläubigen in Glaubensfragen stets lutherisch ${ }^{114}$.

Als 1526 das evangelische Ägidiengymnasium in Nürnberg gegründet wurde, wurde Hessus auf Empfehlung Melanchthons hin dort der erste Lehrer für lateinische Dichtkunst $^{115}$. Die Lateinschule in Nürnberg verband ganz nach dem Konzept Melanchthons die humanistischen Studien mit der lutherischen Theologie ${ }^{116}$. Camerarius und Hessus waren in Nürnberg Kollegen ${ }^{117}$. Sie waren bereits seit 1513 befreundet, als Hessus sich an der Universität Leipzig immatrikulierte, an der Camerarius bereits studierte $^{118}$. In Wittenberg konnte Melanchthon erfolgreich die geordnete Abfolge von humanistischen Studien und Bibelstudium durchsetzen ${ }^{119}$. Ebenso fand Hessus, als er 1536 als Professor für Geschichte nach Marburg berufen wurde, wo auch sein Erfurter Freund Draconites seit zwei Jahren lehrte, eine Universität vor, an der die humanistischen Studien im Sinne Melanchthons gepflegt wurden ${ }^{120}$. Melanchthon hatte Hessus wiederum zu dieser Anstellung empfohlen. Hier lebte und lehrte er bis zu seinem Tod ${ }^{121}$.

Seine Freunde Johannes Draconites und Joachim Camerarius gaben nach seinem Tod Briefe von ihm in Sammlungen heraus ${ }^{122}$. Johannes Draconites veröffentlichte Hessus Briefe 1543 in Marburg. Camerarius verfasste 1533 zudem eine Biographie über seinen Freund Hessus. Diese widmete er Adam Krafft, mit dem er seit seinem

110 Huber-Rebenich/Lütkemeyer, Hessus (Anm. 45), S. 1072.

111 Ebd., S. 1089 f.

112 RAG, (Anm. 47), Helius Eoban Hessus - UniquID: ngIY4T779JQ5txeEcHhx7GuZ, 2.5.2018.

113 Rhein, Philipp Melanchthon und Eobanus Hessus (Anm. 40), S. 290 f.

114 Ebd., S. 294.

115 Ebd., S. 284.

116 Ludwig, Eobanus Hessus in Erfurt (Anm. 11), S. 169.

117 Rhein, Philipp Melanchthon und Eobanus Hessus (Anm. 40), S. 286.

118 RAG, (Anm. 47), Helius Eoban Hessus - UniquID: ngIY4T779JQ5txeEcHhx7GuZ, 2.5.2018; ebd., Joachim

Kammermeister Camerarius - UniquID: ngCS1B577Ca31ryUwCLr7AoP, 2.5.2018.

119 Rhein, Philipp Melanchthon und Eobanus Hessus (Anm. 40), S. 292.

120 Ludwig, Eobanus Hessus in Erfurt (Anm. 11), S. 169.

$121 R A G$, (Anm. 47), Helius Eoban Hessus - UniquID: ngIY4T779JQ5txeEcHhx7GuZ, 2.5.2018.

122 Huber-Rebenich/Lütkemeyer, Hessus (Anm. 45), S. 1110 f. 
Studienbeginn in Erfurt im Jahre 1518 befreundet war ${ }^{123}$. Krafft war es auch gewesen, der 1519 während der Leipziger Disputation die Freundschaft zwischen Camerarius und Melanchthon vermittelt hatte, die sich zu einer engen und lebenslangen Freundschaft festigte $^{124}$.

Auch Adam Krafft und Crotus Rubeanus kannten sich wahrscheinlich bereits vor ihrer gemeinsamen Erfurter Zeit. Crotus wurde im Winter 1510/11 Rektor der Fuldaer Klosterschule. Diese hatte im hessischen Raum grosses Ansehen. Sie stand in engem Verhältnis zur Erfurter Universität und dem dortigen Humanistenkreis ${ }^{125}$. Crotus äusserte während seiner Zeit als Leiter der Klosterschule gegenüber Mutian seinen Unmut über den eigenen Eintritt in den geistlichen Stand. In einem Brief von 1515 kritisierte er ebenso bissig wie Mutian die anderen Geistlichen, denen er Lasterhaftigkeit und mangelnde Bildung vorwarf:

Videtur mihi incivile inter sacrificulos idiotas et pene analphabetas vitam terere, quibuscum sotietas [!] nulla, nisi velis bibere, ludere, fenus et Venerem sequi. ${ }^{126}$

Krafft war vor seiner Immatrikulation in Erfurt im Jahre 1512 Schüler der Klosterschule, weshalb er dort vermutlich von Crotus unterrichtet wurde. Um Juli 1521 war er schliesslich selbst Rektor der Klosterschule ${ }^{127}$. Während seiner Zeit als evangelischer Prediger in Fulda stand Krafft offensichtlich in Kontakt mit den Wittenberger Reformatoren. Es ist etwa ein Brief Luthers an Krafft vom 28. Juli 1522 erhalten, in dem er zum Erhalt dieser Stelle gratuliert und Krafft zu beharrlicher Arbeit auffordert ${ }^{128}$. Der Chronist Apollo von Vilbel berichtet, dass Adam Krafft bei den Fuldaern grosses Ansehen geniesse. Auch sei er seinem Lehrer Martin Luther nicht unähnlich. So soll er etwa den Altardienst seiner Vikarie «vergessen» haben ${ }^{129}$. Während seiner Tätigkeit in Fulda erhielt er 1524 auch Besuch von Philipp Melanchthon ${ }^{130}$.

Als Erhard Schnepf 1534 Marburg verliess, um als Reformator nach Württemberg zu gehen, wurde Johannes Draconites als Theologieprofessor berufen. Draconites hatte scheinbar seit seiner Exkommunikation und Vertreibung aus Miltenberg keine feste Anstellung mehr erhalten, da er häufig seinen Aufenthaltsort wechselte. Schnepf und Draconites hatten sich zeitgleich an der Universität Erfurt immatrikuliert (1509) und wurden dort auch im selben Jahr (1511) zu artistischen Bakkalaren promoviert.

$123 R A G$, (Anm. 47), Johannes Drach Draconites - UniquID: ngND0I072Ml8ycjdhOGcwLzA, 2.5.2018; ebd., Joachim Kammermeister Camerarius - UniquID: ngCS1B577Ca31ryUwCLr7AoP, 2.5.2018; ebd., Adam Krafft Vegetius Crato UniquID: ngPF5e476PX2aeljjOYezNbW, 2.5.2018.

124 Breul-Kunkel, Fulda und Erfurt (Anm. 9), S. 114.

125 Breul-Kunkel, Herrschaftskrise und Reformation (Anm. 28), S. 209.

126 Breul-Kunkel, Fulda und Erfurt (Anm. 9), S. 83 f.

127 RAG, (Anm. 47), Adam Krafft Vegetius Crato - UniquID: ngPF5e476PX2aeljjOYezNbW, 2.5.2018.

128 Schilling, Adam Krafft, der erste hessische Landesbischof (Anm. 50), S. 92.

129 Breul-Kunkel, Herrschaftskrise und Reformation (Anm. 28), S. 224 f.

130 RAG, (Anm. 47), Adam Krafft Vegetius Crato - UniquID: ngPF5e476PX2aeljjOYezNbW, 2.5.2018. 
Es ist also wahrscheinlich, dass sie sich seit ihrer Studienzeit kannten ${ }^{131}$. Sicher ist, dass Schnepf Johannes Draconites als seinen Nachfolger vorschlug. Adam Krafft wiederum ging auf diesen Vorschlag ein und berief Draconites nach Marburg ${ }^{132}$.

Für die Personenverbindungen ist noch $\mathrm{zu}$ erwähnen, dass Justus Jonas und Johannes Draconites 1521 beide Kanoniker am St. Severin-Stift in Erfurt waren ${ }^{133}$. Die Studienzeiten von Feige und Krafft liegen zu weit auseinander, um auf eine Bekanntschaft vor ihrer Marburger Zeit schliessen zu können. Bekannt ist allerdings, dass sie in Marburg ein gutes Verhältnis zueinander hatten ${ }^{134}$.

\section{Schriftstellerische Tätigkeiten und Lutheranhängerschaft}

Einige Humanisten setzten ihre schriftstellerischen Fähigkeiten für die Verbreitung der reformatorischen Lehre ein. Eobanus Hessus war einer der bedeutendsten neulateinischen Dichter im deutschsprachigen Raum ${ }^{135}$. Melanchthon motivierte Hessus immer wieder zum Verfassen neuer Werke. Auf Melanchthons Veranlassung hin verfasste Hessus auch den 〈Ausruf gegen die Heuchelei der Mönchskutte〉 (1527) und die 〈Elegie von der Verleumdung〉 (1538). Melanchthon liess auch Gedichte von Hessus in seinen eigenen Werken abdrucken ${ }^{136}$. Die Psalterübertragung ist Hessus' meist geschätztes Werk ${ }^{137}$, zu der er wiederum von Melanchthon aufgefordert wurde ${ }^{138}$. Dabei handelt es sich nicht allein um eine Übersetzungsarbeit, sondern um eine kommentierende Übertragung ${ }^{139}$. So fügte er über den Text hinaus Erklärungen ein und legte den Text ganz nach der lutherischen Lehre aus ${ }^{140}$. Beispielsweise verwendete er in seiner Übersetzung Schlagworte der lutherischen Rechtfertigungslehre, wie etwa sola fides und sola gratia ${ }^{141}$. Die Psalmenübertragung widmete der gebürtige Hesse seinem Landgrafen ${ }^{142}$.

131 RAG, (Anm. 47), Erhard Schnepf - UniquID: ngZP9Q072YH8kovVtY2olX1K0Zi, 2.5.2018; ebd., Johannes Drach Draconites - UniquID: ngND0I072M18ycjdhOGcwLzA, 2.5.2018.

132 Gerhard Müller, Die Anfänge der Marburger Theologischen Fakultät, in: Hessisches Jahrbuch für Landesgeschichte 6 (1956), S. 164-181, hier: S. 177.

133 Stupperich, Reformatorenlexikon (Anm. 86), S. 69.

134 Schilling, Klöster und Mönche in der hessischen Reformation (Anm. 78), S. 175.

135 Bernstein, Mutianus Rufus und sein humanistischer Freundeskreis in Gotha (Anm. 8), S. 152.

136 Rhein, Philipp Melanchthon und Eobanus Hessus (Anm. 40), S. 286 f.

137 Ludwig, Eobanus Hessus in Erfurt (Anm. 11), S. 158.

138 Rhein, Philipp Melanchthon und Eobanus Hessus (Anm. 40), S. 285.

139 Anja Stewing, Die Psalterübertragung des Eobanus Hessus, in: Humanismus in Erfurt, hg. von Gerlinde Huber-Rebenich und Walther Ludwig (Acta Academiae Scientiarum 7, Humanismusstudien 1), Rudolstadt/Jena 2002, S. 195-211, hier: S. 198.

140 Ebd., S. 200.

141 Ebd., S. 206.

142 RAG, (Anm. 47), Helius Eoban Hessus - UniquID: ngIY4T779JQ5txeEcHhx7GuZ, 2.5.2018. 
Es fällt auf, dass diejenigen Personen aus dem Humanistenkreis, die sich Luther anschlossen, dies meist mit vollem Eifer taten und daher speziell die genuin lutherische Lehre auch gegenüber anderen evangelischen Lehrmeinungen verteidigten. In seinem 1525 erschienenen Werk 〈Antilutheromastix〉, zu dem Melanchthon das Vorwort schrieb, verteidigte Euricius Cordus die Lehre Luthers nicht nur gegenüber altgläubigen Gegnern des Reformators, sondern auch gegen Thomas Müntzer und Andreas Karlstadt ${ }^{143}$. In seiner Mahnschrift an Kaiser Karl V. aus demselben Jahr, zu der Melanchthon wiederum das Vorwort verfasste, appellierte Cordus an den Kaiser, die wahre Religion nun endlich anzuerkennen, warnte vor den trügerischen Machenschaften des Papstes und nahm Luther gegen den Vorwurf in Schutz, dass seine Lehre das Volk gegen die Obrigkeit aufrühre ${ }^{144}$. Cordus war am 25. Juli 1525 in Wittenberg, um diese beiden Werke in den Druck zu geben. Bei seinem Aufenthalt war er vermutlich zu Gast bei Melanchthon. Zumindest ist belegt, dass er bei diesem zusammen mit ihrem gemeinsamen Freund Georg Spalatin zum Essen eingeladen war ${ }^{145}$.

Auch Johannes Draconites war ein besonders eifriger Lutheranhänger. Er hielt 1546 an der Universität Marburg die Gedenkrede auf den Reformator ${ }^{146}$ und gehörte zu denjenigen Theologen, die 1537 die Schmalkaldischen Artikel unterzeichneten ${ }^{147}$. Hintergrund der Entstehung der Artikel war die Befürchtung des Kurfürsten Johann Friedrich von Sachsen, dass Luther aufgrund seines im Jahre 1536 äusserst kritischen Gesundheitszustandes bald sterben würde. Somit beauftragte er den Reformator, seine Lehre in einem Glaubensbekenntnis als eine Art theologischen Testaments zusammenzufassen, um eine Spaltung der evangelischen Seite nach dem Tode Luthers zu verhindern. Dazu sollten die Artikel von allen anderen Reformatoren als gültig unterschrieben werden. Dazu kam es allerdings nicht, denn auf dem Bundestag von Schmalkalden (1537) wurden die Artikel nicht weiter thematisiert, wie ursprünglich geplant, sondern die Unterzeichnung freigestellt. Im Grunde handelte es sich bei den Schmalkaldischen Artikeln also zunächst um eine Privatarbeit Luthers, nicht um eine offizielle Bekenntnisschrift. Mit der freiwilligen Unterschrift bekundeten die Unterzeichner demnach ihre feste Zustimmung zu Luthers Lehre ${ }^{148}$. Seine letzten Lebensjahre verbrachte Draconites in Wittenberg. Hier arbeitete er an der Herausgabe seines grossen Lebenswerkes, einer kommentierten Bibel in hebräischer, chaldäischer, griechischer, lateinischer und deutscher Sprache ${ }^{149}$.

143 Bernstein, Mutianus Rufus und sein humanistischer Freundeskreis in Gotha (Anm. 8), S. 220 f.

144 Dilg, Cordus (Anm. 102), S. $481 \mathrm{f}$.

145 Peter Dilg, Euricius Cordus und Philipp Melanchthon, in: Melanchthon und die Marburger Professoren (1527-1627),

Bd. 2, hg. von Barbara Bauer (Schriften der Universitätsbibliothek Marburg 89), Marburg 1999, S. 849-864, hier: S. 854.

146 Stupperich, Reformatorenlexikon (Anm. 86), S. 69.

147 Friedrich Wilhelm Bautz, DRACONITES (Drach), Johannes, in: Biographisch-Bibliographisches Kirchenlexikon 1 (1990), Sp. 1374-1376.

148 Klaus Breuer, Schmalkaldische Artikel, in: Theologische Realenzyklopädie 30 (1999), S. 214-221, hier: S. 214 ff.

149 Bautz, DRACONITES (Anm. 147), Sp. 1374-1376. 
Als Theologe blieb auch Krafft zeitlebens der lutherischen Lehre treu. Das bedeutet, dass er sich gegen einen Einfluss der Zürcher Reformation in Hessen einsetzte. Er unterzeichnete ebenfalls 1537 zusammen mit Johannes Draconites die Schmalkaldischen Artikel Luthers ${ }^{150}$.

Ganz hinter die Lehrmeinung Luthers stellte sich auch Erhard Schnepf. 1525 war er Mitverfasser des 〈Syngramma Suevicum〉 von Johannes Brenz ${ }^{151}$ gegen das symbolische Abendmahlsverständnis Johannes Oekolampads und sorgte dafür, dass das lutherische Abendmahlsverständnis in der Württemberger Kirchenordnung übernommen wurde ${ }^{152}$, die er selbst verfasste ${ }^{153}$. In Württemberg geriet er auch durch seine lutherische Position in Auseinandersetzungen mit seinem Mitreformator Ambrosius Blarer. Später in Jena wandte er sich gegen die Rechtfertigungs- und calvinistische Abendmahlslehre des Andreas Osiander ${ }^{154}$.

\section{Fazit}

Die Untersuchung hat gezeigt, dass die persönlichen Verbindungen zwischen den Mitgliedern des Humanistenkreises und zu den Reformatoren für die Ausbreitung der Reformation eine bedeutende Rolle gespielt haben. Zunächst einmal war es die im Humanistenkreis stark ausgeprägte Kritik an der zeitgenössischen Kirche, durch die viele Mitglieder leicht zur Begeisterung für die reformatorische Bewegung veranlasst wurden. Sie waren schon durch Erasmus und Mutian für die Missstände sensibilisiert, als Luther diese ebenfalls ansprach. Auch war es für die Erfurter Humanisten nicht neu, im Kollektiv offen und massiv Kritik an den kirchlichen Missständen zu äussern.

Auffällig ist, dass die in diesem Beitrag vorgestellten Mitglieder fest hinter der genuin lutherischen Lehre standen und diese auch gegen Widerstände verteidigten. Die Solidarität mit Luther und dessen Lehre kann dabei durchaus auch auf persönliche Bekanntschaften und Freundschaften zurückgeführt werden, die bereits vor der Reformation geschlossen worden waren. Die starke Verbundenheit innerhalb des Humanistenkreises wird zudem ausschlaggebend dafür gewesen sein, dass die Freunde Luthers auch wiederum andere Mitglieder für die reformatorische Bewegung gewinnen konnten.

Der ehemalige Zusammenhalt innerhalb des Humanistenkreises brach zwar durch die Reformation auseinander, jedoch blieben die engen Verbindungen zwischen den Befürwortern Luthers erhalten, was sich etwa an der gegenseitigen Hilfeleistung bei der Beschaffung von Arbeitsstellen oder der Zusammenarbeit an der Ausbreitung der Reformation äusserte. Alle genannten Personen gelangten im Dienst für die Reformation und die Landgrafschaft Hessen in hohe Positionen. Schnabel gehörte sogar zu den

150 Schilling, Adam Krafft, der erste hessische Landesbischof (Anm. 50), S. 95.

151 RAG, (Anm. 47), Erhard Schnepf - UniquID: ngZP9Q072YH8kovVtY2olX1K0Zi, 2.5.2018.

152 Leppin, Schnepf (Anm. 95), S. 233 ff.

153 RAG, (Anm. 47), Erhard Schnepf - UniquID: ngZP9Q072YH8kovVtY2olX1K0Zi, 2.5.2018.

154 Leppin, Schnepf (Anm. 95), S. 233 ff. 
wenigen namentlich greifbaren Predigern, die bereits vor der Konversion des Landgrafen in Hessen eigenmächtig für die Reformation eintraten und dabei viele Hessen für die reformatorische Lehre gewannen. Die Reformation Hessens ist also in ihrer Anfangsphase nicht allein auf die Initiative des Landgrafen zurückzuführen. Vielmehr konnte Philipp der Großmütige nach seiner Konversion auf Personal zurückgreifen, das bereits reformatorisch wirkte. So hatte sein Personal auch viel früher als er in engem Kontakt mit Luther gestanden und war bereits untereinander freundschaftlich verbunden. An der neu gegründeten Universität Marburg kamen schliesslich einige Erfurter Bekannte und Freunde wieder zusammen. 


\section{Die Professoren der Universität Marburg zwischen Universitäts- und Landesdienst (1527-1567)}

Im Jahr 1527 errichtete Landgraf Philipp der Großmütige die Universität in Marburg. Diese in Zeiten der Reformation gegründete Universität nimmt «von daher in der deut-

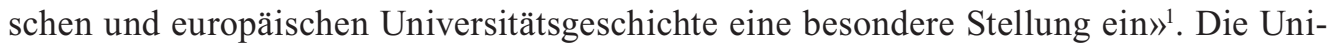
versität Marburg und die Universität Wittenberg «wirkten in hohem Masse als Triebkräfte des Umbruchs $\rangle^{2}$. Schon allein die Loslösung der Universität von Papst und katholischer Kirche fundierte die Marburger Universität auf eine ganz andere Weise, als es bisher üblich war ${ }^{3}$. Ernst Winterhager nennt die Marburger Konzeption ohne die Bindung an die katholische Kirche sogar einen «revolutionären Akt» ${ }^{4}$.

Die Gründung einer Universität war stets ein heikles Unterfangen und in diesem Fall umso mehr, da sich Philipp der Großmütige mit Annahme der lutherischen Lehre nicht nur selbst in eine unsichere Position begab, sondern sich auch seine Universität mit protestantischen Lehrinhalten der Anerkennung nicht sicher sein konnte. Neben Sicherstellung der finanziellen Grundlage war daher die Auswahl der die Universität repräsentierenden Professoren von enormer Bedeutung. Damals wie heute sollten sie helfen, «Universitäten möglichst exzellent zu positionieren, ihre Profile zu schärfen und existentiell zu sichern» ${ }^{5}$.

Es waren vor allem die Professoren der drei höheren Fakultäten, die ausschlaggebend für die Qualität der Ausbildung der zukünftigen landgräflichen Dienerschaft waren: Im theologischen Bereich waren es die Pfarrer, die den neuen Glauben predigen sollten. Die medizinische Fakultät bildete die benötigten Ärzte aus und von der juristischen Fakultät kam der Nachwuchs für die landgräfliche Beamtenschaft und das Hofgericht. Philipp nahm seine «spätmittelalterliche Fürsorgepflicht» wahr, die ihn als Landesherrn für die Religion, Bildung und Wohlfahrt seiner Untertanen in Verantwortung zog ${ }^{6}$. Durch die evangelisch geprägte Lehre an seiner Universität war es Philipp möglich, die Bildung in

1 Wilhelm Ernst Winterhager, Wittenberg und Marburg als Universitäten der Reformation, in: Sachsen und Anhalt Jahrbuch der Historischen Kommission für Sachsen-Anhalt 22 (1999/2000), S. 189-238, hier: S. 189.

2 Ebd.

3 Ebd.

4 Ders., Marburg 1527 - ein neues Universitätsmodell?, in: Neue Modelle im Alten Europa, hg. von. Christoph Kampmann, Köln/Böhlau 2012, S. 49-66, hier: S. 61.

5 Rainer Christoph Schwinges, Berufungswesen - eine Einführung, in: Professorinnen und Professoren gewinnen. Zur Geschichte des Berufungswesens an den Universitäten Mitteleuropas, hg. von dems. und Christian Hesse (Veröffentlichungen der Gesellschaft für Universitäts- und Wissensgeschichte 12), Basel 2012, S. 1-8, hier: S. 1.

6 Gury Schneider-Ludorff, Der fürstliche Reformator. Theologische Aspekte im Wirken Philipps von Hessen von der Homberger Synode bis zum Interim (Arbeiten zur Kirchen- und Theologiegeschichte 20), Leipzig 2006, hier: S. 64. 
theologischer Hinsicht zu lenken und die in diesem Sinne ausgebildeten Theologen und Juristen personell an das Territorium zu binden?

Deshalb soll im Anschluss an die wichtigsten Eckpunkte der Universitätsgeschichte in ihren ersten 40 Jahren eine Untersuchung der zu Lebzeiten Philipps des Großmütigen an die Universität berufenen Professoren der höheren Fakultäten, der Theologie, Jurisprudenz und der Medizin folgen. Hierbei sollen mithilfe der Datenbank ${ }^{8}$ des Repertorium Academicum Germanicum (kurz: RAG) zunächst die Auswahlkriterien zur Besetzung der Professuren ermittelt werden und anschliessend soll das Ineinandergreifen von Universitäts- und Landesdienst analysiert werden. Die quantitative Auswertung basiert auf Zahlen aus der RAG-Datenbank und auch die biografischen Daten einzelner Personen sind hieraus entnommen.

\section{Die Universität Marburg von ihren Anfängen bis zum Tod ihres Gründers}

Am 30. Mai 1527 wurde die neue Universität in Marburg von ihrem ersten Rektor, Johannes Eisermann, eröffnet und am ersten Juli desselben Jahres vom Kanzler Johann Feige feierlich eingeweiht. Im ersten Jahr wurden 105 Personen an der neuen Universität immatrikuliert ${ }^{9}$. Gerade einmal ein Jahr zuvor hatte der noch junge Landgraf Philipp seinen Plan, eine Universität gründen zu wollen, gefasst. Damit knüpfte Philipp wohl an die Pläne seines früh verstorbenen Vaters Wilhelm II. von Hessen an, denn es ist überliefert, dass schon dieser mit dem Gedanken an eine Universitätsgründung im eigenen Territorium gespielt hatte ${ }^{10}$. Letztlich war es dann sein Sohn Philipp, der, von Humanismus und Reformation beeinflusst, diese Überlegung umsetzte und seiner Dynastie zum «Prestigeobjekt» ${ }^{11}$ Universität verhalf.

Die neue Konfession des Landesherrn spielte bei der Gründung der Marburger Universität eine besonders wichtige Rolle, denn Landgraf Philipp der Großmütige hatte sich

7 Peter Baumgart, Universitäten im konfessionellen Zeitalter, Gesammelte Beiträge (Reformationsgeschichtliche Studien und Texte 149), Münster 2006, hier: S. 411; Winterhager, Wittenberg und Marburg (Anm. 1), S. 218; Gerhard Müller, Die Anfänge der Marburger Theologischen Fakultät, in: Hessisches Jahrbuch für Landesgeschichte 6 (1956), S. 164-181, hier: S. 166; Winterhager, Marburg 1527 (Anm. 4), S. 63.

8 An dieser Stelle sei auf den Marburger Professorenkatalog online verwiesen, mit dessen Hilfe die Professorenbiografien der RAG-Datenbank bereits ergänzt wurden, sodass er im Folgenden nicht mehr extra aufgeführt wird.

9 Walter Heinemeyer, Zur Gründung des «universale Studium Marpurgense», in: Academia Marpurgensis. Beiträge zur Geschichte der Philipps-Universität Marburg, hg. von Walter Heinemeyer, Thomas Klein und Hellmut Seier, Marburg 1977, S. 49-92, hier: S. 49.

10 Ebd., S. 53 f.

11 Peter Moraw, Die Universitäten in Europa und in Deutschland. Anfänge und erste Schritte auf einem langen Weg (12.-16. Jahrhundert), in: Gesammelte Beiträge zur deutschen und Europäischen Universitätsgeschichte. Strukturen - Personen - Entwicklungen, hg. von dems. (Education and Society in the Middle Ages and Renaissance 31), Leiden/Boston 2008, S. 229-250, hier: S. 242; Baumgart, Universitäten im konfessionellen Zeitalter (Anm. 7), S. 411; Schneider-Ludorff, Der fürstliche Reformator (Anm. 6), S. 63. 
im Sommer $1524 \mathrm{zu}$ der Lehre Martin Luthers bekannt ${ }^{12}$. Erstmals ${ }^{13}$ wurde im Reich erfolgreich eine Universität durch einen Landesherrn gegründet, der das protestantische Bekenntnis angenommen hatte. Die Universität war daher völlig von der Bindung an die katholische Kirche gelöst. Der Landesherr selbst ersetzte hier die kirchliche Autorität und setzte sich somit an die Spitze der universitären Hierarchie ${ }^{14}$. Eine solche Einrichtung musste gut geplant werden, scheiterten doch so viele neugegründete Universitäten am Fehlen der kaiserlichen Bestätigung oder aus finanziellen Gründen nach nur wenigen Jahren ihres Bestehens ${ }^{15}$. Die finanzielle Grundlage der Universität setzte sich ab 1540 aus säkularisiertem Klostergut zusammen. Die bei der Reformation des Landes aufgelösten Klöster boten eine Vielfalt an Gütern und Vermögen, die der Landesherr nun zur Finanzierung der Universität heranzog ${ }^{16}$. Vorher unterhielt Philipp die Universität vorwiegend aus den landgräflichen Kammereinkünften ${ }^{17}$.

Die Finanzierung war also gesichert, sodass die Marburger Universität zumindest nicht aus diesem Grund scheitern konnte. Allerdings brachte die Gründung durch einen protestantischen Landesherrn ein Problem ganz anderer Art mit sich: Die Bestätigung durch Kaiser und Papst fehlte. Die Bestätigung durch den Papst war für den lutherischen Landesherrn hinfällig geworden. Doch damit die in Marburg durchgeführten Promotionen auch ausserhalb von Philipps Landeshoheit Gültigkeit besassen, musste zumindest die kaiserliche Privilegierung eingeholt werden. Philipp erbat die kaiserliche Bestätigung im Jahr 1531, als Karl V. sich in den Niederlanden aufhielt. Allerdings verweigerte der Kaiser das Privileg für die Marburger Universität ${ }^{18}$. Vier Jahre später versuchte es Philipp erneut, diesmal bei König Ferdinand, der die Geschäfte des abwesenden Kaisers in Vertretung übernommen hatte. Wieder scheiterte Philipps Gesuch, denn

12 Karl Demandt, Geschichte des Landes Hessen, Kassel/Basel 1959, S. 176.

13 Genau genommen ist Marburg die zweite Universität im Reich, die durch einen evangelischen Landesherren in Folge der Reformation gegründet wurde. Die Universität Liegnitz wurde knapp ein halbes Jahr vor der Marburger Universität gegründet. Auch Friedrich II., Herzog von Liegnitz und Brieg, setzte seiner Universität die Ausbildung von protestantischen Theologen und Juristen zum Ziel und verfolgte somit ähnliche Ziele wie Landgraf Philipp in Marburg. Das Bestehen dieser Universität scheiterte an finanziellen Mitteln und auch der Ausbruch der Pest 1527 hat die Universität Liegnitz an ihrem Fortbestehen gehindert. Da auch eine kaiserliche Bestätigung für Liegnitz nicht eindeutig nachweisbar ist, kann Marburg als erste Universität in evangelischer Tradition bezeichnet werden. Hier erfolgte die kaiserliche Bestätigung im Jahr 1541. Vgl. Schneider-Ludorff, Der fürstliche Reformator (Anm. 6), S. 65 f.

14 Ebd, S. 63.

15 Schneider-Ludorff, Der fürstliche Reformator (Anm. 6), S. 64.

16 Demandt, Geschichte des Landes Hessen (Anm. 12), S. 177; Baumgart, Universitäten im konfessionellen Zeitalter (Anm. 7), S. 405.

17 Baumgart, Universitäten im konfessionellen Zeitalter (Anm. 7), S. 405. Bereits im Gründungsjahr der Universität beschloss Philipp, die Universität aus dem Vermögen der aufgelösten Klöster zu finanzieren. Die Dauer der Säkularisation der letzten Klöster, bei denen der Landesherr z.T. noch auf Widerstand stiess, verzögerte die Finanzierung der Universität. Diese wurde deshalb vom Hof direkt finanziert, bis die klösterlichen Mittel für die Universität zur Verfügung standen. Vgl. Peter Unglaube, Landgraf Philipp und die Stadt. Marburgs Umbildung in der Reformationszeit, in: Marburg-Bilder. Eine Ansichtssache. Zeugnisse aus fünf Jahrhunderten, hg. von Jörg Jochen Berns (Marburger Stadtschriften zur Geschichte und Kultur 52), Marburg 1995, S.49-68, hier: S. 60 f.

18 Baumgart, Universitäten im konfessionellen Zeitalter (Anm. 7), S. 398. 
gerade die protestantische Ausrichtung der theologischen Fakultät widerstrebte Ferdinand und seinen Beratern, sodass das erstellte Gutachten die Anforderungen für eine kaiserliche Bestätigung nicht als erfüllt ansah ${ }^{19}$. Erst 1541, also zehn Jahre nach Philipps erstem Gesuch, bestätigte Kaiser Karl V. durch politische Umstände motiviert die Marburger Universität ${ }^{20}$. Mit der Anerkennung durch den Kaiser wurde aus dem hessischen Partikularstudium ein Generalstudium, das nun den älteren Universitäten gleichgestellt war $^{21}$.

Obwohl der Landesherr Anhänger des protestantischen Glaubens war, liess die Universität eine breite Vielfalt an Glaubensrichtungen für Studenten wie auch eingeschränkter für Professoren zu. Es gab anfangs keine offizielle Festlegung, welchen Glauben die Universitätsangehörigen haben durften oder nicht ${ }^{22}$. Erst ab den 1560erJahren änderte sich diese Offenheit gegenüber verschiedenen Glaubensrichtungen. Wenige Jahre vor dem Tod Philipps hatte sein Sohn, Wilhelm IV. von Hessen, neue Statuten für die Universität entworfen, die die ursprüngliche Universitätsordnung von 1529 ersetzen sollten. Dieser Entwurf wurde zur Grundlage für die Universitätsreform im Jahre 1564. Die neue Ordnung sah vor, dass Professoren beim Ablegen ihres Eides ihre Glaubensrichtung näher definierten, was einer Kontrolle der konfessionellen Ausrichtung des Universitätspersonals gleichkam ${ }^{23}$.

\section{Überlegungen zu den Berufungskriterien}

Insgesamt war die Besetzung der Lehrstühle mit guten Professoren ausschlaggebend für den Erfolg einer Universitä $t^{24}$. Bei der Gründung hatte Landgraf Philipp die Professoren für die neue Universität ausgewählt: Er hatte zu Beginn des Jahres eine Kommission einberufen, bei der seine Räte Vorschläge zur Universitätsordnung und zur Lehrstuhlbesetzung beitragen sollten ${ }^{25}$. Qualifiziertes Lehrpersonal war schliesslich für die Ausbildung der zukünftig in der Landgrafschaft Hessen wirkenden Beamten, Theologen und Ärzte massgeblich.

19 Ebd., S. 399 f.

20 Philipp ging im Regensburger Vertrag (13. Juni 1541) auf die politische Linie des Kaisers zu und schwächte somit den Schmalkaldischen Bund. Gewissermassen als Gegenleistung erhielt Philipp nur wenige Wochen später die kaiserliche Bestätigung (16. Juli 1541) für seine Universität. Vgl. Baumgart, Universität im konfessionellen Zeitalter (Anm. 7), S. 402 .

21 Ebd.

22 Ebd., S. 415.

23 Ebd., S. 415 f. Eine genauere Ausführung zur Universitätsordnung und ihrer Reform 1560 liegt von Hans Georg Gundel vor: Hans Georg Gundel, Die Statuten der Universität Marburg von 1560, in: Academia Marpurgensis. Beiträge zur Geschichte der Philipps-Universität Marburg, hg. von Walter Heinemeyer, Thomas Klein und Hellmut Seier, Marburg 1977, S. 111-179.

24 Schwinges, Berufungswesen (Anm. 5), S. 1.

25 Schneider-Ludorff, Der fürstliche Reformator (Anm. 6), S. 67. 
Die Personen, die sich im näheren Umfeld des Landesherrn aufhielten und ihm beratend zur Seite standen, hatten sicherlich Einfluss auf seine Entscheidungen. So wissen wir von Philipps Hofprediger Adam Krafft, der bei der Universitätsgründung zum Theologieprofessor berufen wurde, dass er in Erfurt studiert hatte und dort, wie auch Euricius Cordus, dem Humanistenkreis angehörte ${ }^{26}$. Cordus wiederum wurde erster Medizinprofessor der Marburger Universität, was die Überlegung zulässt, dass diese persönliche Beziehung bei der Professurvergabe eine Rolle gespielt hat. Denn auch wenn letztlich die Entscheidung des Landgrafen massgeblich für die Vergabe der Professur war, sollte die Rolle der persönlichen Beziehungen seiner Diener und Räte nicht unterschätzt werden $^{27}$. Solche Beziehungen scheinen nicht nur in Marburg die Vergabe von Lehrstühlen beeinflusst zu haben. Rainer Christoph Schwinges bezieht sich auf Professoren ganz im Allgemeinen, wenn er feststellt: «Zugehörigkeit war hier das entscheidende Berufungskriterium, der Standard sozialer Nähe, der wissenschaftliche Leistung jedoch nicht ausgeschlossen hat. $\rangle^{28}$

Soziale Nähe beschreibt selbstverständlich nicht nur freundschaftliche Beziehungen, auch familiäre Strukturen gehören dazu. Vor allem lokale Beamten- oder Pfarrfamilien bildeten die Grundlagen für die klassischen «Universitätsfamilien〉, die grosse Teile der Universitätsstellen besetzten und die Ämter untereinander vererben konnten ${ }^{29}$. An der neu gegründeten Universität in Marburg waren solche anfänglich natürlich noch nicht vorhanden. Wirft man allerdings einen Blick auf einen etwas späteren Zeitraum, zeigt sich, dass auch an der Marburger Universität familiäre Strukturen eine Rolle spielten. Als Beispiel kann hier die Beamtenfamilie Lersner vorgestellt werden ${ }^{30}$ : Ludwig Lersner, der aus Marburg stammte, studierte in Leipzig, bevor er in die Dienste des Landgrafen trat und Prokurator am Hofgericht wurde ${ }^{31}$. Zwei seiner vier Söhne, Christoph $^{32}$ und Jakob ${ }^{33}$, wurden Professoren der juristischen Fakultät in Marburg. Jakob übte zeitgleich noch weitere Ämter im Landesdienst aus und war, genau wie sein Vater, am Hofgericht tätig. Jakob war von 1558 bis zu seinem Tod 1579 Vizekanzler der Universität. Sein Neffe Hermann ${ }^{34}$ übernahm nach dem Tod des Onkels dieses Amt.

26 Vgl. zu den Mitgliedern des Erfurter Humanistenkreises den Aufsatz von Anna-Lena Wendel in diesem Band.

27 Wolfgang Eric Wagner, Wer hat im Mittelalter «gerufen»? Fürsten, Städte, Universitäten und ihre Interessen an gelehrten Personen, in: Professorinnen und Professoren gewinnen. Zur Geschichte des Berufungswesens an den Universitäten Mitteleuropas, hg. von Christian Hesse und Rainer Christoph Schwinges (Veröffentlichungen der Gesellschaft für Universitäts- und Wissensgeschichte 12), Basel 2012, S. 11-30, hier: S. 14

28 Schwinges, Berufungswesen (Anm. 5), S. 5 f.

29 Schwinges, Berufungswesen (Anm. 5), S. 5.

$30 \mathrm{Zu}$ den familiären Verknüpfungen der Marburger Beamtenschaft untereinander vgl. Demandt, Geschichte des Landes Hessen (Anm. 12), S. 179.

31 Repertorium Academicum Germanicum (RAG), [www.rag-online.org], Ludwig Lersner - UniquID: ngRH3I072QJ8cgnD1SKg2Pdo, 25.8.2017.

$32 R A G$ (Anm. 31), Christoph Lersner - UniquID: ngEU4P375EM13taWyENtnCqV, 25.8.2017.

$33 R A G$ (Anm. 31), Jakob Lersner - UniquID: ngND7U870OF62cjdhNmc1Lzc, 25.8.2017.

$34 R A G$ (Anm. 31), Hermann Lersner - UniquID: ngJZ4U870KB68yfJdJ0yvHvU, 25.8.2017. 
Anhand dieser Familie wird deutlich, dass hohe Beamtenfamilien begannen, ihren Einflussbereich auf die Universität auszuweiten, indem sie die neugeschaffenen Stellen selbst besetzten und sie dann wiederum innerhalb der Familie weitergaben. Ausserdem kann anhand der Lersners gezeigt werden, wie landgräfliche Beamtenschaft und Universitätspersonal miteinander verknüpft waren. Dazu folgt an späterer Stelle eine genauere Analyse.

Zunächst soll aber erst die Frage gestellt werden, inwiefern geografische Herkunft und vorherige Ausbildung bei der Besetzung der Professuren eine Rolle gespielt haben. Um mögliche Entwicklungen beschreiben zu können, wird der Zeitraum von der Universitätsgründung 1527 bis zum Tod ihres Gründers 1567 in drei Zeitintervalle unterteilt. Diese Intervalle orientieren sich nicht an etwaigen (Professorengenerationen), sondern sind allein der besseren Darstellung geschuldet. Das erste Zeitintervall umfasst die Jahre von 1527 bis 1540, das zweite die Jahre von 1541 bis 1553 und das letzte jene von 1554 bis 1567 .

Schneider-Ludorff nennt als einen zentralen Faktor für die Besetzung die geografische Herkunft der Professoren aus der Landgrafschaft Hessen ${ }^{35}$. Die Auswertung der RAG-Datenbank zeigt, dass für den ersten betrachteten Zeitraum keine grosse Mehrheit der Universitätsprofessoren ausschliesslich aus dem hessischen Gebiet stammte. Von insgesamt 14 Professoren ${ }^{36}$, die von 1527 bis 1540 an den höheren Fakultäten nachgewiesen sind, kamen sechs aus Hessen. Bei den übrigen acht kann mithilfe der Datenbank noch detaillierter festgestellt werden, dass fünf aus dem Alten Reich stammten, während drei Professoren von ausserhalb des Alten Reichs, unter anderem aus Frankreich, zu verorten sind. Die geografische Herkunft ist mit sechs (aus Hessen) zu acht (nicht aus Hessen) also recht ausgewogen.

Bei der zweiten Zeitspanne, die die Jahre von 1541 bis 1553 umfasst, kommen nur drei der insgesamt zehn ${ }^{37}$ in diesem Zeitraum belegten Professoren aus dem hessischen Territorium. Für fünf Professoren ist die geografische Herkunft aus Orten innerhalb des Alten Reiches nachgewiesen, zwei Theologen kommen aus Städten, die ausserhalb des Alten Reiches liegen. So liegt das Verhältnis von Professoren hessischer Herkunft zu Professoren von ausserhalb bei drei zu sieben.

Für die dritte Zeitspanne von 1554 bis 1567 sind ebenfalls zehn ${ }^{38}$ Professoren der höheren Fakultäten belegt. Hier ist festzustellen, dass tatsächlich die aus Hessen stammenden Professoren dominieren. Sechs an der Zahl bilden sie gegenüber nur vier Professoren, die nicht aus Hessen kommen, eine Mehrheit.

35 Schneider-Ludorff, Der fürstliche Reformator (Anm. 6), S. 71.

36 Von den 14 Professoren lehrten sechs an der juristischen Fakultät, drei an der medizinischen Fakultät und fünf an der theologischen.

37 Hier setzt sich die Anzahl der Professoren wie folgt zusammen: sechs Juristen, zwei Theologen und zwei Mediziner.

38 Zwei Professoren der juristischen Fakultät, fünf der theologischen Fakultät und drei Professoren der Medizin bilden die Gruppe von zehn Personen, die in der letzten Zeitspanne als Professoren der höheren Fakultät belegt sind. 


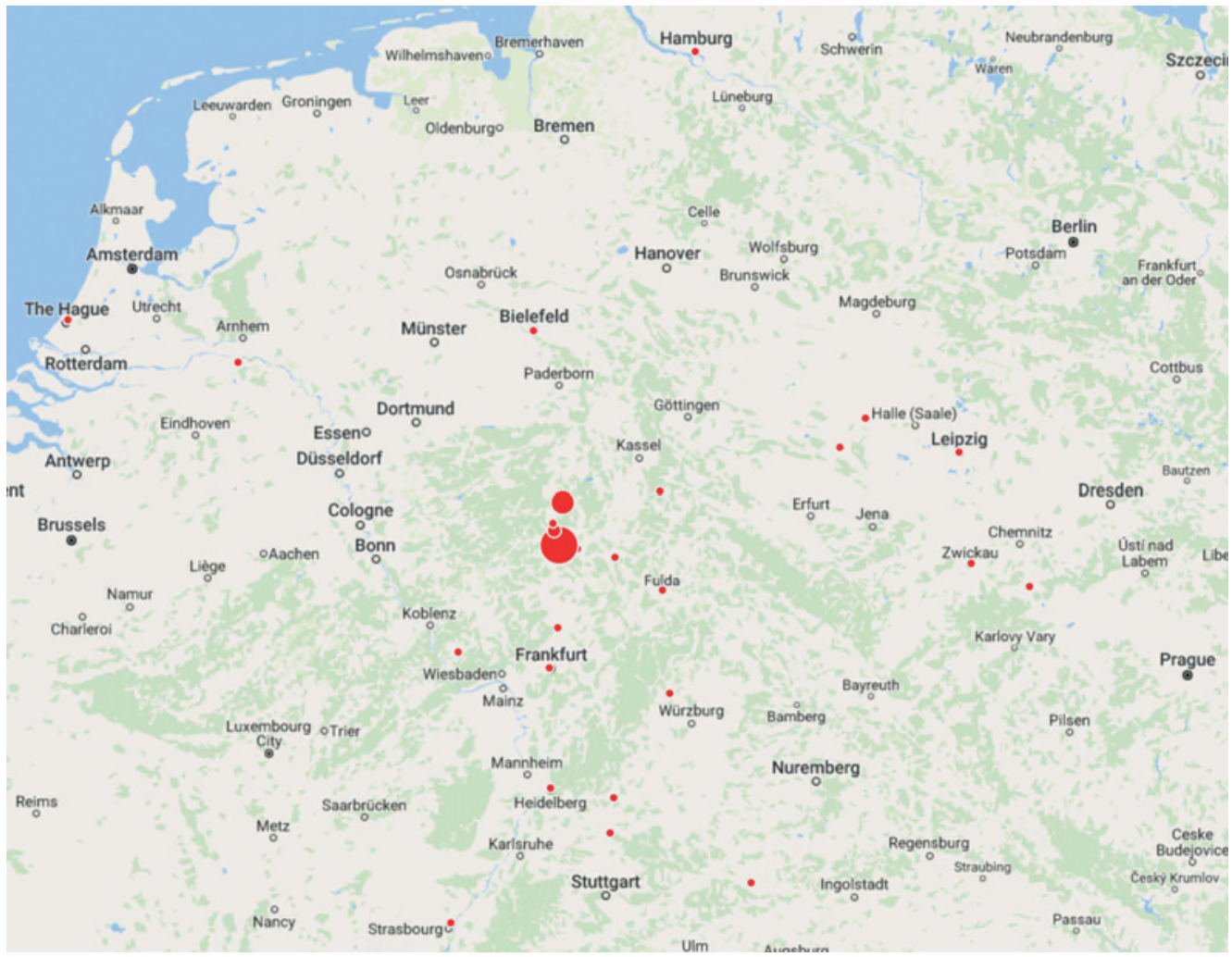

Abb. 1 Herkunftsorte der Marburger Professoren

Ob die geografische Herkunft der Professoren kein ausschlaggebendes Gewicht hatte oder ob es zu wenige qualifizierte hessische Gelehrte gab, die bereit waren, in die Heimat zurückzukehren, kann an dieser Stelle nicht entschieden werden. Die nur wenigen signifikanten Abweichungen der Zahlen zeigen aber, dass stattdessen andere Auswahlkriterien in den Fokus rückten.

Im Gesamten betrachtet, bezog die Universität 15 ihrer Professoren an den höheren Fakultäten aus Hessen, 19 von ausserhalb. Der Trend zur 〈Familienuniversität〉 wird hier vermutlich auch dazu geführt haben, dass sich im Anschluss des betrachteten Zeitraums die Herkunft aus Marburg und anderen hessischen Orten vermehrte, wie das Beispiel der Familie Lersner nahelegt und worauf die Entwicklung der Theologieprofessoren bereits verweist: Betrachtet man diese gesondert, fällt auf, dass während der Gründungsphase - abgesehen von Adam Krafft - nahezu keine Theologen aus Hessen kamen, sondern vorwiegend sogar aus Gebieten ausserhalb des Alten Reiches. Im zweiten Zeitraum stammten sogar beide nachgewiesenen Theologen nicht aus dem Alten Reich. Im letzten Zeitraum vor Philipps Tod zeichnet sich aber ein völlig anderes Bild: Für diese Zeitspanne sind fünf Professoren an der theologischen Fakultät verzeichnet, davon entstammten vier direkt den hessischen Territorien und nur ein einziger einer anderen Region des 
Alten Reichs. Es stellt sich unweigerlich die Frage, wieso sich die geografische Herkunft der Theologen von hauptsächlich ausländischen Territorien hin zu heimischen verschob. Eine Erklärung mag darin zu finden sein, dass der Landgraf und seine Räte in der Qualifikation ein wichtigeres Kriterium bei der Stellenbesetzung sahen als in der geografischen Herkunft. Die beobachtete Veränderung in der theologischen Fakultät im letzten Zeitraum ist darauf zurückzuführen, dass nun schon eine neue Professorengeneration an der eigenen Universität von den vorher als gut befundenen Professoren ausgebildet worden waren. Nun war es nicht mehr nötig, nach qualifizierten Theologen in der Ferne zu suchen, wenn sie schon an der eigenen Universität vorhanden waren. Schaut man sich die Professoren des letzten Zeitraums genauer an, kann diese Vermutung durch die RAGDatenbank gestützt werden: Von den fünf belegten Theologieprofessoren waren alle in Marburg immatrikuliert, drei von ihnen haben ausschliesslich in Marburg studiert, die anderen beiden waren neben je einer anderen Universität noch zusätzlich in Wittenberg.

Wenn die Qualifikation als ein äusserst relevantes Kriterium bei der Auswahl der Professoren angenommen wird, ist es naheliegend, dass die akademische Herkunft wichtiger war als die geografische. Bisher wurde vorwiegend die Meinung vertreten, dass die Professoren der Gründungszeit zum grössten Teil an der Wittenberger Universität gewesen seien ${ }^{39}$, was sich anhand der RAG-Datenbank leicht überprüfen lässt. Zunächst kann festgestellt werden, dass der Grossteil der betrachteten Professorengruppe nicht in Wittenberg war. Von den Professoren der höheren Fakultäten, die mit der Universitätsgründung in Marburg ihre Professur antraten, war lediglich Franz Lambert in Wittenberg, allerdings nicht zum Studium, sondern zum Lehren. Abgesehen von ihm haben in dem ersten Zeitraum nur drei Professoren der höheren Fakultäten in Wittenberg studiert, zwei Theologen und ein Jurist. Für den gesamten ersten Zeitraum bis 1540 ist die Anzahl der Professoren, die in Wittenberg studierten, also überraschend gering. Stattdessen wurden von den zukünftigen Marburger Professoren andere Universitäten im Alten Reich bevorzugt. Dabei gibt es allerdings keine eindeutige Tendenz. Die Studienorte der Professoren von 1527 bis 1540 an den höheren Fakultäten variieren stark ${ }^{40}$. Von den elf Professoren, die nach Ausschluss der in Wittenberg promovierten noch übrig bleiben, haben alle eine Universität im Alten Reich besucht; sechs von ihnen sind zusätzlich noch an Universitäten im Ausland nachgewiesen. Ausserdem zeichnet sich eine weitere interessante Beobachtung ab: Zehn von insgesamt 14 Professoren der höheren Fakultäten bis zum Jahr 1540 waren an mehreren Universitäten immatrikuliert, zehn zuletzt auch in Marburg. Häufig haben sie noch während ihrer Tätigkeit als Professor einen Grad an ihrer Fakultät erworben ${ }^{41}$. Für diese Untersuchung ist es nun aufschlussreich,

39 Vgl. Winterhager, Wittenberg und Marburg (Anm. 1), S. 215; Heinrich Hermelink und Siegried August Kaehler, Die Philipps-Universität zu Marburg 1527-1927. Fünf Kapitel aus ihrer Geschichte (1527-1866). Die Universität Marburg seit 1866 in Einzeldarstellungen. Erster Teil, Marburg 1927, S. 9.

40 Eindeutig bevorzugte Universitäten sind nicht festzustellen. Von Leipzig über Erfurt bis hin zu Köln sind diverse Universitäten des Alten Reiches in den Lebensläufen der ausgewerteten Professoren vertreten.

41 Für einen Professor fehlen jegliche biografische Angaben. Über ihn wissen wir nur, dass er in Marburg Professor an der theologischen Fakultät war. Er kann in die Beobachtungen also nicht mit einbezogen werden: Georg Bilfeldianus. Vgl. RAG (Anm. 31), Georg Bilfeldianus - UniqID: ngQG8B173PY9afmUkQZf4OcH, 25.8.2017. 
die Frage nach dem akademischen Hintergrund und vor allem, wie stark Wittenberger Gelehrte in Marburg vertreten waren, auch auf die späteren Zeiträume auszuweiten.

Im zweiten Zeitraum, also zwischen 1541 und 1553, waren es ebenfalls nur drei von zehn Professoren, die zuvor in Wittenberg studiert und Grade erworben hatten. Insgesamt zeichnet sich im zweiten untersuchten Zeitraum ein sehr ähnliches Bild wie im ersten bereits analysierten Zeitraum ab. Auch in diesem werden Universitäten des Alten Reichs bevorzugt, was wahrscheinlich auch der räumlichen Erreichbarkeit und der Studienfinanzierung geschuldet ist. Sieben von den insgesamt zehn für diesen Zeitraum nachgewiesenen Professoren waren an Universitäten des Alten Reiches immatrikuliert, fünf von ihnen im ausländischen Raum, wobei insgesamt sieben von ihnen an mehreren Universitäten belegt sind.

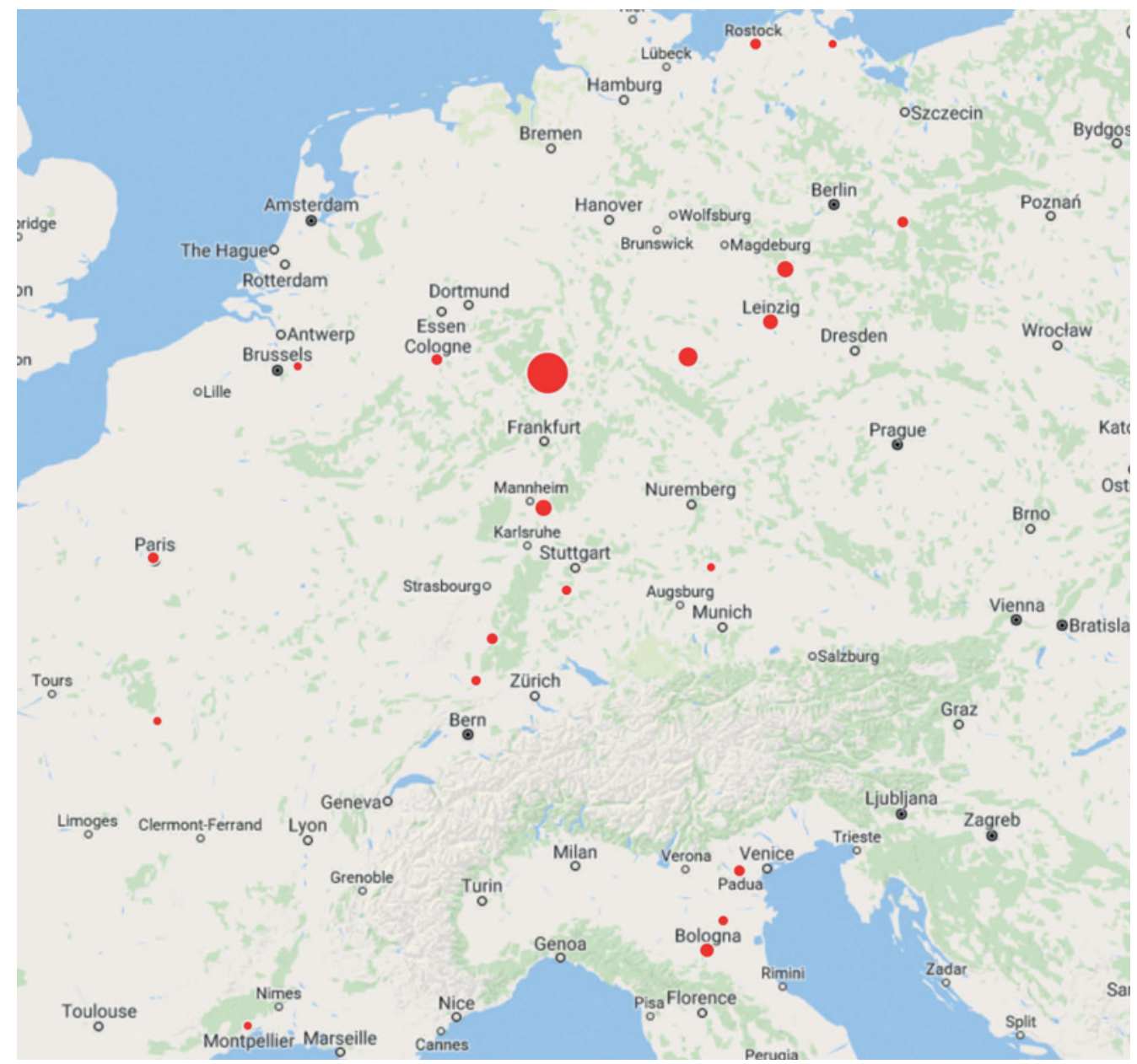

Abb. 2 Studienorte der Marburger Professoren 
Auch im dritten Zeitraum von 1554 bis 1567 sind für die höheren Fakultäten zehn Professoren belegt, davon nur zwei Juristen, fünf Theologen und drei Mediziner. Und genau wie in den beiden vorher betrachteten Zeiträumen haben von ihnen nur drei in Wittenberg studiert ${ }^{42}$. Alle zehn Professoren können an Universitäten im Alten Reich und in Marburg verortet werden, von sechs Professoren sind mehrfache Immatrikulationen zu verzeichnen. Drei Mediziner und ein Theologe sind an Universitäten ausserhalb des Reichs belegt.

Betrachtet man den gesamten Zeitraum, kann festgestellt werden, dass deutlich weniger Professoren der Marburger höheren Fakultäten in Wittenberg studiert haben, als aufgrund der Forschungslage vermutbar gewesen wäre. Ergänzt man die Untersuchungsgruppe jedoch um die Artisten, ergibt die Auswertung der RAG-Datenbank, dass in den ersten sechs Jahren seit Universitätsgründung (bis 1533) sieben von acht der Artistenprofessoren in Wittenberg studiert haben. Dieses Ergebnis unterscheidet sich signifikant von der Untersuchung der höheren Fakultäten. Allerdings verändert sich dies ab dem Jahr 1534 schlagartig, denn ab diesem Zeitpunkt ist unter den Professoren der Artistenfakultät kein Studium in Wittenberg mehr verzeichnet. Diese Entwicklung ist wahrscheinlich der Tatsache geschuldet, dass nun viele der in Marburg immatrikulierten Studenten bereits das Artes-Studium abgeschlossen haben und nun selbst an der Artistenfakultät lehren konnten. Der enge Zusammenhang von Universitätsgründung und Reformation in Hessen legt die Verbindung zu Wittenberg natürlich nahe, zumal Landgraf Philipp in der Tat gehofft hatte, bereits etablierte Wittenberger Theologen für seine Universität $\mathrm{zu}$ gewinnen. Letztendlich spielte Wittenberg aber bei den höheren Fakultäten eine geringe Rolle, obwohl man gerade an der theologischen Fakultät eine deutliche Mehrheit der Professoren mit wittenbergischen akademischen Wurzeln vermutet hätte. Je Zeitraum sind nur drei zukünftige Marburger Professoren in Wittenberg immatrikuliert gewesen, insgesamt waren es somit nur neun von den uns 34 (35) bekannten Professoren der höheren Fakultäten in Marburg innerhalb des untersuchten Zeitraums von 1527 bis $1567^{43}$.

\section{Personelle Verschränkung von Universität und Landesherrschaft}

Rekapitulierend können als Kriterien bei der Professorenauswahl freundschaftliche sowie familiäre Verbindungen genannt werden. Die geografische Herkunft erweist sich als weniger relevant und auch die Bedeutung Wittenbergs muss zumindest für die höheren Fakultäten relativiert werden. Landgraf Philipp musste, abgesehen von den Artisten in den Anfangsjahren, gezwungenermassen auf qualifizierte Personen ausserhalb der

42 Davon zwei Theologen, ein Jurist.

43 Vgl. dazu auch Barbara Bauer, Melanchton in Marburg. Zur Einführung, in: Melanchton und die Marburger Professoren (1527-1627) Bd. 1, hg. von ders. (Schriften der Universitätsbibliothek Marburg 89), Marburg 1999, S. 1-29, hier: S. 4 f., die die Professoren der Artistenfakultät mit berücksichtigt hat, allerdings bei ihrer Aufzählung nach anderen Kriterien vorgeht, sodass keine allgemeinen Schlüsse für diese Untersuchung daraus gezogen werden können. 
Wittenberger Universität zurückgreifen, die dann nicht nur in der Ausbildung der hessischen Pfarrer, Ärzte und Beamte eingesetzt werden sollten, sondern auch für landesherrliche Dienste gerne herangezogen wurden. Gerade bei den Professoren der Gründungszeit war mit Adam Krafft ein Hofprediger an der Universität vertreten, der ausserdem als Visitator tätig war. Bei den Juristen ist vor allem eine Tätigkeit am Hofgericht und als Rat häufig belegt und bei den Medizinern ist das Tätigkeitsfeld sowieso leicht einzugrenzen. Im nächsten Schritt soll nun also untersucht werden, ob sich innerhalb der Fakultäten bestimmte Muster von regelmässig wiederkehrenden Tätigkeiten ergeben oder ob die Nebentätigkeiten tatsächlich völlig unterschiedlich ausfielen ${ }^{44}$.

Von den insgesamt acht Medizinern sind zwei definitiv als Leibärzte des Landesherrn und einer ist als Stadtarzt in Marburg belegt. Als weitere Tätigkeiten der Medizinprofessoren sind verschiedene universitäre Ämter bekannt, häufig waren sie, wie zu erwarten, Rektor oder Dekan.

Eine typische Nebentätigkeit der Theologen ist die des (Hof-)Predigers. Die Auswertung der Datenbank zeigt aber auch, dass es Ausnahmefälle gibt: So ist ein Theologe belegt, der neben verschiedenen theologischen auch die für Juristen typische Tätigkeit als Hofgerichtsrat ausübte. Hier scheint also eine Zusammengehörigkeit von Professur und entsprechender Tätigkeit für den Landesherrn nicht zwingend erforderlich gewesen zu sein.

Dazu sind die weiteren Tätigkeiten der Rechtsprofessoren aus der Literatur recht eindeutig zu rekonstruieren: Sie waren (Hof-)Rat ${ }^{45}$ oder Schöffe, Beisitzer, Kanzleirat, Gesandter, aber auch Anwalt und Assessor, wobei die häufigsten Belege eine Tätigkeit am Hofgericht nachweisen ${ }^{46}$. Anhand dieser Beispiele wird deutlich, wie weit sich Universität und landgräfliche Beamtenschaft überschnitten und wie viel Einfluss der Landesherr tatsächlich noch auf die Universität hatte.

Ein Paradebeispiel dafür ist der erste Universitätsrektor und Rechtsprofessor Johannes Eisermann. Der aus Amöneburg stammende Eisermann studierte in Wittenberg. Danach wurde er bereits 1523 Schöffe und Rat am Hofgericht in Marburg. Mit seinem Amtsantritt als Rektor der Universität übernahm er auch einen Lehrstuhl der juristischen Fakultät. Während der langen Zeit, in der er Professor für ius civile war, hatte er zahlreiche weitere Ämter im Dienste des Landgrafen inne. So war er auch nach seiner Ernennung zum Professor weiterhin als Rat und Schöffe tätig, ausserdem ist er mehrfach als Universitätsrektor belegt. Der letzte Nachweis seiner Professur stammt aus seinem Sterbejahr 1558, sodass davon ausgegangen werden kann, dass er seine Tätigkeit an der Universität bis zu seinem Tod ausübte ${ }^{47}$.

44 Da über den gesamten Zeitraum keine Unterschiede hinsichtlich der Tätigkeiten der Professoren neben der Universitätslehre oder Ämter zu beobachten sind, wird die sich an der Dreiteilung des Zeitraums orientierende Analyse hier aufgehoben. Eine zwischen den einzelnen Fakultäten unterscheidende Analyse ist hier sinnvoller und ergebnisorientierter.

45 Innerhalb der Gruppe von Rechtsprofessoren sind allein für unseren eingeschränkten Zeitraum neun von den insgesamt 14 Juristen als Räte belegt.

46 Hier sind insbesondere ihre Tätigkeiten als Schöffe, Anwalt, Assessor und Beisitzer explizit für das Hofgericht belegt. 47 RAG (Anm. 31), Johannes Eisermann - UniquID: ngZP9Q072YH8kovVtZSo0X1Y0YC, 25.8.2017. 
Zwei Jahre nach Universitätsgründung wurde die juristische Fakultät um eine zweite Professur erweitert. Balthassar Klammer, der aus Kaufbeuren stammte und sein juristisches Studium in Leipzig absolviert hatte, las die «Institutiones〉. Auch er stand im landgräflichen Dienst und wurde nach seinem ersten Jahr der Lehrtätigkeit als Anwalt ans Hofgericht berufen. Er blieb dem Landgrafen und der Universität allerdings nicht so lange erhalten wie sein Kollege Johannes Eisermann. Klammer verliess die Marburger Universität schon 1532 und ging nach Celle, wo er als Hofrat und Kanzleirat nachgewiesen ist. Von seinem weiteren Lebensweg ist bekannt, dass er als Rat, Gesandter, Anwalt und Kanzler an verschiedenen Orten für verschiedene Dienstherren tätig war. Nach Marburg kehrte er nicht mehr zurück ${ }^{48}$.

Betrachtet man diese beiden Beispiele, aber auch die restlichen Professoren der juristischen Fakultät, fällt auf, dass diese besonders häufig neben ihrer Professur am Hofgericht tätig waren. Das Hofgericht in Marburg wurde von Wilhelm II. mit dem Ziel errichtet, die Rechtsprechung in der Landesherrschaft zu zentralisieren und zu vereinheitlichen. Wilhelms Hofgerichtsordnung orientierte sich sehr stark an dem Reichskammergericht. Das Hofgericht kam viermal pro Jahr zusammen und tagte dann drei Wochen lang. Es bestand aus dem Hofrichter, der der Ritterschaft angehörte, und zwölf Beisitzern (von denen mindestens drei Doktoren waren). Landgraf Philipp wandelte um 1524 das temporäre Gericht in eine ständige Behörde um, die mindestens dreimal wöchentlich Gericht halten sollte ${ }^{49}$. Hier waren Professoren wie Balthassar Klammer, Jakob Lersner und Ambrosius Schurer vertreten.

Die enge Verzahnung von Universitätsgründung und Einführung der Reformation in der Landgrafschaft Hessen rechtfertigt es, den Blick noch einmal gezielt auf die theologische Fakultät mit ihrem Personal zu richten und nach deren Einfluss auf die Reformation in der Landesherrschaft zu fragen. Diese, anfänglich ebenso wie die juristische Fakultät mit zwei Professoren konzipiert, wurde innerhalb kurzer Zeit mit einer dritten ausgestattet. Für die medizinische Fakultät war sogar nur eine Professur vorgesehen.

Die erste Wahl bei der Besetzung der Theologieprofessur war Franz Lambert. Der in Avignon geborene ehemalige Franziskanermönch schloss sich der Lehre Zwinglis an und war als Prediger in der Schweiz, in Frankreich und in deutschen Gebieten tätig, bevor er 1523 in Wittenberg die Tätigkeit als Theologieprofessor aufnahm ${ }^{50} .1527$ wurde er dann von Philipp zum Professor an die neugegründete Universität in Marburg berufen, nachdem Lambert schon im Vorfeld bei der Planung und Organisation der neuen Universität dem Landesherrn beratend zur Seite gestanden hatte ${ }^{51}$. Letztlich war er

48 RAG (Anm. 31), Balthasar Klammer - UniquID: ngKA7R577J637zgKeKjzwIwN, 25.8.2017.

49 Vgl. Heinemeyer, Zur Gründung des «universale studium Marpurgense» (Anm. 9), S. 52 f.

50 RAG (Anm. 31), Franz Lambert - UniquID: ngVL6o072Ut82krlpUukhTho, 25.8.2017.

51 Schneider-Ludorff, Der fürstliche Reformator (Anm. 6), S. 67. 
massgeblich an der Ausgestaltung der $\langle\text { Reformatio }\rangle^{52}$ beteiligt und auch die Gestaltung der Universitätsordnung wurde stark von ihm beeinflusst.

Auch Adam Krafft, der bereits als Hofprediger in Marburg wirkte, wurde als Theologieprofessor an die neue Universität berufen. Er gehörte zum Erfurter Humanistenkreis um Helius Eobanus Hessus ${ }^{53}$, wie auch Euricius Cordus oder Justus Jonas. Er absolvierte in Erfurt sein Studium und wurde 1519 zum magister artium promoviert. Danach setzte er sich nach einem Aufenthalt in Leipzig immer stärker mit der Lehre Martin Luthers auseinander und konvertierte $1521 \mathrm{zu}$ dieser. Infolge seiner Konversion war er dann als Prediger der lutherischen Lehre tätig. 1525 ernannte Landgraf Philipp ihn zu seinem Hofprediger, bevor er 1527 zum Hofgerichtsrat und Theologie-professor an der Universität berufen wurde ${ }^{54}$. Bis zu seinem Tod 1558 blieb er der Marburger Universität als Professor erhalten.

Als dritter Professor für Theologie wurde Erhard Schnepf nach Marburg berufen. Seine Tätigkeit begann allerdings erst ein Jahr nach der Universitätsgründung, denn da Adam Krafft auch als Visitator tätig war, konnte dieser seine Lehrtätigkeit nicht regelmässig ausüben. Dadurch war es überhaupt erst notwendig geworden, einen dritten Professor einzustellen ${ }^{55}$. Schnepf war Sohn eines Heilbronner Bürgermeisters und hatte bereits eine Lateinschule in Heilbronn besucht und sich dann 1509 an der Erfurter Universität immatrikuliert. Er schloss die Artistenfakultät als Bakkalar ab und wechselte anschliessend an die theologische Fakultät in Heidelberg. Bevor er vom hessischen Landesherrn zum Theologieprofessor berufen wurde, war er als Prediger, Pfarrer und als Professor an der Artistenfakultät in Heidelberg tätig, nachdem er sich zwischen 1518 und 1520 zum lutherischen Glauben bekannt hatte. Als er 1528 seine Lehrtätigkeit in Marburg aufgenommen hatte, erhob Philipp auch ihn zum Hofprediger ${ }^{56}$.

Es zeichnete sich schon recht früh ab, dass Franz Lambert als Theologieprofessor an der neuen Universität lehren sollte. Er war es, der die neue Kirchenordnung deutlich geprägt hatte. Neben ihm versuchte Philipp auch einen weiteren Theologen für die neue Universität zu gewinnen. Dabei bat der selbstbewusste Landesherr, Personen wie Bugenhagen, Luther oder Melanchton dem Ruf nach Marburg zu folgen. Philipp wollte für seine neue Universität hervorragendes Lehrpersonal. Er versuchte, wie Müller es treffend formulierte, «nach den höchsten Sternen am Gelehrtenhimmel zu greifen» ${ }^{57}$. Wir wissen, dass diese grossen Köpfe der Reformation nicht nach Marburg gekommen

52 Die von Franz Lambert formulierte Reformatio ecclesiarum Hassiae wurde als neue Kirchenordnung von Landgraf Philipp dem Großmütigen zwar bestätigt, aber letztlich doch nicht eingeführt, weil Martin Luther diese Ordnung ablehnte. Vgl. Schneider-Ludorff, Der fürstliche Reformator (Anm. 6), S. 52 und S. 62 f.

53 Der in Frankenberg geborene Eobanus Hessus studierte in Erfurt und wurde ab 1514 Oberhaupt des dortigen Humanistenkreises. Ab 1536 war auch er in Marburg an der Universität als Professor tätig. Vgl. RAG (Anm. 31), Helius Hessus - UniquID: ngIY4T779JQ5txeEcHhx7GuZ, 25.8.2017.

54 RAG (Anm. 31), Adam Krafft - UniquID: ngPF5e476PX2aeljjOYezNbW, 25.8.2017.

55 Schneider-Ludorff, Der fürstliche Reformator (Anm.6), S. 69.

56 RAG (Anm. 31), Erhard Schnepf - UniquID: ngZP9Q072YH8kovVtY2olX1K0Zi, 25.8.2017.

57 Müller, Die Anfänge der Marburger Theologie (Anm. 7), S. 166 f; Hermelink/Kaehler, Die Philipps-Universität Marburg (Anm. 39), S. 9. 
sind, um an der theologischen Fakultät zu lehren. Stattdessen wurde Philipps Hofprediger Adam Krafft zum Professor der Theologie ernannt und lehrte neben Franz Lambert an der neuen Universität.

Indem Philipp zum Zwinglianhänger Franz Lambert mit Schnepf einen lutherischen Gegenpol schaffte und Adam Krafft vor allem für das humanistische Konzept stand, waren an der Universität verschiedene protestantische Strömungen vertreten. Dass Landgraf Philipp nicht auf die lutherische Lehre festgelegt war und die verschiedenen protestantischen Lehren vereinen wollte, schlug sich nur zwei Jahre nach der Universitätsgründung in dem Marburger Religionsgespräch nieder ${ }^{58}$. Gury Schneider-Ludorff beschreibt treffend: «Das war nicht nur mutig, sondern es entsprach dem Selbstverständnis des Landgrafen, die verschiedenen Positionen als legitime Formen der Auslegung der Heiligen Schrift zu akzeptieren, diese miteinander streiten zu lassen und die letzte Entscheidung über die wahre Lehre Gott zu überlassen..» ${ }^{59}$

Auch wenn Philipp nicht die führenden Köpfe der Reformation für die Universität in Marburg gewinnen konnte, waren die Personen, mit denen er die theologische Fakultät besetzte, selbstverständlich nicht zufällig ausgewählt. Denn sie waren es, die Philipp dabei helfen sollten, den evangelischen Glauben im Territorium zu festigen und zu verbreiten. Insbesondere Adam Krafft war es, der Gottesdienste halten und auch Visitationen durchführen musste. Auch allgemein stand er, wie seine beiden Kollegen, dem Landesherrn in Glaubensfragen zur Seite. Diese sehr umfassenden Aufgaben führten aber auch dazu, dass er kaum noch Zeit für die Lehre hatte ${ }^{60}$. Bei Franz Lambert hingegen tritt das genaue Gegenteil ein: Da er der Landessprache nicht mächtig war, kam eine Nebentätigkeit als Pfarrer oder Visitator nicht infrage. Seine Zuhörerschaft war auf jene beschränkt, die der lateinischen Sprache mächtig waren, weshalb er fast ausschliesslich an der Universität tätig war ${ }^{61}$.

Das Beispiel Theobald Thamer zeigt deutlich, dass es trotz sorgfältiger Auswahl durch den Landesherrn auch zu Fehlbesetzungen kommen konnte. Philipps religiöser Offenheit waren nämlich durchaus Grenzen gesetzt, wenn ein Professor drohte, aus einer der protestantischen Spielarten des Christentums auszubrechen. Thamer zog es zurück zum Alten Glauben, was offensichtlich trotz der Offenheit Philipps für verschiedene Glaubensrichtungen nicht mit einer weiteren Beschäftigung an der Universität vereinbar war. 1543 war Theobald Thamer nach Marburg berufen worden. In Straßburg geboren, hatte es ihn zum Studium nach Wittenberg, Erfurt und nach Italien gezogen, wo er in Siena zum Doktor der Theologie promoviert wurde. Bevor er seine Tätigkeit an der Marburger Universität begann, lehrte er in Frankfurt an der Oder Griechisch. Mit seiner Professur in Marburg wurde er gleichzeitig Prediger der Elisabethkirche. Zehn Jahre lang blieb er in Marburg, um Theologie zu lehren und das lutherische Bekenntnis

58 Schneider-Ludorff, Der fürstliche Reformator (Anm.6), S. 168.

59 Ebd., S. $71 \mathrm{f}$.

60 Müller, Die Anfänge der Marburger Theologischen Fakultät (Anm. 7), S. 172.

61 Ebd., S. 167. 
zu predigen ${ }^{62}$. Doch seine Predigtinhalte wichen immer stärker von den Lehren der Reformatoren ab, sodass der Landesherr ihn 1553 aufgrund konfessioneller Konflikte entliess $^{63}$. Nach seiner Entlassung am 15. April 1553 reiste er nach Rom, wo er in der Zeit zwischen seiner Anreise 1553 und seinem Amtsantritt als Domprediger in Minden 1555 zum katholischen Glauben konvertierte. Er wurde 1556 zum Hofprediger in Minden ernannt, bald darauf ist er als Kanoniker und als Ordinarius für Theologie in Mainz belegt. Die letzten Zeugnisse, die zu Thamer vorliegen, verraten uns, dass er 1566 nach Freiburg ging, um dort bis zu seinem Tod am 23. Mai 1569 Theologie zu lehren. Dort war er Dekan der theologischen Fakultät und Ehrenmitglied der Universität ${ }^{64}$.

\section{Fazit}

Obwohl die Marburger Universität als erste protestantische Gründung ein Experiment war, das mit all den Unsicherheiten, die dieses mit sich brachte, als gewagt bezeichnet werden kann, so verlief sie doch erfolgreich. Neben der Schaffung einer soliden Finanzierung über konfiszierte Kirchengüter und der politischen Erringung der kaiserlichen Legitimation waren es gerade die Professoren, vor allem der höheren Fakultäten, die eine gute Positionierung der Universität im Vergleich zu ihrer Konkurrenz ausmachten.

Bei der Auswahl der Professoren spielten neben personellen Netzwerken auch andere Kriterien eine Rolle. Es konnte nachgewiesen werden, dass die geografische Herkunft letztendlich von keiner grossen Bedeutung war. Erst im letzten Abschnitt des untersuchten Zeitraums zeichnet sich eine Änderung zunächst nur an der theologischen Fakultät ab. Hier konnte mit fortschreitender Zeit auf den eigenen theologischen Nachwuchs zurückgegriffen werden, der die 〈reine〉 Lehre bereits vor Ort erlernt hatte und an die nächste Generation weitergeben konnte. Vorher musste der Landgraf geeignete Kandidaten für die Besetzung der Professuren in einem weit grösseren Radius suchen. Als Folge seines Glaubenswandels richtete sich sein Blick naheliegender Weise zuerst nach Wittenberg. Erfolglos verlief sein Bestreben, die grossen Köpfe der Reformation nach Marburg zu ziehen, und er konnte letztlich nur einige Wittenberger Gelehrte als Professoren für die Artistenfakultät gewinnen. An den höheren Fakultäten lehrten schliesslich nur neun Professoren, die ihr Studium in Wittenberg absolviert hatten. Dies hatte zur Folge, dass Philipp seine Professoren aus dem ganzen Reich und über dessen Grenzen hinaus rekrutierte, was darin mündete, dass die Marburger Professoren nicht nur die lutherische Spielart des Protestantismus vertraten, sondern es auch - unter den Theologen - 〈Zwinglianer〉 oder 〈Buceristen〉 gab. Dies zeigt, dass der Landesherr bei der Suche nach Professoren erheblichen Wert auf die akademische Qualifikation legte.

62 RAG (Anm. 31), Theobald Thamer - UniquID: ngAQ3R971BI72pwAuZTp0YmN, 25.8.2017.

63 Ebd.

64 Ebd. 
Welcher protestantischen Strömung sie anhingen, war dabei anfangs zweitrangig, spielte aber sicherlich im Laufe der Konfessionalisierung eine immer stärkere Rolle.

Zur Frage nach der Verschränkung von Universitätspersonal und Landesherrschaft liessen sich einige Antworten finden: Dass die Professoren häufig zu weiteren Tätigkeiten neben ihrer Professur verpflichtet wurden, ist mit einem Blick auf die Biografien in der RAG-Datenbank schnell deutlich geworden. Meist lebten sie nicht von ihrer Professorenbesoldung allein, sondern griffen auf mehrere Einnahmequellen zurück ${ }^{65}$.

Die Untersuchung verdeutlicht, dass die Landgrafschaft und die Universität sehr eng miteinander verzahnt waren. Die Theologieprofessoren waren gleichzeitig oft als (Hof-)Prediger und als Visitatoren tätig, die Lehrstuhlinhaber der Medizin kamen dem Landgrafen als dessen Leibärzte oft näher als andere. Die meisten Informationen zu ihren Nebentätigkeiten fanden sich bei den Juristen. Sie waren Rat, Schöffe und zumeist am Hofgericht tätig. Hier scheint die Überschneidung von Universität und Landgrafschaft am intensivsten.

Doch gerade im Zuge der Reformation nehmen die Theologieprofessoren die wichtigste Stellung ein. Sie waren es, die den Landesherrn bei der Durchführung der Reformation im Territorium unterstützten und richtungsweisend waren. Interessant ist vor allem die Erstbesetzung der theologischen Lehrstühle. Mit drei so unterschiedlichen Professoren, die verschiedene reformatorische Strömungen vertraten, zeigte Philipp nicht nur seine anfängliche religiöse Offenheit, sondern bewies mit dem Marburger Religionsgespräch darüber hinaus, dass er an die Vereinbarkeit der Strömungen zu einer einheitlichen reformierten Lehre glaubte.

Die Besetzung der Lehrstühle war weit über die Universität hinaus von Bedeutung und hatte Auswirkungen auf die Landesherrschaft vor allem in den Bereichen Kirche, Verwaltung und medizinische Versorgung. 


\section{Anschriften der Autorinnen und Autoren}

Silvia Böhnert M. A., Repertorium Academicum Germanicum, Historisches Institut, Abteilung Landesgeschichte, Justus-Liebig-Universität Giessen, Otto-Behaghel-Str. 10 C, D-35394 Giessen,

Silvia.Boehnert@geschichte.uni-giessen.de

Ursula Bütschli M. A., Repertorium Academicum Germanicum, Historisches Institut, Universität Bern, Länggassstrasse 49, CH-3012 Bern, ursula.buetschli@hist.unibe.ch

Vanessa Decker M. A., Repertorium Academicum Germanicum, Historisches Institut, Abteilung Landesgeschichte, Justus-Liebig-Universität Giessen, Otto-Behaghel-Str. 10 C, D-35394 Giessen,

Vanessa.Decker@geschichte.uni-giessen.de

Dr. Kaspar Gubler, Repertorium Academicum Germanicum, Historisches Institut, Universität Bern, Länggassstrasse 49, CH-3012 Bern,

kaspar.gubler@hist.unibe.ch

Lotte Kosthorst M. A., Repertorium Academicum Germanicum, Historisches Institut, Abteilung Landesgeschichte, Justus-Liebig-Universität Giessen, Otto-Behaghel-Str. 10 C, D-35394 Giessen,

Lotte.Kosthorst@geschichte.uni-giessen.de

Elena Magli M. A., Repertorium Academicum Germanicum, Historisches Institut, Universität Bern, Länggassstrasse 49, CH-3012 Bern,

elena.magli@hist.unibe.ch

Prof. Dr. Rainer Christoph Schwinges, Repertorium Academicum Germanicum, Historisches Institut, Universität Bern, Länggassstrasse 49, CH-3012 Bern, rainer.schwinges@hist.unibe.ch

Carmen Tellenbach M. A., Haglen 7, 8750 Glarus, c.tellenbach@gmail.com

Anna-Lena Wendel M. A., Historisches Institut, Abteilung Landesgeschichte, JustusLiebig-Universität Giessen, Otto-Behaghel-Str. 10 C, D-35394 Giessen, Anna.L.Wendel@geschichte.uni-giessen.de 
In diesem Band stellen Mitarbeiterinnen und Mitarbeiter des RAG in Bern und Giessen Forschungen aus den Jahren 2017 und 2018 vor, die aus je eigenen Interessen unter Nutzung der Datenbank des RAG entstanden sind.

Die Arbeiten konzentrieren sich vornehmlich auf das 15. und 16. Jahrhundert und decken vornehmlich den Rheinraum, Hessen-Thüringen, Süddeutschland, Burgund und die Schweiz ab. Thematisch findet man Beiträge über «Doctores so in den püchern lesen», über «Bildung und Geld» am Beispiel von Schaffhausen, über «Ritter an der Universität» zwischen Erfolg und Misserfolg (am Beispiel der Familie von Friedingen), über die Maxime «So soll der jung Adel sich auff das Studieren geben» (am Beispiel der Wetterauer Grafen an den Universitäten des Reichs), über einen «gelehrten Betrüger» in Basel (Prof. theol. Ladislaus Ulricher), über die «Universitas Dolana» (Dôle) als transkulturelle Drehscheibe, über das «Italienstudium der Ärzte» am Jülicher Hof, über den «Humanistenkreis in Erfurt und die Reformation in Hessen» sowie über Marburger Professoren «zwischen Universitäts- und Landesdienst». Die Beiträge zeigen u.a. auch die kartografischen Visualisierungsmöglichkeiten, die das RAG entwickelt hat. 